UNIVERSIDADE DE SÃO PAULO

ESCOLA DE ENGENHARIA DE SÃO CARLOS

DEPARTAMENTO DE GEOTECNIA

\title{
ANÁLISE DE PROVAS DE CARGA DINÂMICA EM TUBULÕES A CÉU ABERTO NO CAMPO EXPERIMENTAL DE FUNDAÇÕES DA EESC/USP
}

DISSERTAÇÃO DE MESTRADO APRESENTADA À ESCOLA DE ENGENHARIA DE SÃO CARLOS - UNIVERSIDADE DE SÃO PAULO, COMO REQUISITO PARA OBTENÇÃO DO TÍTULO DE MESTRE EM GEOTECNIA.

AUTOR: FÁBIO LOPES SOARES

ORIENTADOR: PROF. DR. NELSON AOKI

São Carlos (SP), Dezembro de 2002 
FOLHA DE JULGAMENTO

Candidato: Engenheiro FÁBIO LOPES SOARES

Dissertação defendida e julgada em 13-03-2003 perante a Comissão Julgadora:

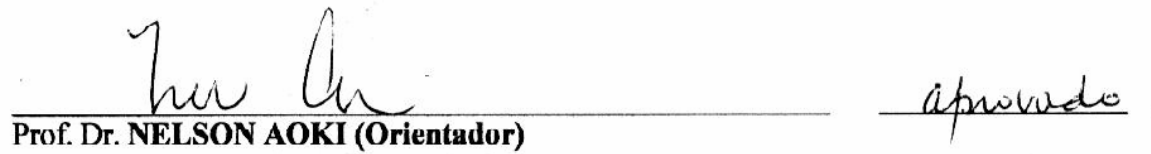

(Escola de Engenharia de São Carlos/USP)

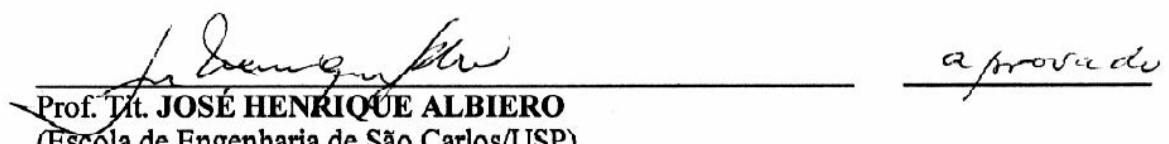

(Eșcola de Engenharia de São Carlos/USP)

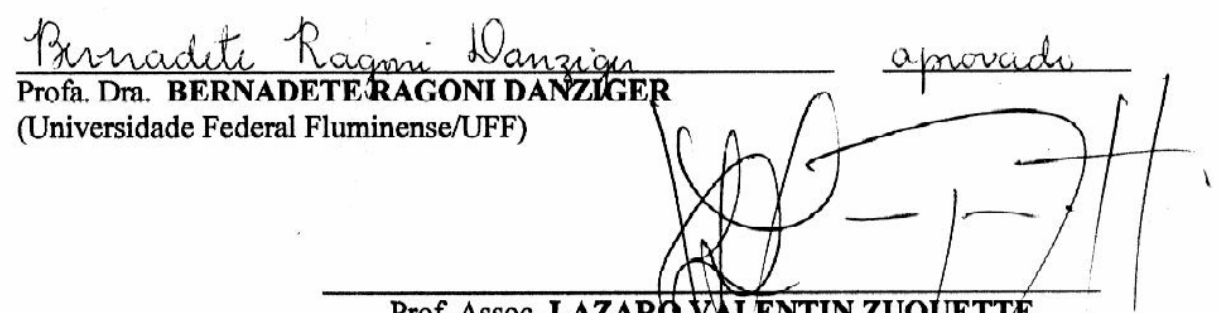

Prof. Assoc. LAZARo ALENTIN ZUQUETTE

Coordenador do Programa delPós-Graduação em Geotecnia

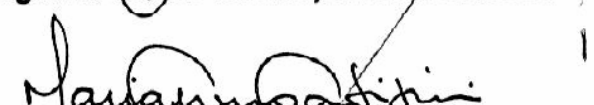

Profa. Assoc. MARIA DO CARMO CALIJURI

Presidente da Comissão de Pós-Graduação da EESC 


\section{DEDICATÓRIA}

A Deus,

Ao meu amor, Mariza, Aos meus Pais, Amilton e Salonia Aos meus irmãos, André e Daniela e a minha avó, Santana.

"A sabedoria é alcançada através da busca do conhecimento, da paciência e da perseverança. Muito pode realizar um sábio, porém muito mais o que ama a Deus e ao próximo como a si mesmo."

Fábio Lopes Soares 


\section{AGRADECIMENTOS}

Agradeço a Deus, por estar sempre ao meu lado, em todos os momentos de minha caminhada.

À Mariza, à minha mãe e ao meu pai pelo amor, carinho e confiança que tiveram em mim.

Ao meu Orientador, Nelson Aoki, por todos os seus ensinamentos, orientação e confiança no meu trabalho e na minha pessoa.

Ao Prof. Cintra, por ter me encaminhado na minha pesquisa e por permitir que eu fizesse um trabalho no campo experimental.

Ao meu amigo Prof. Russo, pela sua disponibilidade e paciência, por ter me ajudado na realização dos ensaios e na análise destes.

Ao meu amigo Mauro Leandro Menegotto, que sempre foi solidário em me ajudar nos trabalhos do campo experimental.

À empresa IN SITU GEOTECNIA, pela concessão do programa CAPWAP 2000 e de todo o equipamento, para realizar a instrumentação dinâmica dos ensaios do presente trabalho.

À empresa SCAC, pelo material cedido, para a realização do ensaio dinâmico.

Aos enge nheiros Túlia, Ígor, Benedito, Campelo e Jorge Beim, que me ajudaram a refletir e amadurecer sobre temas da minha pesquisa.

Aos amigos Wilson Cartaxo e Leonardo Vieira, que concluiram o curso de Engenharia Civil comigo e constituíram a família com quem morava nesta caminhada de mestrado.

Aos amigos Holden e Helano, pela amizade sincera e por estarem sempre presentes nos momentos em que precisei de apoio.

Aos amigos Célio, Jeseley, Cléber, Costa Branco, Darcília, Dirlene, Indira, Jânio, Maurício, Paulo Lopes, Rogério, Thales e Domingos, pela amizade e carinho que carrego de todos. 
A todos os Professores do Departamento de Geotecnia: Nelson Aoki, José Carlos A. Cintra, João Batista Nogueira, Orêncio Monje Vilar, Benedito de Souza Bueno, Nélio Gaioto, José Eduardo Rodrigues, Tarcísio Barreto Celestino, Airton Bortolucci, Lázaro Zuquetti, Heraldo Giacheti e José Henrique Albiero, que contribuíram para o meu crescimento profissional e para realização do meu trabalho.

Aos funcionários do Departamento de Geotecnia Herivelto Moreira, Maristela Batissaco, Álvaro Luiz Nery, Rosa Tomaze, Antônio Garcia, José Luiz Guerra, Benedito Oswaldo de Souza e Oscar, pela colaboração.

Ao CNPQ, pela bolsa de estudos concedida.

Agradeço a todos que, de alguma maneira, ajudaram na concretização deste trabalho. 


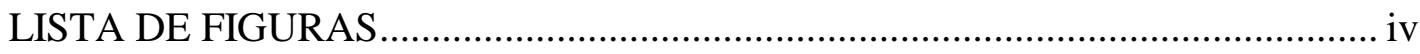

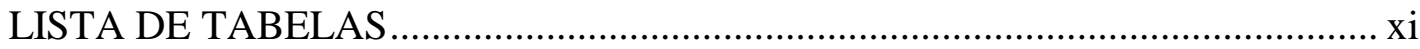

LISTA DE ABREVIATURAS E SIGLAS...........................................................

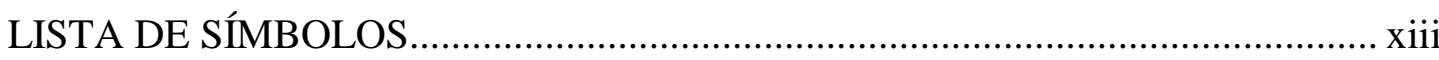

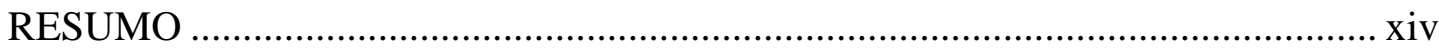

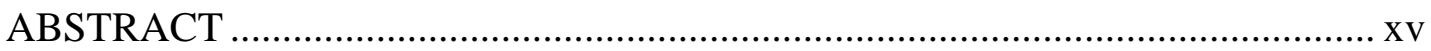

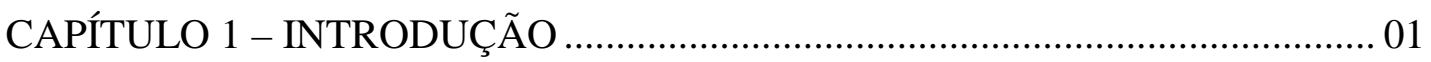

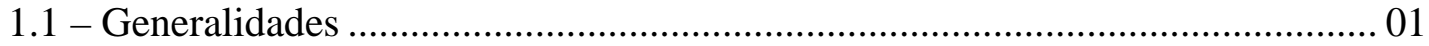

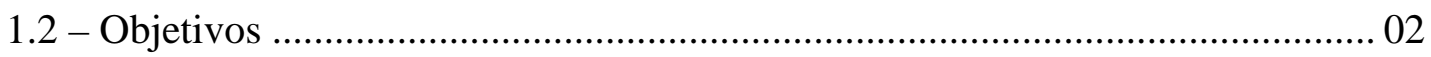

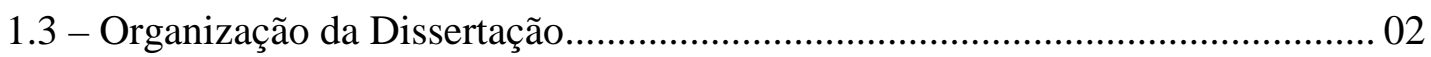

CAPÍTULO 2 - REVISÃO BIBLIOGRÁFICA........................................................ 04

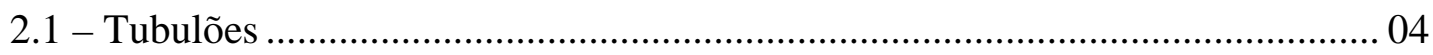

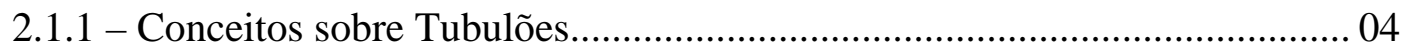

2.1.2 - Vantagens e Desvantagens ....................................................................... 06

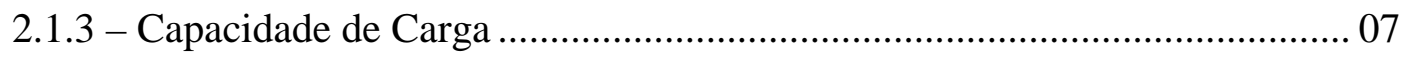

2.1.4 - Comportamento de Tubulões .................................................................. 10

2.2 - Prova de Carga Estática ................................................................................. 13

2.2.1 - Análise da Curva Carga-Recalque ............................................................. 16

2.3 - Prova de Carga Dinâmica ................................................................................ 27

2.3.1 - Fórmulas Dinâmicas ............................................................................ 28

2.3.2 - Teoria da Equação da Onda........................................................................ 30

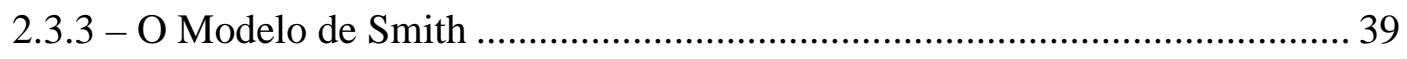

2.3.4 - Técnica de Instrumentação ........................................................................ 41

2.3.5 - Métodos de Análise dos Sinais Obtidos pelo PDA ……………………...... 42

2.3.5.1 - Método de Análise Case ........................................................................... 42

2.3.5.2 - Método de Análise CAPWAP............................................................... 45

2.3.6 - Ensaio de Carregamento Dinâmico de Energia Constante ........................... 51 
2.3.7 - Ensaio de Carregamento Dinâmico de Energia Crescente ......................... 52

2.3.8 - Fórmulas Dinâmicas de Cravação Utilizando Energia Crescente .............. 53

2.4 - Comparação entre Prova de Carga Estática e Dinâmica .................................. 58

CAPÍTULO 3 - CAMPO EXPERIMENTAL DE FUNDAÇÕES .......................... 77

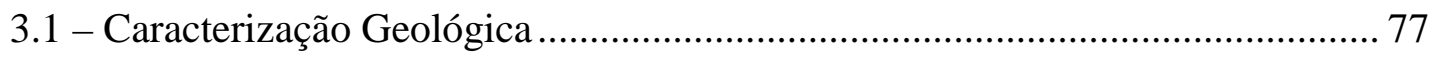

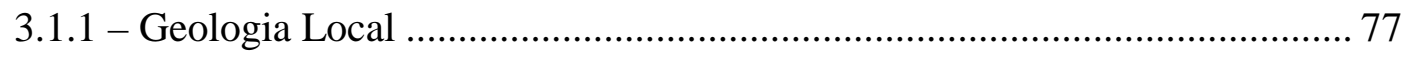

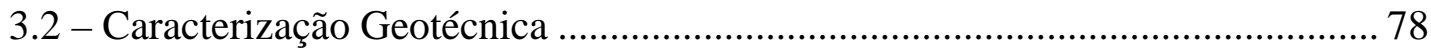

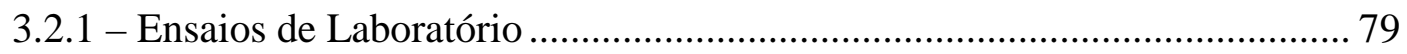

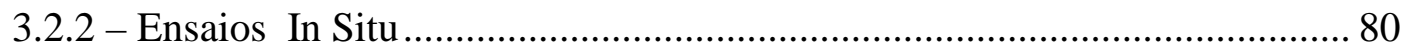

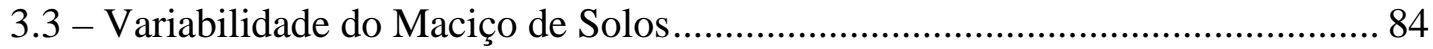

CAPÍTULO 4 - METODOLOGIA E PROCEDIMENTOS .................................. 92

4.1 - Considerações Gerais Sobre os Tubulões.................................................... 92

4.2 - O Ensaio Dinâmico de Energia Crescente....................................................... 95

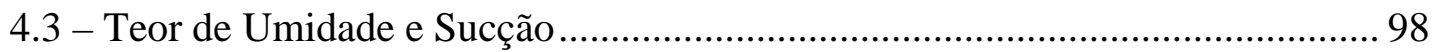

4.4 - Altura de Queda do Martelo do Bate-Estaca .................................................. 98

4.5 - Ensaios Com e Sem Pré-Inundação do Terreno ................................................ 99

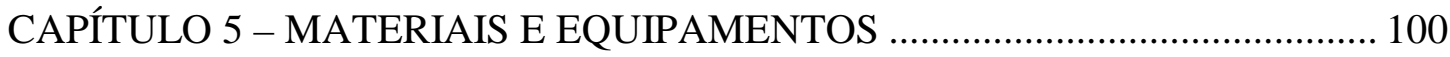

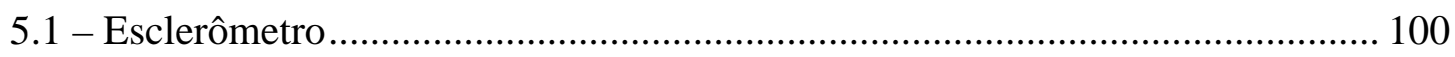

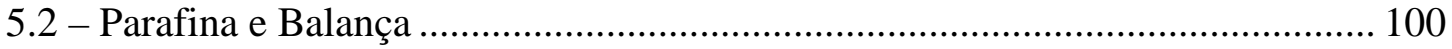

5.3 - Prova de Carga Dinâmica de Energia Crescente ............................................. 101

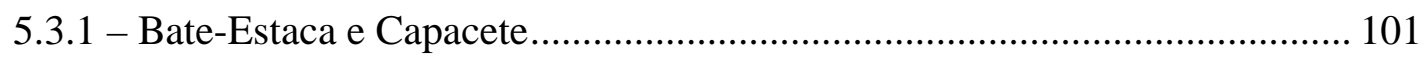

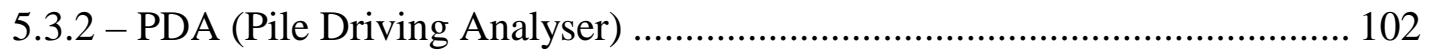

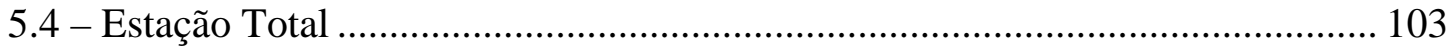

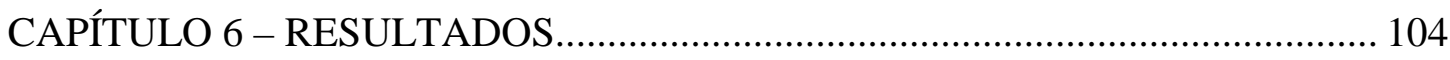

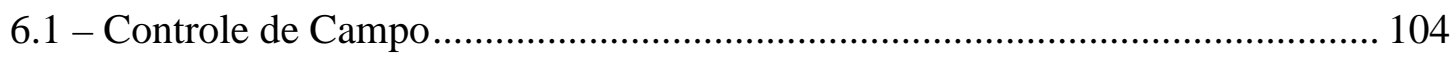

6.1.1 - Propriedade do Concreto dos Tubulões.................................................... 104

6.1 .2 - Estimativa da Sucção Durante os Ensaios ................................................ 104

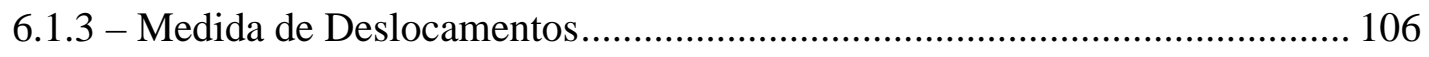

6.2 - Resultados da Prova de Carga Dinâmica de Energia Crescente....................... 108

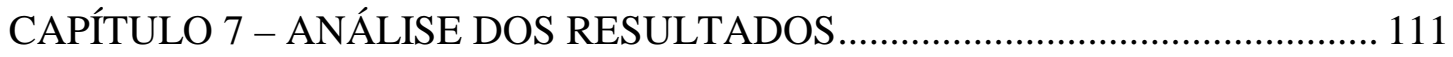


7.1 - Resultados dos Ensaios Estáticos e Dinâmicos................................................... 111

7.2 - Evolução da Parcela de Resistência de Ponta(ou Base) e Lateral ....................... 117

7.3 - Análises Estatísticas do Ensaio Dinâmico ............................................................ 118

7.4 - Comparação entre as Provas de Carga Estática e Dinâmica .............................. 127

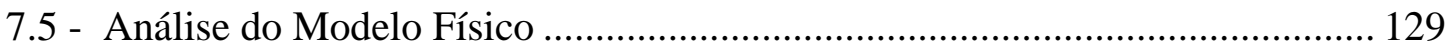

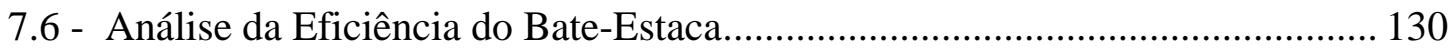

CAPÍTULO 8 - CONCLUSÕES E SUGESTÕES ...................................................... 134

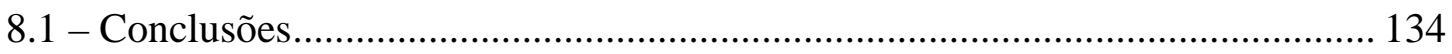

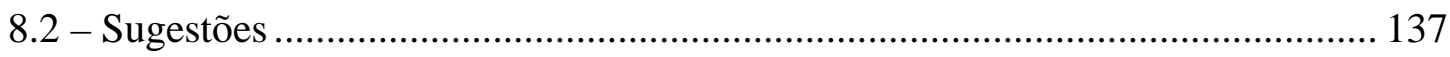

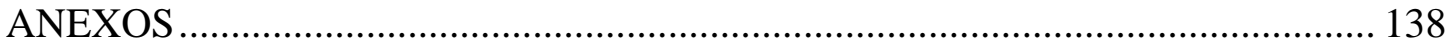

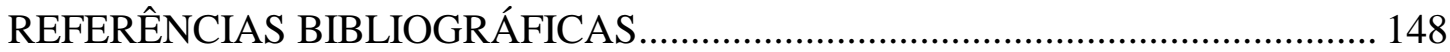




\section{LISTA DE FIGURAS}

Figura 1.1 - Representação do elemento isolado de fundação ............................................ 01

Figura 2.1 - Dados Geométricos de um Tubulão (ALBIERO \& CINTRA, 1996)................ 05

Figura 2.2 - Sistema de Reação com Tirantes (NIYAMA et al., 1996) ................................ 14

Figura 2.3 - Sistema de Reação com Cargueiras (ALONSO apud NIYAMA et al., 1996) . 14

Figura 2.4 - Sistema de Reação com Estacas de Apoio (REESE \& O’NEILL, 1988)........... 15

Figura 2.5 - Modelo Ideal de Curva Carga-Deslocamento Elástico-Plástico (AOKI, 1997)17

Figura 2.6 - Curva Carga-Recalque (AOKI, 1997) .......................................................... 18

Figura 2.7- Curva Carga-Recalque, Estaca de Atrito em Solo Argiloso (AOKI, 1997) ...... 19

Figura 2.8 - Curva Carga-Deslocamento (AOKI, 2000) ..................................................... 19

Figura 2.9 - Curva Carga-Recalque, Estaca de Ponta em Solo Resistente (AOKI, 1997) ... 20

Figura 2.10 - Carga de Ruptura Convencional (NBR 6122, 1996) .....................................2 21

Figura 2.11 - Curva Carga - Recalque de VAN DER VEEN .............................................2 22

Figura 2.12 - Aplicação do Princípio de Hamilton até o limite inferior de

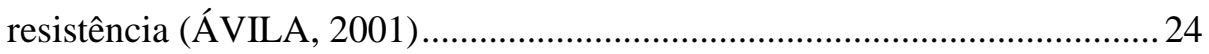

Figura 2.13 - Aplicação do princípio de Hamilton entre o limite inferior e o superior de resistência (ÁVILA, 2001) ...........................................................25

Figura 2.14 - Aplicação do princípio de Hamilton até o pós ruptura (ÁVILA, 2001).......... 26

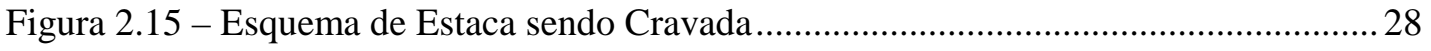

Figura 2.16 - Representação esquemática do sistema de amortecimento ..............................30

Figura 2.17 - Formação da onda no impacto (Apud Niyama, 1991).................................... 31

Figura 2.18 - Deformação do elemento de estaca, devido à propagação da onda.................. 35

Figura 2.19 - Registro típico obtido numa instrumentação dinâmica .................................... 39

Figura 2.20 - Modelo de Smith (Apud Smith, 1960) ........................................................... 40

Figura 2.21 - Esquema de Instrumentação Dinâmica ............................................................ 41

Figura 2.22 - Estaca Instrumentada com acelerômetro e transdutor de deformação (NIYAMA et al. , 1996) 
Figura 2.23 - Processo de Iteração e Simulação feito pelo

CAPWAP (Apud Hannigan, 1990) .46

Figura 2.24 - Processo de ajuste das curvas de força por iteração

(Apud Hannigan, 1990). .48

Figura 2.25 - O melhor ajuste das curvas de força e de velocidade

(Apud Hannigan, 1990). 49

Figura 2.26 - Apresentação dos resultados do CAPWAP (Apud GRL, Inc. 1996) .............. 50

Figura 2.27 - Carregamento Dinâmico Cíclico de Energia Constante (AOKI, 1997)........... 51

Figura 2.28 - Curva Resistência Estática-Deslocamento Dinâmico:

Origem Única (AOKI, 1997) 53

Figura 2.29 - Modelo de Estaca para Fórmulas Dinâmicas (Apud AOKI, 1991)

Figura 2.30 - Comparação das Curvas de Carga-Deslocamento das Provas de

Carga Dinâmica e Estática (AOKI \& NIYAMA , 1991) .58

Figura 2.31 - a) Prova de Carga na Estaca BAR-1 (MASSAD \& WINZ, 2000)

Figura 2.31 - b) Prova de Carga na Estaca HLC-4 (MASSAD \& WINZ, 2000)

Figura 2.32 - Prova de Carga na Estaca MET-1 ( Apud MASSAD \& WINZ, 2000)

Figura 2.33 - Provas de Carga em duas estacas, em São Bernardo do

Campo (MASSAD \& WINZ, 2000)

Figura 2.34 - Provas de Carga em 3 Estacas Escavadas no Campo Experimental de São Carlos ( Apud MASSAD \& WINZ, 2000)

Figura 2.35 - Perfíl Geotécnico e Arranjo das Estacas (KORMANN et al. , 2000)

Figura 2.36 - Resultados das Provas de Carga Estática

(Apud KORMANN et al. , 2000).

Figura 2.37 - Resultados das Provas de Carga Estática e das Simulações do Programa

CAPWAP, para a Estaca CFA-1 (KORMANN et al. , 2000). .65 
Figura 2.38 - Resultados das Provas de Carga Estática e das Simulações do Programa CAPWAP, para a Estaca CFA-2 (KORMANN et al. , 2000)..... .66

Figura 2.39 - Curva carga recalque de Provas de Carga Estática e Dinâmica (FALCONI et al. , 1999) .66

Figura 2.40 - Comparação entre a Carga de Ruptura Determinada por Vários Métodos ......67

Figura 2.41 - Comparação do Ensaio Estático com os Resultados do CAPWAP (Apud Goble, 1980) 67

Figura 2.42 - Curvas Carga-Recalque da Prova de Carga Estática e a Curva Carga-Recalque da Prova de Carga Dinâmica Analisada pelo Programa CAPWAPC (GUORAN \& JIADUO, 2000) .70

Figura 2.43 - Comparação entre Prova de Carga Estática e Dinâmica ( LIMA, 1999)........71

Figura 2.44 - Curvas Carga-Recalque provenientes de Provas de Carga Estática (CARNEIRO, 1999)

Figura 2.45 - Curvas Carga-Recalque provenientes de Provas de Carga Dinâmica (CAMPELO, 1999) .76

Figura 3.1 - Perfil geológico da região de São Carlos, BORTOLUCCI (1983) 77

Figura 3.2 - Seção esquemática da geologia de pequena profundidade em São Carlos (BORTOLUCCI, 1983)..... .78

Figura 3.3 - Curvas granulométricas obtidas para as profundidades de 3,0; 5,0 e 8,0 m, em relação à superfície do terreno (MACHADO, 1998) 79

Figura 3.4 - Localização dos ensaios geotécnicos no campo experimental de fundações ... 81 Figura 3.5 - Perfil do terreno associado às sondagens da campanha 03 (SANTOS, 2001) . 82 Figura 3.6 - Variação do NSPT médio em função da profundidade para cada campanha de sondagem realizada 
Figura 3.7 - a ) Variação da resistência de ponta unitária média qc em função da profundidade para cada campanha.

Figura 3.7 - b) Variação da resistência por atrito lateral unitário média qc em função da profundidade para cada campanha

Figura 3.8 - a) Esquema de localização das campanhas de SPT .84

Figura 3.8 - b) Esquema de localização das campanhas de CPT/CPTU

Figura 3.9 - Chuvas acumuladas durante os anos em que se realizaram ensaios de investigação geotécnica.

Figura 3.10 - Variabilidade do maciço de solos em função do NSPT e estratigrafia para a campanha 01 de sondagem à percussão .86

Figura 3.11 - Variabilidade do maciço de solos em função do NSPT e estratigrafia para a campanha 02 de sondagem à percussão

Figura 3.12 - Variabilidade do maciço de solos em função do NSPT e estratigrafia para a campanha 02 de sondagem à percussão

Figura 3.13 - Variabilidade do maciço de solos em função do NSPT e estratigrafia para as campanhas de sondagens 01,02 e 03

Figura 3.14 - Variabilidade do maciço de solos em função do fs e da estratigrafia para a campanha 01 de penetração contínua "CPT"

Figura 3.15 - Variabilidade do maciço de solos em função do qc e da estratigrafia para a campanha 01 de penetração contínua "CPT"

Figura 3.16 - Variabilidade do maciço de solos em função do fs e da estratigrafia para a campanha 02 de penetração contínua "CPTU".

Figura 3.17 - Variabilidade do maciço de solos em função do qc e da estratigrafia para a campanha 02 de penetração contínua "CPTU" 
Figura 3.18 - Variabilidade do maciço de solos em função do qc e da estratigrafia para as campanhas 01 e 02 de penetração contínua "CPTU" 90

Figura 4.1 - Detalhe geométrico do tubulão antes da prova de carga estática ..................... 93

Figura 4.2 - a) Detalhe geométrico do tubulão TE01 após a prova de carga dinâmica......... 93

Figura 4.2 - b) Foto da transição de materiais do fuste do tubulão TE01 ............................93

Figura 4.2 - c) Foto do encontro entre o fuste e a base do tubulão TE01 .............................93

Figura 4.3 - a) Detalhe geométrico do tubulão TE02 após a prova de carga dinâmica.........94

Figura 4.3 - b) Foto da transição de materiais do fuste do tubulão TE02 ........................... 94

Figura 4.3 - c) Foto do encontro entre o fuste e a base do tubulão TE02 ............................94

Figura 4.4 - a) Detalhe geométrico do tubulão TE03 após a prova de carga dinâmica.........94

Figura 4.4 - b) Foto da transição de materiais do fuste do tubulão TE03 …......................... 94

Figura $4.4-$ c) Foto do encontro entre o fuste e a base do tubulão TE03 …….................... 94

Figura 4.5 - a) Detalhe geométrico do tubulão TE04 após a prova de carga dinâmica.........95

Figura 4.5 - b) Foto da transição de materiais do fuste do tubulão TE04 ........................... 95

Figura 4.5 - c) Foto do encontro entre o fuste e a base do tubulão TE04 ...........................95

Figura 4.6 - Localização dos tubulões especiais no Campo Experimental de

Fundações da EESC/USP............................................................................ 96

Figura 4.7 - a) Vista da realização da prova de carga dinâmica de energia crescente ..........97

Figura 4.7 - b) Vista de um dos acelerômetros e um dos transdutores de deformação .........97

Figura 4.8 - Destruição de Parte da Cabeça do Tubulão TE01 …….....................................98

Figura 4.9 - Inundação do Tubulão TE01 ……............................................................ 99

Figura 5.1 - Determinação da Resistência do Concreto Através do Esclerômetro ................ 100

Figura 5.2 - Determinação do Peso Específico do Concreto.................................................. 101

Figura 5.3 - Realização da Prova de Carga de Energia Crescente ....................................... 101

Figura 5.4 - Acelerômetro e Transdutores de Deformação ................................................. 102 


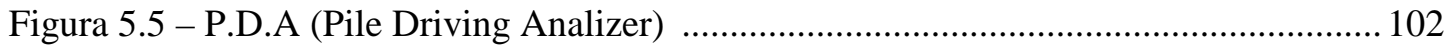

Figura 5.6 - Levantamento Topográfico feito com Estação Total ....................................... 103

Figura 6.1 - Variação da pressão de sucção com a profundidade, terreno não-inundado ... 105

Figura 6.2 - Variação da pressão de sucção com a profundidade, terreno pré-inundado...... 105

Figura 6.3 - Comparação entre medida de deslocamento do topo através do

PDA e do papel e lápis para o TE 01 106

Figura 6.4 - Comparação entre medida de deslocamento do topo através do

PDA e do papel e lápis para o TE 02 106

Figura 6.5 - Comparação entre medida de deslocamento do topo através do

PDA e do papel e lápis para o TE 03

Figura 6.6 - Comparação entre medida de deslocamento do topo através do PDA e do papel e lápis para o TE $041^{\circ}$ e $2^{\circ}$ Ensaio........

Figura 6.7 - Comparação entre medida de deslocamento do topo através do PDA e do papel e lápis para o TE $043^{\circ}$ e $4^{\circ}$ Ensaio. .108

Figura 6.8 - Resistência total x deslocamento dinâmico para TE01 109

Figura 6.9 - Resistência total x deslocamento dinâmico para TE02 . 109

Figura 6.10 - Resistência total x deslocamento dinâmico para TE03 110

Figura 6.11 - Resistência total x deslocamento dinâmico para TE04 110

Figura 7.1 - Curva carga-recalque do tubulão TE01 111

Figura 7.2 - Curva carga-recalque do tubulão TE02 112

Figura 7.3 - Curva carga-recalque do tubulão TE03 112

Figura 7.4 - Curva carga-recalque do tubulão TE04

Figura 7.5 - Parcela de resistência de ponta e lateral em função da energia aplicada ao sistema 117

Figura 7.6 - Análise estatística da resistência mobilizada total 
Figura 7.7 - Análise estatística da resistência lateral mobilizada .......................... 120

Figura 7.8 - Análise estatística da resistência lateral mobilizada ........................... 121

Figura 7.9 - Análise estatística da resistência lateral mobilizada ........................... 122

Figura 7.10 - Análise estatística da resistência lateral mobilizada .......................... 123

Figura 7.11 - Análise estatística da resistência lateral mobilizada .......................... 124

Figura 7.12 - Análise estatística da resistência lateral mobilizada .......................... 125

Figura 7.13 - Análise estatística da resistência lateral mobilizada .......................... 126

Figura 7.14 - Eficiência do Bate-Estaca para o $1^{\circ}$ Ensaio do TE01 ….................................. 130

Figura 7.15 - Eficiência do Bate-Estaca para o $2^{\circ}$ Ensaio do TE01......................... 130

Figura 7.16 - Eficiência do Bate-Estaca para o $1^{\circ}$ Ensaio do TE02 ...................................... 131

Figura 7.17 - Eficiência do Bate-Estaca para o $2^{\circ}$ Ensaio do TE02 ..................................... 131

Figura 7.18 - Eficiência do Bate-Estaca para o $1^{\circ}$ Ensaio do TE03 ..................................... 131

Figura 7.19 Eficiência do Bate-Estaca para o $2^{\circ}$ Ensaio do TE03............................ 132

Figura 7.20 Eficiência do Bate-Estaca para o $1^{\circ}$ Ensaio do TE04 …................................... 132

Figura 7.21 Eficiência do Bate-Estaca para o $2^{\circ}$ Ensaio do TE04 ….................................... 132

Figura 7.22- Eficiência do Bate-Estaca para o $3^{\circ}$ Ensaio do TE04 ….................................. 133

Figura 7.23- Eficiência do Bate-Estaca para o $4^{\circ}$ Ensaio do TE04 …...................................... 134 


\section{LISTA DE TABELAS}

Tabela 2.1 - Valores de Jc para o método CASE (RAUSCHE et al. , 1985) .........................44

Tabela 2.2 - Valores de C3 sugeridos por SOUZA FILHO \& ABREU (1990) ..................... 56

Tabela 2.3 - Características Gerais das estacas e Subsolo ( MASSAD \& WINZ, 2000)..... 61

Tabela 2.4 - Máxima Carga Aplicada e Máximo Recalque dos Tubulões .............................74

Tabela 2.5 - Resistência Mobilizada e Deslocamentos de Tubulões provenientes de

Provas de Carga Dinâmica, Analisadas pelo Programa CAPWAP …….......... 76

Tabela 3.1- Frações granulométricas constituintes dos solos (MACHADO, 1998) .............. 80

Tabela 3.2 - Valores de peso específico seco e teor de umidade obtidos ao longo do perfil de coleta de blocos indeformados (MACHADO, 1998) .................... 80

Tabela 3.3 - Resultados dos ensaios de caracterização e compactação

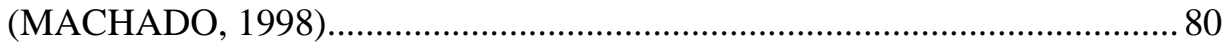

Tabela 3.4 - Valores de chuvas acumuladas 4 meses antes das campanhas ............. 85

Tabela 4.1 - Seqüência de realização das provas de carga dinâmica de energia crescente.. 96

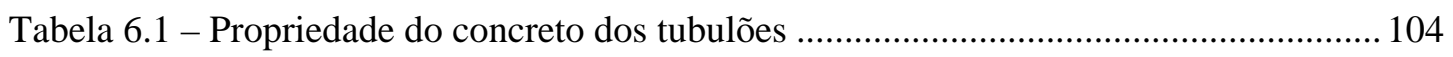

Tabela 7.1 - Tensões Máximas Aplicadas no Solo Abaixo das Bases dos Tubulões ...........114

Tabela 7.2 - Análise do último golpe da prova de carga dinâmica de energia crescente ..... 115

Tabela 7.3 - Resultados das Provas de Carga Estática ........................................................ 127

Tabela 7.4 - Resultados Médios da Análise Estatística das Provas de Carga Dinâmica...... 127

Tabela 7.4 - Resultados Médios da Análise Estatística das Provas de Carga Dinâmica...... 129 


\title{
LISTA DE ABREVIATURAS E SIGLAS
}

\author{
ABNT - Associação Brasileira de Normas Técnicas \\ CAPWAP - Case Pile Wave Analysis Program \\ CASE - Case Institute of Technology \\ NBR - Norma Brasileira Registrada \\ PDA - Pile Driving Analyser
}




\section{LISTA DE SÍMBOLOS}

$Q$ - Carga ou carregamento

$\mathrm{d} Q$ - Incremento infinitesimal de carga

$Q_{\mathrm{u}}$ - Carga última ou de ruptura

$Q_{1}$ - Carga limite correspondente ao deslocamento $\mathrm{s}_{1}$

$Q_{\text {pic }}$ - Carga de pico

$s$ - Deslocamento ou recalque

$s_{\mathrm{p}}-$ Deslocamento ou recalque permanente

$s_{\mathrm{u}}$ - Deslocamento permanente correspondente a carga última

$s_{1}$ - Deslocamento ou recalque limite que define a ruptura convencional

$s_{\text {pic }}-$ Deslocamento ou recalque na carga de pico

$R_{t}-$ Resistência total (estática + dinâmica)

Rt - Resistência total (estática + dinâmica)

RS - Resistência estática

RD - Resistência dinâmica

$\mathrm{R}_{\mathrm{T}}$ - Resistência estática mobilizada analisada pelo CAPWAP (resistência lateral + resistência de ponta)

$\mathrm{R}_{\mathrm{L}}$ - Resistência lateral mobilizada

$\mathrm{R}_{\mathrm{P}}-$ Resistência de ponta mobilizada

D - Deslocamento do topo do tubulão medido com papel e lápis

DMX - Máximo deslocamento do topo do tubulão medido a nível dos sensores 


\section{RESUMO}

SOARES, F. L. (2002). Análise de provas de carga dinâmica em tubulões a céu aberto, no campo experimental de fundações da EESC. São Carlos, 2002. 158p. Dissertação (Mestrado) - Escola de Engenharia de São Carlos, Universidade de São Paulo.

Apresenta-se o conceito de elemento isolado de fundação em tubulão, e analisa-se 10 provas de carga dinâmica de energia crescente, nos tubulões, considerando as provas de carga estática realizadas anteriormente nos mesmos. Os ensaios são realizados em tubulões a céu aberto, situados em maciço de solo da formação Rio Claro e Itaqueri, no Campo Experimental de Fundações da USP/EESC. As análises baseiam-se em curvas de resistência $\mathrm{x}$ deslocamento e gráficos que mostram a evolução da resistência mobilizada com o aumento da energia aplicada, resultantes dos impactos do ensaio dinâmico de energia crescente (metodologia PDA e análises CAPWAP).

Analisam-se também a influência da pré-inundação e da variação da sucção do maciço de solos nos ensaios dinâmicos, o efeito do reensaio e a variabilidade nos resultados de ensaios de investigação geotécnica (SPT e CPT), realizados no Campo Experimental.

Os resultados das provas de carga dinâmica de energia crescente mostram que a resposta do sistema isolado de fundação em tubulão é diferente a cada nível de energia aplicada e que a história de carregamento do elemento isolado de fundação é de extrema importância para análise dos ensaios nele realizado.

Palavras-Chave: Tubulões a Céu Aberto, Prova de Carga Estática, Prova de Carga Dinâmica, Solo Não-Saturado 


\section{ABSTRACT}

SOARES, F. L. (2002). Analysis of dynamic loading test in large diameter bored piles, in the experimental field of EESC. São Carlos, 2002. 158p. Dissertação (Mestrado) Escola de Engenharia de São Carlos, Universidade de São Paulo.

The concept of an isolated foundation element in large diameter bored pile is presented and 10 dynamic loading tests with increased energy are analysed. The interpretation of the dynamic loading tests has been proceeded with due consideration of the results of static loading tests performed previously. The loading tests have been carried out in large diameter bored piles founded in Rio Claro and Itaqueri soil formation, situated in the Experimental Foundation Field of USP/EESC. The analyses are based on resistance $\mathrm{x}$ displacement curves and selected graphics illustrating the development of mobilized resistance with increasing applied energy during a dynamic loading test (PDA methodology and CAPWAP type analysis).

The influence of previous inundation in soil mass and suction variation are also analysed, as well as the effect of test repetition and variability in SPT and CPT results.

The results obtained with the dynamic loading tests with increasing energy revealed a distinct behaviour of the isolated foundation system for each level of applied energy, showing that the loading history is an aspect of extreme relevance to an adequate analysis of the dynamic tests perfomed.

Keywords: Large Diameter Bored Piles, Static Load Test, Dynamic Loading Test, Unsaturated Soil. 


\section{CAPÍTULO 1 - INTRODUÇÃO}

\section{1 - Generalidades}

Os tubulões a céu aberto representam o tipo de fundação empregado, em larga escala, na maioria das obras de fundações de médio a grande porte no Brasil, sobretudo, no interior de São Paulo, devido ao seu baixo custo e também por encontrar-se em um solo poroso, que apresenta facilidade para escavação manual, e, simultaneamente, estabilidade em cortes verticais.

Para o melhor entendimento deste trabalho, esclarece-se alguns termos geotécnicos utilizados:

O elemento isolado de fundação, visto na Figura 1.1, é o sistema formado pelo elemento estrutural de fundação (EEF) e o maciço de solo (MS) que o envolve, CINTRA \& AOKI (1999). A fundação de uma obra é um conjunto de elementos isolados de fundação que suportam as cargas impostas.

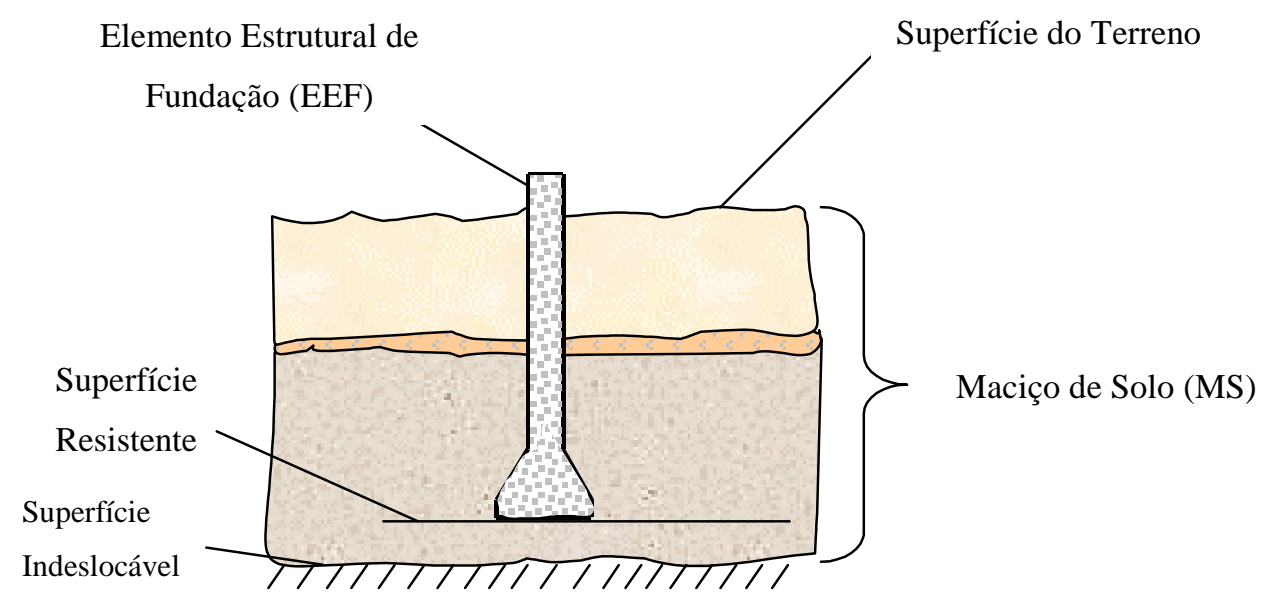

Figura 1.1 - Representação do elemento isolado de fundação 
O comportamento do elemento isolado de fundação depende basicamente das propriedades dos materiais, da geometria do elemento estrutural de fundação e dos elementos de solo que fazem parte do sistema. O objetivo da prova de carga estática ou dinâmica é a determinação da capacidade de suportar a carga do sistema.

Uma estaca pode estar submetida a um carregamento estático ou dinâmico. O carregamento diz-se estático, quando se aplicam acréscimos de carga infinitamente pequenos, por um período de tempo infinitamente grande. Já o carregamento diz-se dinâmico, quando é caracterizado pela aplicação de uma carga que varia ao longo do tempo. Segundo ÁVILA 2001, um exemplo típico de um carregamento dinâmico, que dura alguns milisegundos, é o impacto de um martelo caindo de uma certa altura, que é chamado também de carregamento transiente, pois é aplicado durante um intervalo de tempo finito.

A capacidade de carga do sistema é a máxima resistência oferecida pelo elemento isolado de fundação, a qual é limitada pelo elo mais fraco do sistema: elemento estrutural ou o maciço de solos.

\section{2 - Objetivos}

Esta dissertação tem como objetivo analisar o comportamento de tubulões a céu aberto do Campo Experimental de Fundações da EESC/USP, através de resultados de provas de carga estática e dinâmica, levando em consideração o período transcorrido entre a realização desses dois tipos de prova de carga, o efeito do reensaio e da sucção.

\section{3 - Organização da Dissertação}

Após a introdução, será apresentada, no Capítulo 2, a revisão bibliográfica sobre o assunto em estudo. Primeiro, relatar-se-á sobre os conceitos de tubulão, as vantagens e desvantagens do seu uso, a capacidade de carga e o comportamento de tubulões. Em seguida, abordaremos a prova de carga estática e a análise da curva carga-recalque, e como último item deste capítulo, teremos a prova de carga dinâmica, as fórmulas 
dinâmicas, a teoria da equação da onda, as técnicas de instrumentação, os métodos de análise CASE e CAPWAP e a diferença do ensaio dinâmico de energia constante e crescente. No Capítulo 3, abordaremos o Campo Experimental de São Carlos, considerando a caracterização geológica, geotécnica e a variabilidade do maciço de solos. No Capítulo 4, relataremos a metodologia e os procedimentos adotados, para a realização das provas de carga dinâmica de energia crescente. No Capítulo 5 , mostraremos os materiais e equipamentos utilizados nos ensaios. Já no Capítulo 6, apresentaremos todos os resultados da pesquisa corrente. No Capítulo 7, faremos uma análise dos resultados, considerando a história do carregamento dos tubulões. No Capítulo 8 e último apresentamos as conclusões e sugestões para futuros trabalhos. 


\section{CAPÍTULO 2 - REVISÃO BIBLIOGRÁFICA}

\section{1 - Tubulões}

\subsection{1 - Conceitos sobre Tubulões}

A NBR-6122 (1996), Norma Brasileira para Projeto e Execução de Fundações, define tubulão como um elemento de fundação profunda, de geometria cilíndrica, em que, pelo menos na sua etapa final, há descida de operário.

Segundo CAPUTO (1977), os tubulões são fundações construídas concretando-se um poço aberto no terreno, ou fazendo descer, por escavação interna, um tubo, geralmente de concreto armado ou de aço, que é posteriormente cheio com concreto simples ou armado. No caso de revestimento com tubo metálico, este poderá ou não ser recuperado.

Segundo BERBERIAN (1999), a rigor, a única diferença entre estacas e tubulões é o fato de que, no tubulão, sempre se prevê a descida do homem, para escavá-lo ou fiscalizar sua execução.

ALBIEIRO \& CINTRA (1996) dizem que, com a utilização de equipamentos mecânicos, para a escavação, a prática de descida de alguém até a base do tubulão poderá ser abandonada, mesmo nos casos de fustes de grande diâmetro. Afirmam também que, em muitos casos, torna-se complicado diferenciar os tubulões das estacas escavadas, e, assim, eles podem ser considerados como estacas escavadas, de grande diâmetro, com ou sem base alargada.

ALBIEIRO \& CINTRA (1996) relatam que atualmente, na literatura internacional, as fundações chamadas de tubulões no Brasil são tratadas como estacas escavadas, moldadas "in loco", com base alargada. 
Um esquema típico em pespectiva e em corte longitudinal de um tubulão pode ser visto na Figura 2.1.

ALBIEIRO \& CINTRA (1996) agrupam os tubulões em dois tipos básicos: os tubulões a céu aberto e os que empregam ar comprimido. Os tubulões a céu aberto podem ser com contenção lateral ou sem contenção lateral.

Os tubulões sem contenções laterais, também chamados de pocinhos, têm seu fuste aberto por escavação manual ou mecânica, sendo que a base é , em geral,

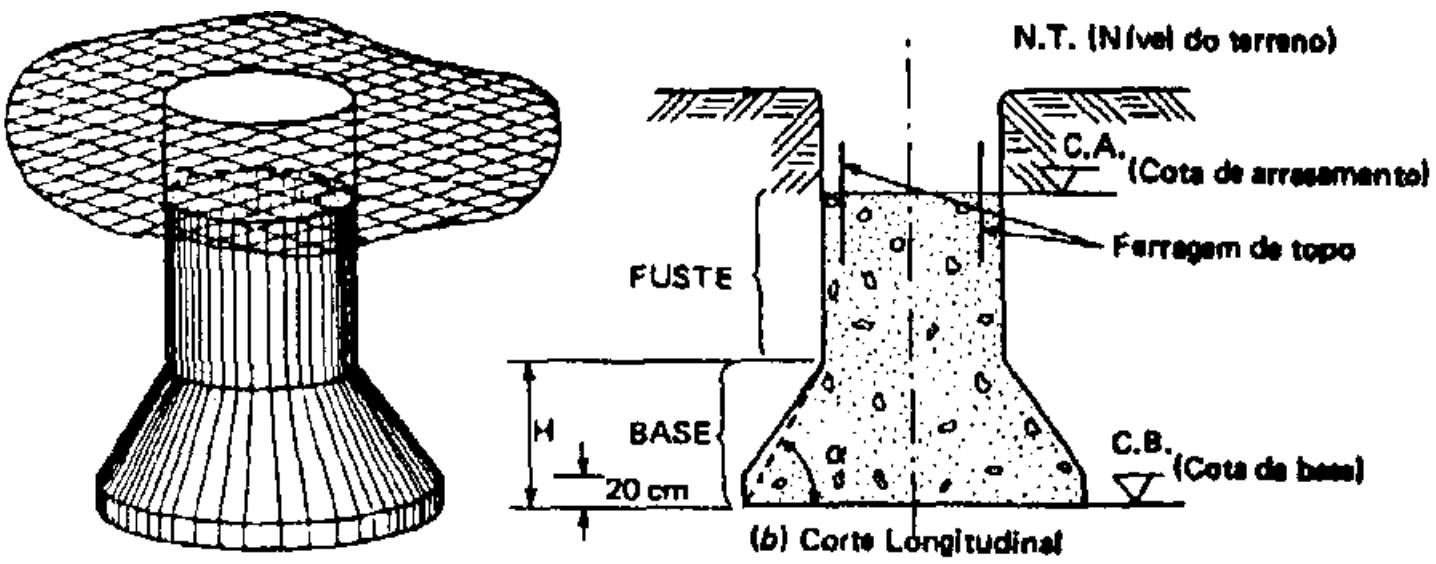

(a) Porspectiva

Figura 2.1 - Dados Geométricos de um Tubulão (ALBIERO \& CINTRA, 1996)

escavada manualmente. Já os tubulões a céu aberto, com o uso de contenção lateral, podem ter contenção parcial da ordem de dois metros ou contenção contínua.

BERBERIAN (1999) afirma que os tubulões pneumáticos ou a ar comprimido são escavados abaixo do nível d'água, sob pressão de ar comprimido, para expulsar (secar) a água do interior da escavação, e que, neste caso, os tubulões serão sempre revestidos por camisas de aço ou concreto.

ALONSO \& GOLOMBEK (1996) afirmam que, em face do desenvolvimento de outros tipos de fundações e dos custos e riscos envolvidos na execução de tubulões 
pneumáticos, estes vêm sendo menos utilizado na engenharia de fundações, com algumas exceções no ramo rodoviário, em obras de arte fora do perímetro urbano.

\subsection{2 - Vantagens e Desvantagens}

BERBERIAN (1999) diz que a escolha de um determinado tipo de fundação está baseada na trilogia de condições básicas de segurança, economia e rapidez.

HARTIKIAINEN \& GAMBIN (1994); HEYDENRYCH \& DE BEER (1975); BROMS et al (1988) e BERBERIAN (1999) citam alguns fatores que explicam o extenso uso de tubulões:

- Durante a escavação, é possível classificar o solo retirado e compará-lo às condições de projeto;

- O diâmetro dos tubulões e as profundidades de assentamento das bases podem ser modificadas durante a escavação, para compensar as condições iniciais de previsão do solo;

- Podem ser escavados através de matacões e camadas muito resistentes;

- Os custos de mobilização e desmobilização são menores, quando comparados à utilização de bate-estacas e outros equipamentos;

- Pode suportar a carga de cada pilar em um fuste único, não sendo necessário o uso de diversas estacas;

- Não produz vibrações, quando a escavação é manual, ou produz muito pouca quando mecânica.

REESE (1978) apresenta algumas desvantagem em relação ao emprego de tubulões na engenharia de fundações:

- A boa qualidade dos tubulões depende totalmente da técnica construtiva empregada; 
- A inspeção, durante as etapas de execução dos tubulões, requer uma soma de conhecimentos e experiências consideráveis, já que normalmente não é possível investigar se o fuste do tubulão apresenta-se em perfeito estado;

- Com relação à resistência ao cisalhamento do solo de apoio ao tubulão, esta é reduzida, devido aos trabalhos de escavação;

- Durante a realização de provas de carga estática em tubulões, atingir a ruptura pode ser dispendiosa, uma vez que um tubulão é projetado, para suportar cargas de elevadas magnitudes.

CINTRA (1993) afirma que algumas vantagens conduziram a uma preferência indiscriminada pelo emprego de tubulões no estado de São Paulo, principalmente, no interior do Estado, criando situações críticas, pois o uso, muitas vezes, de tubulões em situações totalmente desaconselháveis, tanto em nível técnico quanto no aspecto de segurança de funcionários, conduziu ao registro de casos de recalques excessivos após a aplicação das cargas e desmoronamentos durante o processo executivo dos tubulões. Ocorreu também a criação de um mercado que não aceitava outro tipo de fundação, forçando a adoção de elevadas taxas de trabalho para o solo, levando à redução da segurança em relação à ruptura e, mesmo, a recalques.

\subsection{3 - Capacidade de Carga}

CINTRA \& AOKI (1999) definem a capacidade de carga de um elemento isolado de fundação como a carga que provoca a ruptura do sistema (elemento estrutural-maciço de solo), o qual apresenta valor limitado pela resistência do elemento estrutural.

Segundo BAZANT (1961), a capacidade de carga de tubulões pode ser escrita como função de inúmeras variáveis independentes do problema, como: carga aplicada no topo 
(forma de aplicação), recalque, comprimento enterrado, diâmetro, módulo de elasticidade do material constituinte do elemento estrutural de fundação.

A capacidade de carga de um elemento isolado de fundação pode ser determinada através de métodos empíricos, métodos semi-empíricos, métodos teóricos e provas de cargas estáticas e dinâmicas.

MELLO (1975) diz que o método empírico é um procedimento de "prescrição de bolso".

Já os métodos teóricos, segundo ALONSO (1983), não conduzem a resultados satisfatórios como é o caso do método teórico de TERZAGHI (1943).

Segundo DÉCOURT (1998), os métodos semi-empíricos apresentam correlações com boas probabilidades de acerto, pois a filosofia contida nas mesmas estabelece, através de ajustes estatísticos, equações que têm, embutidos em sua essência, os princípios definidos no método teórico e/ou empírico.

ALBIEIRO \& CINTRA (1996) dizem que as provas de cargas em protótipos se constituem na maneira mais confiável, para estabelecer o valor da carga limite última.

A capacidade de carga do elemento isolado de fundação profunda pode ser dividida em duas parcelas distintas: uma parcela de resistência de ponta e outra de atrito lateral. Uma prática comumente utilizada no Brasil admite, como sendo nula a parcela de resistência por atrito lateral, ao longo do fuste dos tubulões.

CARNEIRO (1999) afirma que a parcela de atrito é muito importante no comportamento dos tubulões. Deve-se considerar a contribuição da parcela de atrito lateral, visto que há uma colaboração real, principalmente quando se tratar de solo colapsível. 
SANTOS (2001) realiza provas de carga estática em tubulões e considera a influência da inundação no comportamento destes, bem como o caráter colapsível do solo e a importância da parcela de sucção na capacidade de carga dos tubulões.

Segundo CHANG \& WONG (1987), a parcela de resistência por atrito lateral tem grande importância para tubulões executados em rochas alteradas, e os projetos atuais de dimensionamento de tubulões são conservativos, já que não consideram a parcela de atrito lateral.

Ainda segundo CHANG \& GOH (1988), a contribuição por atrito lateral, para a determinação da capacidade de carga de tubulões, é negligenciada, e o projeto resultante é freqüentemente conservativo para tubulões executados em solos residuais e rochas alteradas.

A resistência devido ao atrito lateral, na maioria das vezes, é estimada através dos métodos $\alpha$ e $\beta$. O método $\alpha$ relaciona a resistência por atrito lateral unitária com a coesão não drenada do solo, determinada através de ensaios não drenados triaxiais e ensaios pressiométricos. $\mathrm{O}$ método $\beta$ relaciona a resistência por atrito lateral unitária com a tensão efetiva vertical.

Segundo MEYERHOF (1988), o tamanho e tipo de carregamento e inclinações das estacas também influenciam o valor da resistência por atrito lateral.

MATSUI (1993), KOIKE et al. (1988) e VAN IMPE (1991) afirmam que a resistência lateral unitária aumenta com o crescimento do recalque da estaca, atingindo um valor de pico, quando então sofre uma diminuição até manter um valor constante.

CARNEIRO (1999) avalia o comportamento de tubulões a céu aberto, instrumentados, em solo não-saturado e colapsível; conclui que a influência do atrito na capacidade de carga de um tubulão é muito importante. Nos tubulões com base alargada, ensaiados com o solo pré-inundado por 48 horas, obsevou-se que $25 \%$ da carga aplicada foi suportada pelo atrito lateral e os $75 \%$ restantes pela resistência de base. Nos tubulões sem base alargada, a contribuição do atrito lateral na capacidade de carga passa a ser de 70 a $80 \%$, e apenas 30 a $20 \%$ representando a carga da base. Já nos tubulões com base 
alargada, a proporção de atrito lateral ficou na faixa de 70 e $30 \%$ para a base, para o ensaio na umidade natural, mas, no reensaio, na situação de pré-inundação por 48 horas a situação se inverteu, uma faixa de 20 e $30 \%$ para o atrito lateral e 80 a $70 \%$ para a base.

A resistência de base ou de ponta unitária de tubulões pode ser estimada através de diversas relações empíricas, como as de JAMIOLKOWSKI \& LANCELLOTTA (1988), FRANKE (1989), GHIONNA et al. (1993), KRUIZINGA (1988) e REESE \& O’NEILL (1988).

\subsection{4 - Comportamento de Tubulões}

Segundo KLOSINSKI (1977), o comportamento de tubulões é diferente do comportamento de estacas escavadas de pequeno diâmetro (entre 30 e $50 \mathrm{~cm}$ ), as quais possuem a principal parcela da capacidade de carga como sendo a resistência por atrito lateral, enquanto nos tubulões, a parcela de resistência de base é a principal parcela da capacidade de carga.

MORDHORST (1988) afirma que um dos principais objetivos da instalação de estacas escavadas ou tubulões em solos arenosos é atribuída à resistência que estes solos possuem. 
FRANKE \& GARBHECHT (1977) afirmam que, para tubulões em solos arenosos, a influência do comprimento do fuste não apresenta significativa diferença do valor da pressão na base do tubulão, tanto para tubulões com comprimentos diferentes e com base ou sem base alargada.

O’NEILL \& REESE apud DE BEER (1988) dizem que, para solos argilosos, o atrito lateral é completamente mobilizado para recalques do topo da estaca, variando entre 3 e 10 milímetros ou recalques relativos de 0,392 até $1,3 \%$.

CARNEIRO (1999) avalia o comportamento de tubulões a céu aberto, instrumentados, em solo não-saturado e colapsível. Conclui que, em nenhuma prova de carga foi observada qualquer tendência de que algum tubulão ensaiado fosse apresentar a ruptura nítida mencionada na NBR-6122, isto é, a definição de um patamar descendente vertical, causado pela aplicação de uma carga que provocasse recalques incessantes.

CAMPELO et al. (2000) analisam provas de carga dinâmicas realizadas em oito tubulões a céu aberto, escavados mecanicamente no campo experimental de fundações da USP/São Carlos. Conclui que a utilização das curvas adimensionalizadas de resistência mobilizada, deslocamento e energia pode ser útil na avaliação do comportamento de tubulões, tanto com a finalidade de saber quem comanda esse comportamento (se a resistência do solo ou a resistência estrutural do elemento) quanto a melhor definição da resistência mobilizada última.

CARNEIRO (1999) avalia o comportamento de tubulões a céu aberto, instrumentados, em solo não-saturado e colapsível. Conclui que a variação da carga máxima, em decorrência da variação do teor de umidade, no caso por inundação da cava de superfície em torno do tubulão, apresentou um surpreendente patamar de $40 \%$, quando se compara o tubulão sem pré-inundação - que atingiu carga máxima de 1500 kN - com o tubulão com pré-inundação - que atingiu carga máxima de 900 kN. 
SANTOS (2001) verifica, através de resultados de provas de carga em tubulões a céu aberto, em solo não-saturado e colapsível, que a sucção tem um efeito direto no comportamento dos tubulões a céu aberto, e, comparando-se ensaios inundados com os ensaios sem inundação do terreno, o colapso do solo apresenta-se mais elevado com o aumento da pressão de sucção. 


\section{2 - Prova de Carga Estática}

A prova de carga estática é um ensaio típico mais tradicional de verificação de desempenho de uma fundação. $O$ ensaio consiste em obter a curva carga-recalque, a fim de analisar o comportamento da fundação. No Brasil, as provas de carga estática são regidas pela NBR-3472.

NIYAMA et al. (1996) afirmam que, dentre os ensaios de campo utilizados na engenharia de fundações, destacam-se as provas de carga estática, como um dos mais importantes. Seu emprego no Brasil data provavelmente de 1928, quando foi realizado o estudo das fundações do edifício Martinelli em São Paulo.

Segundo AOKI (1997), a prova de carga estática busca reproduzir a história do carregamento real de uma construção, que se realiza em estágios de carga quase sempre crescentes, ao longo do tempo, visando à avaliação da segurança que a fundação apresenta em relação ao estado último ou de ruptura.

NIYAMA et al. (1996) dizem que uma grande vantagem da prova de carga estática é se tratar de um ensaio em que se repercute o complexo comportamento do conjunto solo-fundação, influenciado pela modificação provocada no solo pelos trabalhos de infra-estrutura da obra e execução das fundações e pelas incertezas decorrentes das dificuldades executivas da fundações.

AOKI (1997) afirma que a forma de aplicação de uma carga " $\boldsymbol{Q}$ ” é dita estática, quando se leva um tempo infinito para se atingir o valor " $\boldsymbol{Q}$ " em incrementos infinitesimais de carga $\boldsymbol{d} \boldsymbol{Q}$. A aplicação da carga " $\boldsymbol{Q}$ " é dita instantânea, quando ela é atingida em um único estágio de carregamento, e o tempo " $\mathrm{t}$ " de aplicação da carga é igual a zero.

Para execução de uma prova de carga estática à compressão, existem três tipos de sistemas de reação: os tirantes, as cargueiras e as estacas de apoio, que podem ser vistos nas Figuras 2.2, 2.3 e 2.4, respectivamente. 


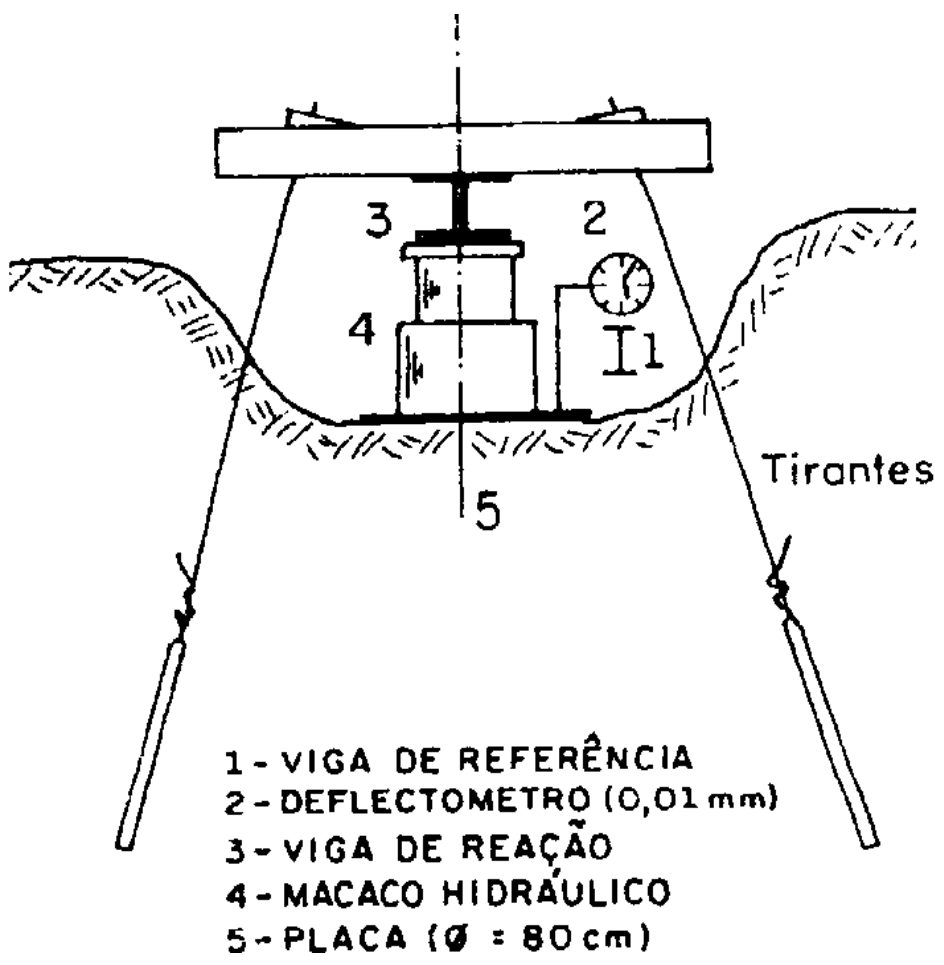

Figura 2.2 - Sistema de Reação com Tirantes (NIYAMA et al., 1996)

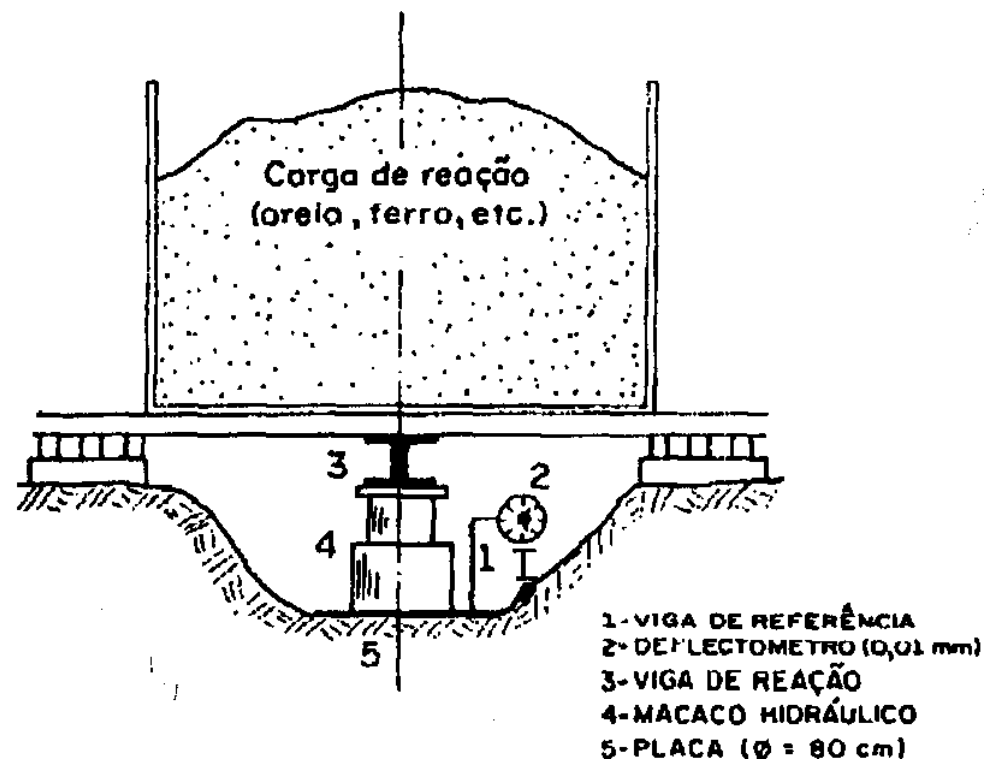

Figura 2.3 - Sistema de Reação com Cargueiras (ALONSO apud NIYAMA et al., 1996) 


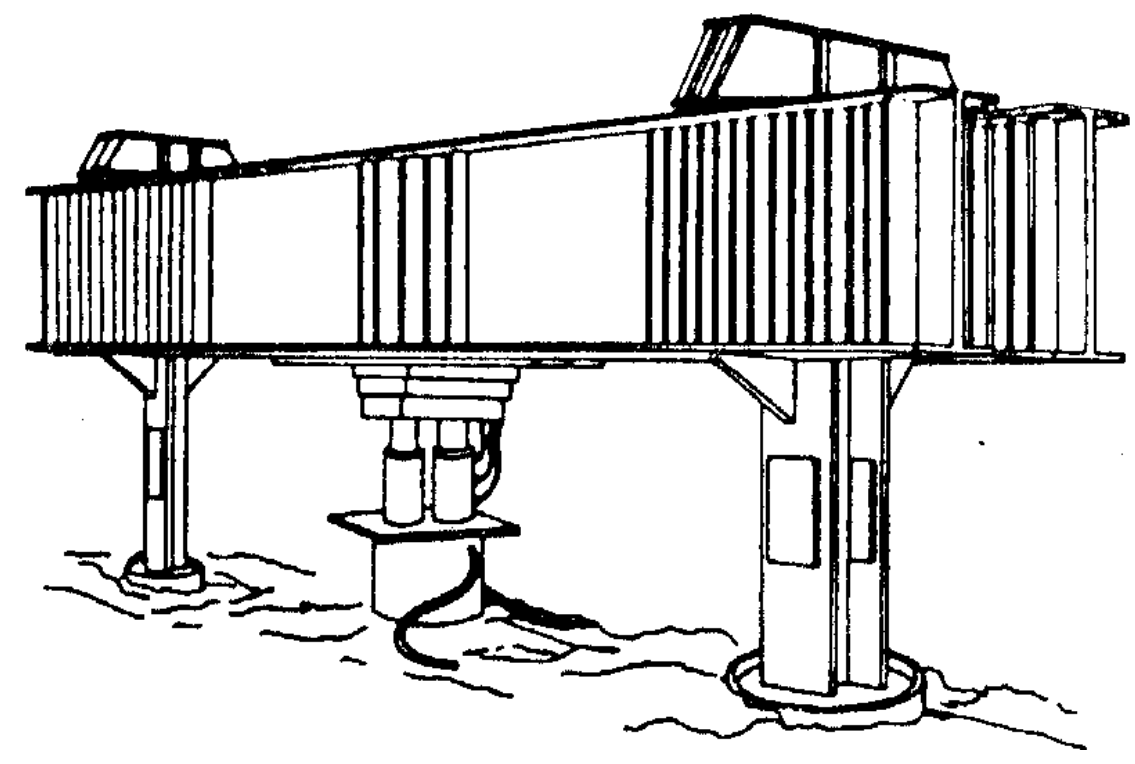

Figura 2.4 - Sistema de Reação com Estacas de Apoio (REESE \& O’NEILL, 1988)

FELLENIUS (1980), GODOY (1983) e MILITITSKY (1991) apresentam os métodos de ensaio usados na execução de prova de carga estática e as interpretações dos resultados. Estes métodos estão citados abaixo:

a) SML ou SM (Slow Maintained Load Test) - carregamento lento de carga mantida. Este ensaio é efetuado em estágios de carga crescentes, de incrementos iguais, mantendo-se, em cada estágio, a carga constante até a estabilização do recalque.

b) QML ou QM (Quick Maintained Load Test) - carregamento rápido de carga mantida. Este ensaio é efetuado em 30 a 40 estágios de carga crescentes, em incrementos iguais, mantidos por 5 a 15 minutos por estágios de carregamentos.

c) CRP (Constant Rate of Penetration) - carregamento sob velocidade constante de penetração. Este ensaio força a estaca a se deslocar, penetrando no solo a uma velocidade constante da ordem de $0,5 \mathrm{~mm} / \mathrm{min}$. 
d) CLT ou SCT (Cyclic Load Test ou Swedish Cyclic Test) - carregamento cíclico. Este ensaio é uma prova de carga cíclica, o carregamento cíclico é crescente, podendo-se ou não aguardar a estabilização do recalque, antes de se proceder a descarga em cada ciclo.

A NBR-3472 estabelece dois tipos de provas de carga aceitas para determinação da capacidade de carga de um elemento de fundação: a QML (carregamento rápido) e a SML (carregamento lento), com a estabilização para cada estágio.

Segundo FELLENIUS (1980), o ensaio do tipo rápido (QML), com aplicação de estágios em intervalos constantes de tempo, é mais representativo por apresentar uma melhor definição da curva carga-recalque e é superior ao ensaio tipo lento (SML) do ponto de vista técnico, prático e econômico, pois se reduz o tempo de ensaio, e melhoram-se as estimativas do comportamento do elemento ensaiado.

MILITITSKY (1991) afirma que, da mesma forma que a velocidade da solicitação influi na resistência ao cisalhamento dos solos, especialmente das argilas, altera o comportamento das fundações em solos argilosos. A elevada velocidade de carregamento provoca aumento de capacidade de carga e de rigidez.

A afirmação de MILITITSKY (1991) serve para alertar a necessidade de análise cuidadosa, ao se comparar ensaios com métodos diferentes.

\subsection{1 - Análise da Curva Carga-Recalque}

Adotou-se, neste item, o conceito sugerido por CINTRA (1998), considerando que:

a) Carga última ou Ruptura Física - é a resistência máxima que o sistema solofundação pode oferecer, teoricamente correspondendo a recalques finitos (estado limite último). 
b) Capacidade de Carga e Carga de Ruptura - refere-se a qualquer critério de ruptura, incluindo-se a ruptura física (critério de Van Der Veen, por exemplo) e a ruptura convencional (imposição de um recalque arbitrário para caracterização de ruptura - critério da NBR 6122/96, por exemplo).

c) Carga Mobilizada - é a resistência máxima oferecida pelo sistema estaca-solo para um nível de energia aplicada, geralmente não representando a carga de ruptura física.

AOKI (1997) afirma que a determinação da carga estática última exige um sistema de reação adequado, para levar o sistema à ruptura.

A seguir, apresentaremos alguns modelos de comportamento da curva cargarecalque. A Figura 2.5 apresenta o modelo ideal de curva carga-recalque no caso em que todos os materiais do sistema estaca-maciço de solos apresentam comportamento elástico-perfeitamente plástico.

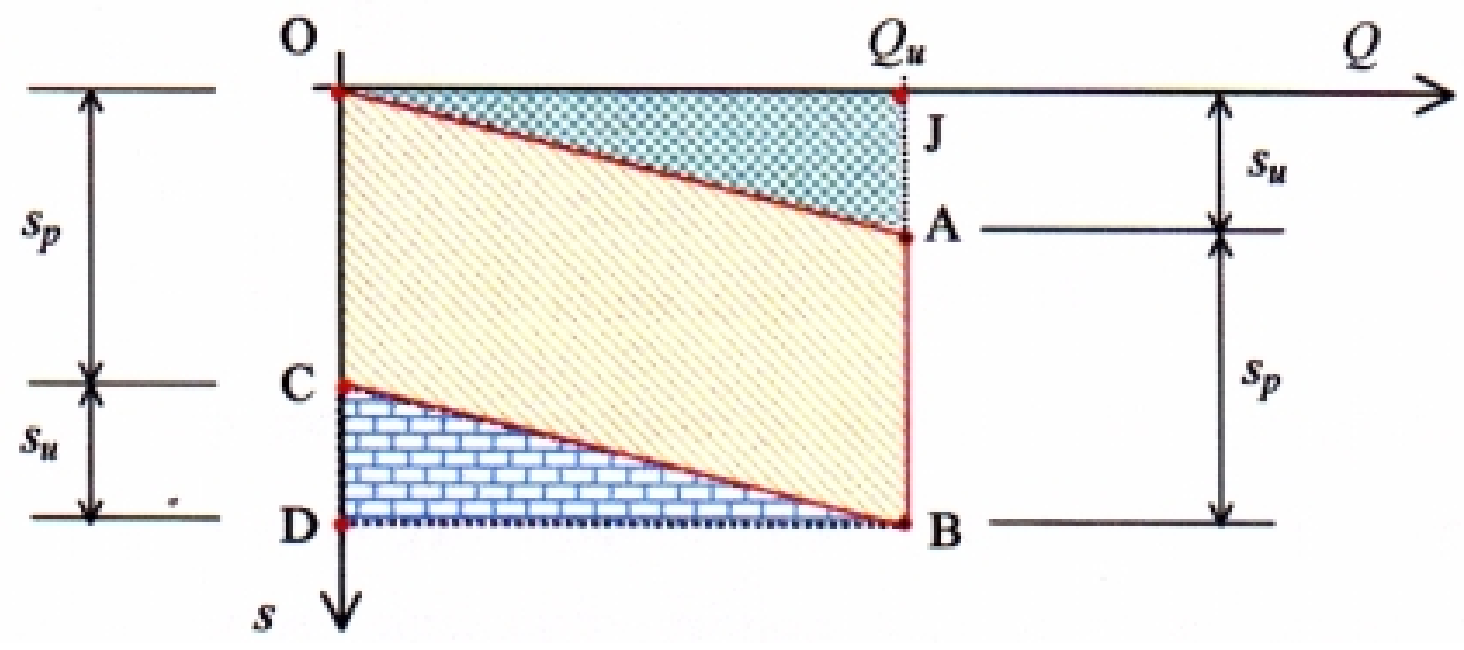

Figura 2.5 - Modelo Ideal de Curva Carga-Deslocamento Elástico-Plástico (AOKI, 1997)

A Figura 2.6 apresenta uma curva carga-recalque típica, em que se verifica um trecho inicial aproximadamente linear, seguido de um trecho de curvatura variada, 
devido ao comportamento não linear, função da geometria da estaca, das propriedades reológicas dos materiais e da proximidade da superfície do indeslocável.

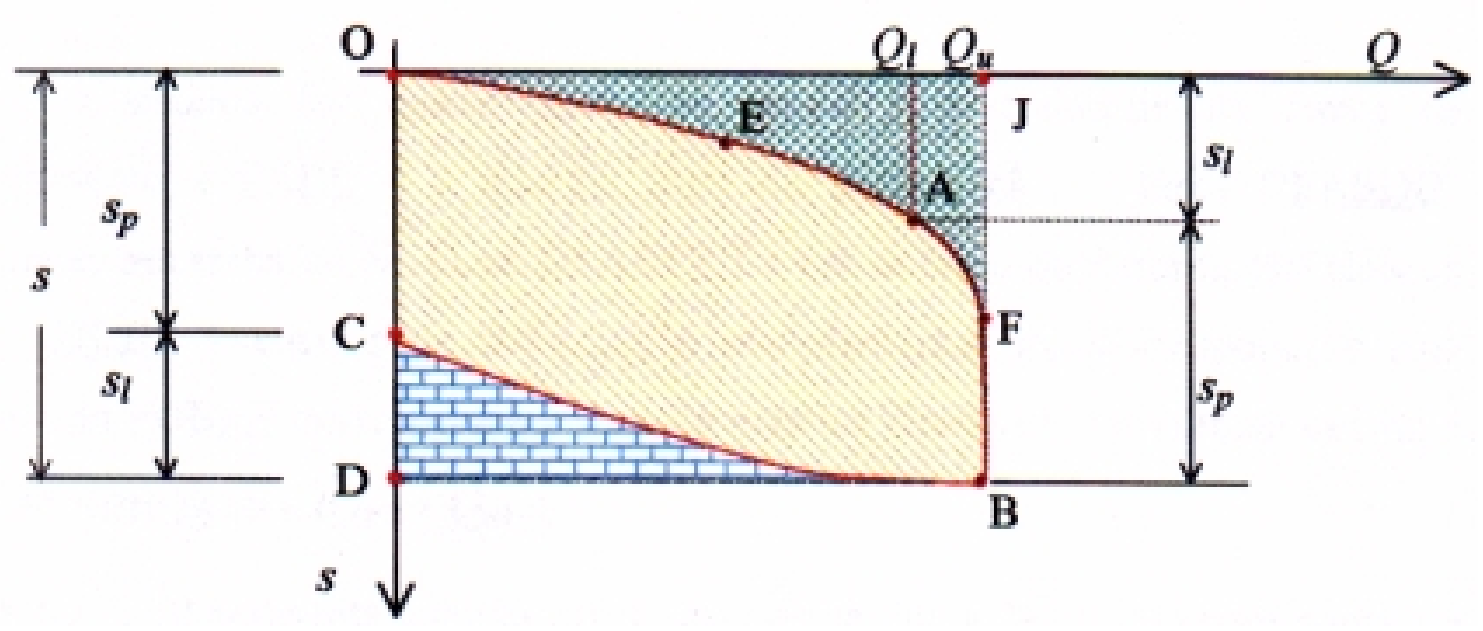

Figura 2.6 - Curva Carga-Recalque (AOKI, 1997)

A Figura 2.7 mostra a curva carga-recalque típica de estaca de atrito em solo argiloso. Nesse caso, a curva apresenta um trecho aproximadamente linear até um determinado ponto onde ocorre um pico de carga máxima mobilizada $\mathrm{Q}_{\text {pic }}$ para o recalque $s_{\text {pic }}$, a partir do qual ocorre uma redução de resistência por atrito lateral, com diminuição da carga mobilizada, que se estabiliza no valor da carga $\mathrm{Q}_{\mathrm{u}}$ sobre a assintota vertical da curva carga -recalque. 


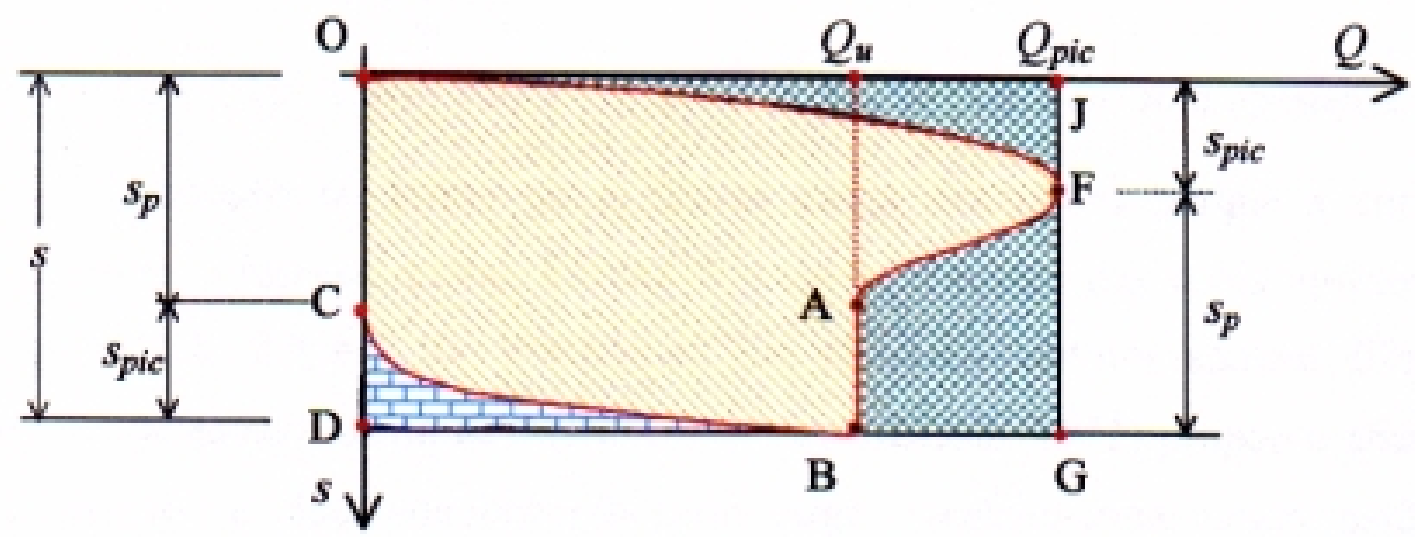

Figura 2.7- Curva Carga-Recalque, Estaca de Atrito em Solo Argiloso (AOKI, 1997)

A Figura 2.8 mostra o caso em que o deslocamento do sistema cresce com o aumento de carga, e a assintota vertical da curva tende para o infinito.

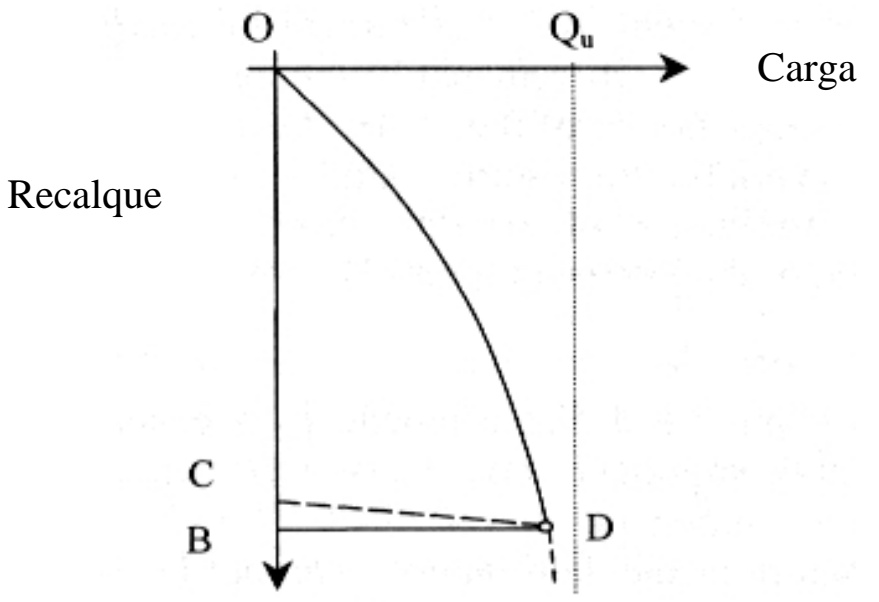

Figura 2.8 - Curva Carga-Deslocamento (AOKI, 2000)

Já a Figura 2.9 apresenta a curva carga-recalque típica de estacas com ponta em solo resistente, em que predomina a resistência de ponta. 


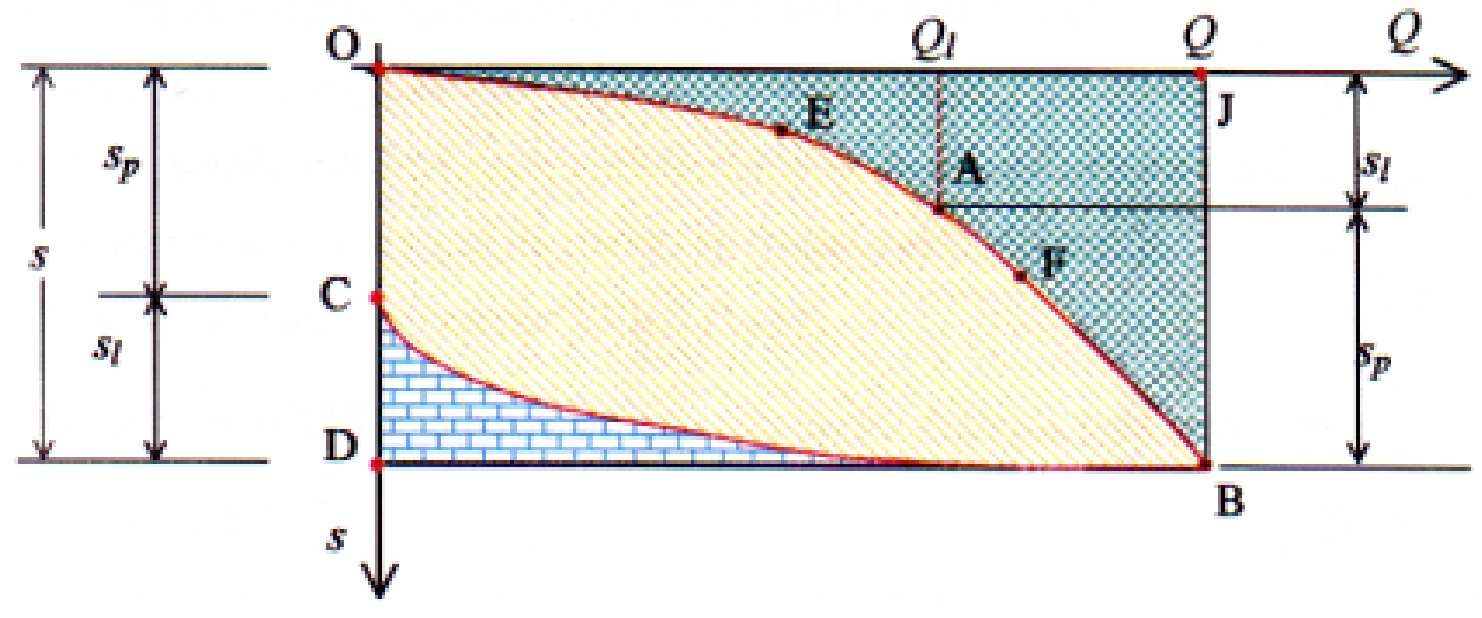

Figura 2.9 - Curva Carga-Recalque, Estaca de Ponta em Solo Resistente (AOKI, 1997)

Através das curvas mostradas nas Figuras 2.6 à 2.9, observa-se que a forma da curva carga-recalque é muito variada. Como geralmente uma prova de carga não é levada até a ruptura física, houve a necessidade de se determinar um valor de carga que limitasse o uso da fundação. Sendo assim, diversos engenheiros convencionaram métodos, para limitar a carga a ser aplicada ao sistema solo-fundação ou criaram métodos, para a extrapolação da curva carga-recalque interrompidas prematuramente, denominando esta carga limite como carga de ruptura. Dessa forma, o termo carga de ruptura indica um tipo de ruptura convencional ou física.

Em VESIC (1975) são abordados os diversos métodos para se determinar a carga de ruptura.

Segundo FELLENIUS (1980), para ser útil a definição de ruptura precisa ser baseada em alguma regra matemática, e gerar um valor independente da variação de escalas e de opiniões de uma determinada pessoa. De alguma maneira, ela precisa considerar a forma da curva carga-recalque, ou, caso não o faça, levar em conta o comprimento da estaca ( que a forma da curva indiretamente considera). Sem essa definição apropriada, toda a interpretação perde o significado. 
Alguns métodos, por serem de importância para este trabalho, serão descritos a seguir.

A NBR-6122 (1996) estabelece que a carga de ruptura pode ser convencionada como aquela que corresponde ao recalque $\rho_{\mathrm{r}}$, apresentado na curva carga-recalque da Figura 2.10.

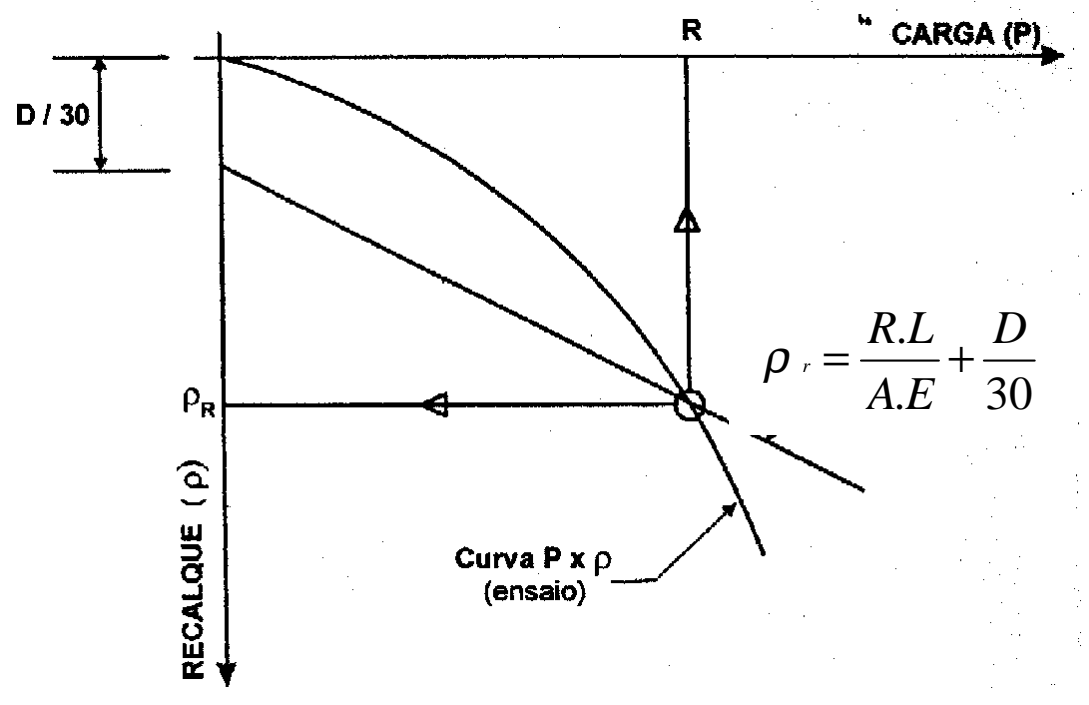

Figura 2.10 - Carga de Ruptura Convencional (NBR 6122, 1996)

Onde,

$\mathrm{R} \rightarrow$ Carga de Ruptura Convencional

$\mathrm{L} \rightarrow$ Comprimento da Estaca

$\mathrm{A} \rightarrow$ Área da Seção Transversal da Estaca

$\mathrm{E} \rightarrow$ Módulo de Elasticidade da Estaca

$\mathrm{D} \rightarrow$ Diâmetro (em mm) do Círculo Circunscrito a

Estaca, exceto para Estacas Barretes.

DAVISSON (1972) define ruptura convencional em uma prova de carga estática para o recalque igual a:

$$
S=\frac{Q \cdot L}{A \cdot E}+\frac{D}{120}+3,8 m m
$$


Onde,

$\mathrm{Q} \rightarrow$ Carga de Ruptura Convencional

$\mathrm{L} \rightarrow$ Comprimento da Estaca

$\mathrm{A} \rightarrow$ Área da Seção Transversal da Estaca

$\mathrm{E} \rightarrow$ Módulo de Elasticidade da Estaca

$\mathrm{D} \rightarrow$ Diâmetro (em mm) do Círculo Circunscrito a Estaca, Exceto para Estacas

Barretes.

VAN DER VEEN (1953) propõe que a curva carga-recalque seja representada através de uma expressão matemática do tipo:

$$
\mathrm{P}=\mathrm{R}\left(1-\mathrm{e}^{-\mathrm{a} \cdot \rho}\right)
$$

Esta curva, definida por essa expressão matemática, é assintótica a uma reta vertical que caracteriza a carga de ruptura (R), conforme ilustra a Figura 2.11.

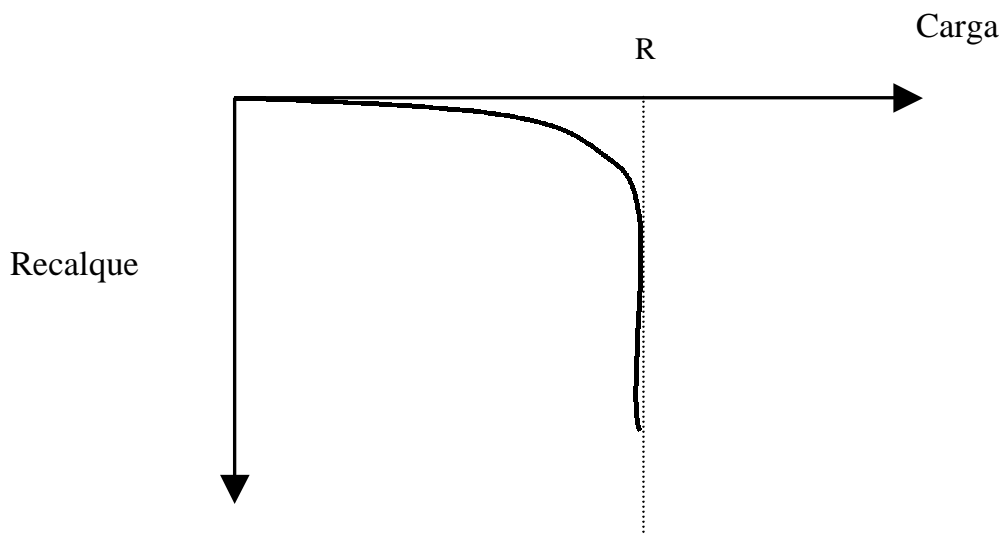

Figura 2.11 - Curva Carga - Recalque de VAN DER VEEN 
TERZAGHI (1943) considera como carga de ruptura a que corresponde a um recalque igual a $10 \%$ do diâmetro da ponta da estaca.

Dentre outros métodos bastante conhecidos, além dos já listados, para determinação da carga de ruptura, podemos citar: o método de BRINCH HANSEN, EULER \& ROY, DE BEER, CHIN, o Código de Boston e o de Nova Iorque.

AOKI (1997) afirma que a definição de carga última é tema controvertido, talvez porque só considere as variáveis cargas e recalques na sua definiçãa. Para determinação da carga de ruptura, ele propõe a utilização do conceito de energia complementar, baseado no teorema de HAMILTON.

De acordo com CLOUGH \& PENZIEN (1975) o princípio de Hamilton pode ser expresso da seguinte forma:

$$
\int_{t 1}^{t 2} \delta(T-V) d t+\int_{t 1}^{t 2} \delta\left(W_{n c}\right) d t=0
$$

$T=$ energia cinética total do sistema

$V=$ energia do sistema, incluindo a energia de deformação e a energia potencial de qualquer força conservativa externa.

$W_{n c}=$ trabalho efetuado pelas forças não conservativas que atuam no sistema, incluindo o amortecimento e quaisquer cargas externas

$\delta=$ variação ocorrida durante o intervalo de tempo indicado

AOKI (1997) afirma que o princípio de Hamilton diz que a variação de energia cinética e potencial, mais a variação do trabalho efetuado pelas forças não consevativas, durante o intervalo de tempo $t_{1}$ e $t_{2}$, dentro do sistema, é zero. No ensaio dinâmico, abordado no próximo item, é possível calcular a energia transferida ao sistema estacasolo. AOKI (1997) mostra a aplicação do princípio de Hamilton na cravação de estacas, em que o sistema estaca-maciço de solos é submetido a ação de um impacto do martelo, de energia cinética total $T$, que mobiliza a resitência total $R_{t}$ (estática+dinâmica) e provoca o deslocamento máximo $D$. As Figuras 2.12 a 2.14 mostram as curvas $R_{t}$ x $D$ e 
as variações de $T, V$ e $W_{n c}$ para diversas condições de carregamento dinâmico de energia crescente. Na figura 2.12, no instante $t_{1}$, imediatamente antes do impacto do martelo no topo da estaca, toda a energia do sistema está armazenada na forma de energia cinética $\mathrm{T}_{1}$ (ponto $\mathrm{O}$ ). Após um tempo $\Delta t\left(\Delta t=t_{2}-t_{1}\right)$, toda esta energia cinética transforma-se em energia potencial $V_{l}$, representada pela área $O A_{l} C_{l} O$. O trecho $O A_{l}$ representa a fase de carregamento do sistema, quando ocorre a mobilização de uma resistência $R_{1} \mathrm{e}$ provoca um deslocamento máximo igual ao trecho $O C_{l}$. Nessa fase aplicou-se o princípio de Hamilton entre os tempos $t_{1}$, que corresponde ao instante imediatamente anterior ao impacto do martelo e $t_{2}$, quando ocorreu o deslocamento máximo $\left(O C_{1}\right)$ do sistema. Aplicando-se o princípio de Hamilton na fase de descarregamento (trecho $A_{1} B_{1}$ ), nota-se que toda a energia potencial $V_{l}$ é convertida em energia de deformação elástica $V_{e l}$, pois a curva de descarregamento é coincidente com a de carregamento e o deslocamento final é igual a zero. Este fato, durante o ensaio dinâmico, é notado pelo registro de um deslocamento permanente $S$ (nega) igual a zero e um deslocamento máximo $D_{l}$ igual ao deslocamento elástico $K_{l}$ (repique). Nesse caso, o sistema estacasolo apresentou um comportamento perfeitamente elástico $(S=0)$.

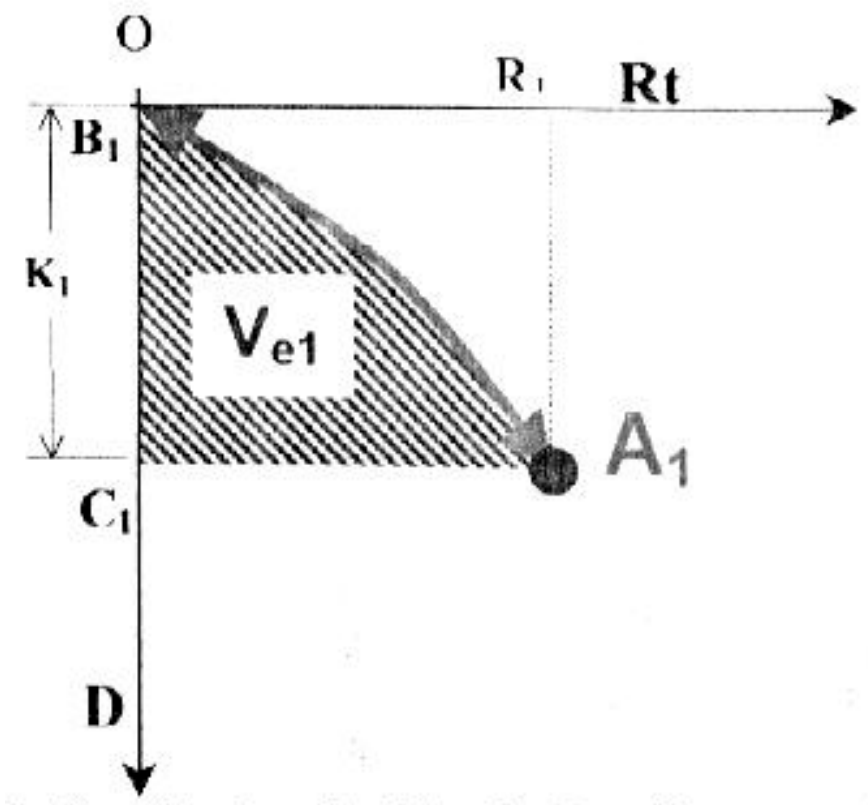

Figura 2.12 - Aplicação do Princípio de Hamilton até o limite inferior de resistência (ÁVILA, 2001) 
Aplicando-se uma energia cinética superior à do caso anterior $\left(T_{2}>T_{1}\right)$, a resistência mobilizada atinge um valor $R_{2}$, Figura 2.13, e o deslocamento total um valor $O C_{2}$. Utilizando o princípio da conservação da energia na fase de carregamento, percebe-se novamente a energia cinética $T_{2}$ sendo totalmente transformada em energia potencial $V_{2}$, agora representada pela área $\mathrm{OA}_{2} \mathrm{C}_{2} \mathrm{O}$. Quando descarregado, o sistema descreve a curva $A_{2} B_{2}$, mostrando que uma parte da energia potencial $V_{2}$ foi transformada em trabalho $W_{n c} \quad(S>0)$ e outra parte em energia de deformação elástica $V_{e 2}\left(K_{2}\right)$

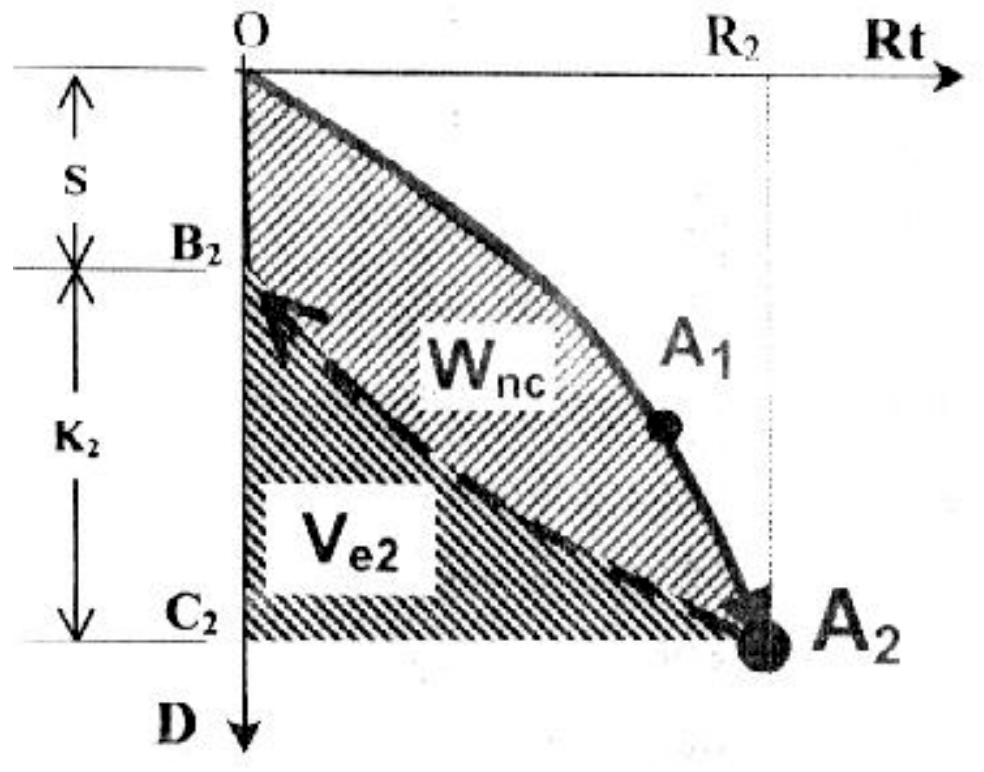

Figura 2.13 - Aplicação do princípio de Hamilton entre o limite inferior e o superior de resistência (ÁVILA, 2001)

O ponto a partir do qual começa ocorrer a plastificação de algum material constituinte do sistema (ponto $A_{l}$ ), define o limite inferior de resitência (lower bound). Essa plastificação é notada pelo surgimento de deslocamentos permanentes (nega).

A Figura 2.14 mostra que aumentando ainda mais a energia cinética, pelo aumento da altura de queda do martelo, a curva de carregamento descreve a trajetória $\mathrm{OA}_{3}$. 


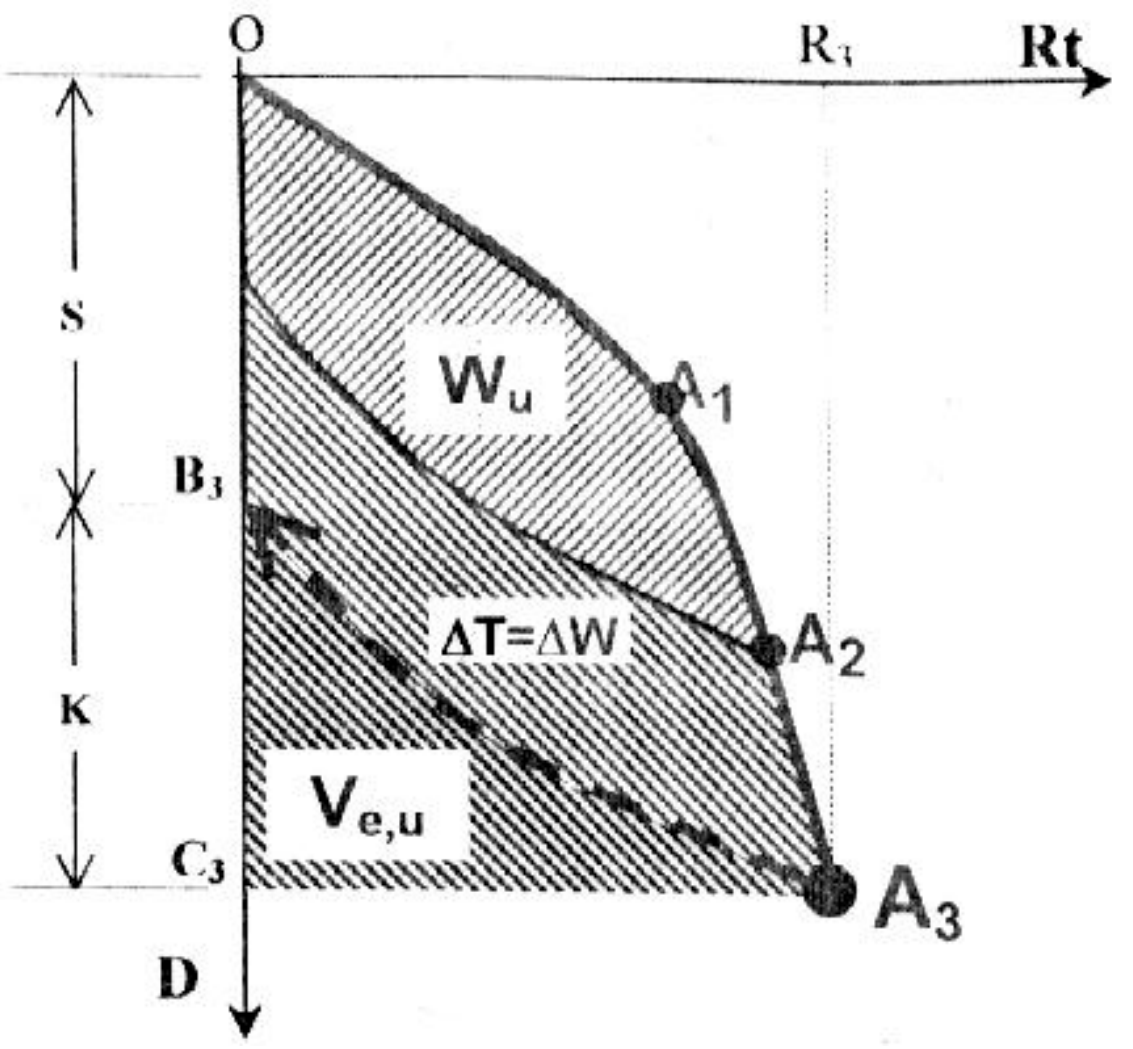

Figura 2.14 - Aplicação do princípio de Hamilton até o pós ruptura (ÁVILA, 2001)

A partir de $A_{2}$, todo acréscimo de energia cinética $\Delta T$ é transformado em acréscimo de trabalho $\Delta W$, caracterizando o pós-ruptura. No pós-ruptura, o sistema cessa sua capacidade de absorver energia de deformação elástica e todo o acréscimo de energia é transformado em trabalho, isto é, a taxa de variação da energia de deformação é igual a taxa de variação do trabalho das forças atuantes. Nesta etapa, o sistema desloca-se como corpo rígido configurando o trecho $A_{2} A_{3}$. Considerando os teoremas de análise limite em Mecânica dos Solos, o início desse trecho define o limite superior de resistência (upper bound), configurando uma superfície de ruptura do sistema. Ao limite superior corresponde à máxima resistência do sistema. Já o limite inferior de resistência (lower bound) é igual à menor resistência a partir da qual um material do sistema começa a plastificar-se (ponto $A_{1}$ ). 


\section{3 - Prova de Carga Dinâmica}

NIYAMA et al. (1996) afirmam que a prova de carga dinâmica de um elemento de fundação é um ensaio em que se aplica um carregamento dinâmico axial, com o objetivo de obter, principalmente, uma avaliação de sua capacidade de carga, com a utilização de uma instrumentação adequada e da aplicação da teoria de equação deonda.

No Brasil, a prova de carga dinâmica é regida pela NBR-13208/94 e é conhecida como Ensaio de Carregamento Dinâmico.

NIYAMA \& AOKI et al. (1996) relatam que tradicionalmente o controle de estacas cravadas se restringia à medida de nega devido à simplicidade desse procedimento. Posteriormente, a compreensão do fenômeno sofreu avanços significativos, principalmente a partir da solução da equação da onda por algoritmos apresentada por SMITH (1960), a qual se tornou prática com os computadores, ocorrendo uma rápida difusão deste ensaio em todo o mundo. No Brasil, esta técnica foi introduzida inicialmente, para o controle da cravação das estacas das plataformas marítimas da Petrobrás, no início da década de 1980 (NIYAMA et al., 1982). A partir de 1983, foi sendo aplicada em obras de fundação em terra. As provas de carga dinâmica têm recebido também outra conceituação nesse meio, mais recentemente, trata-se do procedimento de se aplicarem golpes sucessivos do martelo, com energias crescentes, medindo-se a resistência à cravação, através da instrumentação (AOKI, 1989; AOKI \& NIYAMA, 1991).

GONÇALVES et al. (1996) afirmam que a execução de prova de carga dinâmica, com auxílio do PDA (Pile Driving Analyzer), vem se tornando uma ferramenta muito prática e econômica, para auxiliar os projetistas nas tomadas de decisões.

NAVAJAS \& NIYAMA (1996) dizem que é viável a realização de ensaios dinâmicos em estacas moldadas "in loco", para a avaliação da capacidade de carga. 


\subsection{1 - Fórmulas Dinâmicas}

AOKI (1997) afirma que, na primeira fase histórica (1820-1950), a capacidade de carga estática, para a ação de um impacto da série de impactos de energia constante, era calculada com o modelo das fórmulas dinâmicas de cravação, baseadas no impacto Newtoniano, no princípio da conservação da energia e na hipótese de mobilização instantânea da capacidade de resistência do solo, ao longo da estaca. Este processo compara a energia potencial " $U$ ", aplicada pelo sistema de cravação, ao trabalho realizado pelas forças não conservativas "W" mais as perdas de energia "E". A energia potencial é devido ao peso do martelo erguido em uma altura " $H$ ", visto na Figura 2.15, e o trabalho realizado refere-se à resistência última vezes a penetração permanente. As expressões abaixo resumem o que foi escrito:

$$
\begin{aligned}
& \mathrm{U}=\mathrm{W}+\mathrm{E} \\
& \mathrm{W} \cdot \mathrm{H}=\mathrm{Ru} \cdot \mathrm{s}+\mathrm{E}
\end{aligned}
$$

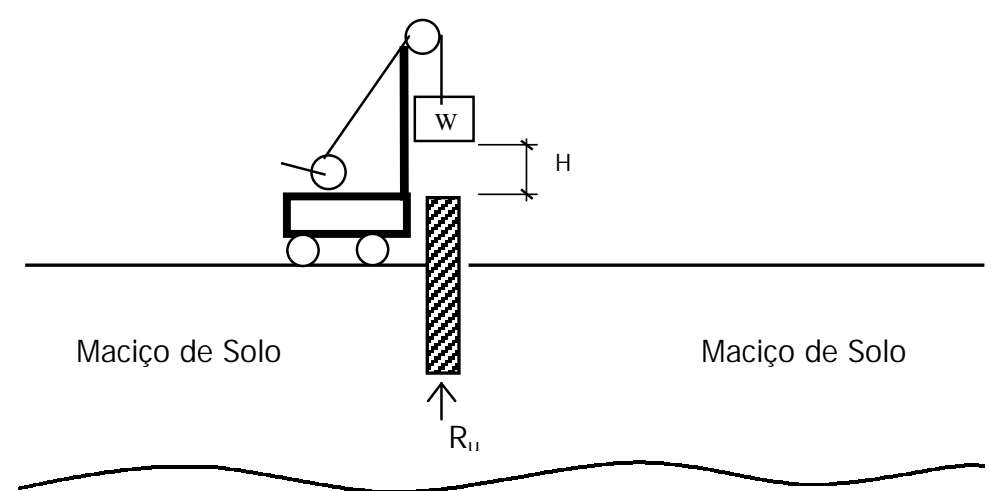

W - Peso do martelo

$\mathrm{H}$ - altura de queda do martelo

$\mathrm{Ru}$ - Resistência à cravação (dinâmica e estática)

s - Penetração permanente da estaca por golpe (nega)

E - Perdas de energia nos sistemas de cravação e amortecimento

Figura 2.15 - Esquema de Estaca sendo Cravada 
CHELLIS (1951) lista 38 fórmulas dinâmicas, enquanto SMITH (1960) diz que os editores do Engineering News Record tinham, até a presente data, cerca de 450 fórmulas.

WHITAKER \& BULLEN (1981) afirmam que a fórmula de Weisbach foi, em 1820, a primeira fórmula dinâmica da história. Seguindo cronologicamente a evolução das fórmulas, temos a de Sanders, quem, em 1851 propôs a seguinte expressão:

$R=\frac{W H}{8 . s}$

Onde: : R - Resistência oferecida pelo solo

Coeficiente de segurança igual a 8 (oito)

Em 1898, é publicada a fórmula do Engineering News, por Wellington, mostrada através da expressão abaixo.

$R=\frac{W \cdot H}{s+C}$

onde: $\mathrm{R}$ - Resistência.

$\mathrm{C}$ - coeficiente dependendo do valor de repique.

HILEY propõe a seguinte expressão, WHITAKER \& BULLEN (1981) :

$R=\frac{\eta \cdot W \cdot H}{s+C / 2}+W+P$ 
onde: $\mathrm{P}-$ Peso da estaca

$$
\begin{aligned}
& C=C 1+C 2+C 3 \\
& \mathrm{C} 1=\text { compressão temporária do sistema de amortecimento } \\
& \mathrm{C} 2=\text { compressão temporária da estaca } \\
& \mathrm{C} 3 \text { = compressão temporária do solo sob a estaca ("quake” de ponta) }
\end{aligned}
$$
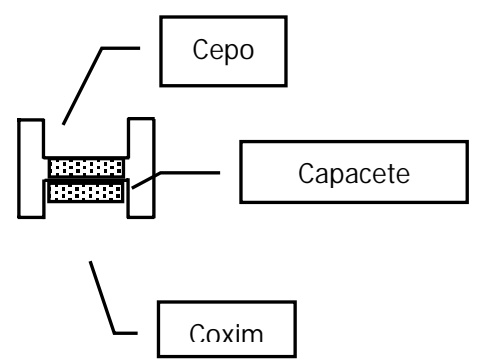

Figura 2.16 - Representação esquemática do sistema de amortecimento

$$
\eta=\frac{W+r^{2} \cdot P}{W+P}
$$

$\mathrm{r}$ - coeficiente de restituição

Atualmente, existem inúmeras fórmulas dinâmicas de cravação de estacas, sem que haja uma concordância com relação às suas utilizações. Um dos principais problemas da utilização das fórmulas dinâmicas é a sua pobre representação dos sistemas de cravação, de amortecimento e das perdas de energia.

\subsection{2 - Teoria da Equação da Onda}

Devido à simplicidade das fórmulas dinâmicas surgiu a análise da cravação de estacas pela equação da onda, a qual estuda o fenômeno da propagação da onda de 
compressão longitudinal em estacas, causada pelo impacto do martelo durante a cravação.

NIYAMA (1983) mostra que, para a análise da teoria da onda, estuda-se o comportamento de uma estaca em que é aplicada uma força " $F$ " decorrente do impacto do martelo no topo da mesma, no tempo " $t$ ".

No primeiro instante, todas as partículas estão em repouso, após o impacto do martelo, há a formação da onda que se propaga na estaca como mostra a Figura 2.17. A parte superior da estaca é comprimida, as partículas do seu material são aceleradas, e a onda propaga-se através da estaca com uma velocidade c.

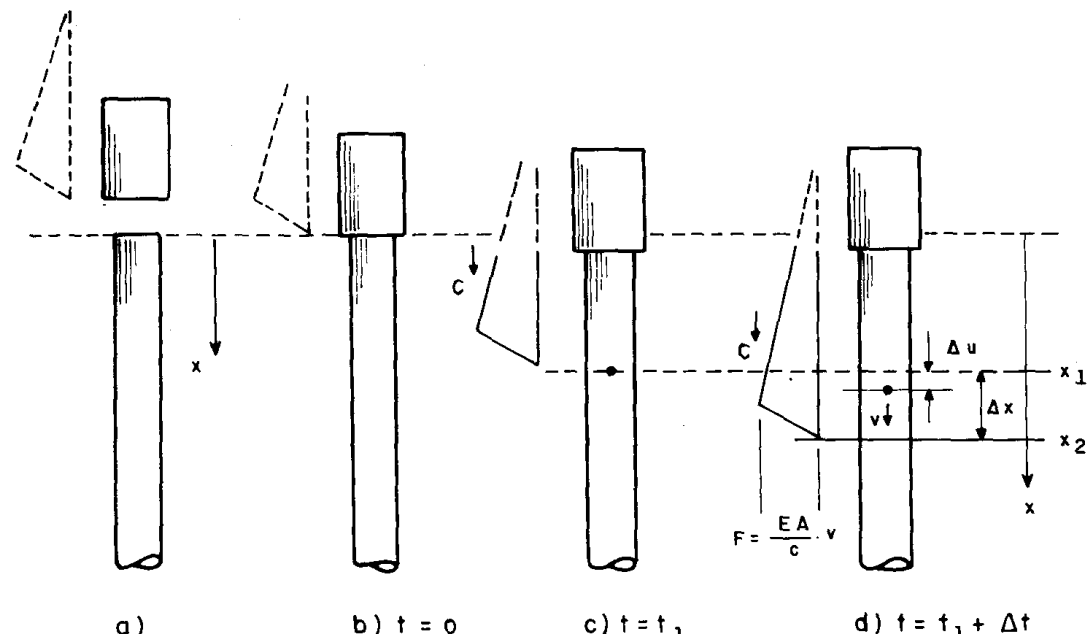

Figura 2.17 - Formação da onda no impacto (Apud Niyama, 1991).

Durante um intervalo de tempo $\Delta t$, a onda atravessou e transmitiu uma onda de compressão por uma distância $\Delta x$, intervalo este que imprimiu uma velocidade $v$ na partícula, inicialmente em repouso $(v=0 ; t=t 1)$, situada na frente da onda. Esta partícula com velocidade $v$ deslocou-se $\Delta u$ da sua posição inicial, que corresponde ao 
encurtamento elástico do elemento de comprimento $\Delta x$. É importante não confundir a velocidade de propagação da onda de compressão $c$ com a velocidade da partícula $v$. Dito isto, temos:

$$
\begin{aligned}
& c=\frac{\Delta x}{\Delta t} \\
& \varepsilon=\frac{\Delta u}{\Delta x} \\
& v=\frac{\Delta u}{\Delta t} \\
& a=\frac{\Delta v}{\Delta t}
\end{aligned}
$$

De (2.10) (2.11) e (2.12), tem-se:

$$
\varepsilon=\frac{v}{c}
$$

Pela lei de Hooke, temos:

$$
\sigma=E \cdot \varepsilon
$$

$\frac{F}{A}=E . \varepsilon \quad, \quad$ substituindo (2.14), tem-se:

$$
F=\frac{E \cdot A}{c} \cdot v
$$


Em que: E - Módulo de Elasticidade do material da estaca

A - Área da seção transversal da estaca

A equação (2.15) mostra a proporcionalidade entre a força e a velocidade, e este fator, que vale $\frac{E . A}{c}$, é denominado de impedância $(Z)$. A força $F$ também pode ser escrita como:

$F=Z . v$

A relação expressa na equação acima é a base das medidas na equação da onda. O P.D.A. (Pile Driving Analyzer) mede, independentemente, a deformação, que é convertida em força, e a aceleração que é integrada para se obter velocidade. Quando a velocidade é multiplicada pela impedância, $\frac{E . A}{c}$, o resultado é comparado ao da força medida. Essa relação é uma referência de como está a proporcionalidade dos sinais e uma verificação da qualidade dos dados de força e de velocidade, determinados independentemente.

Aplicando a segunda lei de Newton no trecho $\Delta x$, podemos obter:

$F=m \cdot a$, que equivale a

$F=\rho \cdot A \cdot \Delta x \cdot \frac{\Delta v}{\Delta t}$

em que $\rho$ é a massa específica do material da estaca.

Considerando o elemento inicialmente em repouso $\left(v_{0}=0 ; \Delta v=v\right)$, de (2.10), (2.15) e (2.17), resulta:

$F=\frac{E \cdot A}{c} \cdot v=\rho \cdot A \cdot c \cdot v$

$c^{2}=\frac{E}{\rho}$ 
Da equação (2.18), podemos concluir que a velocidade de propagação da partícula depende das características de módulo de elasticidade e massa específica da estaca.

Vale salientar que cada material (aço, concreto e madeira) tem uma velocidade de propagação da onda.

Com relação ao equilíbrio de força, seja o segmento de estaca da Figura 2.18, com área de seção transversal $A$, módulo de elasticidade $E$ e massa específica $\rho$, sujeito a um estado de tensão, em um tempo $t$, proveniente da propagação de uma onda longitudinal de compressão. O elemento infinitesimal $d x$, sujeito a um estado de tensão, sofre deslocamento, devido às deformações elásticas provocadas pelo carregamento. As forças $F 1$ e $F 2$ são esforços normais que atuam, respectivamente, na parte inferior e superior do elemento em estudo e valem:

$$
\begin{aligned}
& F 1=E \cdot A \frac{\partial u}{\partial x} \\
& F 2=E \cdot A\left[\frac{\partial u}{\partial x}+\frac{\partial^{2} u}{\partial x^{2}} \cdot d x\right]
\end{aligned}
$$




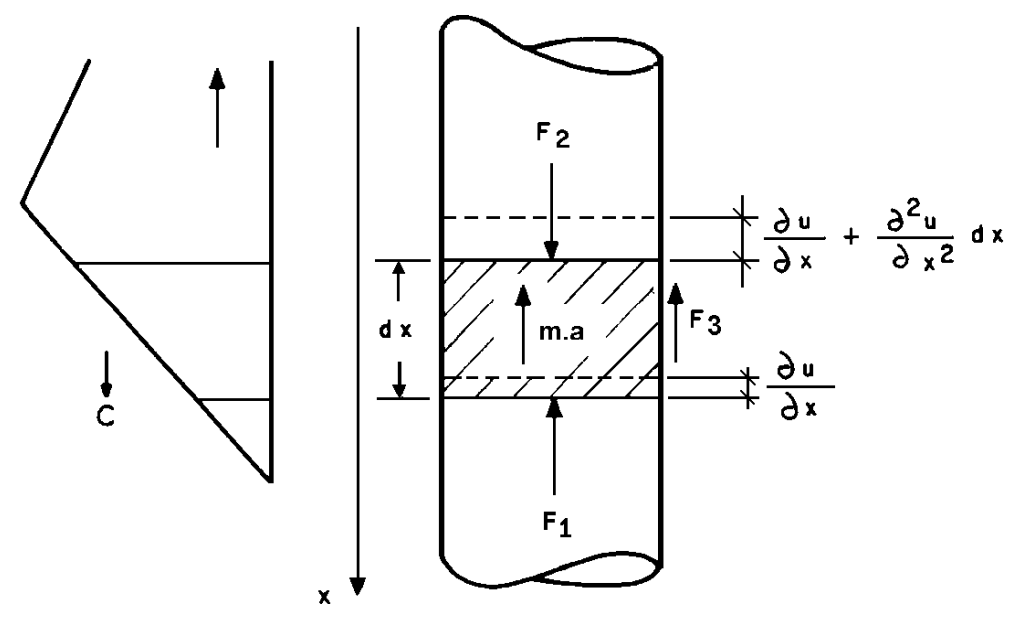

Figura 2.18 - Deformação do elemento de estaca, devido à propagação da onda

A força $F 3$ corresponde à resistência do solo, ao longo de $d x$, e m.a representa a resistência do elemento à passagem da onda (força de inércia). Fazendo o equilíbrio de forças, temos:

$m . a=F 2-F 1-F 3$

sendo:

$$
F 3=s . U \cdot d x
$$

onde: $\mathrm{s}-$ atrito lateral local mobilizado

$$
\mathrm{U} \text { - perímetro do elemento }
$$

\section{Como:}

$c^{2}=\frac{E}{\rho} \quad ; \quad a=\frac{\partial^{2} u}{\partial t^{2}} \quad$ e $\quad m=A . d x . \rho, \quad$ substituindo $\quad$ as equações. (2.19), (2.20), (2.22) em (2.21), teremos: 


$$
\begin{aligned}
& A . d x \cdot \rho \cdot \frac{\partial^{2} u}{\partial t^{2}}=\left[\frac{\partial u}{\partial x}+\frac{\partial^{2} u}{\partial x^{2}} \cdot d x\right] \cdot E \cdot A-E \cdot A \frac{\partial u}{\partial x}-s \cdot U \cdot d x \\
& A . d x \cdot \rho \cdot \frac{\partial^{2} u}{\partial t^{2}}=\frac{\partial^{2} u}{\partial x^{2}} \cdot d x \cdot E \cdot A-s \cdot U \cdot d x \\
& \frac{\partial^{2} u}{\partial t^{2}}=c^{2} \cdot \frac{\partial^{2} u}{\partial x^{2}}-\frac{s \cdot U}{\rho \cdot A} \\
& c^{2} \cdot \frac{\partial^{2} u}{\partial x^{2}}-\frac{\partial^{2} u}{\partial t^{2}}=\frac{s \cdot U}{\rho \cdot A}
\end{aligned}
$$

A equações (2.23) representa a condição de equilíbrio dinâmico das forças que atuam em um volume infinitesimal de uma estaca, a uma profundidade $x$, em um tempo t. Esta equação é uma diferencial parcial pelo fato de apresentar duas variáveis independentes: a posição $x$ e o tempo $t$. A expressão tem como valores constantes a área $A$, o perímetro $U$, a massa específica $\rho$ e o módulo de elasticidade $E$; como variáveis dependentes, tem o deslocamento $u(x, t)$, a velocidade $v(x, t)$, a aceleração $a(x, t)$, o atrito local mobilizado $s(x, t)$ e as forças $F 1, F 2$ e $F 3$.

A solução geral dessa equação diferencial parcial, de segunda ordem, não homogênea, é o deslocamento $u(x, t)$.

$$
u(x, t)=f(x-c t)+g(x+c t)
$$

Ela representa duas ondas de deslocamento propagando-se em sentidos opostos, ao longo do eixo da estaca, com velocidades c, em que permanecem válidos os efeitos de superposição. A partir desta solução, obtêm-se também as funções força (F) e velocidade (v) de partícula, as quais mantem uma relação de proporcionalidade, através de uma constante denominada Impedância $(Z)$, do tipo:

$$
\mathrm{F}=\mathrm{Z} . \mathrm{v}
$$


As ondas ascendentes (originadas da reflexão) conduzem informações dos efeitos externos e internos (atrito lateral, danos, variação das camadas etc.), os quais provocam justamente estas reflexões. Dessa forma, novos arranjos entre as expressões matemáticas permitem identificar isoladamente as amplitudes das ondas descendentes e ascendentes, através das equações abaixo:

$\mathrm{F}_{\text {descendente }}=(\mathrm{F}+\mathrm{Z} . \mathrm{v}) / 2$

$\mathrm{F}_{\text {ascendente }}=(\mathrm{F}-\mathrm{Z} . \mathrm{v}) / 2$

Para a interpretação das ondas ascendentes ou refletidas, são estudados os efeitos das condições de contorno da estaca, tais como resistência de ponta, atrito lateral e mudança na impedância da estaca. Dependendo das condições da resistência na ponta, por exemplo, uma onda de compressão incidente pode-se refletir na extremidade da estaca, como uma onda de compressão ou de tração. No caso em que há pouca resistência na ponta, a onda faz com que a estaca próxima da ponta seja puxada para baixo, gerando a força de tração. No caso contrário, de se ter uma alta resistência de ponta, a estaca próxima da ponta é comprimida, gerando-se uma onda de compressão refletida. No momento da reflexão, neste último caso, a magnitude da onda de compressão pode chegar ao dobro do valor incidente, ocasionando esmagamento e danos naquela região.

Em geral, cada onda descendente, percorrendo uma distância dx, tem sua amplitude diminuída em 1/2 $\mathrm{RA}(\mathrm{x}) \mathrm{dx}$, em que $\mathrm{RA}(\mathrm{x})$ é um quinhão de resistência de atrito lateral na posição $\mathrm{x}$, assim como cada onda ascendente tem um incremento de mesmo valor. Desta forma, a influência do solo começa a se manifestar, com a chegada das primeiras ondas de reflexão. Através dos conceitos e expressões mencionados resumidamente, pode-se deduzir a resistência à penetração (Rt), dada por: 
$\mathrm{Rt}=1 / 2\left[\left(\mathrm{Ft}_{1}+\mathrm{Ft}_{2}\right)+\mathrm{Z}\left(\mathrm{vt}_{1}-\mathrm{vt}_{2}\right)\right] \quad$ Eq. (2.28)

$t_{1}$ e $t_{2}$ representam os instantes de impacto e de retorno da reflexão da ponta;

$\mathrm{Ft}_{1}$ e $\mathrm{Ft}_{2}$ representam as forças nos instantes $\mathrm{t}_{1}$ e $\mathrm{t}_{2}$

$\mathrm{vt}_{1}$ e $\mathrm{vt}_{2}$ representam as forças nos instantes $\mathrm{t}_{1}$ e $\mathrm{t}_{2}$.

Esta equação representa, de fato, a fórmula básica do ensaio dinâmico da estaca. Ela mostra explicitamente que a resistência de atrito lateral e de ponta pode ser determinada através da medição adequada dos registros de força e de velocidade total, em qualquer ponto da estaca. Usualmente se utilizam instrumentos que medem a deformação específica, que permite calcular a força e a aceleração, as quais se integram e permitem obter a velocidade. O registro contínuo ao longo do tempo, obtido através desta instrumentação dinâmica, das grandezas de força e velocidade em um ponto da estaca junto ao topo, resulta um par de curvas, em que as mesmas se apresentam em função do tempo. A Figura 2.19 ilustra um registro típico assim obtido. As duas curvas mantêm a proporcionalidade, até que comecem a chegar as ondas refletidas, devido às singularidades originadas a partir da interação da estaca com o terreno, em geral, representadas por forças de atrito lateral. 


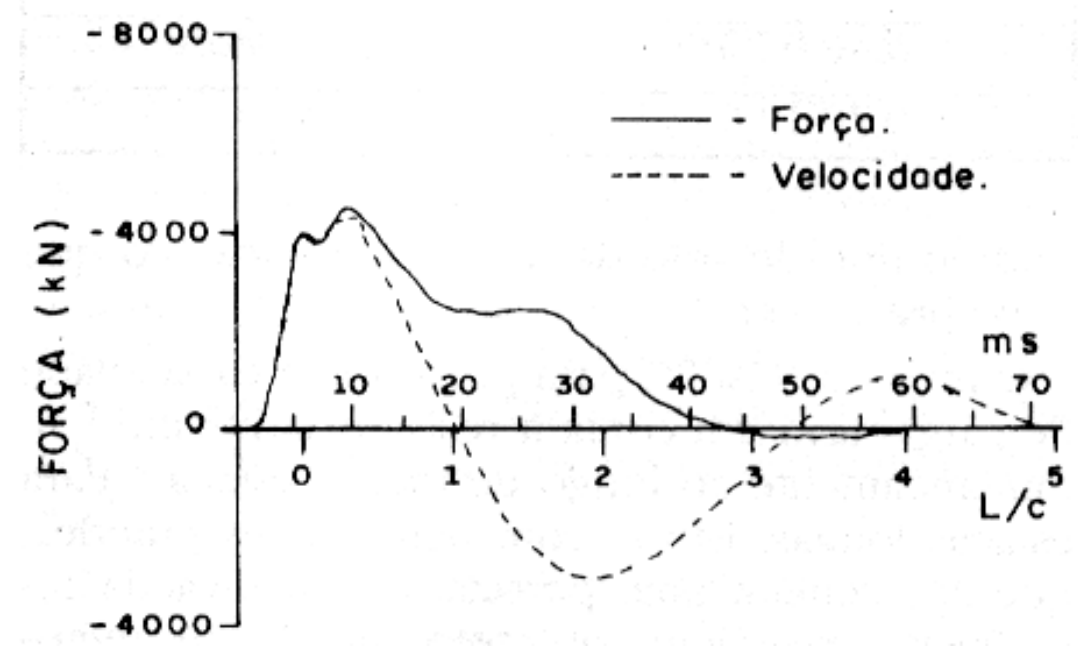

Figura 2.19 - Registro típico obtido numa instrumentação dinâmica

\subsection{3 - O Modelo de Smith}

SMITH (1960) afirma que D. V. Isaacs, em 1931, foi o primeiro que advertiu sobre a ação da onda durante a cravação de estacas.

Utilizando o conceito da equação da onda, a integração numérica e os computadores eletrônicos, em 1960, E. A. L Smith, propôs um modelo matemático, para representar o fenômeno de cravação de estacas, tornando-se a base para o seu desenvolvimento. Através da Figura 2.20, pode-se observar o modelo numérico proposto, em que se representam os elementos, como o martelo, o cepo, o capacete e a estaca por uma série de pesos e molas.

Os elementos rígidos e pesados foram representados por pesos, sem elasticidade, como o capacete. Já a estaca, que é compressível, foi dividida em comprimentos unitários e molas individuais, que representam seu peso e elasticidade, respectivamente. Para o martelo, esquematizado na Figura 2.20, considerou-se o mesmo como possuidor de peso e elasticidade. As forças de resistência do solo são representadas pela combinação de molas elasto-plásticas e pistons lineares ligados em cada elemento de 
estaca cravado. O tempo, durante o qual ocorre a ação, é dividido em intervalos pequenos, como $1 / 4.000 \mathrm{~s}$. As ações de cada peso e cada mola são calculadas separadamente para cada um e para todos os intervalos de tempo, sendo determinadas matematicamente as resistências e penetrações da estaca em qualquer instante e para qualquer tipo de terreno.

(A) SISTEMA REAL

(B) MODELO

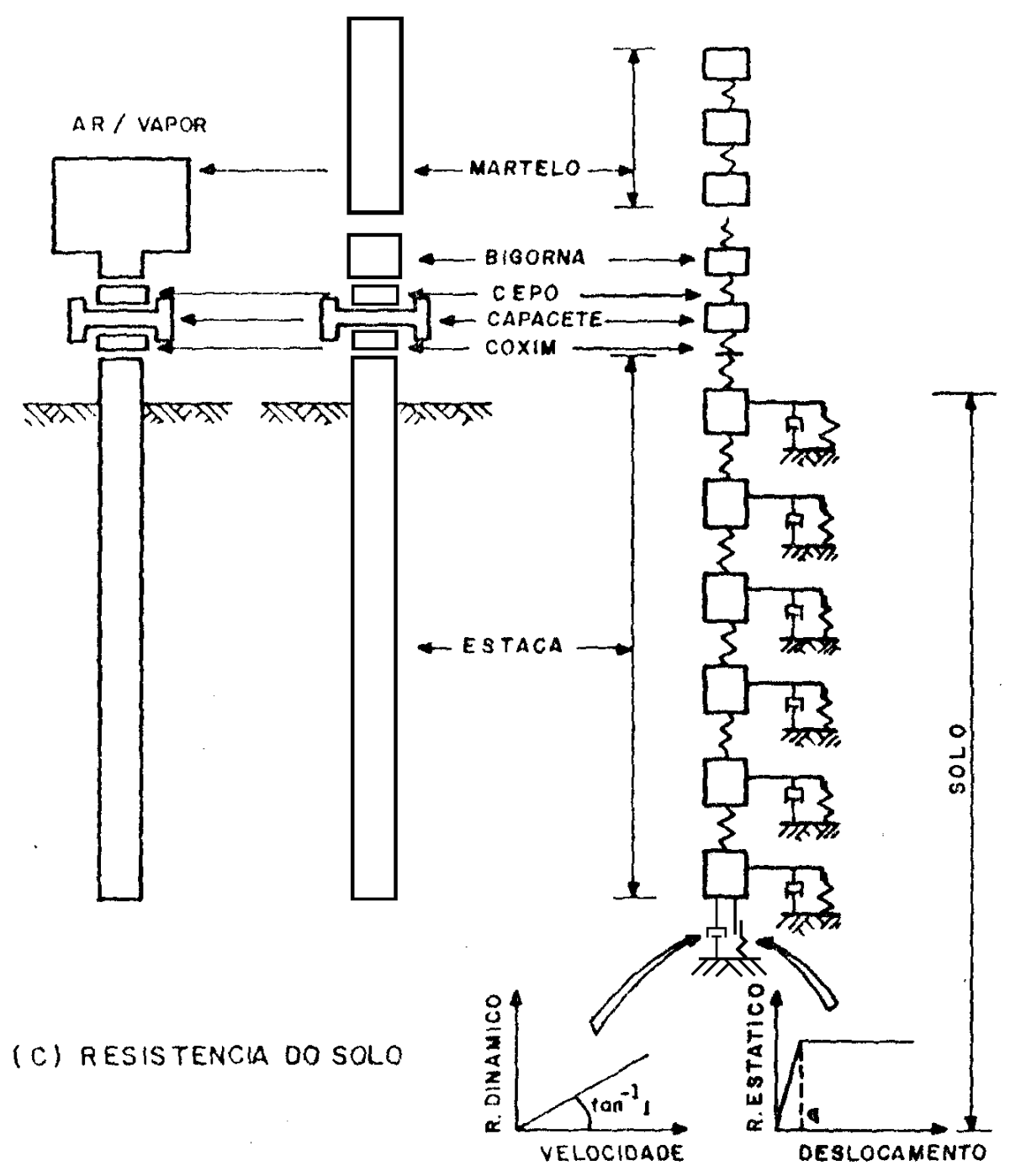

Figura 2.20 - Modelo de Smith (Apud Smith, 1960) 


\subsection{4 - Técnica de Instrumentação}

Para realizar a instrumentação dinâmica, é utilizado um conjunto básico de instrumentos e de equipamentos, para a aquisição e o tratamento de dados. Um dos esquemas mais difundidos utiliza o PDA (Pile Driving Analyzer), como ilustrado na Figura 2.21.

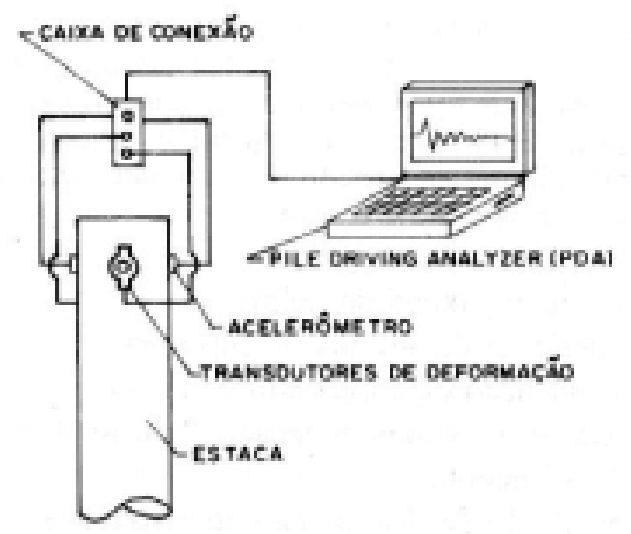

Figura 2.21 - Esquema de Instrumentação Dinâmica

Outros conjuntos de equipamentos podem ser utilizados para esta finalidade. De qualquer forma, a instrumentação básica se constitui de transdutores de deformação específica e de acelerômetros, os quais permitem obter, respectivamente, registro de força e velocidade. Estes instrumentos são fixados aos pares, em uma seção da estaca, próxima do seu topo, em posições diametralmente opostas, a fim de compensar os efeitos de momento fletor. Na Figura 2.22, pode ser observado um par destes instrumentos, afixados em uma estaca cravada. Os sinais enviados pelos instrumentos são processados pelo PDA, que pode calcular vários parâmetros de interesse, sendo o principal a resistência à penetração da estaca no solo, através do método simplificado "CASE" ou similar. Estes sistemas permitem obter ainda: força máxima do impacto, energia máxima do golpe, eficiência do sistema de cravação, verificação de dano estrutural e sua posição, valores máximos de tensão, velocidade e deslocamentos e avaliação da distribuição de resistência. 


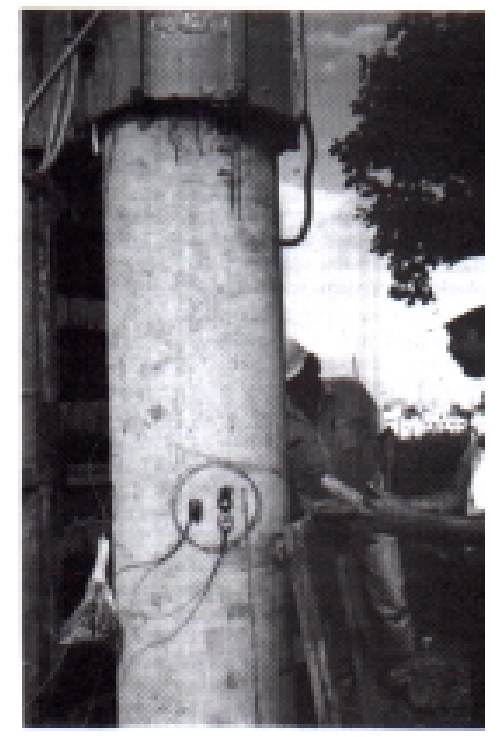

Figura 2.22 - Estaca Instrumentada com acelerômetro e transdutor de deformação (NIYAMA et al. , 1996)

\subsection{5 - Métodos de Análise dos Sinais Obtidos pelo PDA}

Segundo LIMA (1999), a cravação de uma estaca pode ser analisada através de dois modelos: o primeiro simplificado, representado pelo impacto de duas barras, e o segundo, mais elaborado, proposto por SMITH (1960), isto é, a estaca é discretizada em elementos de massa e molas.

\subsubsection{1 - Método de Análise Case}

A estimativa da capacidade de carga, através do método de "CASE", é dada pela soma do atrito lateral e da resistência de ponta através da fórmula expedida:

$$
\mathrm{Rt}=1 / 2\left[\left(\mathrm{Ft}_{1}+\mathrm{Ft}_{2}\right)+\mathrm{Z}\left(\mathrm{vt}_{1}-\mathrm{vt}_{2}\right)\right]
$$


A resistência à penetração, Rt, é considerada como sendo igual à soma de duas parcelas: uma estática RS, e outra dinâmica RD, que depende da velocidade. Assim, tem-se:

$\mathrm{Rt}=\mathrm{RS}+\mathrm{RD}$

A resistência dinâmica é considerada proporcional à velocidade da ponta da estaca, vp,

$\mathrm{RD}=\mathrm{J}_{\mathrm{c}} \cdot \mathrm{EA} / \mathrm{c} \cdot \mathrm{vp}$

Em que $\mathrm{J}_{\mathrm{c}}$ é uma constante de amortecimento; E é o módulo de elasticidade, e A é a área da seção transversal da estaca. Daí, pode-se deduzir que:

$\mathrm{vp}=2 . \mathrm{vt}-\mathrm{c} / \mathrm{EA} \cdot \mathrm{Rt}$

Fazendo -se as devidas substituições, vem:

$\mathrm{RD}=\mathrm{J}_{\mathrm{c}} \cdot\left[2 \cdot(\mathrm{EA} / \mathrm{c}) \cdot \mathrm{vt}_{1}-\mathrm{Rt}\right]$

Se, no instante $t_{1}=0$, não houver ondas ascendentes, provenientes de reflexões, existe a proporcionalidade entre a força e a velocidade de partícula, podendo-se escrever:

$\mathrm{RD}=\mathrm{J}_{\mathrm{c}} \cdot\left[2 \mathrm{Ft}_{1}-\mathrm{Rt}\right]$ 
A resistência estática, então, é obtida como diferença entre a resistência total e a dinâmica:

$\mathrm{RS}=\mathrm{Rt}-\mathrm{J}_{\mathrm{c}} \cdot\left[2 \mathrm{Ft}_{1}-\mathrm{Rt}\right](2.35)$

RAUSCHE et al. (1985) afirmam que a constante de amortecimento do CASE, $\mathrm{J}_{\mathrm{c}}$, depende do tipo de solo, prevalecendo o tipo de solo da ponta da estaca, e, após comparar os resultados dos ensaios estáticos levados à ruptura com os dos ensaios dinâmicos, desenvolveu-se a Tabela 2.1.

Os resultados foram obtidos pela resolução da equação 2.30 , utilizando o valor de Jc como incógnita, conhecidas as outras variáveis.

Tabela 2.1 - Valores de Jc para o método CASE (RAUSCHE et al. , 1985)

\begin{tabular}{|c|c|c|}
\hline Tipo de Solo & Intervalos de $\mathrm{J}_{\mathrm{c}}$ Sugeridos & Melhor valor de $\mathrm{J}_{\mathrm{c}}$ \\
\hline Areia & $0,05-0,20$ & 0,05 \\
\hline Areia Siltosa & $0,15-0,30$ & 0,15 \\
\hline Silte Arenoso & $0,25-0,45$ & 0,30 \\
\hline Silte Argiloso & $0,40-0,70$ & 0,55 \\
\hline Argila & $0,60-1,10$ & 1,10 \\
\hline
\end{tabular}

Segundo NIYAMA (1991), o método CASE, para previsão da capacidade de carga, leva em conta a resistência atuando simultaneamente ao longo de toda a estaca. Para estacas longas que apresentam uma parcela significativa de resistência proveniente do atrito lateral, este método de cálculo pode subestimar a capacidade de carga durante 
as cravações mais difíceis, quando a cabeça da estaca repica. A velocidade no topo da estaca torna-se negativa, antes que a onda refletida na ponta alcance esta parte superior, que, quando isso ocorre, esta parte da estaca estará deslocando-se para cima, provocando o descarregamento de uma parcela de resistência lateral, invertendo os sinais das forças de atrito. Nesse caso, para a previsão da capacidade de carga, deve ser feita uma correção.

\subsubsection{2 - Método de Análise CAPWAP}

O CAPWAP (Case Pile Wave Analysis Program), foi desenvolvido inicialmente por Rausche em 1970, em sua tese de doutorado, na Case Western Reserve University. $\mathrm{Na}$ análise de cravação da estaca existem três incógnitas: as forças na estaca, o deslocamento da estaca e as condições de contorno da estaca. Se duas das três são conhecidas, a outra pode ser determinada. O programa usa os registro de força e velocidade obtidos no PDA. Com os valores da força e do deslocamento da estaca quantificados, o programa CAPWAP, utilizado por um engenheiro experiente, pode determinar as condições de contorno, através de um processo de tentativa e erro de ajuste ("match") dos sinais. As condições de contorno incluem a resistência última mobilizada da estaca, a distribuição de resistência e as características de quake e damping.

As últimas versões do programa utilizam um modelo de segmentos de estaca, em que cada elemento é definido por sua impedância $\left(\frac{E . A}{c}\right)$. O comprimento de cada elemento de estaca é escolhido de maneira que cada segmento tenha o mesmo tempo de propagação da onda.

O solo é modelado utilizando-se a teoria da propagação da onda padrão, aplicando os componentes elasto-plásticos e visco-lineares, para representarem as forças 
de reação estática e dinâmica do solo. Cada reação do solo é descrita pela resistência estática última, o quake e a constante de amortecimento damping. O programa usa o modelo de estaca contínua, a velocidade registrada na cabeça da estaca e o modelo do solo assumido, que consta da distribuição da resistência do solo, quakes e as características de amortecimento (damping) de cada elemento de solo, ao longo do fuste e sob a ponta. Com os dados de entrada do deslocamento da estaca e as condições de contorno assumidas, o programa calcula a curva de força na cabeça da estaca. Essa força calculada é comparada com a força que foi medida durante o ensaio pelo PDA. Em um processo iterativo do computador, a sensibilidade do engenheiro é usada para modificar o modelo do solo, até que o melhor ajuste ("best match") entre as curvas de força medidas e calculadas seja atingido. O modelo do CAPWAP e o processo de iteração estão ilustrados na Figura 2.23.

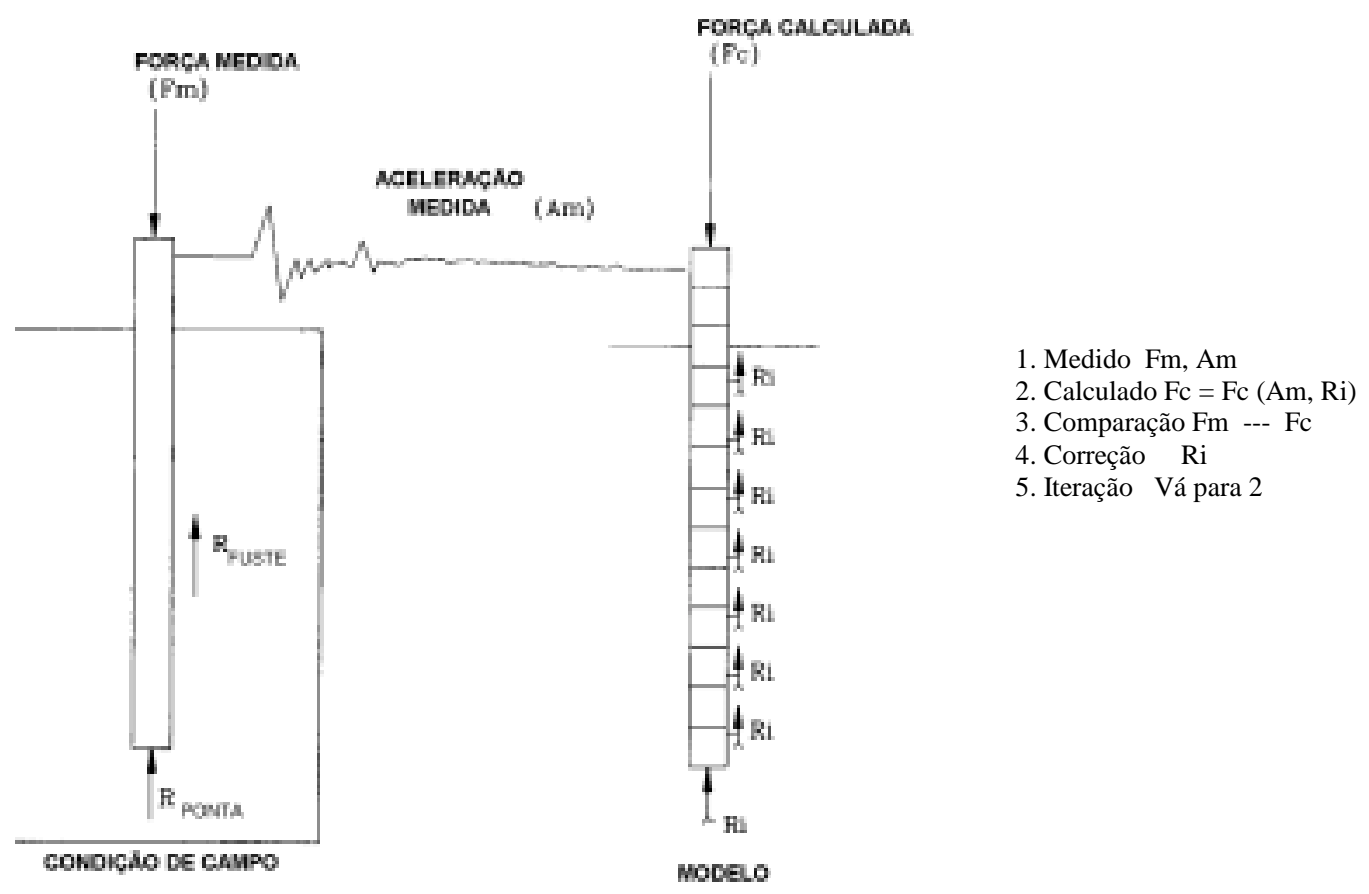

Figura 2.23 - Processo de Iteração e Simulação feito pelo CAPWAP (Apud Hannigan, 1990) 
As forças de resistência do solo causam reflexões iguais e opostas nas ondas de força e de velocidade. Estas reflexões ocorrem no tempo $\frac{2 . x}{c}$, em que $x$ é a profundidade da resistência do solo e $c$ a velocidade da onda na estaca. No tempo $\frac{2 . L}{c}$, onde $L$ é o comprimento da estaca, as forças de resistência da ponta são refletidas. O processo de ajuste das curvas medidas e calculadas nos vários tempos é controlado por diversos fatores. A distribuição de resistência por atrito, o modelo de resistência na ponta e a resistência última mobilizada são um dos fatores de maior influência no ajuste das curvas. Durante o processo de iteração o programa avalia a qualidade do ajuste ("match quality") pelas diferenças relativas às curvas medidas e calculadas. O número do "match quality" é calculado pela soma dos valores individuais do "match quality" em quatro regiões das curvas. Um processo típico de iteração, para a obtenção dos ajustes é mostrado na Figura 2.24. O ajuste foi feito em cinco tentativas. $\mathrm{O}$ processo de obtenção do melhor ajuste é mostrado de baixo para cima, na Figura 2.24, em que um melhor ajuste significa um menor valor do match. As primeiras tentativas foram realizadas através da modificação das parcelas da distribuição de resistência (fuste e ponta). Já as últimas tentativas de ajuste foram no modelo de solo, sob a ponta (gap, quake, plug) e na modificação dos parâmetros de descarregamento. 


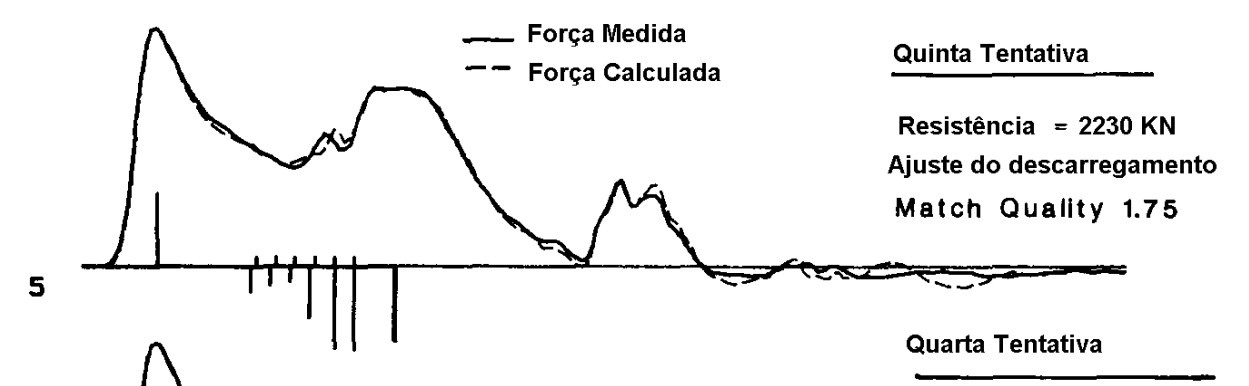

4

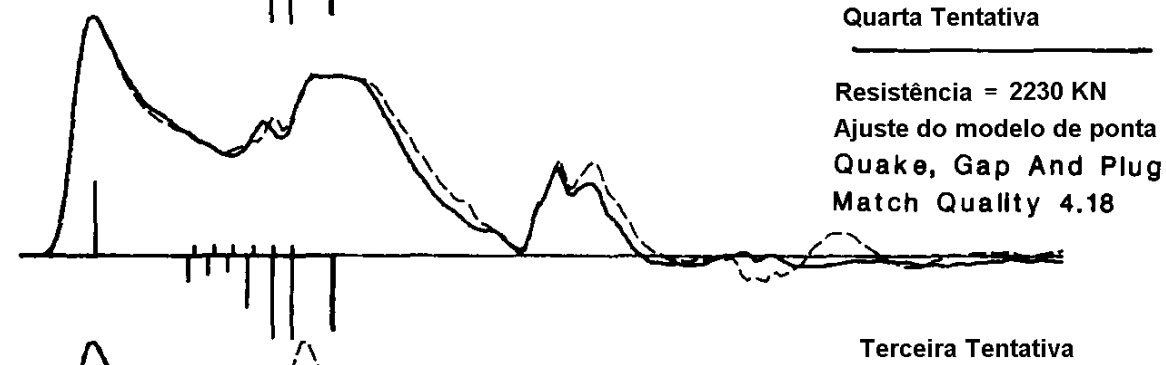

3
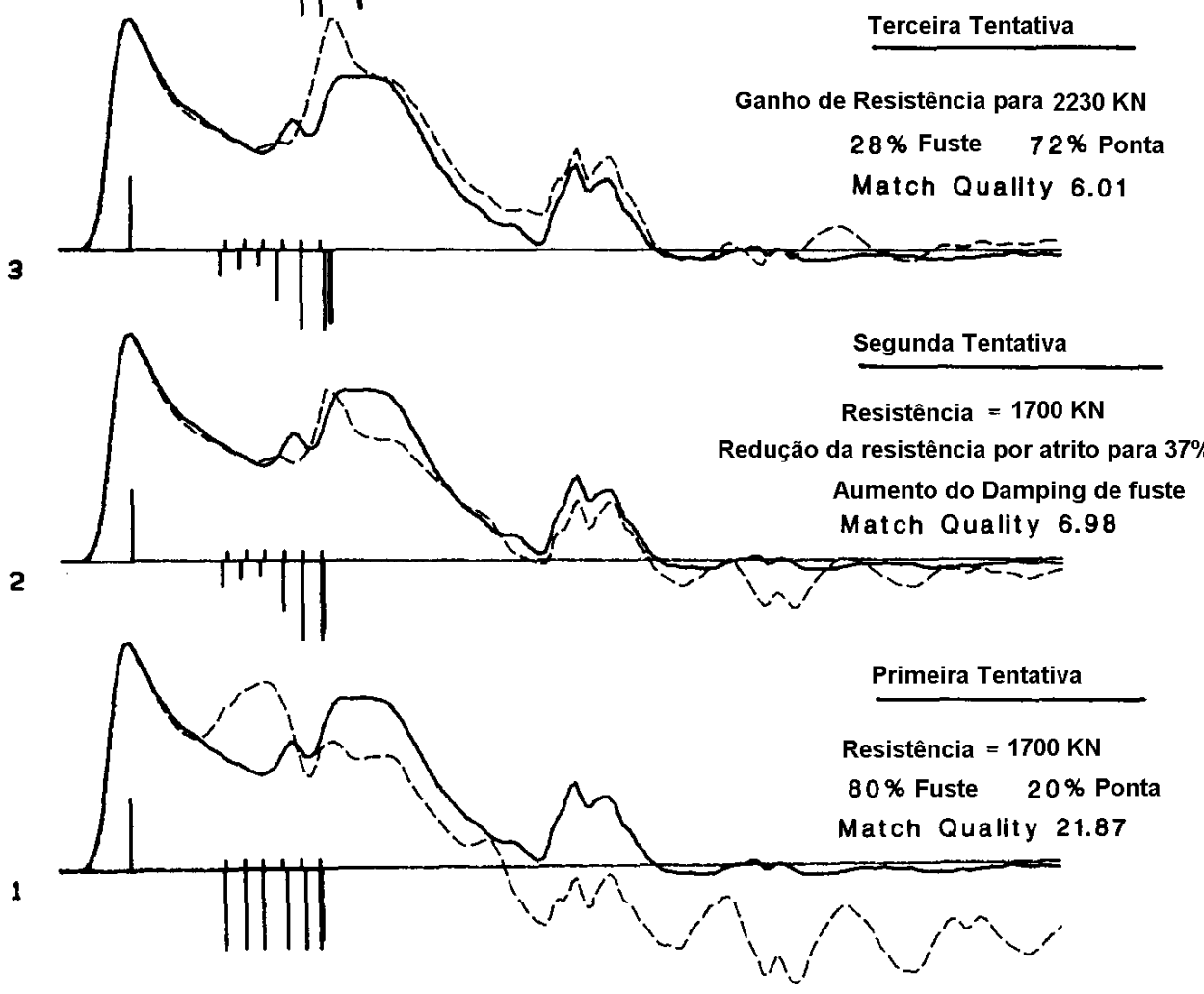

Figura 2.24 - Processo de ajuste das curvas de força por iteração (Apud Hannigan, 1990)

O melhor ajuste (“best match") é obtido, como mostra na Figura 2.25, quando não é mais possível uma melhor concordância entre os sinais medidos e calculados. 


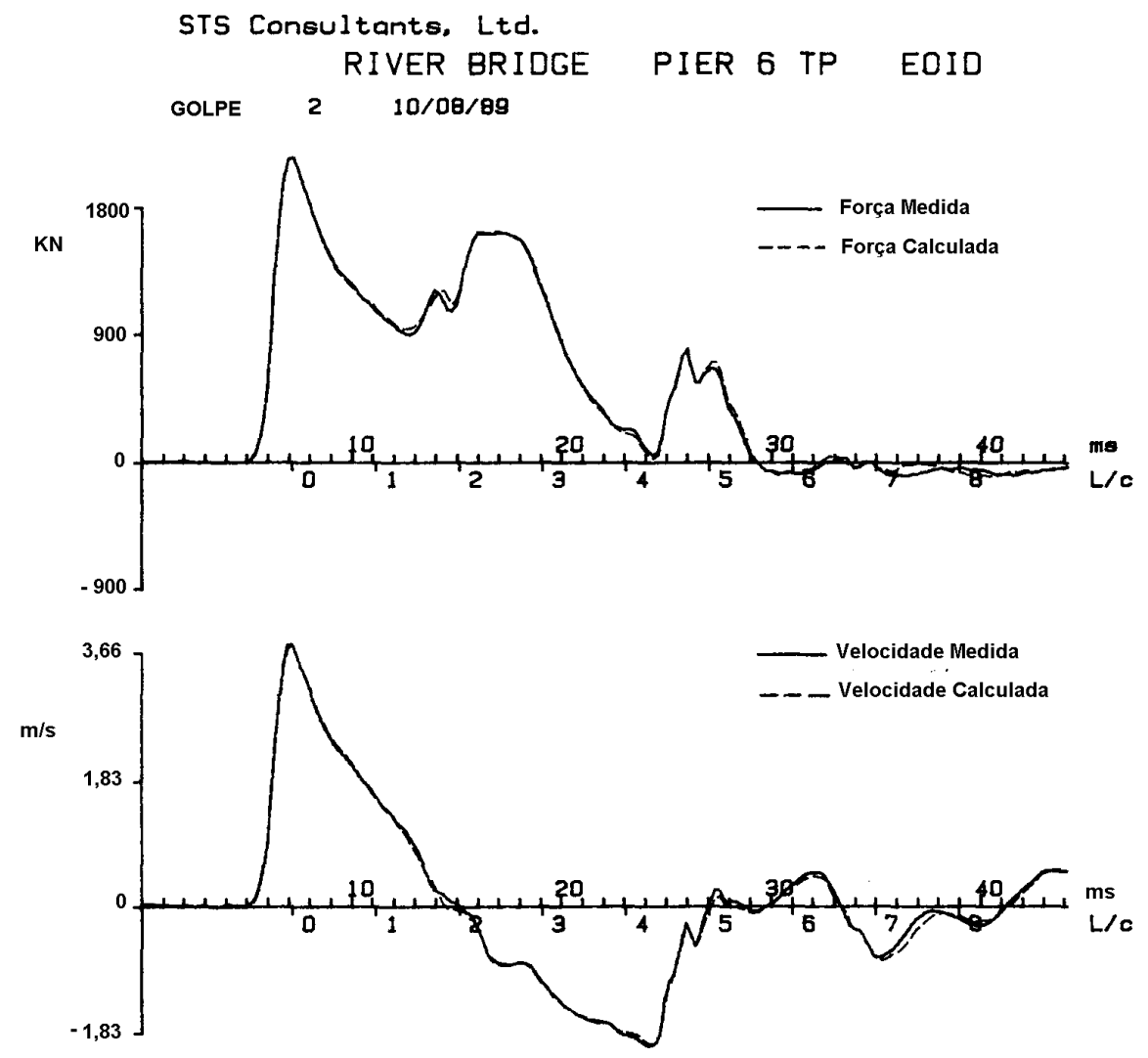

Figura 2.25 - O melhor ajuste das curvas de força e de velocidade (Apud Hannigan, 1990)

Segundo HANNIGAN (1990), a unicidade e a exatidão do modelo do solo são verificadas usando a curva de força medida como entrada e confirmando o "best match" entre as curvas de velocidade medidas e calculadas na cabeça da estaca. Entretanto, DANZIGER et al. (1996) fizeram retro-análises de registros de estacas cravadas em uma areia calcária, concluindo que a solução do tipo $C A P W A P$ não é única. Alguns registros foram escolhidos, e os ajustes das curvas foram realizados pelo mesmo engenheiro, a partir de diferentes parâmetros iniciais. Foi observada a possibilidade de atingir-se curvas de velocidade similares através de diferentes parâmetros do solo. 
Uma vez atingido o "best match", o programa gera o modelo de solo que gerou este ajuste, com os valores da resistência última mobilizada, a distribuição de resistência ao longo da profundidade, o quake e o parâmetro damping.

O programa CAPWAP também simula o ensaio de carregamento estático, usando o modelo da estaca, a distribuição de resistência do solo e o quake. O ensaio de carregamento estático simulado é feito através da aplicação de incrementos de carga na cabeça da estaca e do cálculo da penetração do elemento, associado a valores estáticos de resistência. Através desta análise, a curva carga - deslocamento da cabeça da estaca é determinada. O critério de resistência convencional adotado é o de Davisson.

O resultado final do CAPWAP está resumido nos quatro gráficos da Figura 2.26. $\mathrm{Na}$ parte superior esquerda, está o ajuste das curvas de força medida no campo e calculada pelo programa. No gráfico superior direito, estão os sinais de força e de velocidade, os quais permitem determinar a resistência mobilizada. No lado esquerdo inferior, está a simulação do ensaio de carregamento estático, com seus valores de resistência total, lateral e de ponta, além de seus deslocamentos. Finalmente, o gráfico inferior direito, dividido em duas partes, mostra a distribuição de resistência pelo atrito lateral unitário na parte superior e a distribuição de resistência no solo na parte inferior.

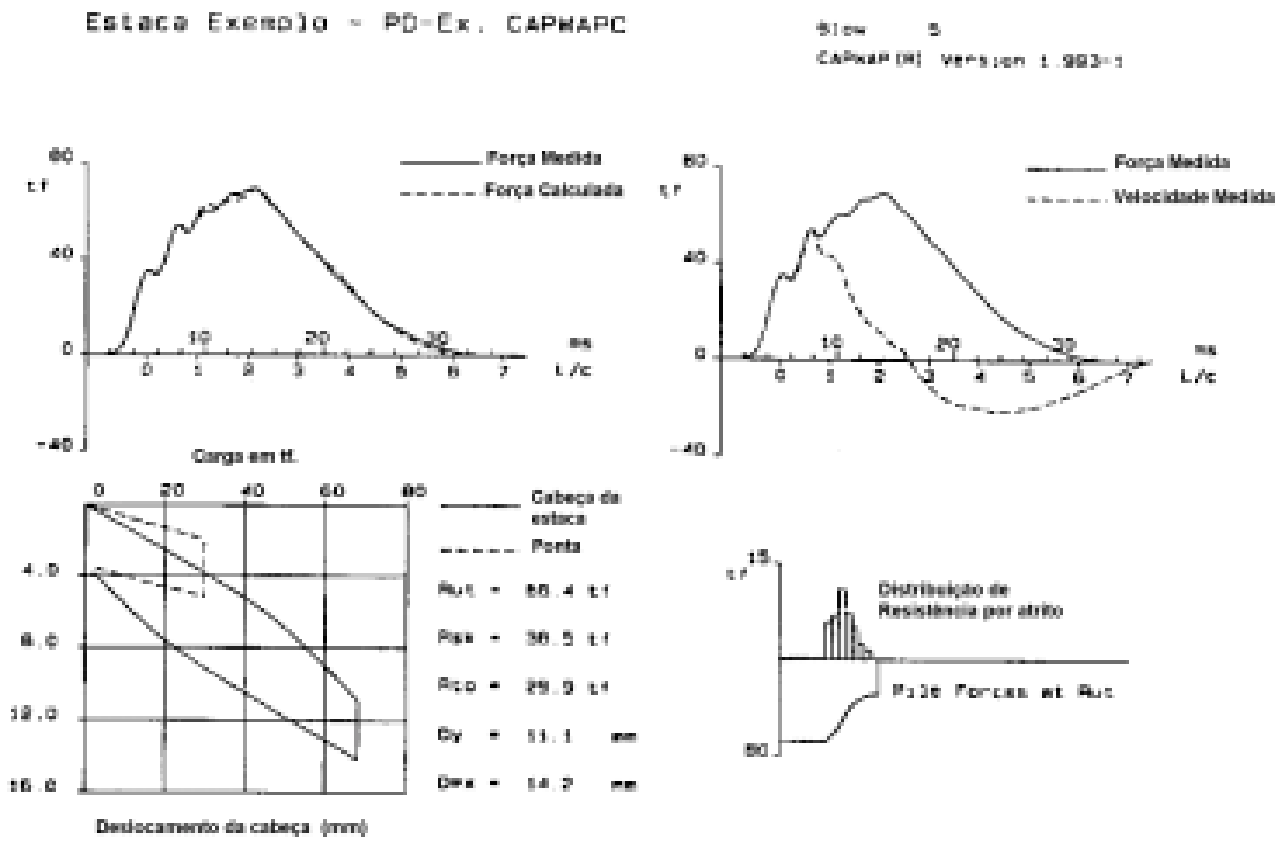

Figura 2.26 - Apresentação dos resultados do CAPWAP (Apud GRL, Inc. 1996) 


\subsection{6 - Ensaio de Carregamento Dinâmico de Energia Constante}

AOKI (1997) afirma que, no ensaio de carregamento dinâmico com impactos de energia constante, aplica-se uma série de impactos de igual energia, geralmente 10 golpes de altura constante do martelo, sobre o sistema de amortecimento + estaca + maciço de solos. Em cada impacto, registra-se o deslocamento na seção próxima do topo da estaca com papel e lápis, segundo o procedimento de CHELLIS (1951), e/ou procedese a instrumentação com o sistema PDA, em que se registram a aceleração e as deformações específicas da mesma seção, ao longo do tempo de duração do evento.

Neste ensaio, para obtenção da curva Resistência x Deslocamento, adota-se o referencial no topo inicial da estaca. Impactos de mesma energia provocam os mesmos deslocamentos $\mathrm{D}(\mathrm{D}=s+k)$, que descrevem as mesmas curvas $\mathrm{OABC}, \mathrm{CDEF}$ e FGHI , visto na Figura 2.27.

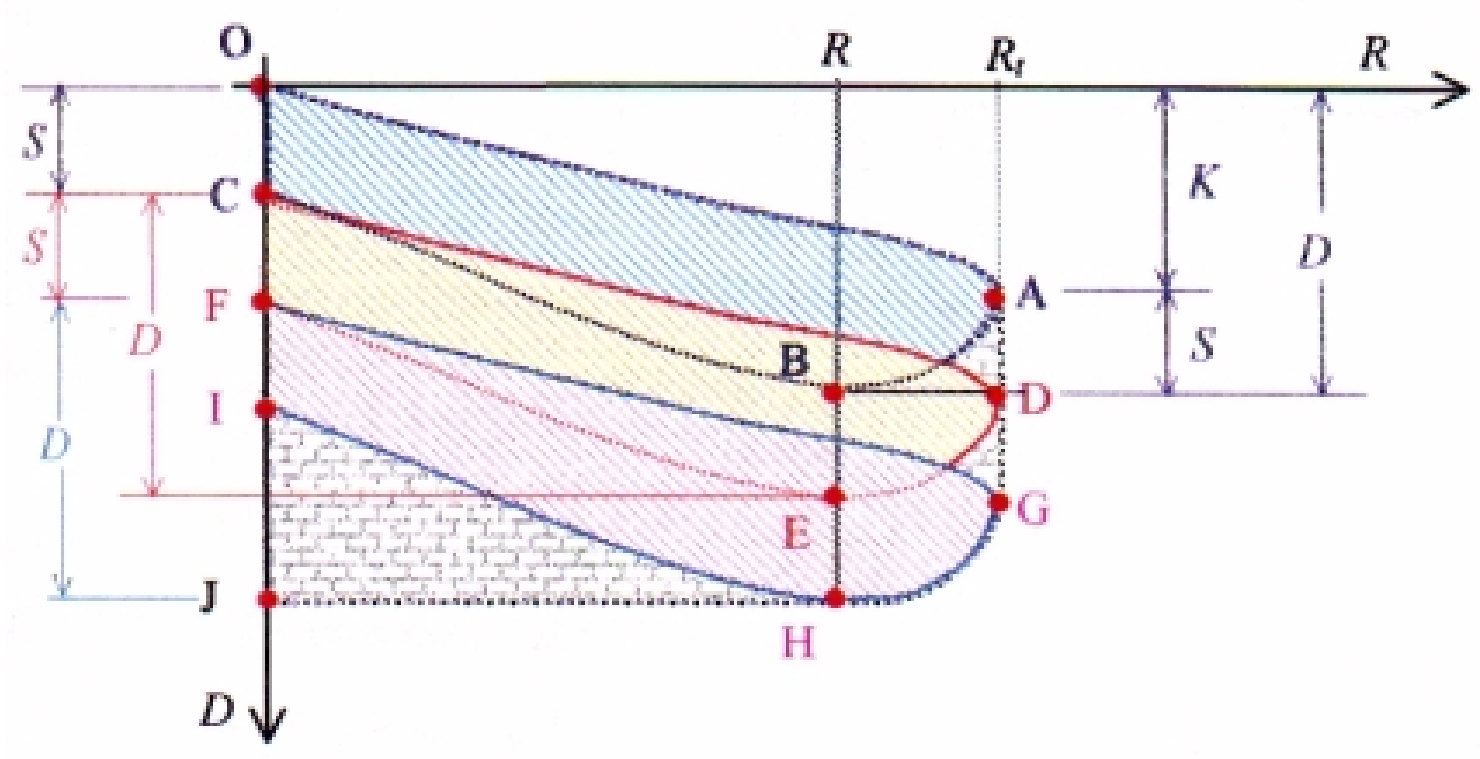

Figura 2.27 - Carregamento Dinâmico Cíclico de Energia Constante (AOKI, 1997)

Por se adotar o referencial sempre na cabeça da estaca, tem-se a impressão de que se atingiu a resistência última do sistema pelos pontos $\mathrm{ADG}$. O mesmo ponto da 
curva Resistência x Deslocamento é mostrado, para sucessivos golpes, no ensaio de carregamento dinâmico de energia constante, não definindo uma curva.

AOKI (1991) diz que, para atingir a ruptura, é necessário provocar grandes deslocamentos, a resistência correspondente a pequenas penetrações da estaca no solo são valores mobilizados e não últimos.

\subsection{7 - Ensaio de Carregamento Dinâmico de Energia Crescente}

Segundo AOKI (1989), no ensaio de carregamento dinâmico, somente com impactos de energia crescente é possível mobilizar a resistência última do sistema.

As energias crescentes neste ensaio são obtidas pelo aumento das alturas de queda do martelo que golpeia a estaca. Dessa forma, quando, em sucessivos impactos de energia crescente, a resistência mobilizada permanecer invariável, tem-se a resistência última do sistema.

TERZAGHI (1943) afirma que se mobiliza toda a resistência disponível, estando este valor sobre a reta assíntota da curva resistência-deslocamento.

No ensaio mostrado na Figura 2.28, retirada de AOKI (1997), observa-se a curva resistência-deslocamento dinâmico, para o ensaio de carregamento dinâmico de energia crescente, em que se tem o referencial sempre na cabeça da estaca. Neste ensaio, foram aplicados três golpes de energias crescentes, mobilizando resistências estáticas e provocando deslocamentos máximos correspondentes. Esses deslocamentos são compostos de parcelas elásticas $K$ e parcelas permanentes $S$. As curvas OAG, OBH e OCI mostram os sucessivos golpes aplicados com suas respectivas resistências mobilizadas e deslocamentos. Este procedimento vai sendo realizado até caracterizar a ruptura do sistema. 


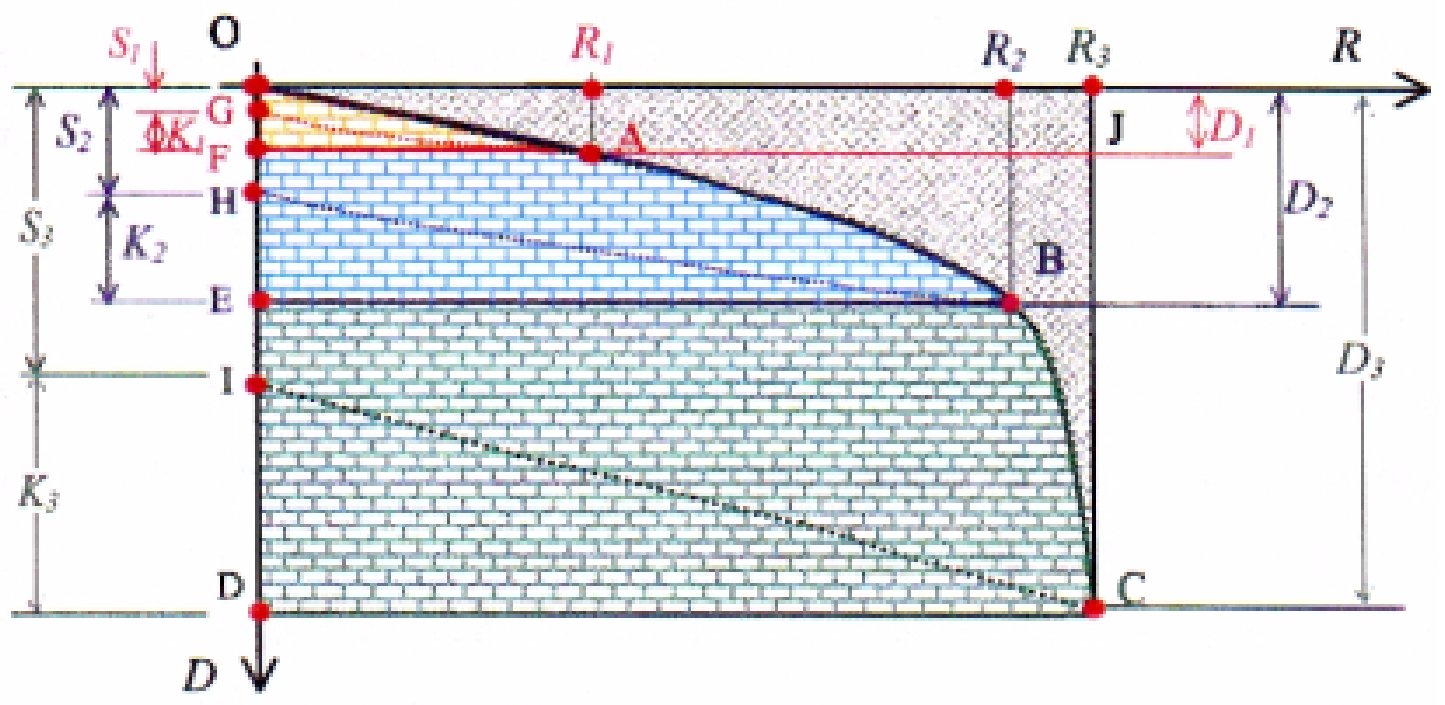

Figura 2.28 - Curva Resistência Estática-Deslocamento Dinâmico: Origem Única (AOKI, 1997)

\subsection{8 - Fórmulas Dinâmicas de Cravação Utilizando Energia Crescente}

NIYAMA et al. (1996) apresentam o modelo mostrado na Figura 2.29, de uma estaca de concreto de área $\mathrm{A}$, comprimento L e módulo de elasticidade $\mathrm{E}$, com ponta sobre uma camada de solo de espessura C. A aplicação de um golpe de energia líquida EMX provoca deformação elástica e plástica, no solo e na estaca. A penetração permanente da ponta da estaca no solo corresponde à nega "s" e à parcela elástica, devido à deformação das camadas de solo, ao "quake"da ponta $\mathrm{C}_{3}$. A deformação elástica do fuste, devido à energia $\mathrm{EMX}$, é dada pela parcela $\mathrm{C}_{2}$. $\mathrm{O}$ valor de $\mathrm{K}$ $\left(\mathrm{K}=\mathrm{C}_{2}+\mathrm{C}_{3}\right)$ corresponde ao deslocamento, devido às deformações elásticas do solo, sob a ponta, e do fuste e é geralmente conhecido por repique elástico da estaca pelo indicado na Figura 2.29. O valor de $\mathrm{DMX}(\mathrm{DMX}=\mathrm{K}+\mathrm{s})$ é o deslocamento máximo do topo da estaca.

Vale salientar que o valor de "s", muitas vezes, não representa somente a parcela devida às deformações plásticas do solo e pode englobar, também, uma parcela de deformação elástica devida às cargas residuais remanescentes no fuste. 


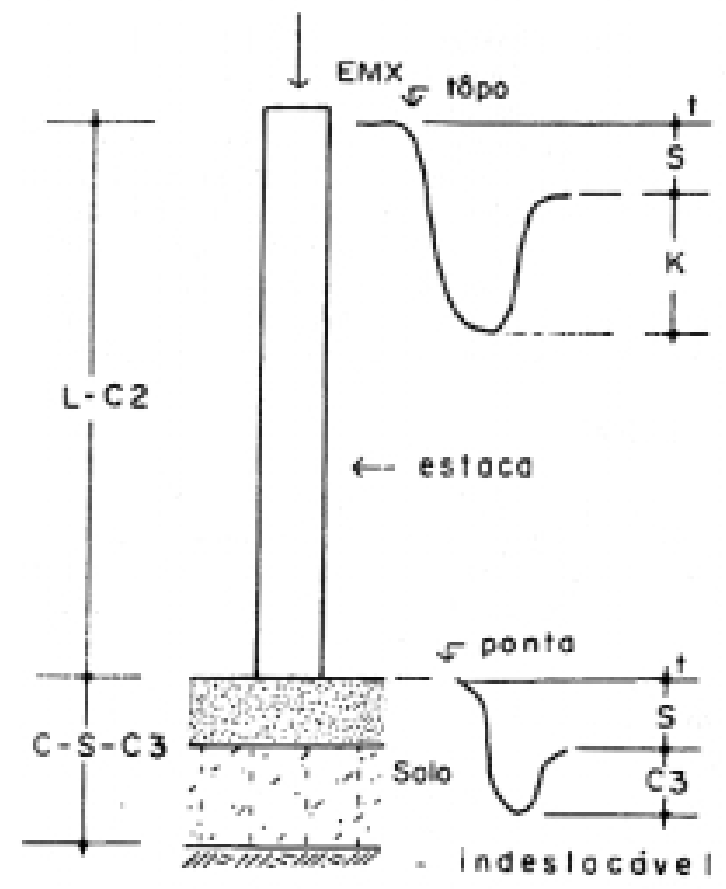

Figura 2.29 - Modelo de Estaca para Fórmulas Dinâmicas (Apud AOKI, 1991)

AOKI (1986), baseado em CHELLIS (1951), afirma que a estaca pode ser considerada como uma mola, para verificar o valor da resistência última, desde que $\mathrm{RMX}$ varie diretamente com o $\mathrm{C} 2$, isto é, usar a própria estaca como instrumento de controle de resistência do solo.

Segundo UTO et al. (1985), AOKI (1986) e VELLOSO (1987), a carga mobilizada pode ser determinada pelo deslocamento do topo da estaca como indicado na Figura 2.29.

UTO et al. (1985) surgerem a seguinte expressão:

$R M X=\frac{A \cdot E \cdot\left(S+C_{3}+2 \cdot C_{2}\right)}{2 \cdot e_{0} \cdot L}+\frac{N^{\prime} \cdot U \cdot L_{c}}{e_{F}}$ 
Em que:

N’ = Média do SPT ao longo da estaca

$\mathrm{e}_{\mathrm{F}}=2,5$ fator de correção

$e_{0}=\sqrt[3]{\frac{2 . W}{W_{P}}} \rightarrow$ Fator de correção

Os autores aconselham adotar $\mathrm{C}_{3}=\mathrm{s}$.

AOKI (1986) propõe a seguinte fórmula:

$$
\begin{gathered}
R M X=\frac{C_{2} \cdot A \cdot E}{L} \\
C_{2}^{\text {máx }}=\int_{0}^{L} \frac{R(Z) \cdot d z}{A \cdot E}
\end{gathered}
$$

VELLOSO (1987) propõe a seguinte expressão:

$$
R M X=\frac{\left(K-C_{3}\right) \cdot A \cdot E}{\alpha \cdot L}
$$

Em que:

$\mathrm{C}_{3}=2,5 \mathrm{~mm}$

$\alpha=\beta+0,6(1-\beta) \approx 0,7$

$\beta=R_{P} / R$

$\mathrm{R}_{\mathrm{P}}$ corresponde à parcela de ponta da estaca 
SOUZA FILHO \& ABREU (1990) recomendam que, em caso de não medição de C3, adotam-se os coeficientes sugeridos na Tabela 2.2.

Tabela 2.2 - Valores de C3 sugeridos por SOUZA FILHO \& ABREU (1990)

\begin{tabular}{|c|c|}
\hline Tipo de Solo & C3 (mm) \\
\hline Areia & $0,0-2,5$ \\
\hline Areia Siltosas e Siltes Arenosos & $2,5-5,0$ \\
\hline Argilas Siltosas e Siltes Argilosos & $5,0-7,5$ \\
\hline Argilas & $7,5-10$ \\
\hline
\end{tabular}

AOKI (1991) afirma que, por ocasião da ruptura, os deslocamentos do topo da estaca se devem predominantemente à penetração da ponta no solo, com progressivo aumento da nega "s" e com a parcela elástica C2, tendendo para um valor constante. Os valores "s", "C2" e "C3" são correspondentes a cada nível de carga mobilizada RMX aplicada e podem ser determinados a partir do diagrama de cravação. O parâmetro C3 não é uma variável do solo, e sim dependente do nível de energia aplicada.

MACHADO (1995) relata que em seus ensaios, a adoção de C3 =2,5 mm ou $\mathrm{C} 3=\mathrm{s}$, causa discrepância nos resultados, e a adoção de valores de C3 crescentes com a energia apresentou uma melhora sensível nas estimativas de RMX pelas fórmulas de UTO et al. (1985) e VELLOSO (1987), como também afirma que C3 é função do tipo do solo abaixo da ponta da estaca e do nível de energia aplicado.

BALECH \& AOKI (2000) afirmam que o quake da ponta de uma estaca é dependente do nível de energia cinética aplicado no sistema estaca-solo, não pode ser considerado como um parâmetro do solo. Alguns sistemas estaca-solo não apresentam 
uma variação muito visível, devido ao fato dos mesmos estarem apresentando ruptura nítida, ou a mobilização da resistência de ponta não se alterar com o aumento do nível de energia aplicado.

CAMPELO (2000) afirma que as variáveis amortecimento de CASE (de ponta), de Smith (lateral e de ponta), quake (lateral e de ponta) são dependentes do nível de energia, não sendo, pois, parâmetros do solo. 


\section{4 - Comparação entre Prova de Carga Estática e Dinâmica}

AOKI \& NIYAMA (1991) fazem uma avaliação comparativa entre as provas de carga dinâmica, de energia crescente e estática, realizadas em duas estacas de concreto centrifugado, de ponta aberta, com diâmetro externo de $50 \mathrm{~cm}$ e espessura da parede de $9 \mathrm{~cm}$. As provas de carga dinâmica foram analisadas através dos métodos CASE e CAPWAP. As provas de carga estática foram feitas no início, com carregamento lento e rápido no final. A análise comparativa dos resultados das provas de carga dinâmica e estática mostram concordância bastante satisfatória, não somente quanto à carga de ruptura, mas também na curva carga-deslocamento, que pode ser vista na Figura 2.30.

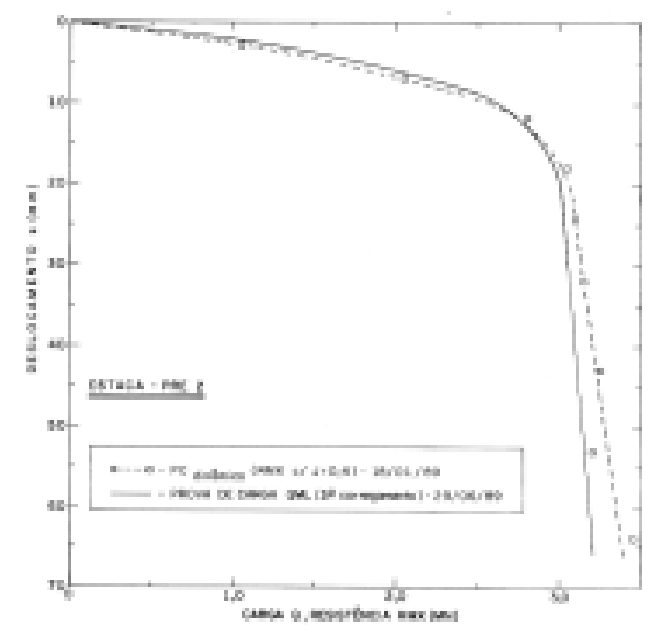

(a)

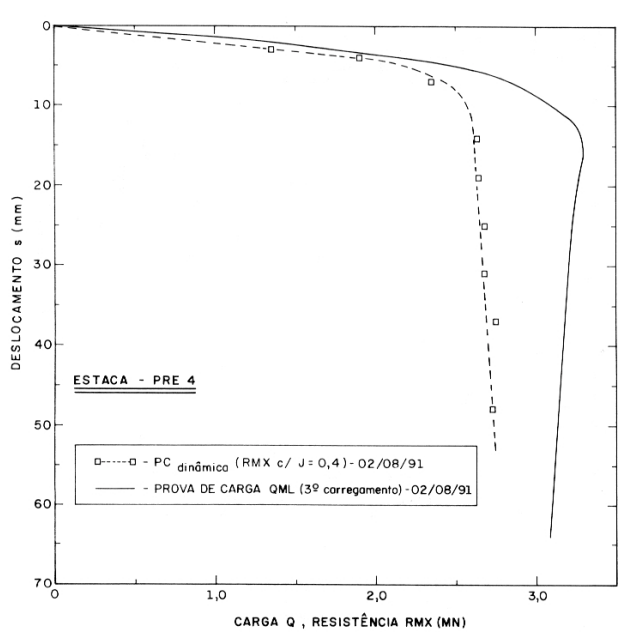

( b )

Figura 2.30 - Comparação das Curvas de Carga-Deslocamento das Provas de Carga Dinâmica e Estática (AOKI \& NIYAMA, 1991)

BERNARDES \& NORDAL (1991) estudam a capacidade de carga de duas estacas-modelo de alumínio, cravadas em um solo arenoso, e observam que a carga de ruptura calculada através das medições dinâmicas se aproxima da capacidade de carga 
estática, caso a energia aplicada pelo golpe do martelo seja suficiente para provocar penetração da ponta da estaca entre 5 e $10 \%$ do diâmetro.

Resultados de pesquisa com modelos analíticos POULOS (1981) e provas de carga em estacas - AUDIBERT \& DOVER (1981) - mostram que o efeito de alta velocidade de carregamento, devido principalmente ao efeito da velocidade de deformação, é o de aumento da resistência limite das estacas em relação ao comportamento estático.

YAO et al. (1988) afirmam que, em Taiwan, a experiência tem mostrado que a curva carga-deslocamento da prova de carga estática e da prova de carga dinâmica foram muito próximas. Todos os resultados estáticos aparentaram ser maiores que os dinâmicos.

BERNARDES et al. (1991) exibem uma análise CAPWAPC dos pontos das provas de carga dinâmica executadas em duas estacas de concreto e mostram que o quake de ponta C3 é crescente com o nível de energia aplicada, confirmando que se trata de uma variável dependente, e não de um parâmetro do solo.

ANDREO et al. (2000) relatam resultados de ensaios de carregamento dinâmico, com energia crescente (DLT), executados em duas estacas pré-fabricadas de concreto, com seções quadradas $(26 \times 26$ e 29×29 cm) cravadas em folhelho de formação Taubaté/SP, analisadas pelo método CAPWAPC e comparadas com valores previstos pelo método semi-empírico de Décourt e Quaresma (1982). O autor conclui que o método Décourt e Quaresma subestima a resistência lateral e superestima a resistência de ponta. Afirma também que, como os ensaios foram executados um dia após a cravação essas diferenças podem estar influenciadas pelo processo de re-equilíbrio do sistema.

ANDREO et al. (2000) afirmam que a utilização dos métodos de controle de fundações profundas, utilizando-se estacas pré-fabricadas de concreto, em particular nos casos em que se prevê a existência de carregamento adicional proveniente da atuação do atrito lateral negativo, parece ser bastante confiável e menos conservador se comparada 
à avaliação efetuada, tendo por base os métodos tradicionais estáticos empíricos, em particular, o método Décourt e Quaresma.

TERZAGHI \& PECK (1948), MELLO (1975) e MILITITSKY (1991) afirmam que a velocidade de carregamento influi nos resultados de uma prova de carga. Muitos destes autores consideram que o carregamento rápido em argila pode levar a uma capacidade de carga e rigidez maior que o carregamento lento, devido aos efeitos viscosos ou de poro-pressões, e o carregamento lento conduz a uma redução da capacidade de carga e da rigidez.

MASSAD \& WINZ (2000) dizem que a questão das relações entre as provas de carga estática, lenta e rápidas, e dinâmica ainda tem sido objeto de polêmicas, apesar da NBR-6122 permitir uma livre escolha entre carregamentos lentos ou rápidos, no caso de provas de carga estáticas.

MASSAD \& WINZ (2000) analisam casos de provas de carga estática e dinâmica. As provas de carga analisadas envolveram solos do pré-cambriano da grande São Paulo e solos de decomposição de arenito, da cidade de São Carlos. As estacas de diversos tipos foram instaladas: no campo experimental da EPUSP/ABEF; em São Bernardo do Campo (SP); e no campo experimental de São Carlos (EESC-USP). A Tabela 2.3 mostra as características gerais do local e do subsolo. E as Figuras 2.31 à 2.34 mostram as provas de carga realizadas, diante das quais, nesta presente pesquisa, os autores concluem que a velocidade de carregamento tem pouca influência na capacidade de carga. No caso específico de São Carlos, as diferenças constatadas nas curvas cargarecalque, quando se comparavam os carregamentos lentos e rápidos, eram aparentes: elas se devem às cargas residuais e à compactação estática do solo da ponta, após o primeiro carregamento. Para outro tipo de solo, como é o caso das argilas marinhas, a velocidade de carregamento pode influir nos resultados das provas de carga, ou seja, cada solo deve ser analisado individualmente. 
Tabela 2.3 - Características Gerais das estacas e Subsolo ( MASSAD \& WINZ, 2000).

\begin{tabular}{|c|c|c|c|c|c|c|c|c|c|c|c|c|c|}
\hline \multirow{2}{*}{ Local } & \multirow{2}{*}{ Estaca } & \multicolumn{2}{|c|}{ Carregamento } & \multicolumn{2}{|l|}{ Tipo } & \multirow{2}{*}{ Dimensöed } & \multirow{2}{*}{$\begin{array}{l}\text { Altura } \\
\text { (m) }\end{array}$} & \multicolumn{2}{|c|}{ Subsolo } & \multirow{2}{*}{ SPTP } & \multirow{2}{*}{ SPT: } & \multirow{2}{*}{$\begin{array}{l}\text { Sond. } \\
\text { gem } \\
\text { (n') }\end{array}$} & \multirow{2}{*}{ Fonte } \\
\hline & & $\leftarrow$ & Tipo & Estaca & Seção & & & Fuste & Ponta & & & & \\
\hline \multirow{10}{*}{$\begin{array}{c}\text { Campo } \\
\text { Experimental } \\
\text { da } \\
\text { EPUSP/ABEF }\end{array}$} & \multirow[t]{2}{*}{ BAR-1 } & 1 & Lento & Bacrete & Retangular & $(165 \times 40) \mathrm{cm}^{2}$ & 7,0 & \multirow{10}{*}{$\begin{array}{c}\text { Silte arenoso } \\
\text { com pouca } \\
\text { mica, } \\
\text { proveniente } \\
\text { da } \\
\text { decomposiçào } \\
\text { de } \\
\text { Migmatito }\end{array}$} & \multirow{10}{*}{$\begin{array}{c}\text { Silte arenoso } \\
\text { com pouca } \\
\text { mica, } \\
\text { proveniente } \\
\text { da } \\
\text { decomposiçaào } \\
\text { de } \\
\text { Migmatito }\end{array}$} & 34,1 & 48,3 & $\mathbf{S}_{1}$ & \multirow{10}{*}{$\begin{array}{c}\text { ABEF } \\
\text { (1989) } \\
\text { MASSAD } \\
\text { (1991b) }\end{array}$} \\
\hline & & 2 & Rápido & Barrete & Retangular & $(165 \times 40) \mathrm{cm}^{2}$ & 7,0 & & & & & & \\
\hline & \multirow[t]{2}{*}{ HLCA } & 1 & Lento & Hélice continua & Circular & $6-35 \mathrm{~cm}$ & 6,7 & & & 14,4 & 27,7 & $\mathrm{~S}_{3}$ & \\
\hline & & 2 & Rápido & Hélice continua & Circular & $4=35 \mathrm{~cm}$ & 6,7 & & & & & & \\
\hline & \multirow[t]{2}{*}{ MET-1 } & 1 & Lento & Metálica & Perfil I & $10^{n}$ & 6,9 & & & 118 & 28,0 & St & \\
\hline & & 2 & Rápido & Metalica & Perfil I & $10^{n}$ & 6,9 & & & & & & \\
\hline & \multirow[t]{2}{*}{ PRE-2 } & & Rápido & Concreto centrifugado & Circular & $\phi=50 \mathrm{~cm} \phi=32 \mathrm{~cm}$ & 8,7 & & & 11,8 & 28.0 & $S_{4}$ & \\
\hline & & & Dinâmico & Concreto centrifu gado & Circular & $4-50 \mathrm{~cm} \phi=32 \mathrm{~cm}$ & 8,7 & & & & & & \\
\hline & \multirow[t]{2}{*}{ PRÉ-4 } & & \begin{tabular}{|l} 
Rápido \\
\end{tabular} & Concreto centrifugado & Circular & $\phi_{c}=50 \mathrm{~cm} \phi=32 \mathrm{~cm}$ & 6,0 & & & 16,5 & 22,6 & St & \\
\hline & & & Dinâmico & Concreto centrifugado & Circular & $\phi=50 \mathrm{~cm} \phi-32 \mathrm{~cm}$ & 6,0 & & & & & & \\
\hline \multirow{4}{*}{$\begin{array}{c}\text { São Bernardo } \\
\text { do Campo } \\
\text { Perfil } \\
\text { Habitaçoes I } \\
\end{array}$} & \multirow[t]{2}{*}{ E522 } & 2 & Lento & Hélice continua & Circular & $1-27,5 \mathrm{~cm}$ & 11,0 & \multirow{4}{*}{$\begin{array}{l}\text { Sille arenoso pouco } \\
\text { argiloso com mica } \\
\text { pouco a medianemente } \\
\text { compecto (solo residual) }\end{array}$} & \multirow{4}{*}{$\begin{array}{l}\text { Silte atenoso pouco } \\
\text { argidoso com mica } \\
\text { poucco a mediannamente } \\
\text { compacto (solo residual) }\end{array}$} & 7.6 & 10 & $S_{\gamma}$ & \multirow{4}{*}{$\begin{array}{c}\text { MASSAD } \\
\text { (1991b) }\end{array}$} \\
\hline & & 3 & Rápido & Hélice continua & Circular & $=27,5 \mathrm{~cm}$ & 11,0 & & & & & & \\
\hline & \multirow[t]{2}{*}{$\mathrm{E} 523$} & 1 & Lento & Hélice continua & Circular & $1=27.5 \mathrm{~cm}$ & 15,0 & & & 8,5 & 12 & $\mathrm{~S}_{6}$ & \\
\hline & & 2 & Rápido & Hélice continua & Circular & $-20,5 \mathrm{~cm}$ & 15,0 & & & & & & \\
\hline
\end{tabular}

\begin{tabular}{|c|c|c|c|c|c|c|c|c|c|c|c|c|c|}
\hline \multirow{12}{*}{$\begin{array}{c}\text { Campo } \\
\text { Fxperimental } \\
\text { de } \\
\text { Sáo Carlos }\end{array}$} & \multirow{4}{*}{$\mathrm{D}-3 \mathrm{3am}$} & 11. & Lento & \multirow{4}{*}{ Escavada } & \multirow{4}{*}{ Circular } & \multirow{4}{*}{$-35 \mathrm{~cm}$} & \multirow{4}{*}{10,0} & \multirow{12}{*}{$\begin{array}{c}\text { Areia } \\
\text { argilosa } \\
(0-6,40 \mathrm{~m} \text { : } \\
\text { solo sedimentar, } \\
\text { laterizado; } \\
6,40-13,0 \mathrm{~m} \text { : } \\
\text { solo residual) }\end{array}$} & \multirow{12}{*}{$\begin{array}{l}\text { Areia } \\
\text { argilosa } \\
\text { (solo } \\
\text { residual) }\end{array}$} & \multirow{4}{*}{5,4} & \multirow{4}{*}{7,7} & \multirow{4}{*}{$S_{2}$} & \multirow{12}{*}{$\begin{array}{c}\text { SACILOTTO } \\
\text { (1992) }\end{array}$} \\
\hline & & $2 \mathrm{R}$ & Rapido & & & & & & & & & & \\
\hline & & $3 R$ & Rapido & & & & & & & & & & \\
\hline & & $4 \mathrm{~L}$ & Lento & & & & & & & & & & \\
\hline & \multirow{4}{*}{$D-40 \mathrm{~cm}$} & IL & Lento & \multirow{4}{*}{ Escavada } & \multirow{4}{*}{ Circular } & \multirow{4}{*}{$-40 \mathrm{~cm}$} & \multirow{4}{*}{10,0} & & & \multirow{4}{*}{5,4} & \multirow{4}{*}{7,7} & \multirow{4}{*}{$S_{2}$} & \\
\hline & & $2 \mathrm{R}$ & Rápido & & & & & & & & & & \\
\hline & & $3 R$ & Rápido & & & & & & & & & & \\
\hline & & $4 \mathrm{~L}$ & Lento & & & & & & & & & & \\
\hline & \multirow{4}{*}{ D-socm } & $1 \mathrm{~L}$ & Lento & \multirow{4}{*}{ Escavada } & \multirow{4}{*}{ Circular } & \multirow{4}{*}{$-50 \mathrm{~cm}$} & \multirow{4}{*}{10,0} & & & \multirow{4}{*}{5,4} & \multirow{4}{*}{7,7} & \multirow{4}{*}{$S_{2}$} & \\
\hline & & $2 \mathrm{R}$ & Rápido & & & & & & & & & & \\
\hline & & $3 R$ & Rapido & & & & & & & & & & \\
\hline & & $4 \mathrm{~L}$ & Lento & & & & & & & & & & \\
\hline
\end{tabular}

NOTAS: SPT $\mathrm{f}=$ Valor médio do SPT ao longo do fuste

$\mathrm{SPT}_{\mathrm{p}}=$ Valor médio do SPT na ponta

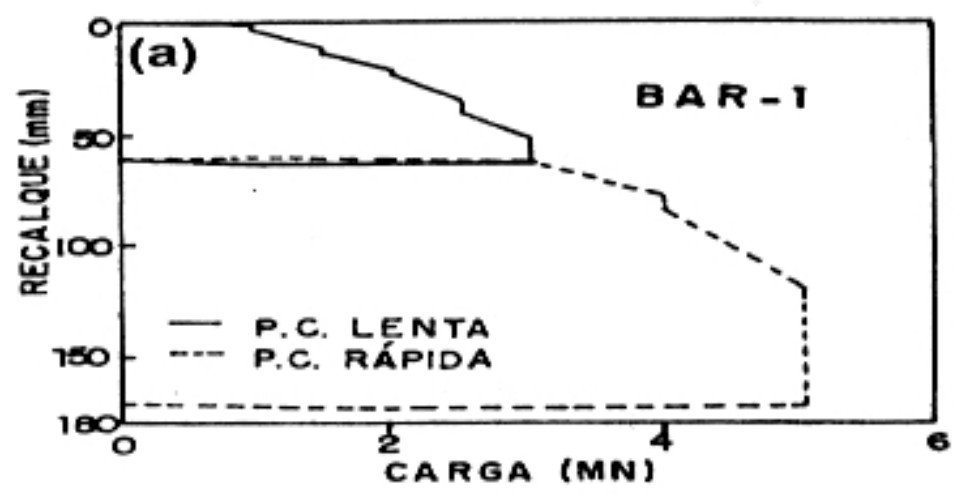

( a )

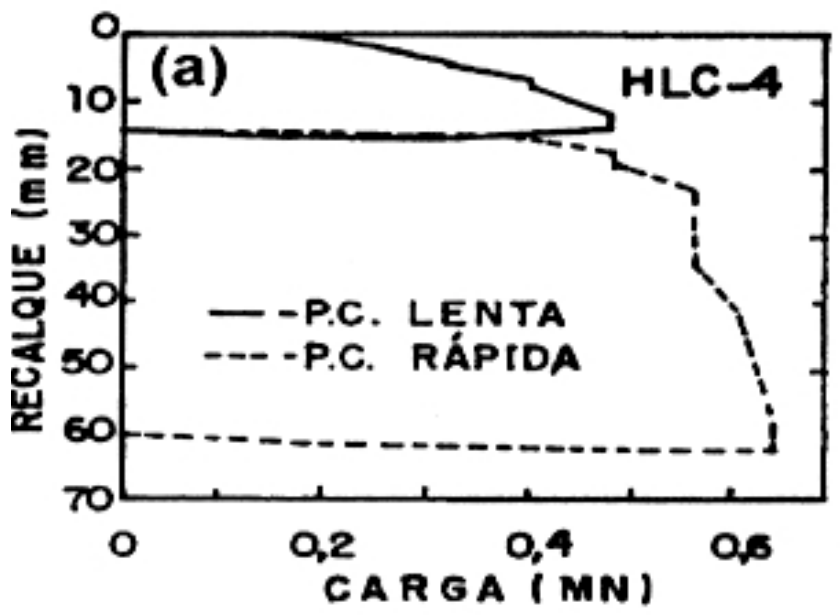

( b )

Figura 2.31 - a) Prova de Carga na Estaca BAR-1 (MASSAD \& WINZ, 2000).

b) Prova de Carga na Estaca HLC-4 


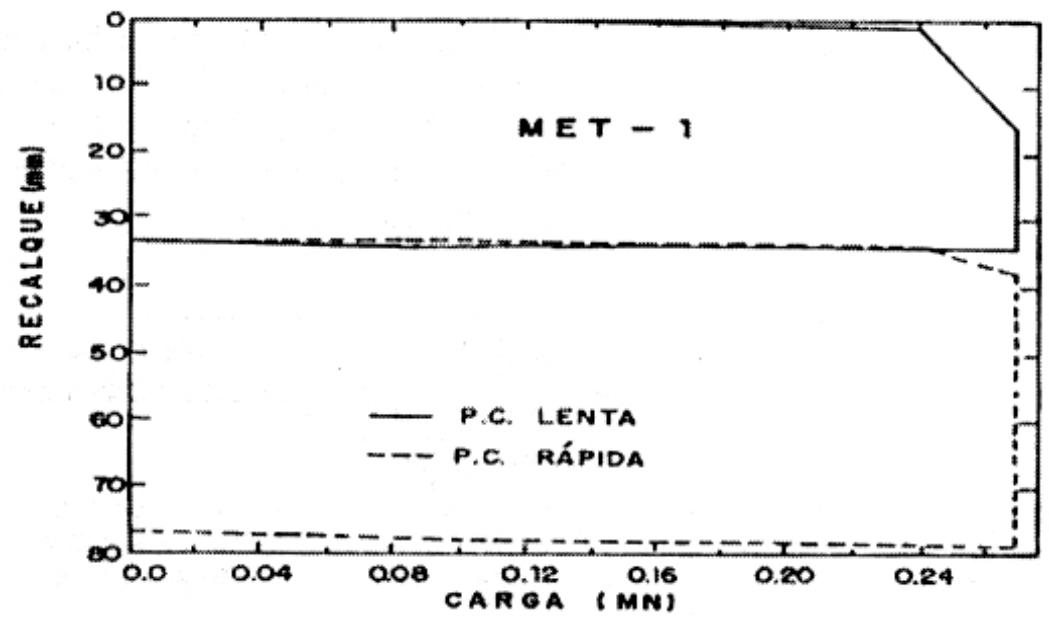

Figura 2.32 - Prova de Carga na Estaca MET-1 ( Apud MASSAD \& WINZ, 2000)
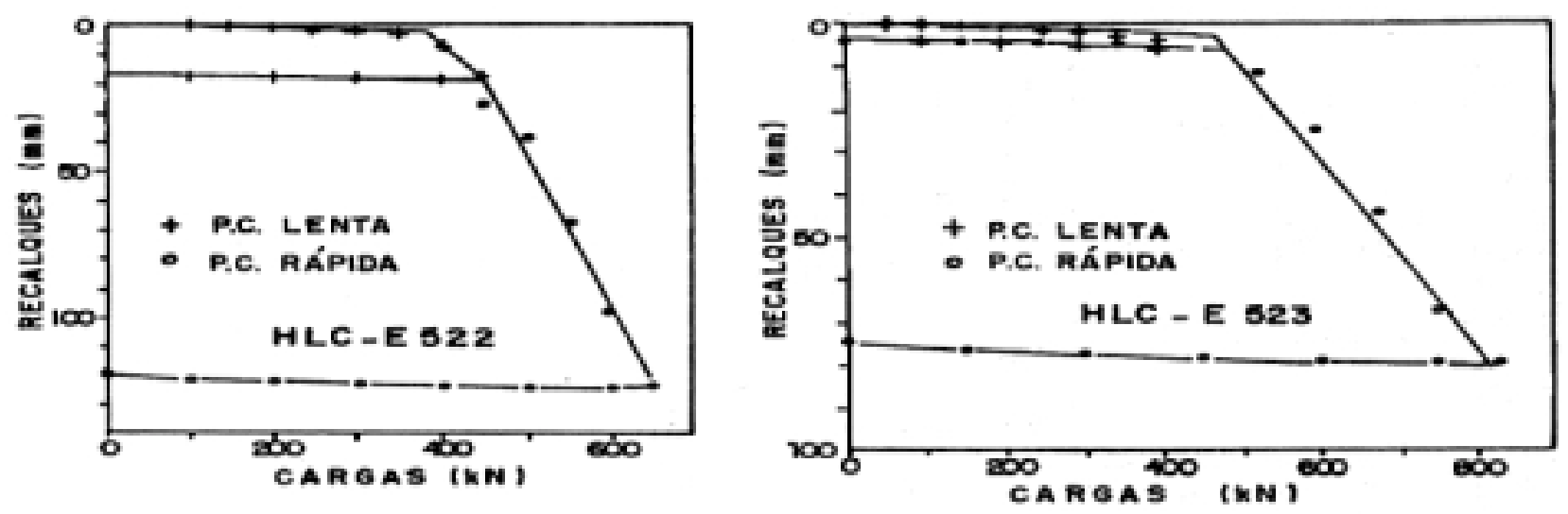

Figura 2.33 - Provas de Carga em duas estacas, em São Bernardo do Campo (MASSAD \& WINZ, 2000). 

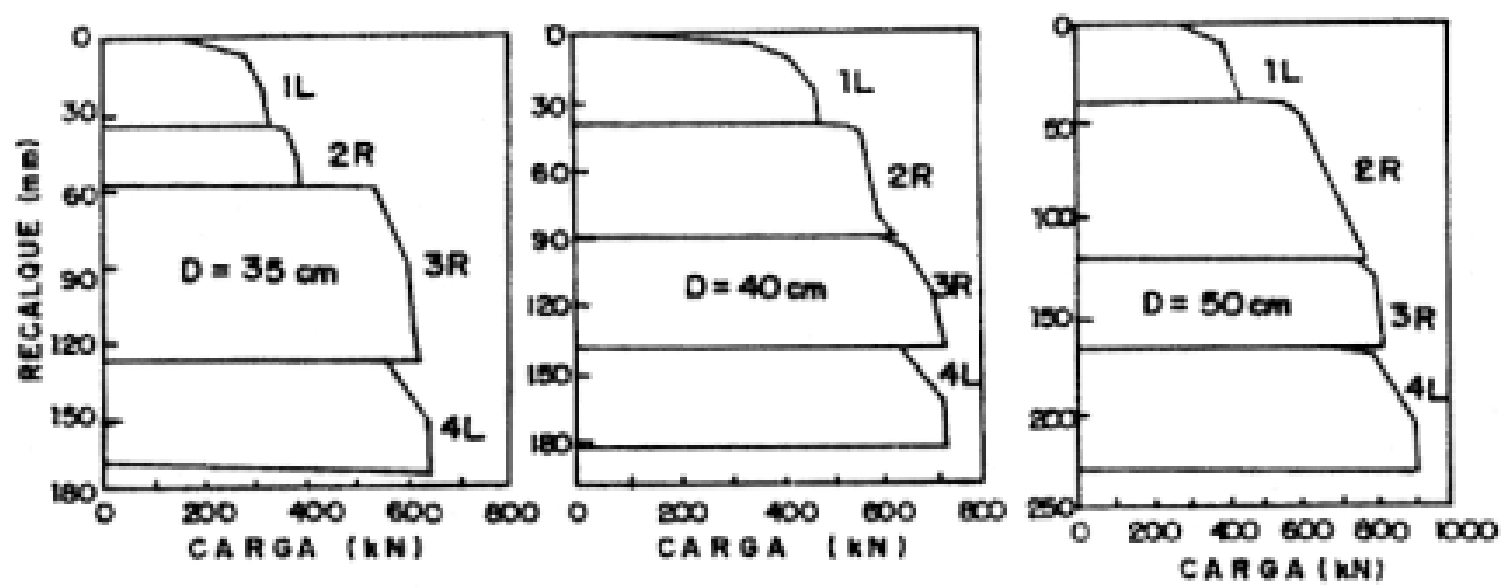

Figura 2.34 - Provas de L'arga em 3 Estacas Escavadas no Lampo Experımental de Sảo Larlos ( Apud MASSAD \& WINZ, 2000)

DÉCOURT (1998) afirma que o conceito de ruptura física não é diretamente aplicável a estacas escavadas. Nesse tipo de fundação, em que uma contribuição de ponta reduzida está associada a pequenos deslocamentos, a mobilização de resistências tende a aumentar continuamente com os recalques. Assim, é de se esperar que a sucessão de ciclos de carregamento estático ou dinâmico, conduza a maiores resistências, pois deslocamentos permanentes vão se acumulando.

LIU et al. (1996) analisam ensaios estáticos e dinâmicos de estacas escavadas, executados em mesmos elementos. Verificam que, se uma prova de carga estática é executada após uma prova de carga dinâmica, uma resistência maior será encontrada no ensaio estático. Quando as provas de carga estática foram conduzidas antes dos ensaios dinâmicos, estes últimos tenderam a mobilizar maiores resistências. Tal comportamento é atribuído à compressão contínua do solo, sob a ponta das estacas, o qual estando inicialmente em um estado fofo, tende a ser compactado com a aplicação das cargas.

MASSAD (1992) e MARIORANO et al. (1996) afirmam que a interpretação das curvas carga-recalque exige uma certa cautela, pois a imposição de um ciclo de carregamento, estático ou dinâmico, provoca o aparecimento de tensões residuais tanto no solo como na estaca. As tensões residuais não modificam a carga de ruptura do elemento, mas a forma da curva carga-recalque de ciclos subsequentes pode ser 
sensivelmente alterada. De um modo geral, as cargas residuais tendem a conferir um comportamento mais rígido ao sistema estaca-solo.

KORMANN et al. (2000) analisam duas estacas hélice contínua através de provas de carga estática e dinâmica. $\mathrm{O}$ perfil do sítio experimental onde foram feitas as provas de carga e as características da estaca podem ser vistos na Figura 2.35. As Figuras 2.36 a 2.38 mostram as curvas carga-recalque das provas de carga estática. Os autores concluem que uma comparação entre resultados de provas de carga estática e dinâmica, executadas em um mesmo elemento, não pode deixar de considerar que o primeiro ensaio modifica as condições da estaca. Esse fato assume maior importância no caso de estacas escavadas, pois, muitas vezes, a mobilização plena das resistências requer grandes deslocamentos, particularmente na ponta. É de se esperar que a sucessão de ciclos de carregamento, estáticos ou dinâmicos, conduza a maiores resistências, pois deslocamentos permanentes se acumulam. Assim, a comparação entre provas de carga estática e dinâmica, executadas em um mesmo elemento, deve considerar os efeitos de cada ciclo de carregamento. A aplicação desse conceito às curvas das provas de carga estática e às simulações do programa CAPWAP das duas estacas apresentou, dentro de limites razoáveis, um bom resultado.
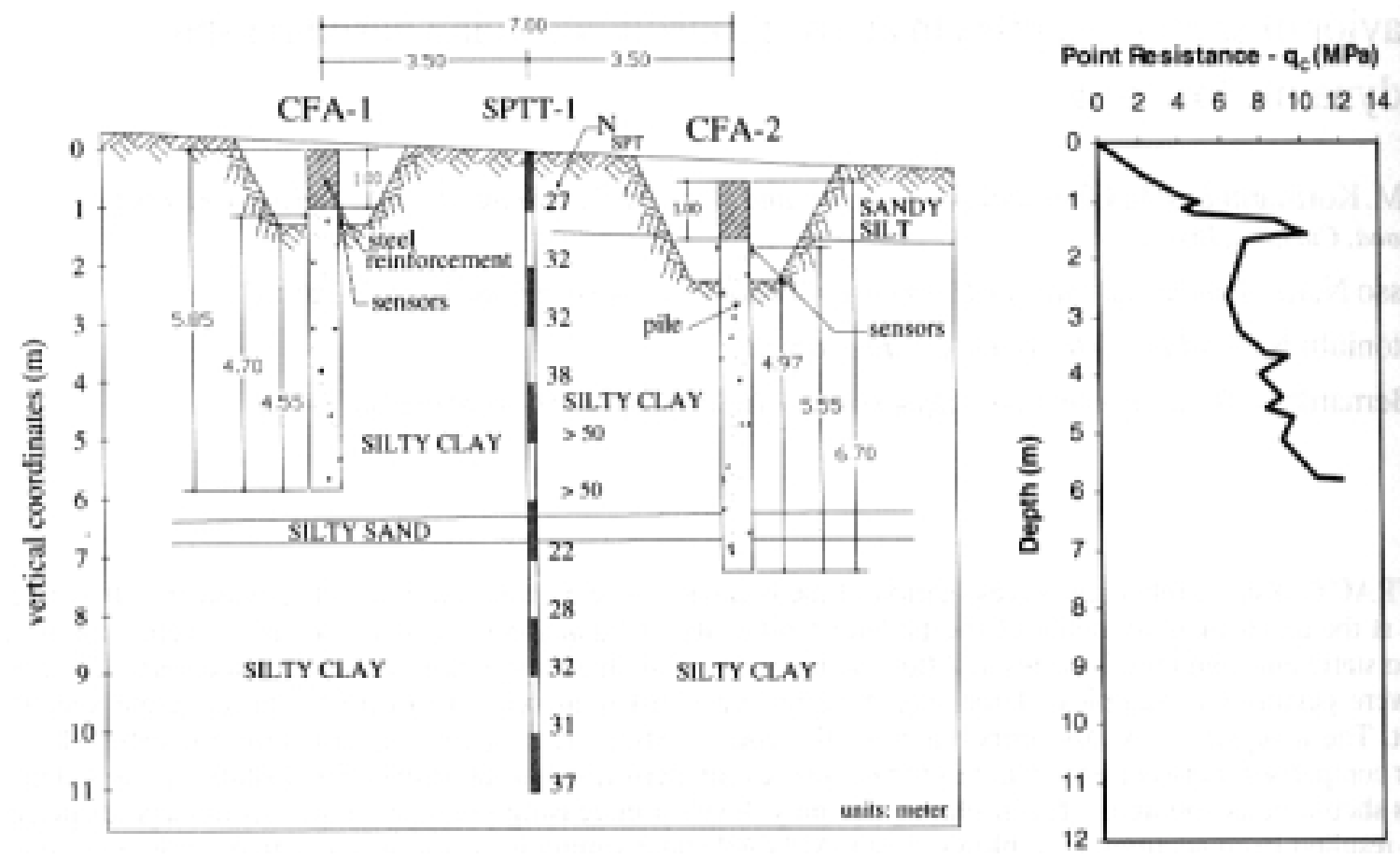

Figura 2.35 - Perfíl Geotécnico e Arranjo das Estacas (KORMANN et al. , 2000) 


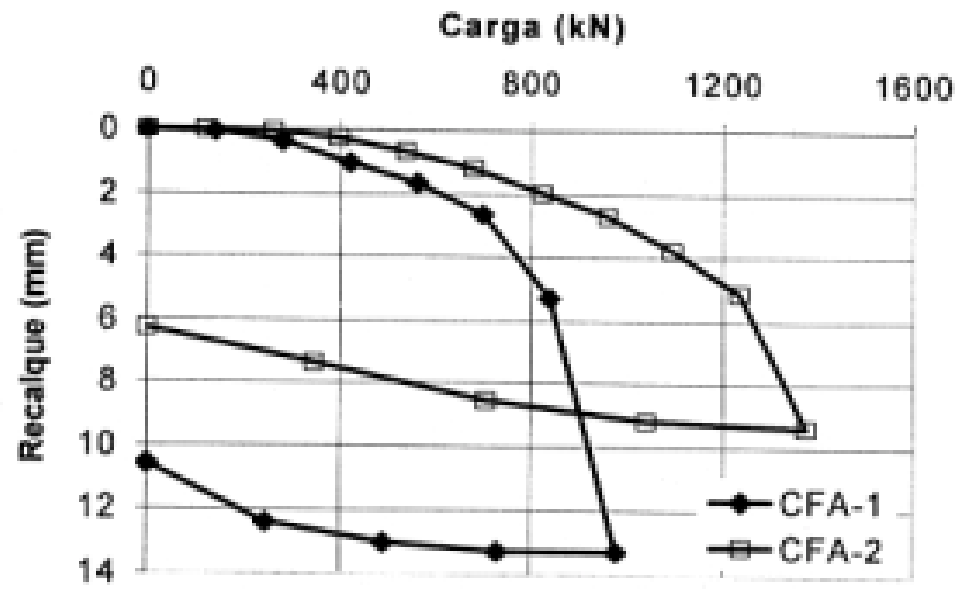

Figura 2.36 - Resultados das Provas de Carga Estática ( Apud KORMANN et al. , 2000)

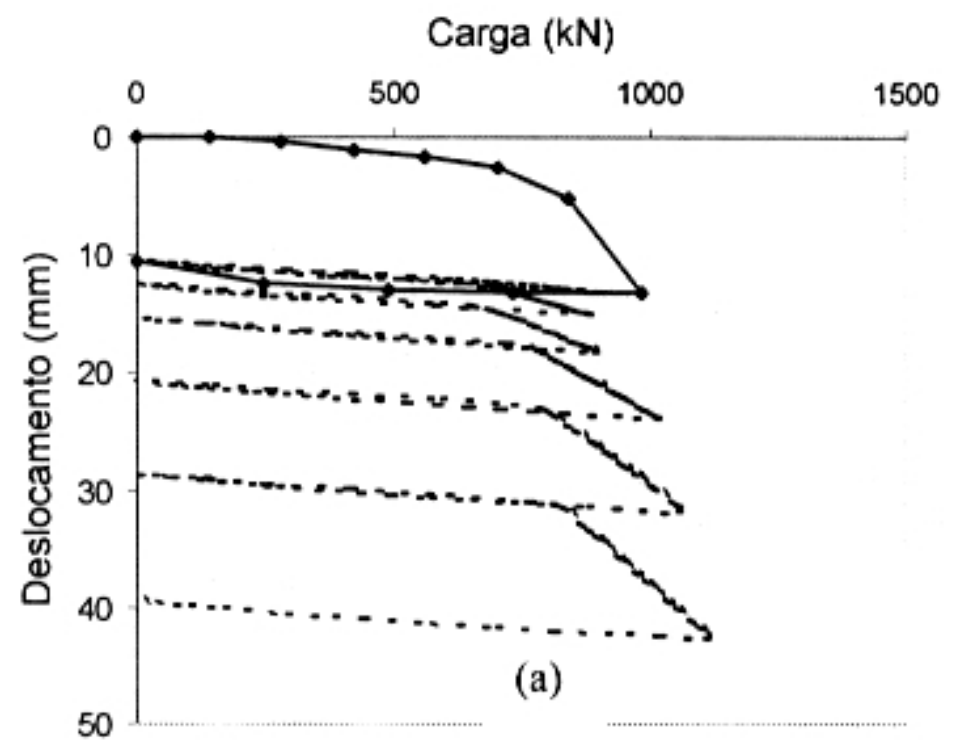

Figura 2.37 - Resultados das Provas de Carga Estática e das Simulações do Programa CAPWAP, para a Estaca CFA-1 (KORMANN et al. , 2000) 


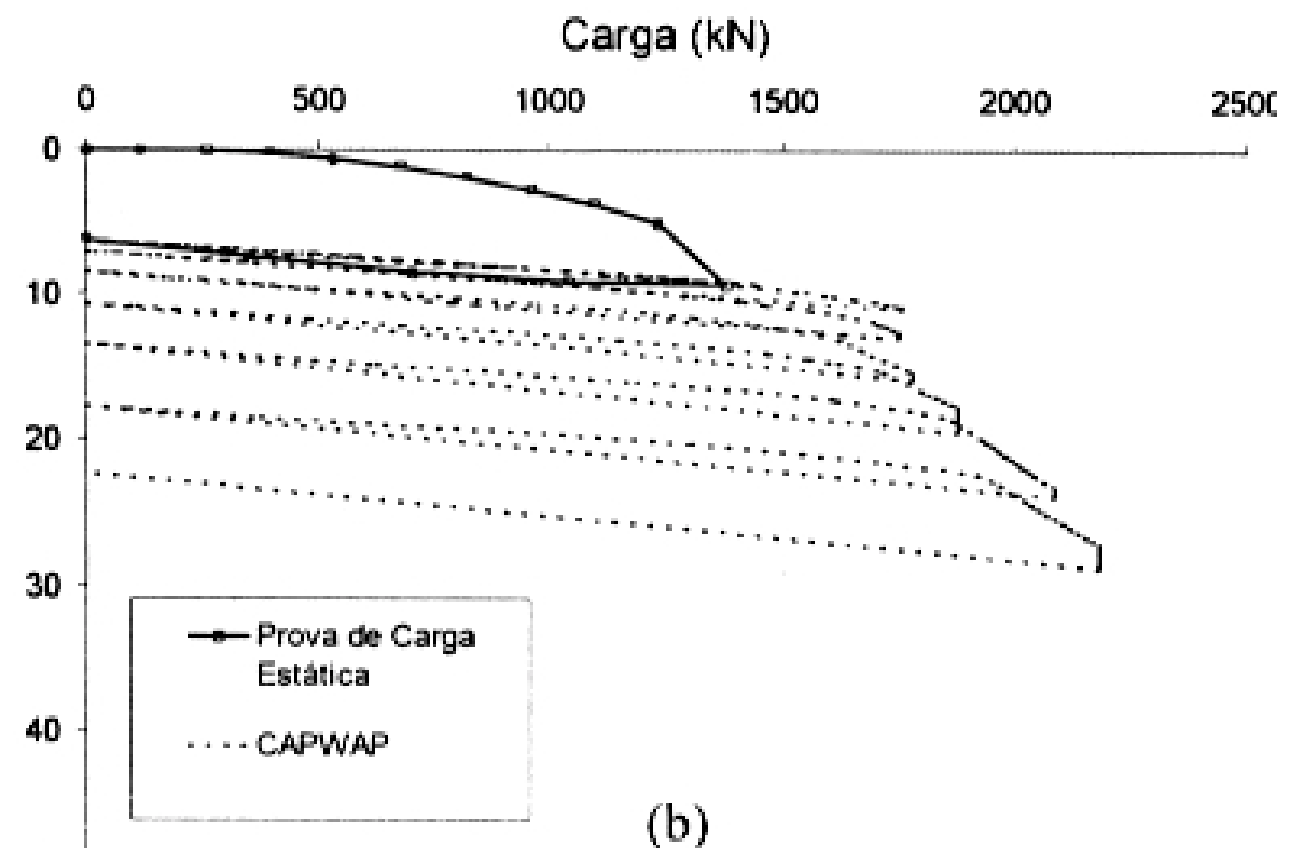

Figura 2.38 - Resultados das Provas de Carga Estática e das Simulações do Programa CAPWAP, para a Estaca CFA-2 (KORMANN et al. , 2000)

FALCONI et al. (1999) apresentam o resultado de uma prova de carga estática e dinâmica, Figura 2.39, realizada em uma estaca hélice contínua, e mostram a curva carga-recalque do ensaio estático e dinâmico, analisados pelos métodos CASE e CAPWAP. Em seguida, faz uma comparação entre a carga de ruptura determinada por vários métodos para este ensaio, que pode ser vista na Figura 2.40.

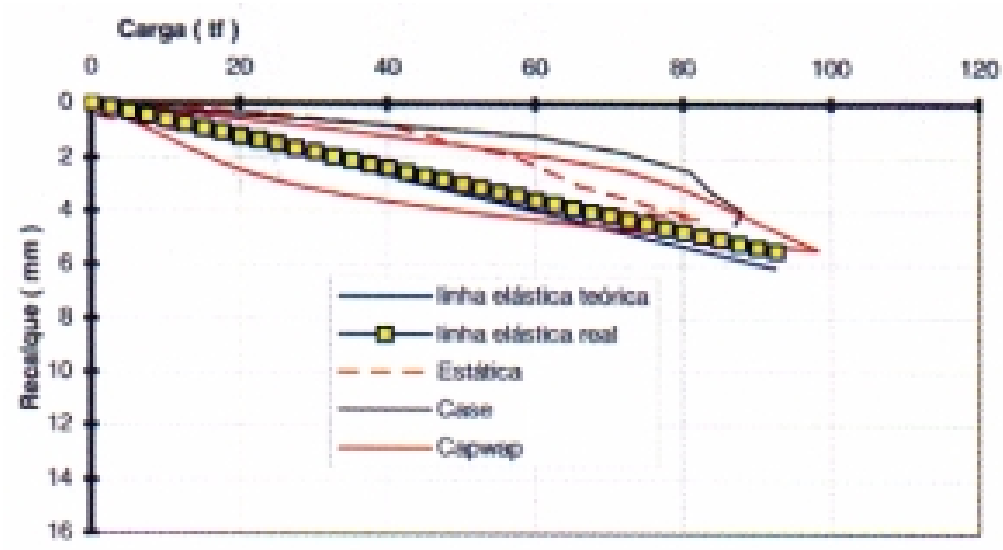

Figura 2.39 - Curva carga recalque de Provas de Carga Estática e Dinâmica (FALCONI et al. , 1999) 


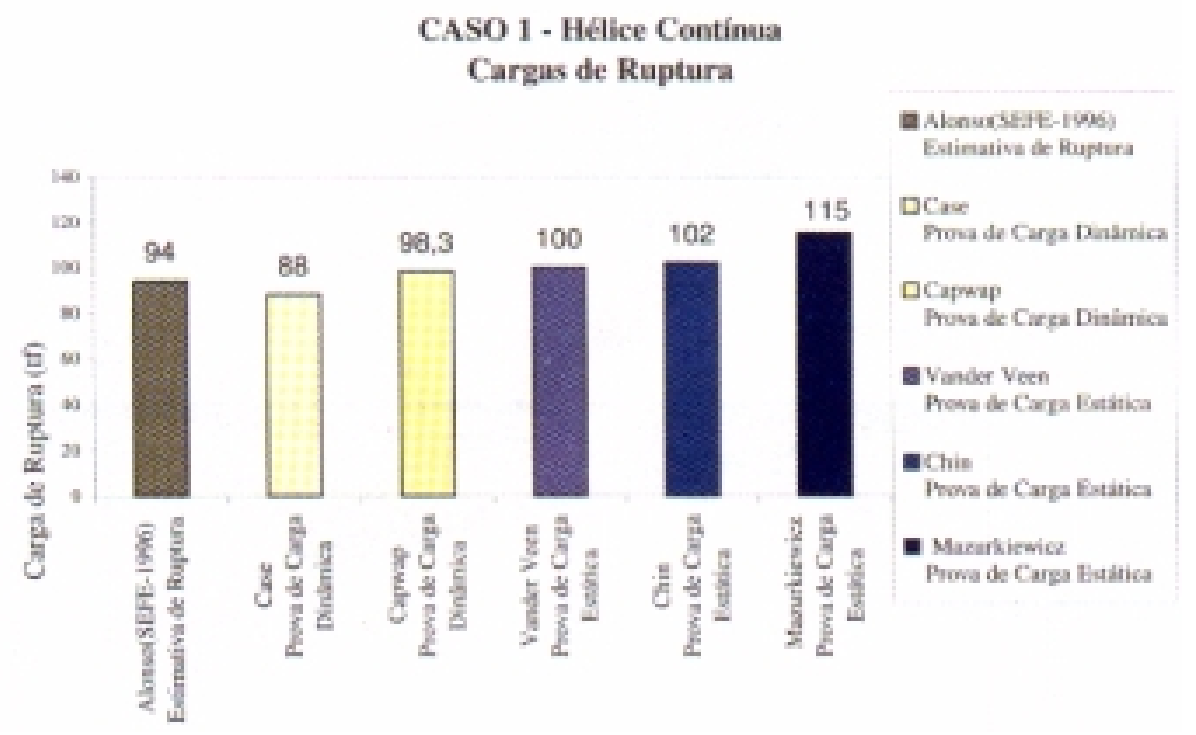

Figura 2.40 - Comparação entre a Carga de Ruptura Determinada por Vários Métodos

GOBLE et al. (1980) apresentam correlações entre valores da resistência última determinada pela análise CAPWAP e por ensaios de carregamento estático. Essas comparações mostram uma correlação de $\pm 15 \%$, conforme a Figura 2.41.

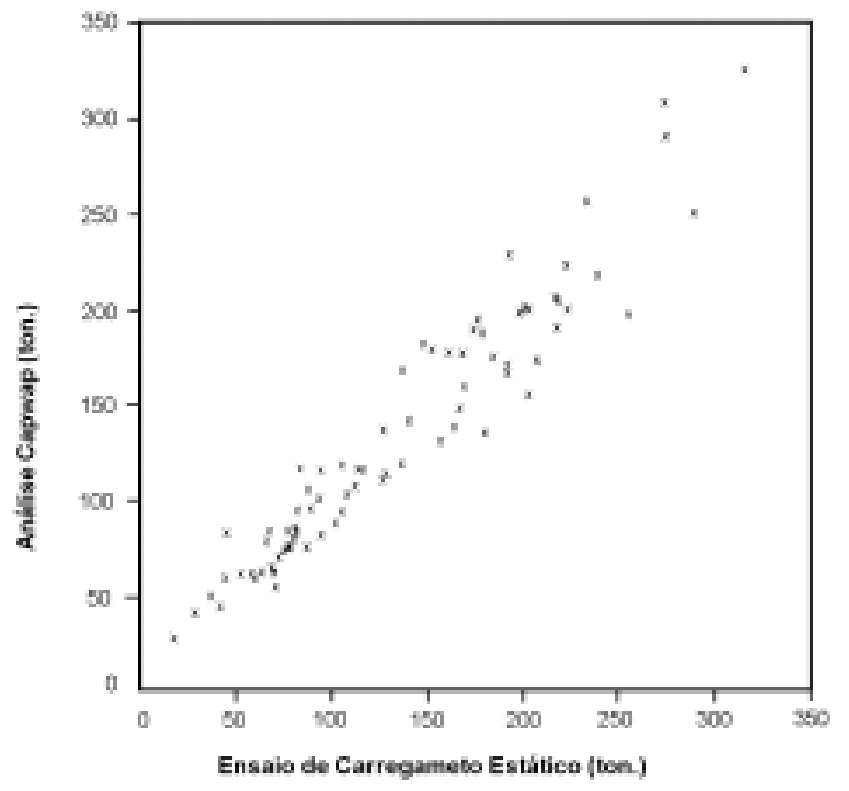

Figura 2.41 - Comparação do Ensaio Estático com os Resultados do CAPWAP

(Apud Goble, 1980) 
CHENG \& AHMAD (1988) comparam os resultados de provas de carga estática e dinâmica interpretadas pelo critério de Davisson. Os autores concluem que o impacto deve produzir uma penetração permanente no solo da ordem de $2 \mathrm{~mm}$, para aplicação do método, isto é, se a penetração for menor, a análise dinâmica poderia subestimar a capacidade de carga da estaca.

AOKI \& ALONSO (1989) correlacionam 19 provas de carga em estacas de concreto armado centrifugado, submetidas à prova de carga estática lenta (SML) e à prova de carga dinâmica de um único impacto. Interpretam as provas de carga por diferentes métodos baseados em medidas de repique elástico e nos métodos de CASE e CAPWAP. Concluem que a comparação entre as cargas interpretadas pelo método CASE E CAPWAP são conservadoras, em média 16 a $20 \%$ a menos, quando comparadas com a carga de ruptura estática extrapolada, a partir das curvas carga-recalque pelo método de Van Der Veen.

CAMPELO (2000) analisa provas de carga dinâmica em sete tubulões, de oito metros de comprimento e 0,60 m de diâmetro, sendo quatro com 1,5 m de base alargada. As resistências mobilizadas são determinadas pelo PDA e pela utilização de métodos que empregam medidas de repique elástico, em particular, os métodos de ChellisVelloso e UTO et al. (1985). Várias sequências de carregamento foram efetuadas, de modo a se ter uma idéia da influência de carregamentos sucessivos no comportamento de tubulões. Conclui-se que o método de UTO et al. (1985) superestima, em demasia, as resistências mobilizadas, enquanto o método de Chellis-Velloso subestima. Uma razoável concordância deste método com as resistências encontradas pelas análise CAPWAP, ocorre somente, quando mais carregamentos são imprimidos aos tubulões, por causa do gradual comportamento de tubulões escavados em tubulões cravados, pelo acúmulo de tensões residuais de cravação, devido ao sucessivo processo de compactação do solo, abaixo da base dos tubulões. $O$ autor afirma que se verificou que, em um tubulão submetido a uma inundação prévia do terreno por 48 horas, as resistências mobilizadas foram inferiores às encontradas nos demais, para um mesmo nível de energia. 
ZHENG et al. (2000) correlacionam resultados de provas de carga estática e dinâmica em nove estacas tubulares de concreto protendido de 30 e $40 \mathrm{~cm}$ de diâmetro. Concluem que, se a resistência do solo tem uma adequada mobilização, os resultados das provas de carga dinâmica e estática têm uma boa correlação para a maioria destas estacas.

GUORAN \& JIADUO (2000) analisam 8 estacas, sendo cinco tubulares de concreto com diâmetro de $80 \mathrm{~cm}$ (A-6, B-3, B-3b, B-3c e B-2), duas tubulares de aço aço com diâmetro de 90 cm (T-2 e E-6) e uma quadrada de seção (60x60) cm² (B-3a). A Figura 2.42 mostra as curvas carga-recalque da prova de carga estática e a curva cargarecalque da prova de carga dinâmica, analisada pelo programa CAPWAPC. Concluem que existe uma boa correlação entre os resultados. 

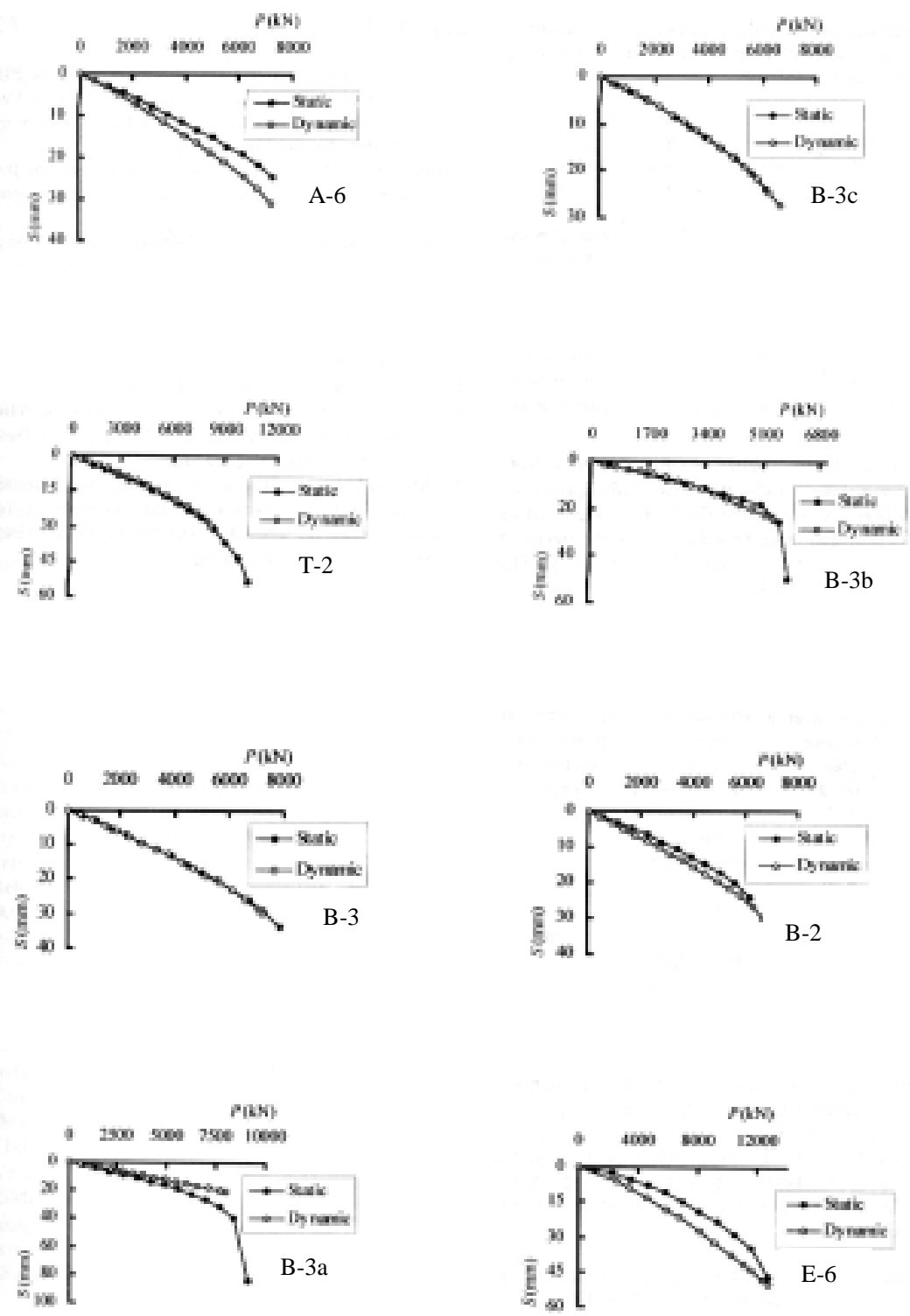

Figura 2.42 - Curvas Carga-Recalque da Prova de Carga Estática e a Curva Carga-Recalque da Prova de Carga Dinâmica Analisada pelo Programa CAPWAPC (GUORAN \& JIADUO, 2000)

LIMA (1999) compara resultados de provas de carga estática e dinâmica realizadas em um estaca tipo trilho (TR-68), cravada no campo experimental de fundações da USP/São Carlos. As provas de carga confimam que a estaca 
provavelmente está limitada pela resistência estrutural última do trilho. A comparação entre a prova de carga estática e a dinâmica é melhor vizualizada na Figura 2.43. Todas as análises do ensaio dinâmico apresentam resultados satisfatórios, em relação ao estático. Observa-se, na Figura 2.43, que o ensaio dinâmico, utilizando medida de repique e analisado pela proposta de VELLOSO (1987), possui a forma da curva mais semelhante ao da prova de carga estática.

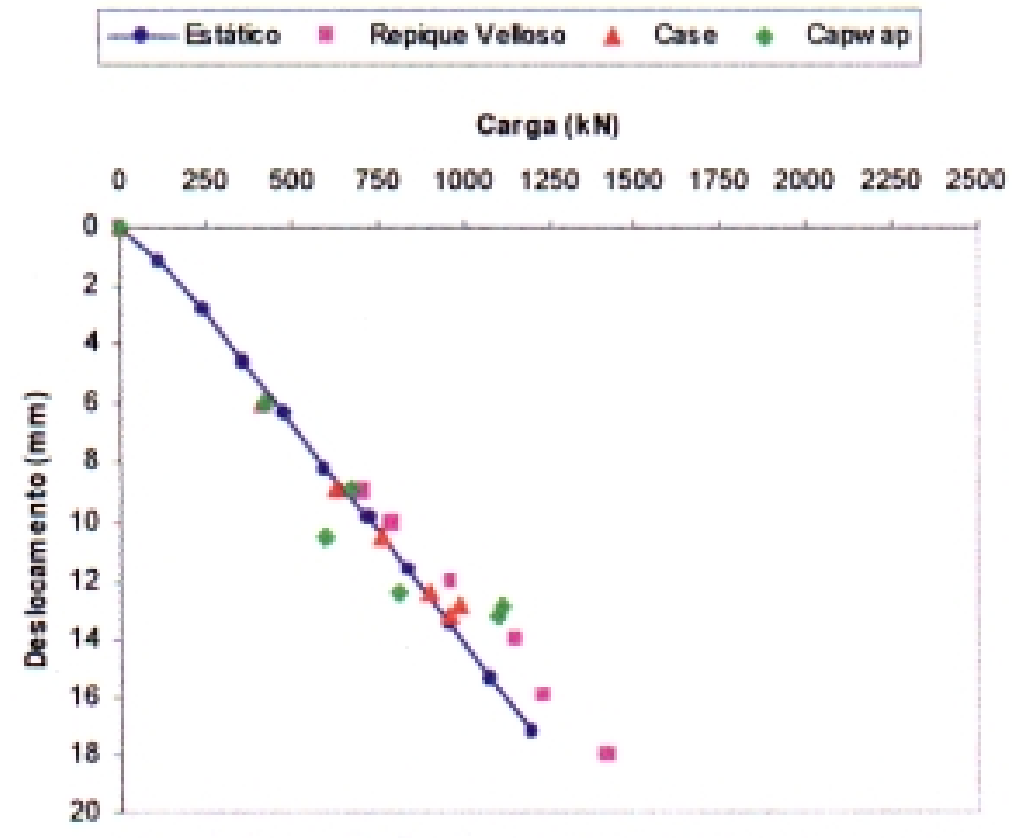

Figura 2.43 - Comparação entre Prova de Carga Estática e Dinâmica ( LIMA, 1999) 
CARNEIRO (1999) realiza provas de carga estática, no campo experimental da USP/São Carlos, em cinco tubulões, de oito metros de comprimento e 0,60 m de diâmetro, sendo três com 1,5 m de base alargada. $\mathrm{O}$ resultado das provas de carga podem ser vistos através das curvas carga-recalque das Figuras 2.44 (a) à 2.44 (j). O resumo das cargas máximas aplicadas e dos deslocamentos máximos de cada ensaio estão na Tabela 2.4 .

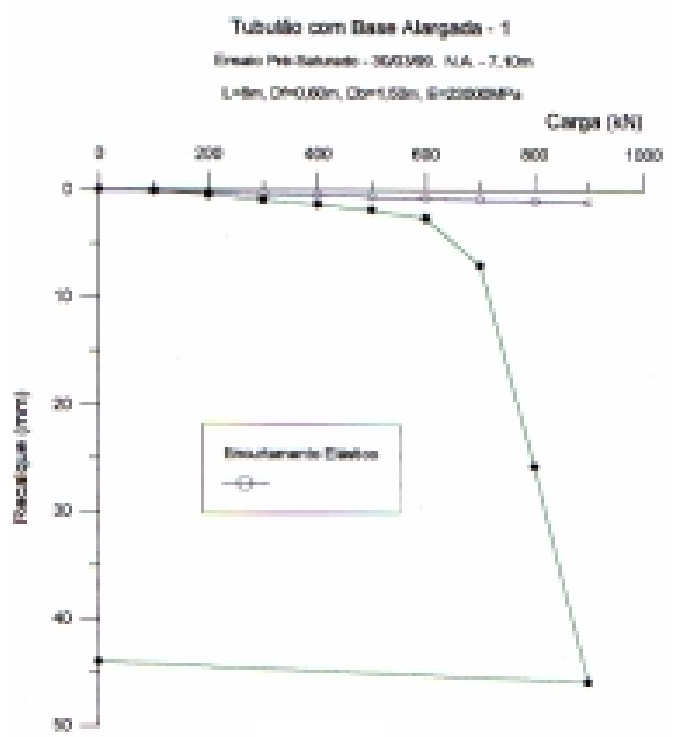

(a)

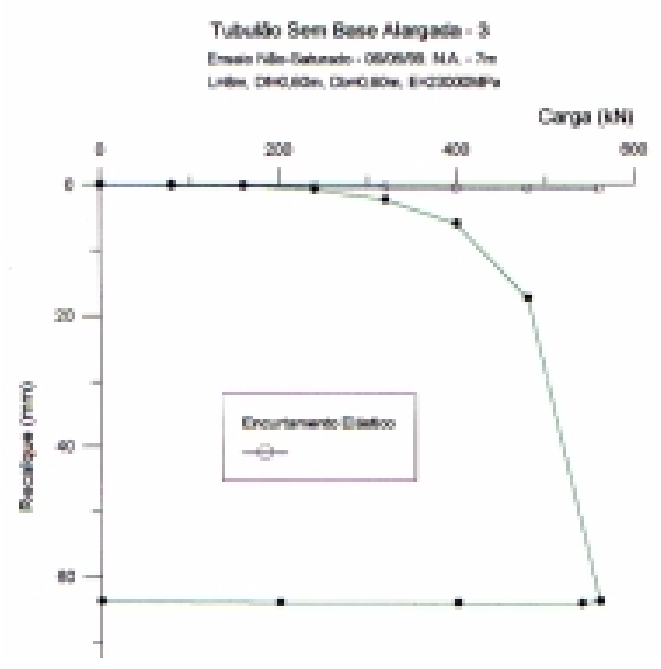

(c)

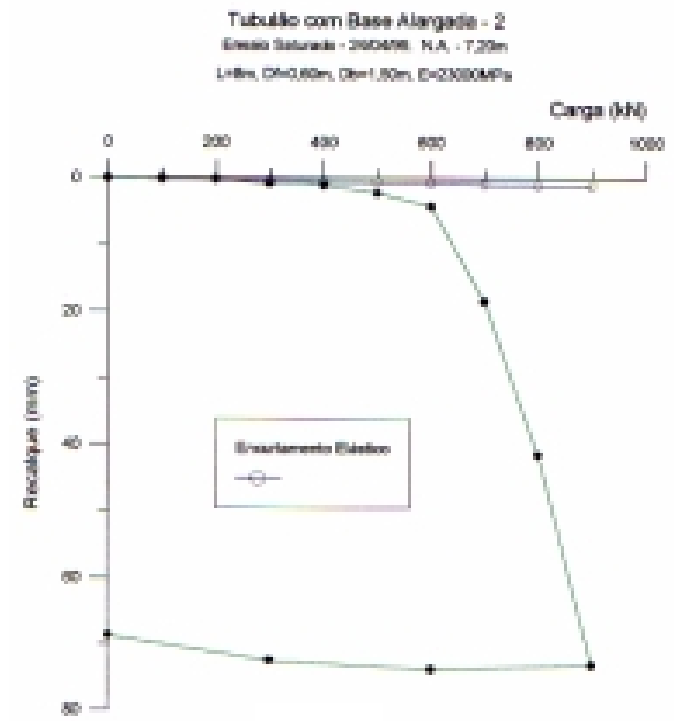

(b)

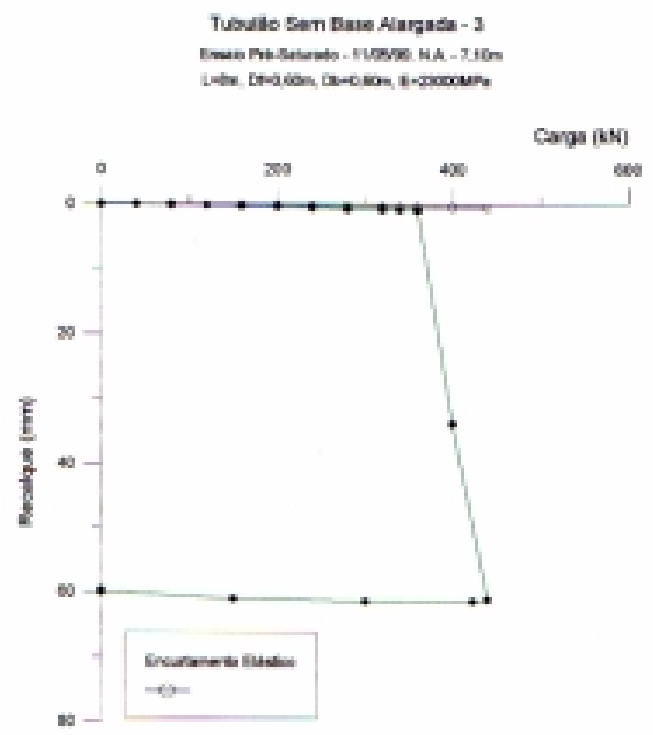




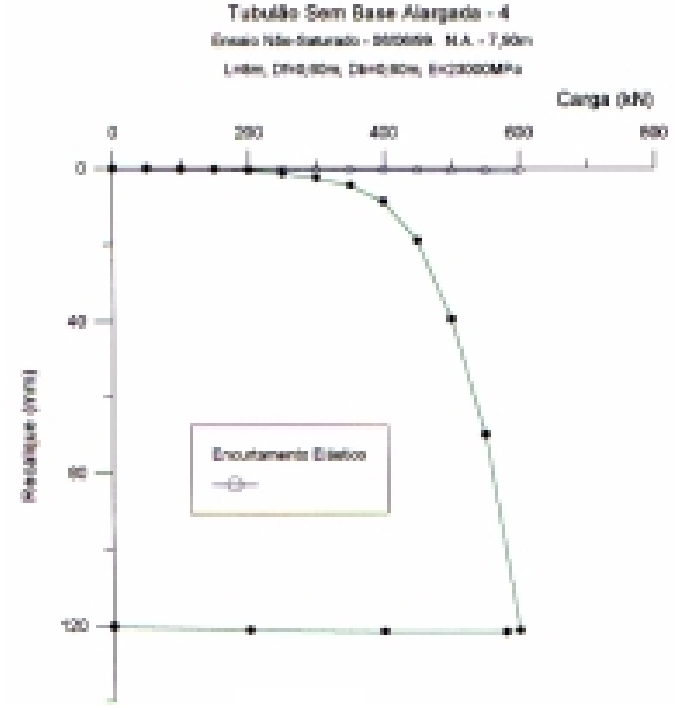

(e)
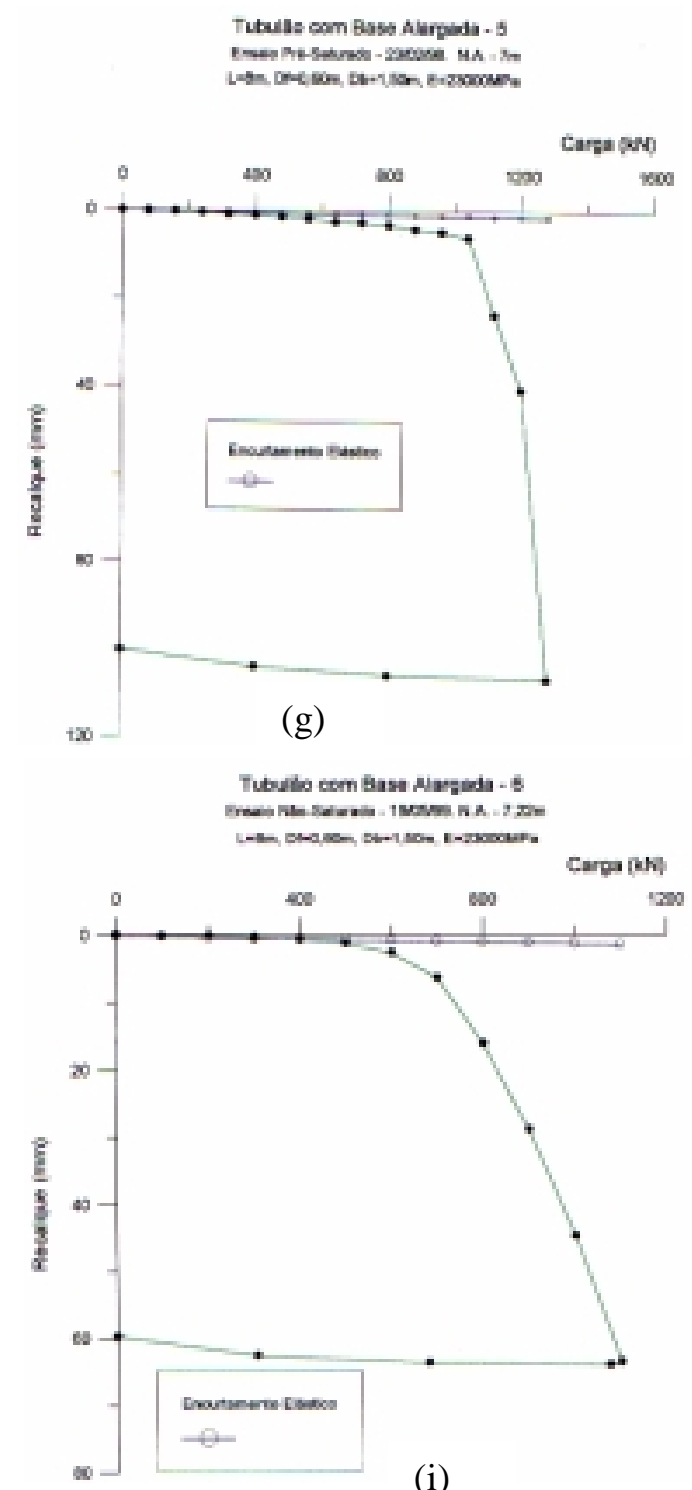

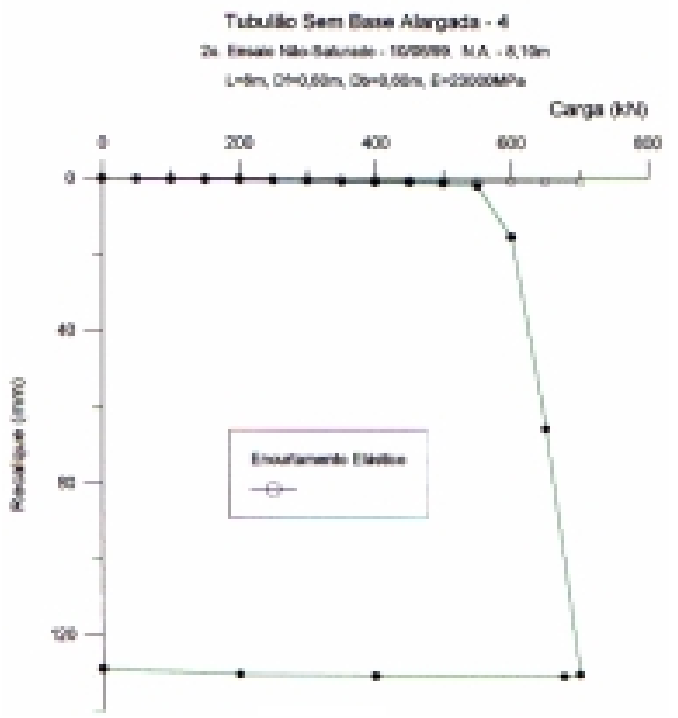

(f)
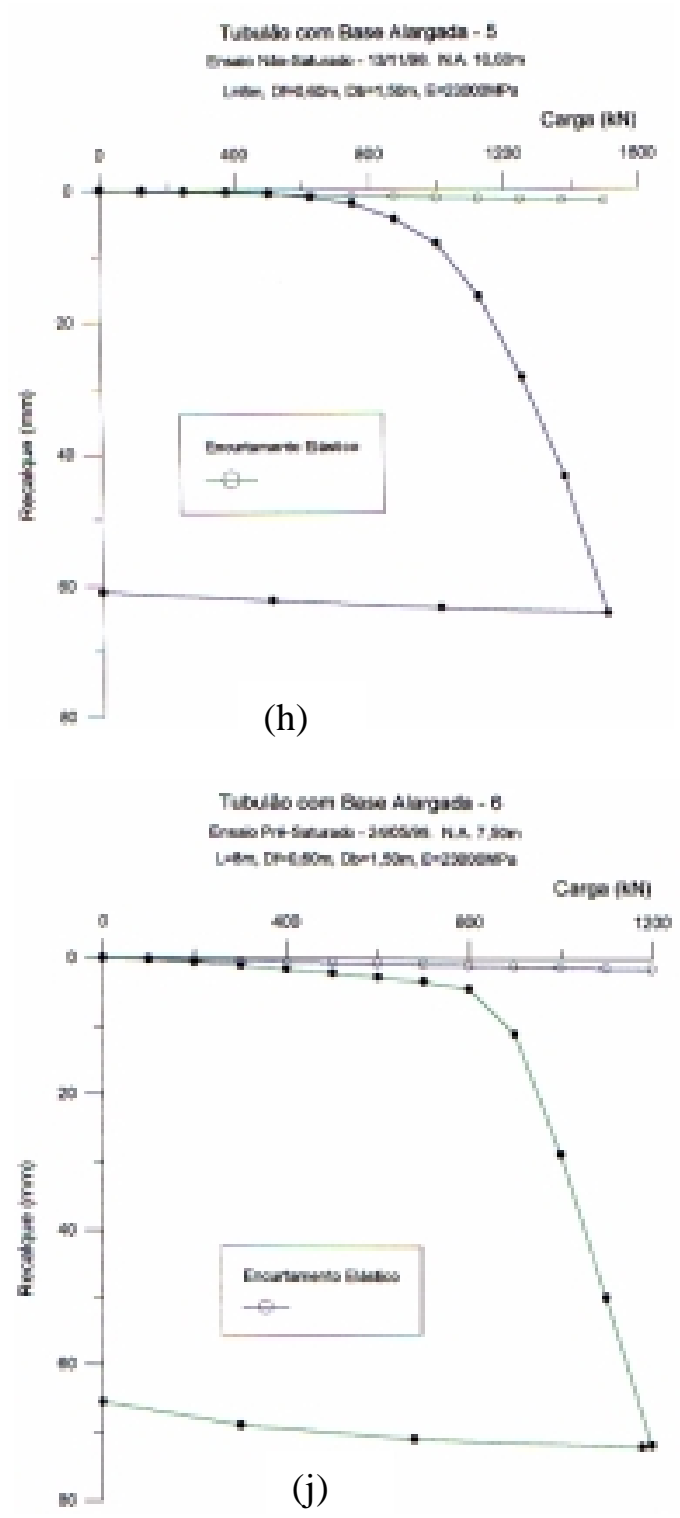

Figura 2.44 - Curvas Carga-Recalque provenientes de Provas de Carga Estática ( CARNEIRO, 1999) 
Tabela 2.4 - Máxima Carga Aplicada e Máximo Recalque dos Tubulões

\begin{tabular}{|c|c|c|c|c|c|}
\hline & $\begin{array}{l}\text { Tubulão } 1 \\
\text { c/base alarg. } \\
\text { c/pré-inund. }\end{array}$ & $\begin{array}{l}\text { Tubulão } 2 \\
\text { c/base alarg. } \\
\text { c/pré-inund. }\end{array}$ & $\begin{array}{c}\text { Tubulão } 3 \\
\text { s/base alarg. } \\
\text { s/inund. }\end{array}$ & $\begin{array}{c}\text { Tubulão } 3 \\
\text { (Reensaio) } \\
\text { s/base alarg. } \\
\text { s/inund. }\end{array}$ & $\begin{array}{l}\text { Tubulão } 4 \\
\text { s/base alarg. } \\
\text { s/pré-inund. }\end{array}$ \\
\hline $\begin{array}{c}\text { Máximo } \\
\text { Recalque (mm) }\end{array}$ & 45,88 & 73,06 & 63,74 & 61,21 & 121,42 \\
\hline \multirow[t]{2}{*}{$\begin{array}{l}\text { Máxima Carga } \\
\text { Aplicada }(\mathrm{kN})\end{array}$} & 900 & 900 & 560 & 440 & 600 \\
\hline & $\begin{array}{l}\text { Tubulão } 4 \\
\text { (Reensaio) } \\
\text { s/base alarg. } \\
\text { s/pré-inund. }\end{array}$ & $\begin{array}{l}\text { Tubulão } 5 \\
\text { c/base alarg. } \\
\text { s/inund. }\end{array}$ & $\begin{array}{c}\text { Tubulão } 5 \\
\text { (Reensaio) } \\
\text { c/base alarg. } \\
\text { c/inund. }\end{array}$ & $\begin{array}{c}\text { Tubulão } 6 \\
\text { c/base alarg. } \\
\text { s/inund. }\end{array}$ & $\begin{array}{l}\text { Tubulão } 6 \\
\text { (Reensaio) } \\
\text { c/base alarg. } \\
\text { c/pré-inund. }\end{array}$ \\
\hline $\begin{array}{c}\text { Máximo } \\
\text { Recalque (mm) }\end{array}$ & 9,05 & 64,52 & 41,88 & 63,48 & 71,65 \\
\hline $\begin{array}{l}\text { Máxima Carga } \\
\text { Aplicada }(\mathrm{kN})\end{array}$ & 700 & 1500 & 1280 & 1100 & 1200 \\
\hline
\end{tabular}

CAMPELO (2000) realiza provas de carga dinâmica, no campo experimental da USP/São Carlos, em sete tubulões, de oito metros de comprimento e 0,60 m de diâmetro, sendo quatro com 1,5 m de base alargada. . O resultado das provas de carga dado pelas curvas de resistência mobilizada $\mathrm{x}$ deslocamento mobilizado, analisadas pelo método CAPWAP e pelo método de CHELLIS pode ser visto através das Figuras 2.45 (a) à 2.45 (g). O resumo das cargas mobilizadas máximas e dos deslocamentos mobilizados de cada ensaio podem ser vistos na Tabela 2.5. 

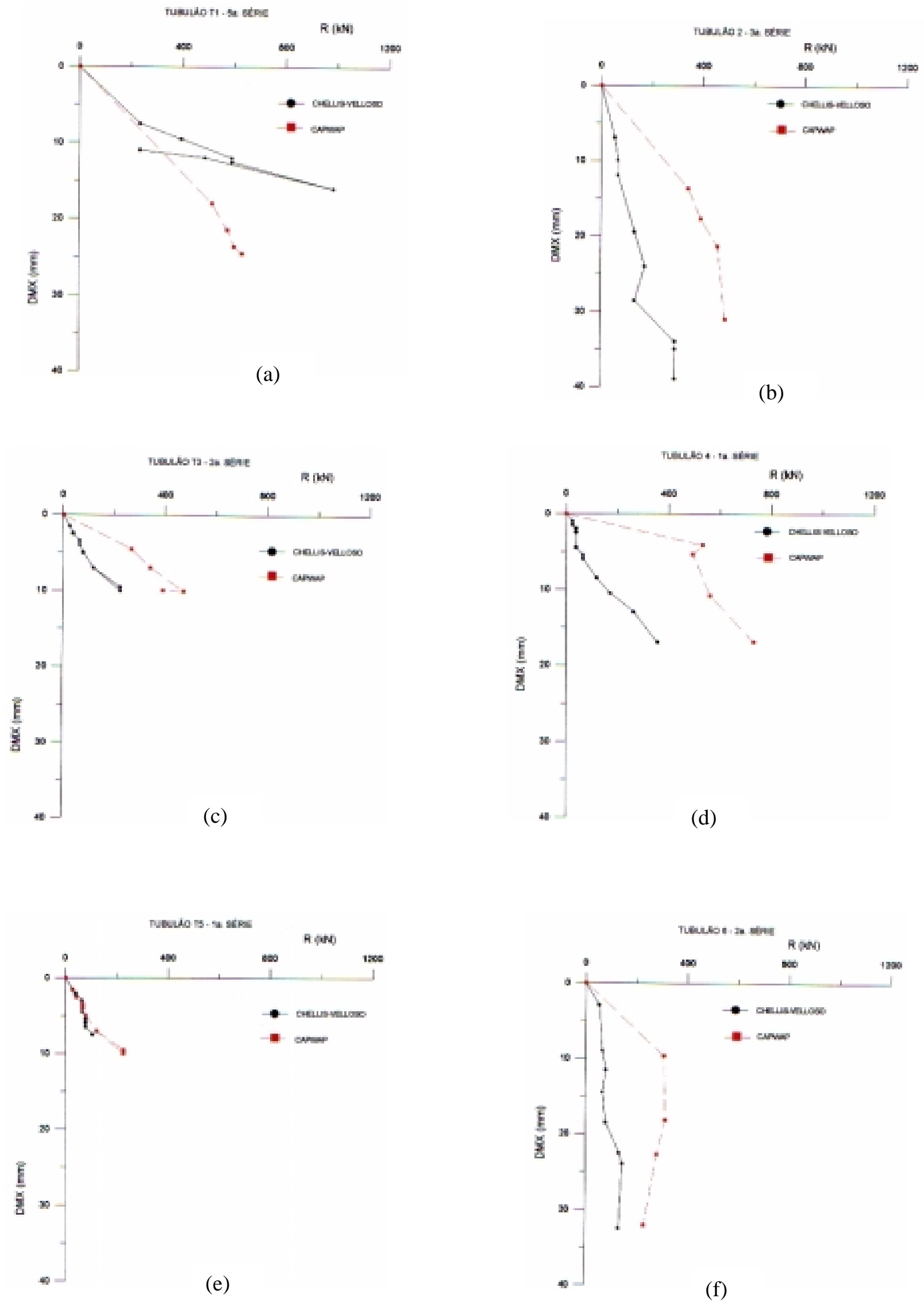


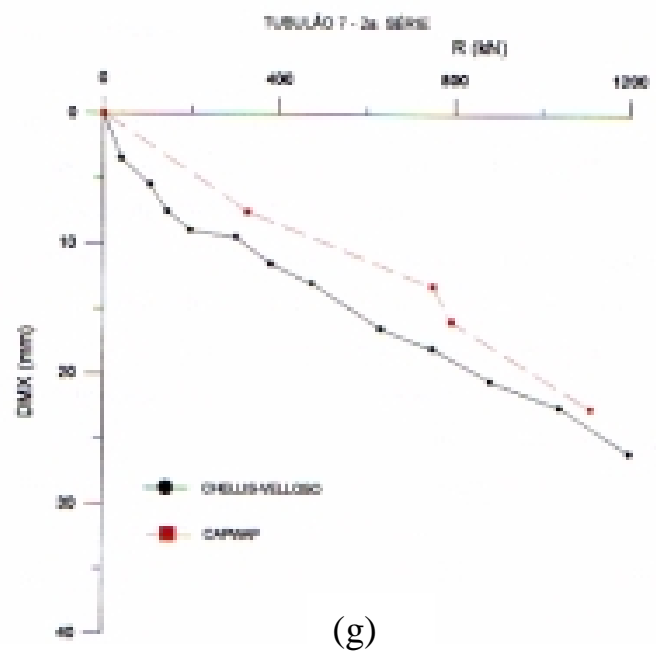

Figura 2.45 - Curvas Carga-Recalque provenientes de Provas de Carga Dinâmica (CAMPELO, 1999)

Tabela 2.5 - Resistência Mobilizada e Deslocamentos de Tubulões provenientes de Provas de Carga Dinâmica, Analisadas pelo Programa CAPWAP.

\begin{tabular}{|c|c|c|c|c|}
\hline & $\begin{array}{l}\text { Tubulão } 1 \\
\text { c/base alarg. } \\
5^{\circ} \text { Série }\end{array}$ & $\begin{array}{c}\text { Tubulão } 2 \\
\text { s/base alarg. } \\
3^{\circ} \text { Série }\end{array}$ & $\begin{array}{c}\text { Tubulão } 3 \\
\text { c/base alarg. } \\
2^{\text {o }} \text { Série }\end{array}$ & $\begin{array}{c}\text { Tubulão } 4 \\
\text { c/base alarg. } \\
1^{\circ} \text { Série }\end{array}$ \\
\hline $\begin{array}{l}\text { Deslocamento } \\
\text { (mm) }\end{array}$ & 24,0 & 25,1 & 10,0 & 16,9 \\
\hline \multirow[t]{2}{*}{$\begin{array}{c}\text { Resistência } \\
\text { Mobilizada }(\mathrm{kN})\end{array}$} & 630 & 486 & 470 & 730 \\
\hline & $\begin{array}{c}\text { Tubulão } 5 \\
\text { s/base alarg. } \\
1^{\text {o Série }}\end{array}$ & $\begin{array}{c}\text { Tubulão } 6 \\
\text { s/base alarg. } \\
\text { 2º Série }\end{array}$ & $\begin{array}{c}\text { Tubulão } 7 \\
\text { c/base alarg. } \\
\text { 20 Série }\end{array}$ & \\
\hline $\begin{array}{l}\text { Deslocamento } \\
\text { (mm) }\end{array}$ & 10,0 & 31,9 & 22,6 & \\
\hline $\begin{array}{c}\text { Resistência } \\
\text { Mobilizada }(\mathrm{kN})\end{array}$ & 228 & 311 & 1110 & \\
\hline
\end{tabular}




\section{CAPÍTULO 3 - CAMPO EXPERIMENTAL DE FUNDAÇÕES}

\section{1 - Caracterização Geológica}

\subsection{1 - Geologia Local}

A cidade de São Carlos/SP está situada na zona de transição das unidades geomorfológica das Cuestas Basálticas e do Planalto Ocidental. Localizada a cerca de $800 \mathrm{~m}$ de altitude, em relação ao nível do mar, assenta-se sobre rochas do grupo São Bento, compostas por arenitos da Formação Botucatu e Pirambóia e derrames de efusivas basálticas da Formação Serra Geral. A Figura 3.1 mostra o perfil geológico da região de São Carlos.

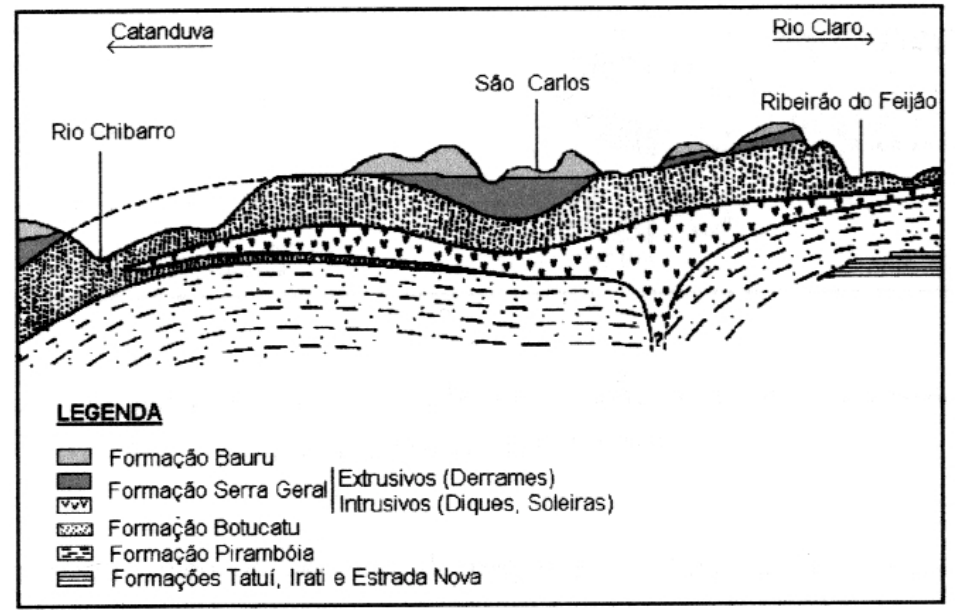

Figura 3.1 - Perfil geológico da região de São Carlos, BORTOLUCCI (1983)

A ação do intemperismo e da erosão, com posterior retrabalhamento nos materiais do Grupo Bauru e das Formações Serra Geral e Botucatu, originou depósitos superficiais aluviais e coluviais, denominados geologicamente de Sedimento Cenozóico. 
A Figura 3.2 mostra um perfil típico da geologia de pequena superfície da área urbana de São Carlos, com descrição das litologias predominantes.

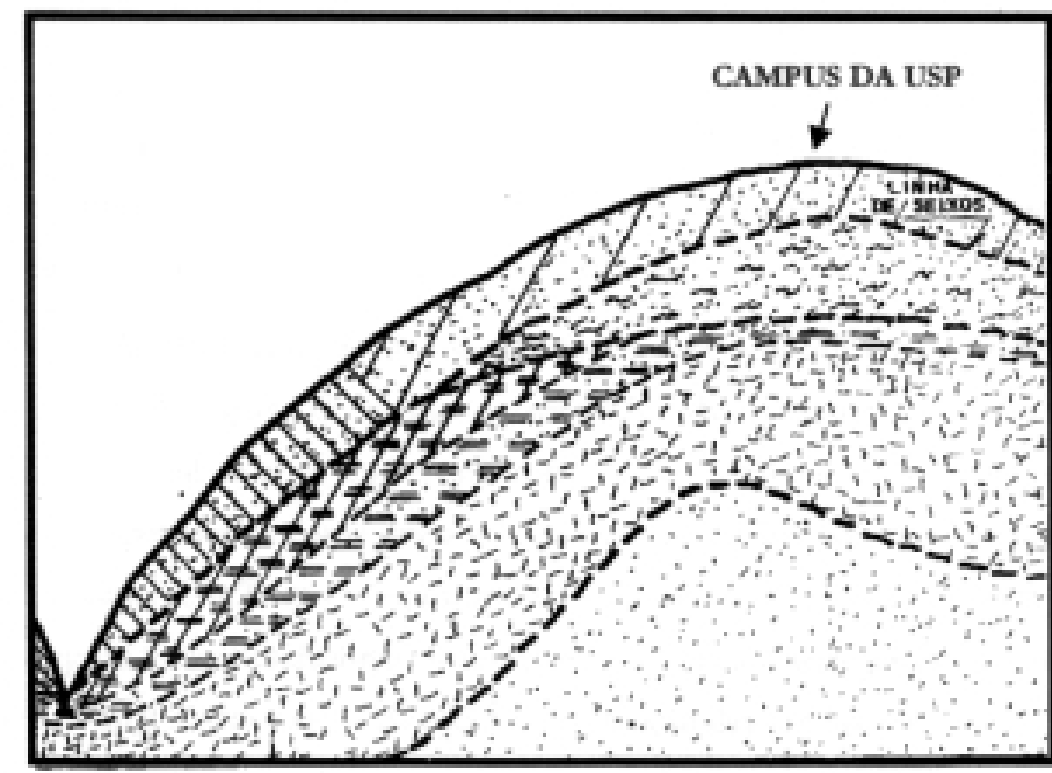

LEGENDA

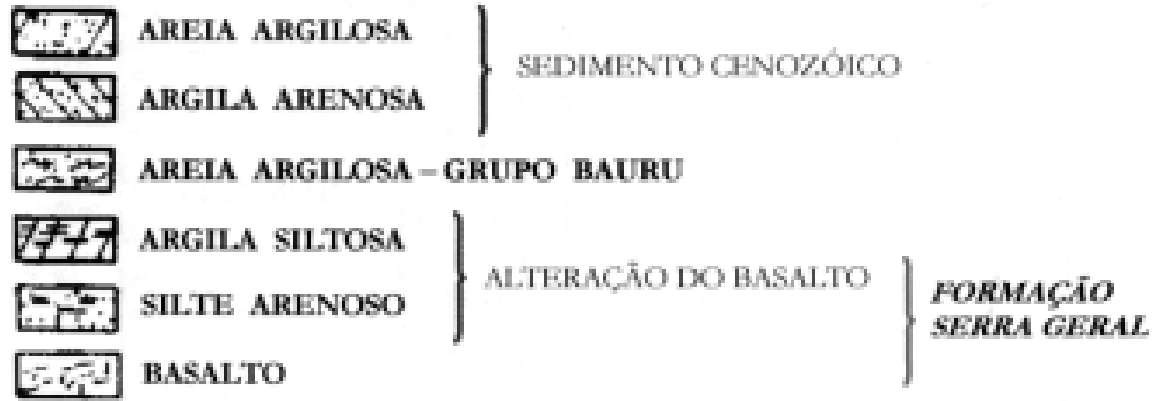

Ei_ą ARENTTO - FORMAÇÃo BOTUCATU

Figura 3.2 - Seção esquemática da geologia de pequena profundidade em São Carlos (BORTOLUCCI, 1983).

\section{2 - Caracterização Geotécnica}

A área do Campo Experimental de Fundações em São Carlos foi caracterizada geotecnicamente através de diversos ensaios laboratoriais e in situ. 


\subsection{1 - Ensaios de Laboratório}

Os ensaios de laboratório foram realizados de amostras indeformadas retiradas de um poço com diâmetro de $1,2 \mathrm{~m}$, a cada metro, até atingir uma profundidade de $10,0 \mathrm{~m}$. Em todas as amostras extraídas, realizaram-se ensaios de caracterização, ensaios de compressão confinada convencional saturada, com controle de sucção, triaxiais convencionais saturados, com sucção controlada.

Todos os ensaios de laboratórios citados e utilizados neste trabalho foram obtidos por MACHADO (1998). A Figura 3.3 apresenta as curvas granulométricas obtidas para as profundidades de 3,0 m, 5,0 m e 8,0 m, em relação à superfície do terreno.

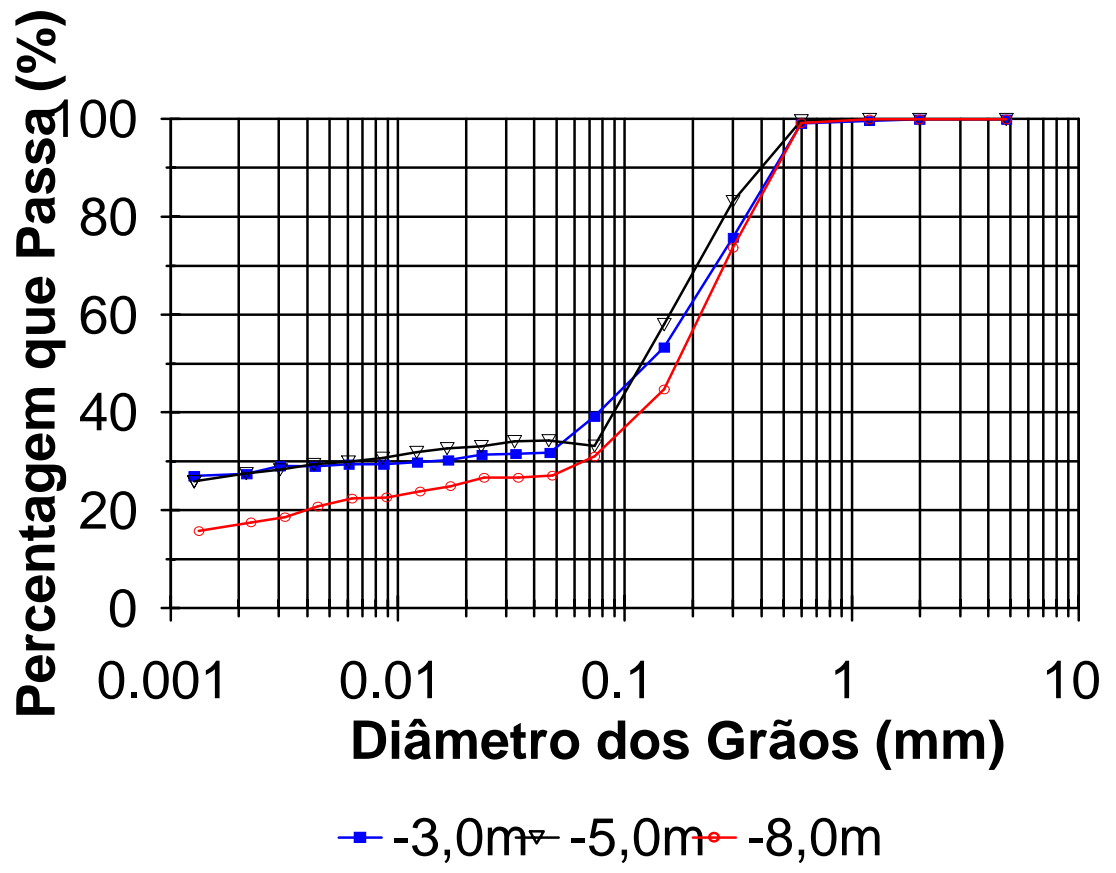

Figura 3.3 - Curvas granulométricas obtidas para as profundidades de 3,0; 5,0 e 8,0 m, em relação à superfície do terreno (MACHADO, 1998).

A Tabela 3.1 mostra as frações granulométricas constituintes dos solos; a Tabela 3.2 mostra os valores de peso específico seco e teores de umidade obtidos ao longo do perfil de coleta de blocos indeformados. Já a Tabela 3.3 mostra os resultados dos ensaios de caracterização e compactação. 
Tabela 3.1: Frações granulométricas constituintes dos solos (MACHADO, 1998)

\begin{tabular}{c|c|c|c}
\hline Prof. (m) & Areia (\%) & Silte (\%) & Argila (\%) \\
\hline $3 \mathrm{~m}$ & 60,8 & 11,9 & 27,3 \\
\hline $5 \mathrm{~m}$ & 66,7 & 5,90 & 27,4 \\
\hline $8 \mathrm{~m}$ & 68,9 & 13,7 & 17,4 \\
\hline
\end{tabular}

Tabela 3.2: Valores de peso específico seco e teor de umidade obtidos ao longo do perfil de coleta de blocos indeformados (MACHADO, 1998).

\begin{tabular}{c|c|c|c|c|c|c|c|c|c}
\hline & 1 & 2 & 3 & 4 & 5 & 6 & 7 & 8 & 9 \\
\hline $\mathrm{w}(\%)$ & 13,7 & 14,6 & 15,8 & 16,8 & 16,4 & 17,2 & 19,1 & 16,7 & 18,3 \\
\hline$\gamma_{\mathrm{d}}\left(\mathrm{kN} / \mathrm{m}^{3}\right)$ & 12,5 & 13,6 & 13,8 & 14,3 & 14,4 & 14,7 & 15,2 & 16,1 & 16,6 \\
\hline$\gamma\left(\mathrm{kN} / \mathrm{m}^{3}\right)$ & 14,2 & 15,6 & 16,0 & 16,7 & 14,8 & 17,1 & 18,1 & 18,8 & 19,6 \\
\hline $\mathrm{e}$ & 1,17 & 0,99 & 0,96 & 0,90 & 0,88 & 0,84 & 0,78 & 0,68 & 0,63 \\
\hline
\end{tabular}

Tabela 3.3: Resultados dos ensaios de caracterização e compactação (MACHADO, 1998)

\begin{tabular}{c|c|c|c|c|c}
\hline Prof. $(\mathrm{m})$ & $\gamma_{\mathrm{dmax}}\left(\mathrm{kN} / \mathrm{m}^{3}\right)$ & $\mathrm{w}_{\mathrm{ot}}(\%)$ & $\mathrm{w}_{\mathrm{L}}(\%)$ & $\mathrm{w}_{\mathrm{P}}(\%)$ & $\gamma_{\mathrm{s}}\left(\mathrm{kN} / \mathrm{m}^{3}\right)$ \\
\hline $3 \mathrm{~m}$ & 18,7 & 14,0 & 27,9 & 16,0 & 27,1 \\
\hline $5 \mathrm{~m}$ & 18,4 & 14,8 & 30,9 & 19,8 & 27,5 \\
\hline $8 \mathrm{~m}$ & 18,9 & 11,2 & 28,4 & 17,2 & 27,1 \\
\hline
\end{tabular}

\subsection{2 - Ensaios In Situ}

Realizaram-se 29 ensaios penetrométricos, dos tipos: SPT (sondagen de simples reconhecimento com medida do índice de penetração), SPT-T (sondagen de simples reconhecimento com medida do índice de penetração e do torque), CPT (ensaio de penetração contínua, "Cone Mecânico”), CPTU (ensaio de penetração contínua com medida de poro-pressão, "Cone Elétrico") e CROSS-HOLE. Estes ensaios estão divididos da seguinte forma: 


\section{Ensaios SPT e SPT-T:}

- Campanha 01 (06/10/1988): 5 SPT (S1 a S5);

- Campanha 02 (25/08/1998): 5 SPT (SP.1 a SP.5);

- Campanha 03 (26/04/1999): 5 SPT-T ( SPt.1 a SPt.5).

\section{Ensaios CPT / CPTU:}

- Campanha 01 (06/10/1988): 5 CPT (D1 a D5);

- Campanha 02 (07/2000): 5 CPTU (USP1 a USP5);

A Figura 3.4 a seguir mostra a localização de cada ensaio.

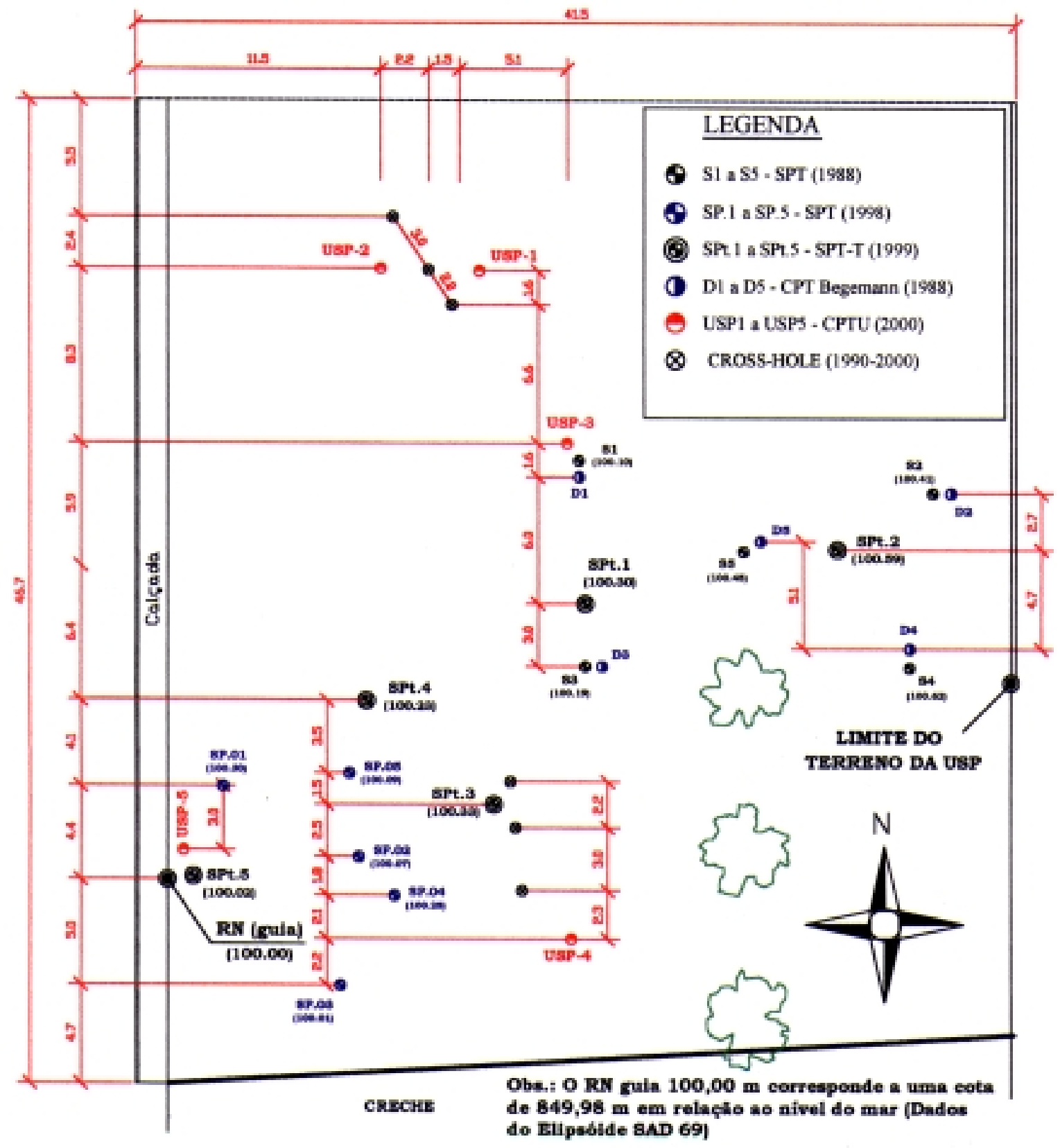

Figura 3.4 - Localização dos ensaios geotécnicos no campo experimental de fundações 
Nas campanhas verifica-se uma camada superficial de areia argilosa marrom escura, de aproximadamente 6,5 m de espessura (sedimento cenozóico). Em seguida, tem-se uma linha de seixo de cerca de 0,20 m de espessura, e, logo após, há uma camada composta de areia argilosa de cor variegada (solo residual do grupo Bauru). Com relação ao nível d'água, este variou de $-7,1$ a $-10,2 \mathrm{~m}$, de acordo com a época do ano em que se realizaram as sondagens. A Figura 3.5 mostra um perfil associado, resultado da campanha 03.

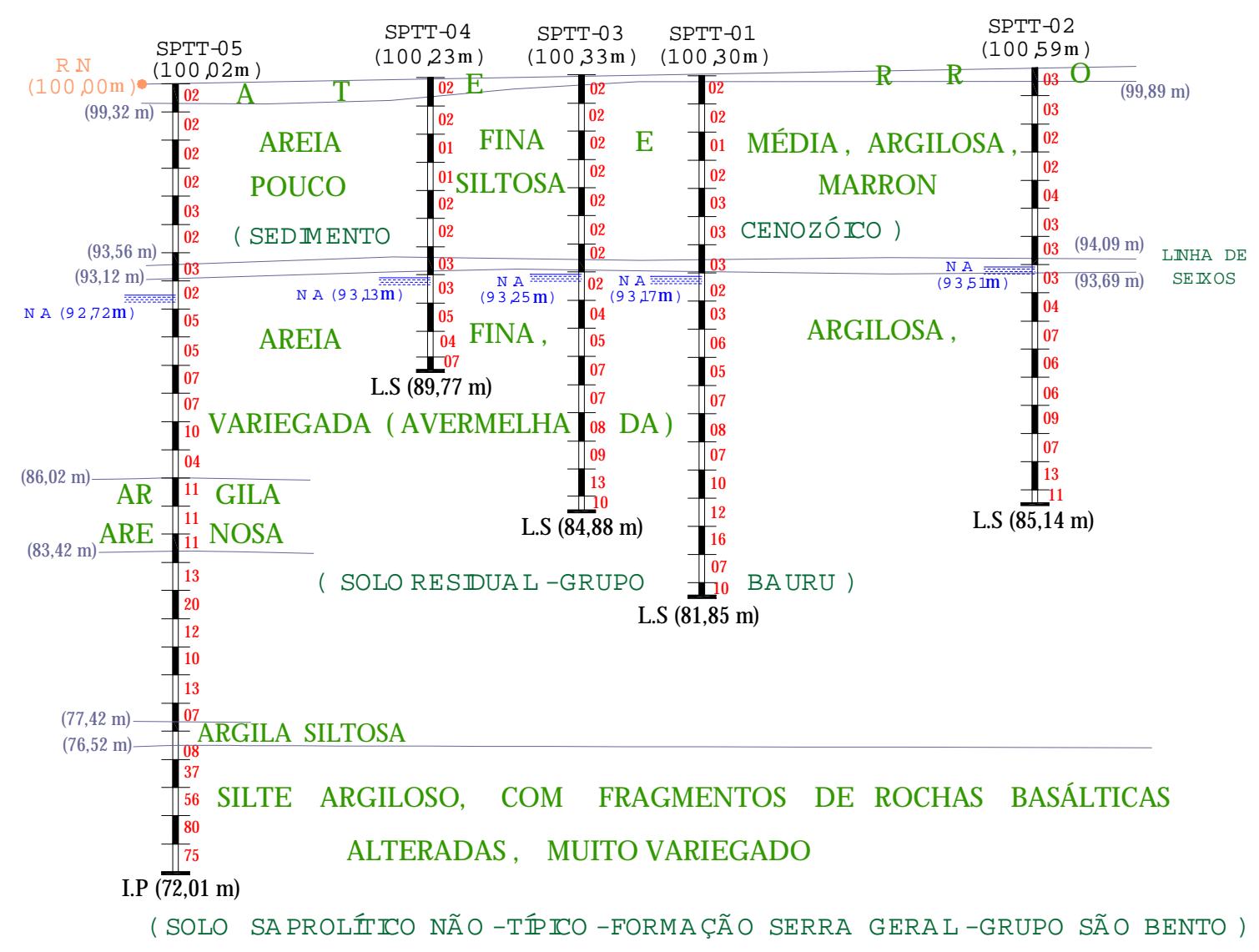

Figura 3.5 - Perfil do terreno associado às sondagens da campanha 03 (SANTOS, 2001).

A variabilidade do maciço de solo pode ser vista, quando se plotam, na Figura 3.6, os valores médios de $\mathrm{N}_{\mathrm{SPT}}$ para cada campanha. Com a profundidade, estes valores apresentam uma variação de $\pm 50 \%$. O mesmo acontece com os valores de $\mathrm{q}_{\mathrm{c}}$ (Figura 3.7.a). Já os valores de $f_{s}$ (Figura 3.7.b) não podem ser comparados entre campanhas, 
pois existe diferença entre valores de atrito lateral entre o cone mecânico (campanha 01) e o cone elétrico (campanha 02).

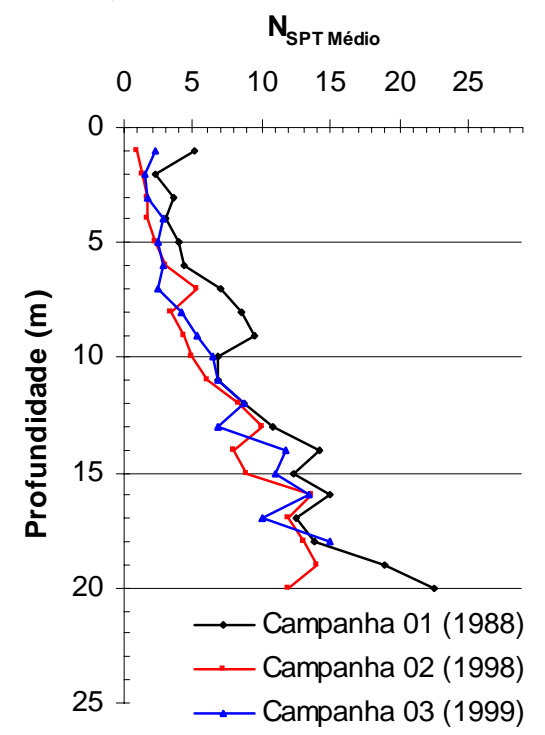

Figura 3.6 - Variação do $\mathrm{N}_{\mathrm{SPT}}$ médio em função da profundidade para cada campanha de sondagem realizada.

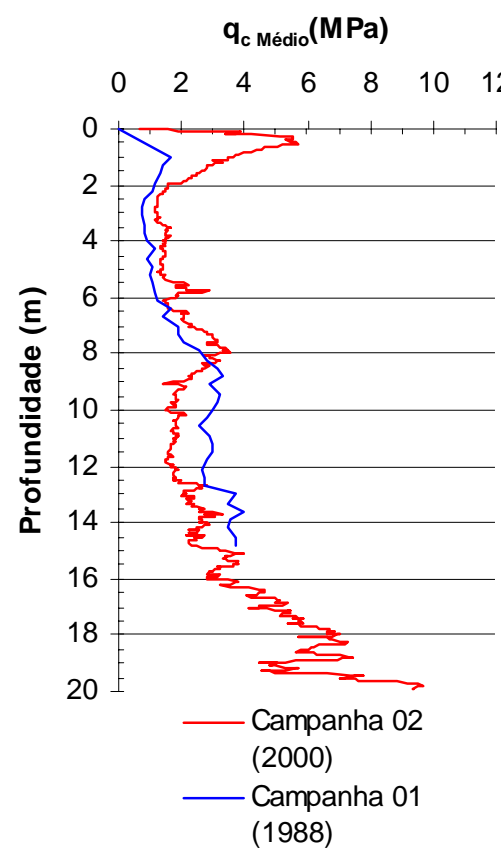

a)

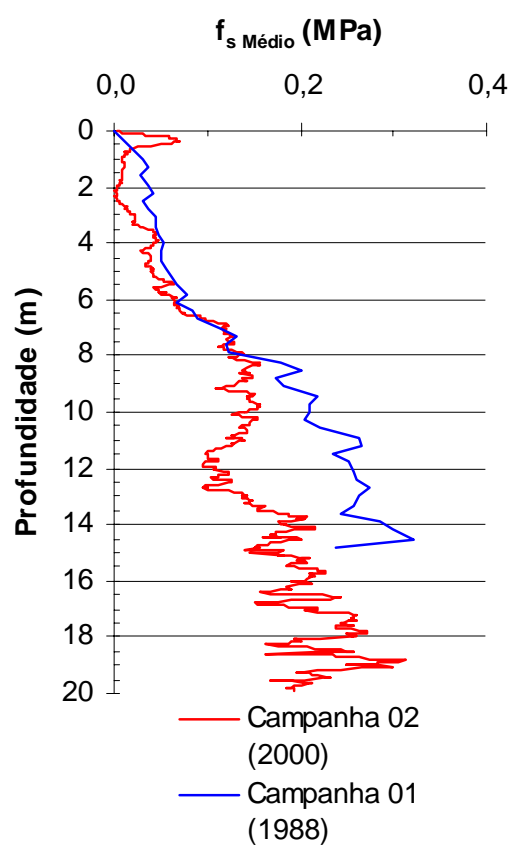

b)

Figura 3.7 - a ) Variação da resistência de ponta unitária média $q_{c}$ em função da profundidade para cada campanha.

b) Variação da resistência por atrito lateral unitário média $q_{c}$ em função da profundidade para cada campanha. 


\section{3 - Variabilidade do Maciço de Solos}

Analisa-se a variabilidade do maciço de solo avaliando os valores de $\mathrm{N}_{\mathrm{SPT}}, \mathrm{q}_{\mathrm{c}} \mathrm{e}$ $\mathrm{f}_{\mathrm{s}}$, para diferentes furos em diferentes profundidades, com a estratigrafia do local, a distribuição espacial dos ensaios, considerando a pluviosidade, e o nível do lençol freático médio.

As Figuras 3.8.a e 3.8.b mostram um esquema espacial de como estão localizadas as campanha de SPT e CPT/CPTU, respectivamente.

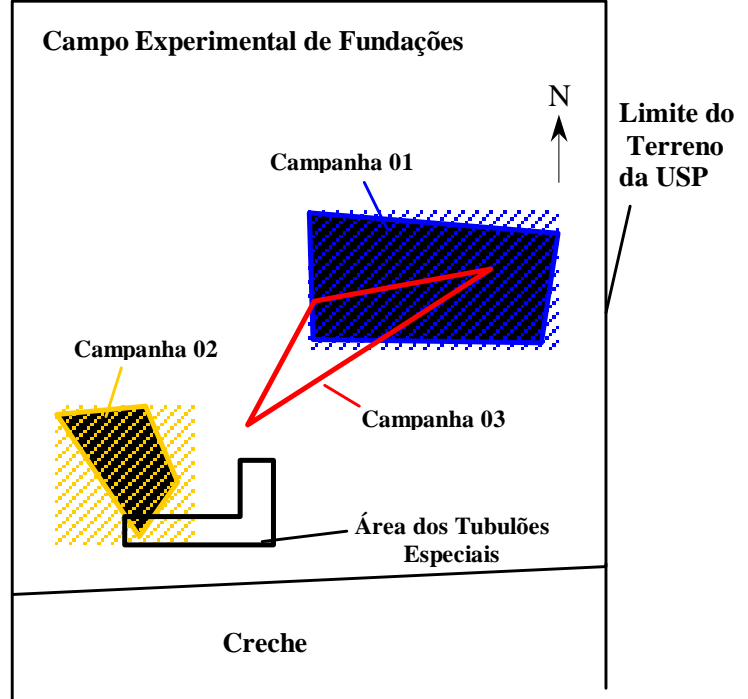

a)

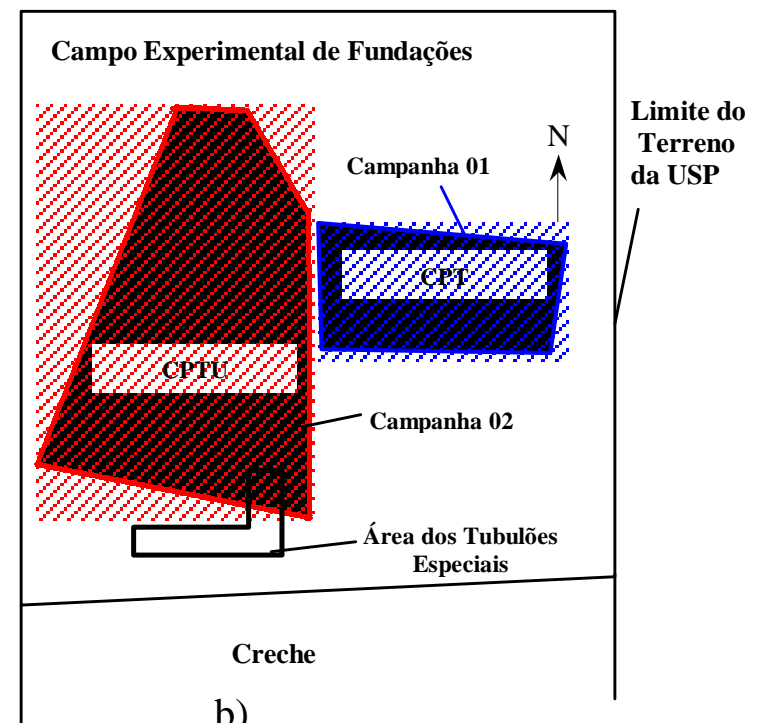

b)

Figura 3.8 - a) Esquema de localização das campanhas de SPT

b) Esquema de localização das campanhas de CPT/CPTU

A Figura 3.9 apresenta as chuvas acumuladas em cada mês, durante os anos em que houve investigação geotécnica. As Figuras 3.10 a 3.18 mostram a variabilidade do maciço de solos em função da estratigrafia, para todas a campanhas de SPT e CPT/CPTU. A Tabela 3.4 mostra os valores das chuvas acumuladas 4 meses antes de serem realizadas as campanhas 
Tabela 3.4 - Valores de chuvas acumuladas 4 meses antes das campanhas

\begin{tabular}{|l|l|}
\hline Campanha 01 (SPT) & $22,5 \mathrm{~mm}$ \\
\hline Campanha 02 (SPT) & $115 \mathrm{~mm}$ \\
\hline Campanha 03 (SPT) & $1092,4 \mathrm{~mm}$ \\
\hline Campanha 01 (CPT) & $22,5 \mathrm{~mm}$ \\
\hline Campanha 02(CPTU) & $221 \mathrm{~mm}$ \\
\hline
\end{tabular}

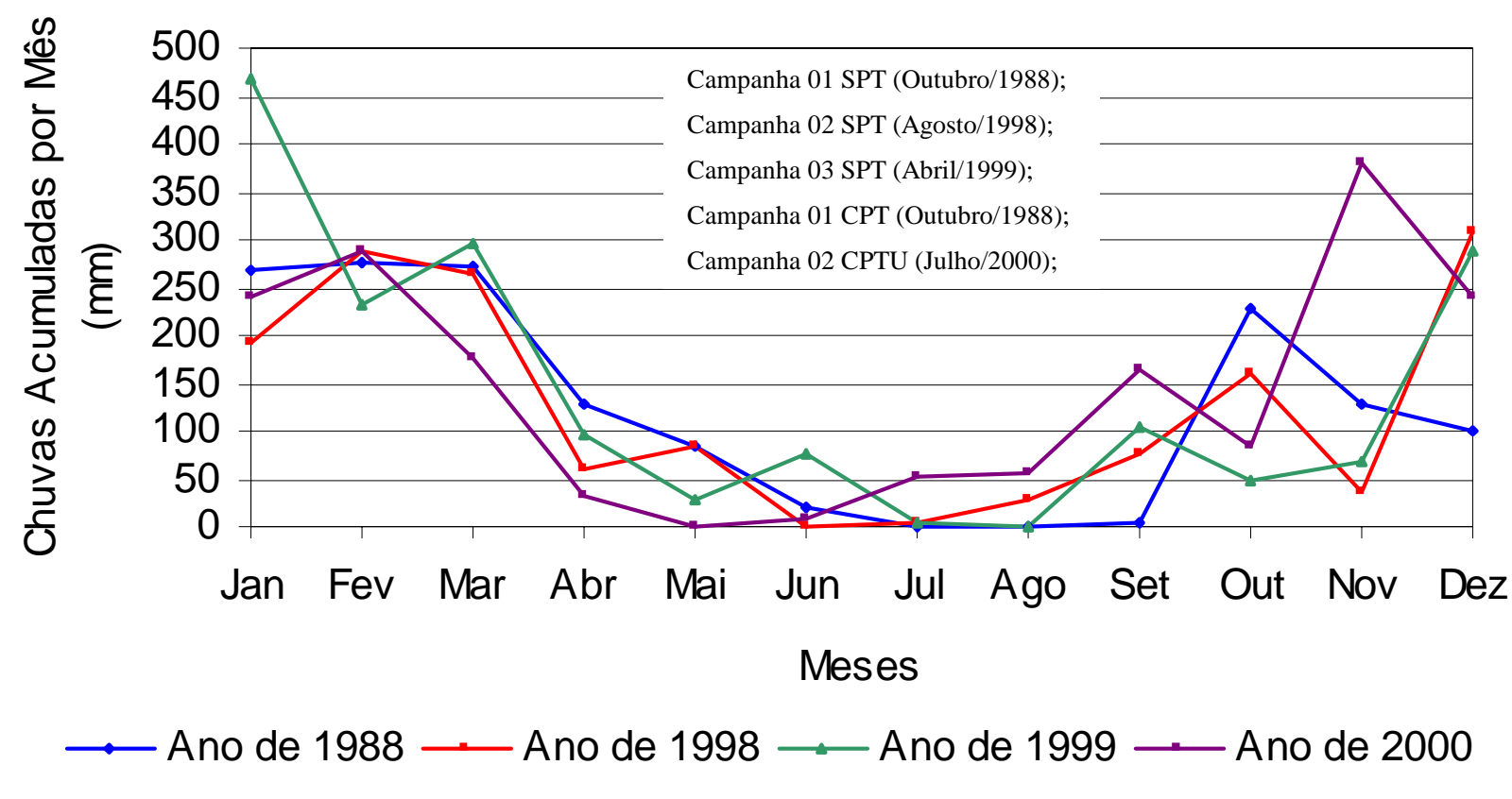

Figura 3.9 - Chuvas acumuladas durante os anos em que se realizaram ensaios de investigação geotécnica. 


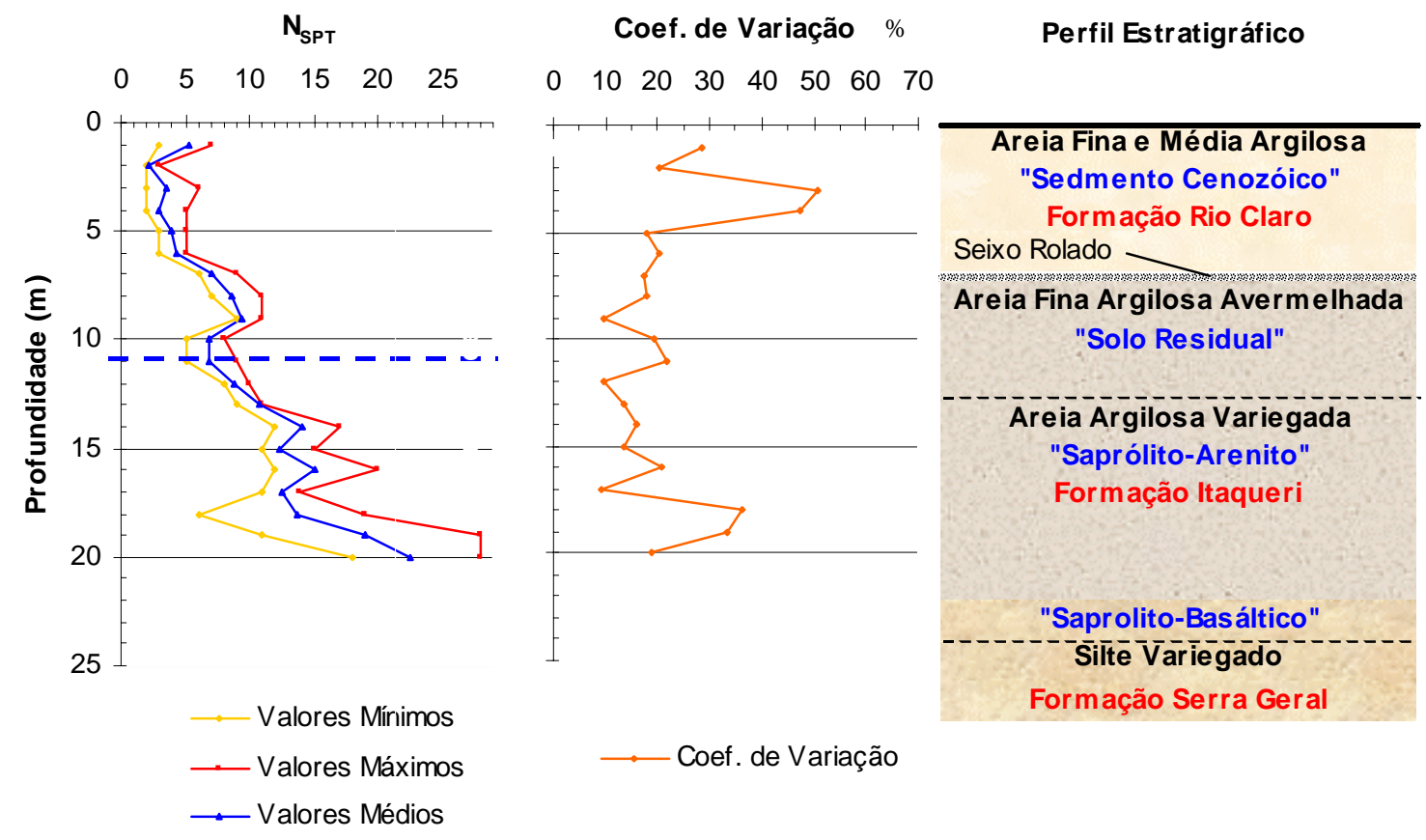

Figura 3.10 - Variabilidade do maciço de solos em função do $\mathrm{N}_{\mathrm{SPT}}$ e estratigrafia para a campanha 01 de sondagem à percussão

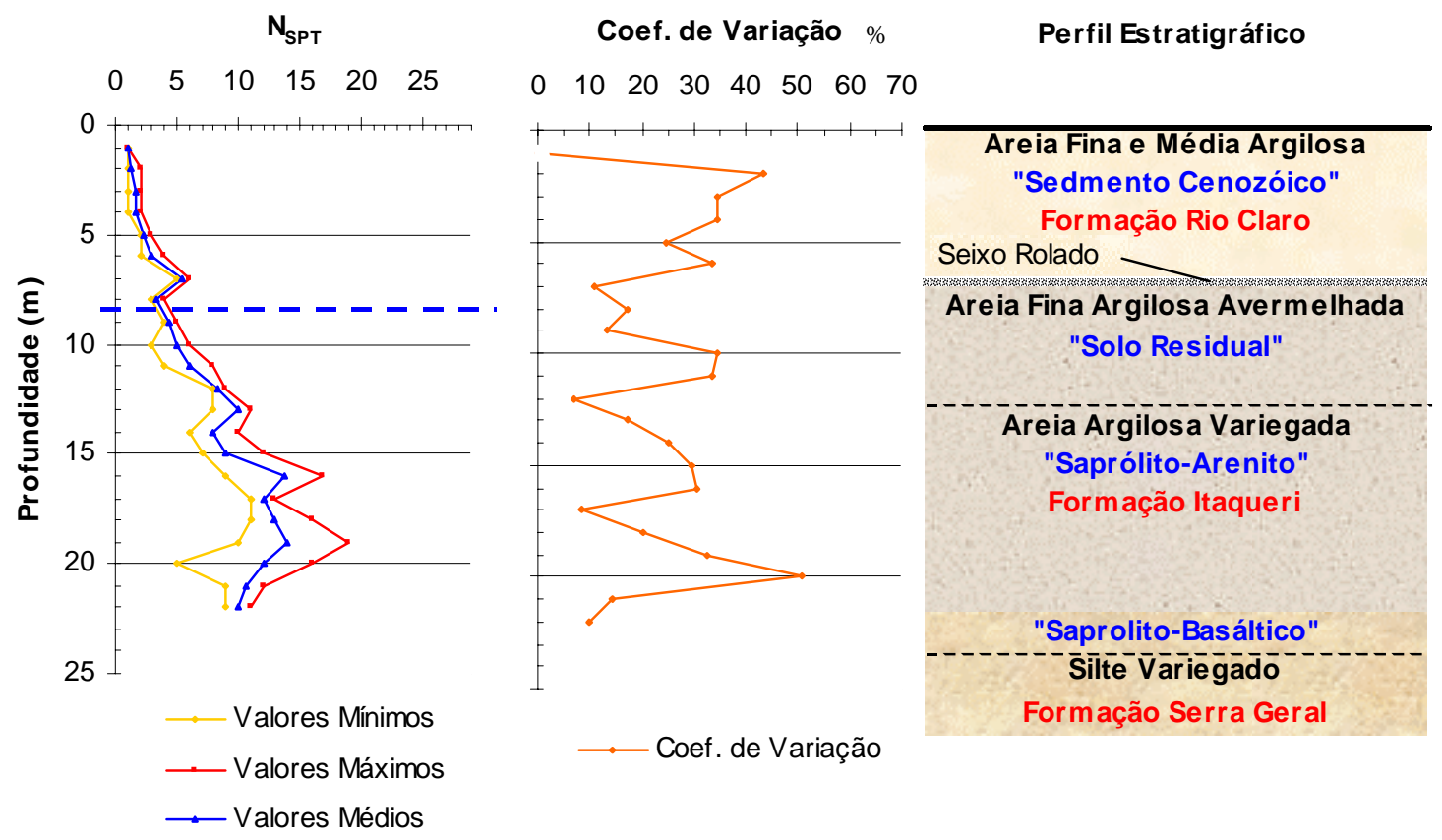

Figura 3.11 - Variabilidade do maciço de solos em função do $\mathrm{N}_{\mathrm{SPT}}$ e estratigrafia para a campanha 02 de sondagem à percussão 


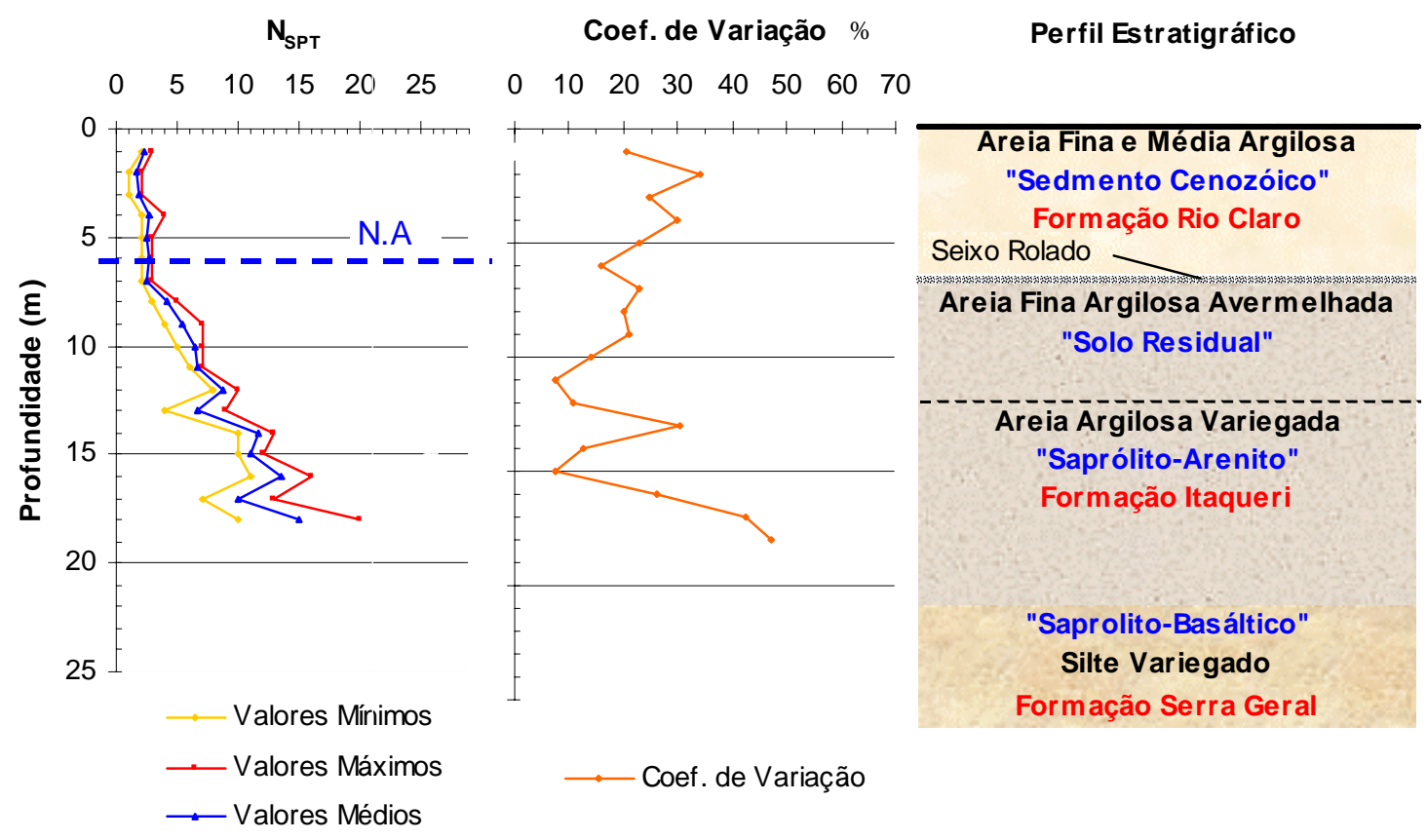

Figura 3.12 - Variabilidade do maciço de solos em função do $\mathrm{N}_{\mathrm{SPT}}$ e estratigrafia para a campanha 03 de sondagem à percussão

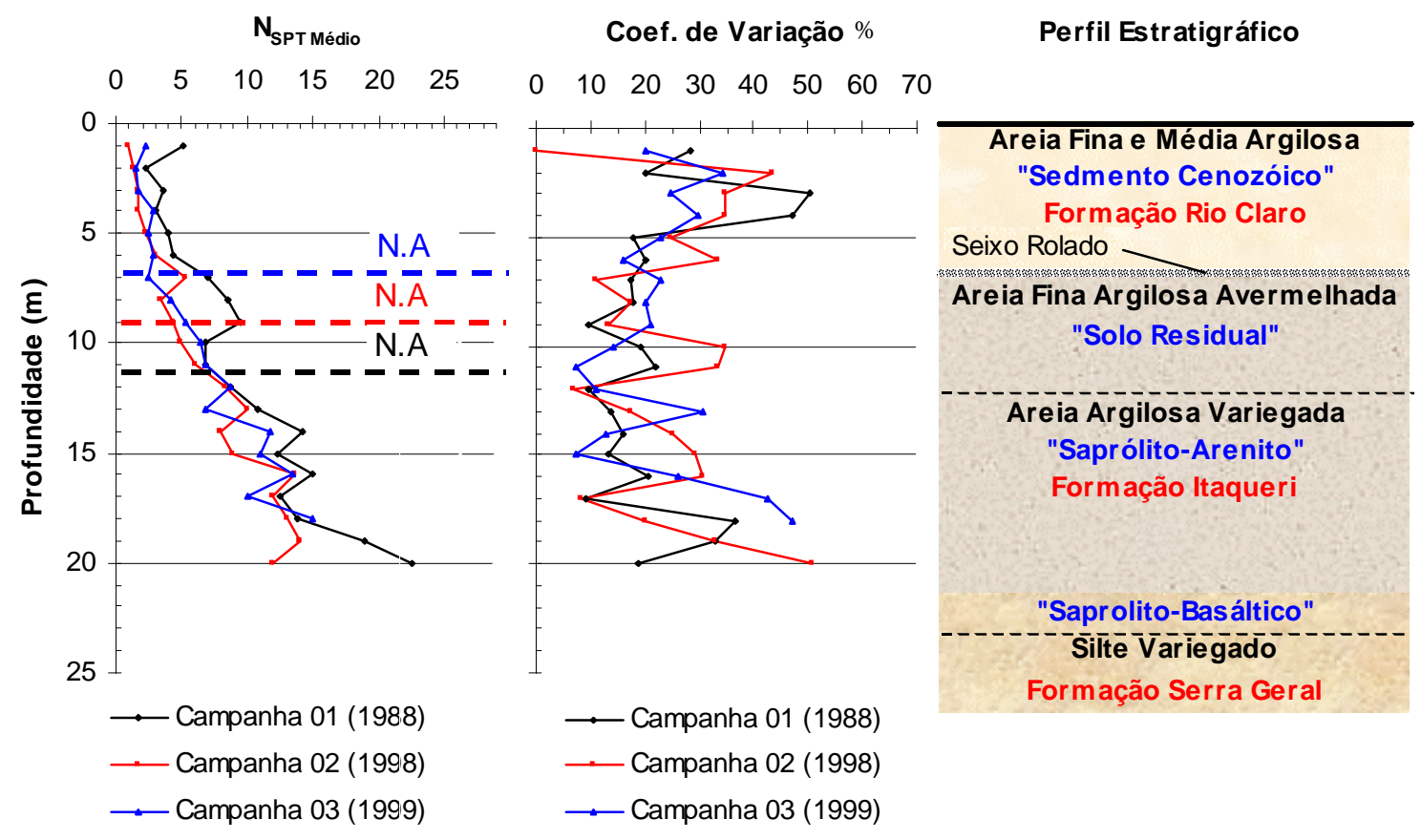

Figura 3.13 - Variabilidade do maciço de solos em função do $\mathrm{N}_{\mathrm{SPT}}$ e estratigrafia para as campanhas de sondagens 01,02 e 03 


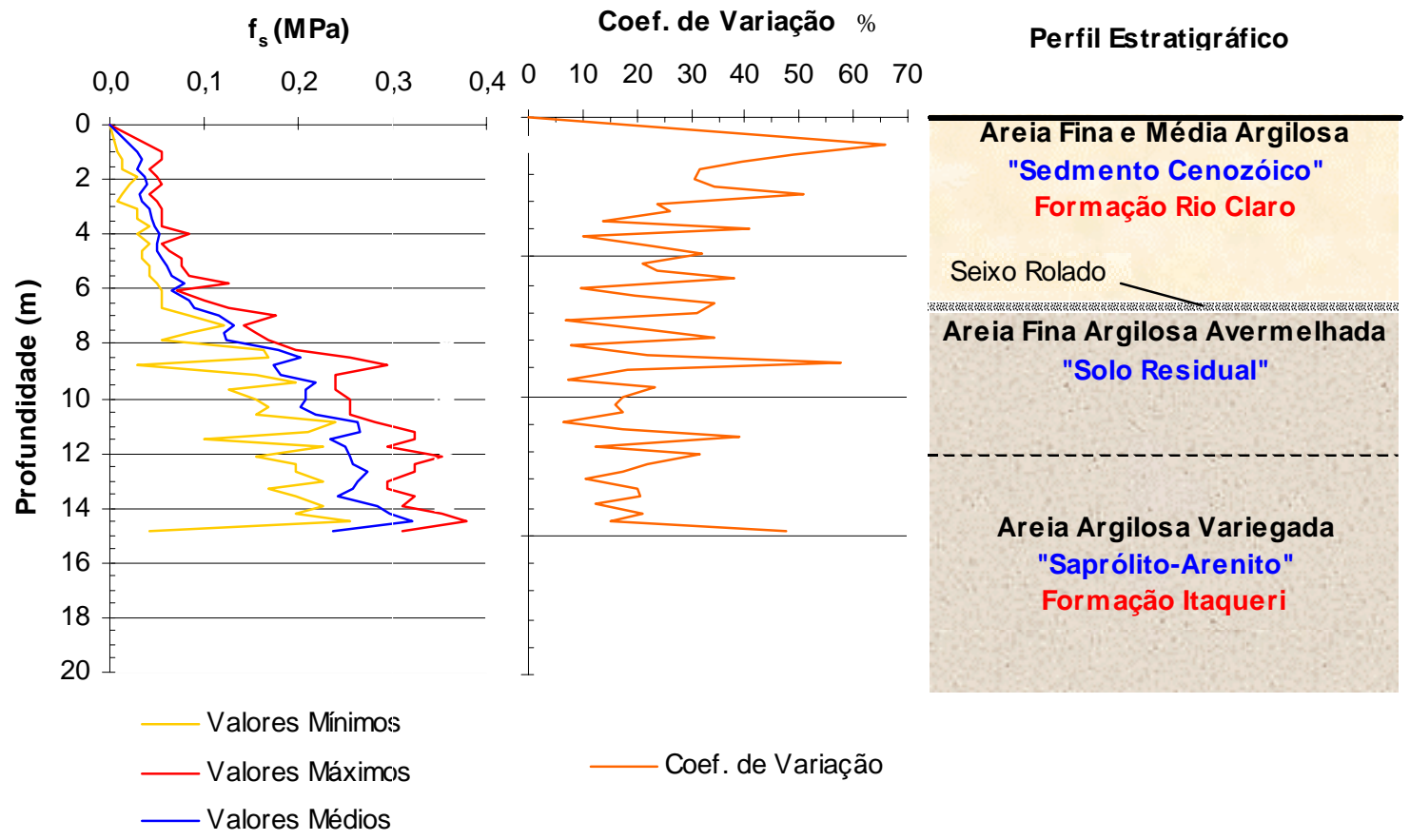

Figura 3.14 - Variabilidade do maciço de solos em função do $\mathrm{f}_{\mathrm{s}}$ e da estratigrafia para a campanha 01 de penetração contínua "CPT"

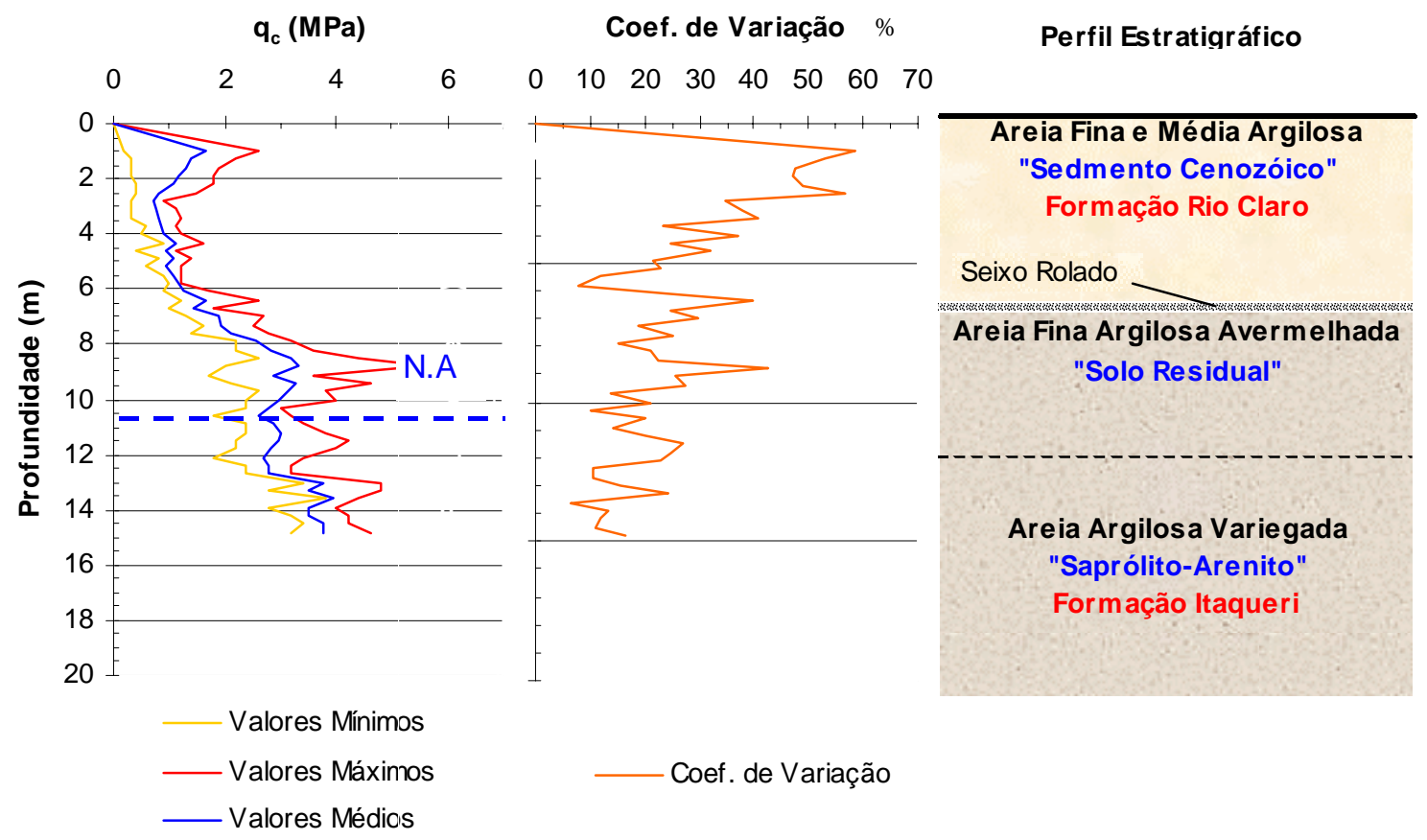

Figura 3.15 - Variabilidade do maciço de solos em função do $\mathrm{q}_{\mathrm{c}}$ e da estratigrafia para a campanha 01 de penetração contínua "CPT". 

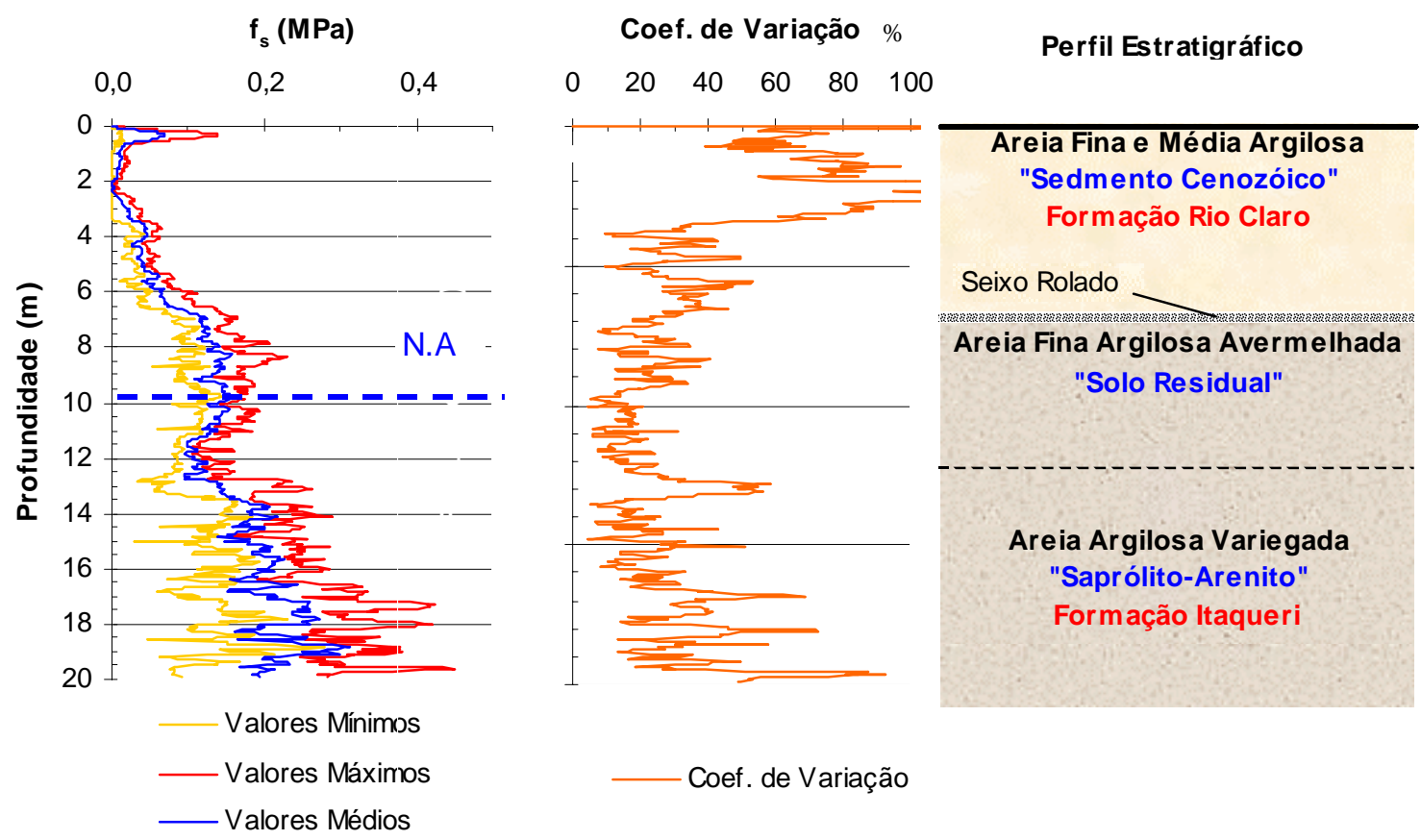

Figura 3.16 - Variabilidade do maciço de solos em função do $f_{s}$ e da estratigrafia para a campanha 02 de penetração continua "CPTU"

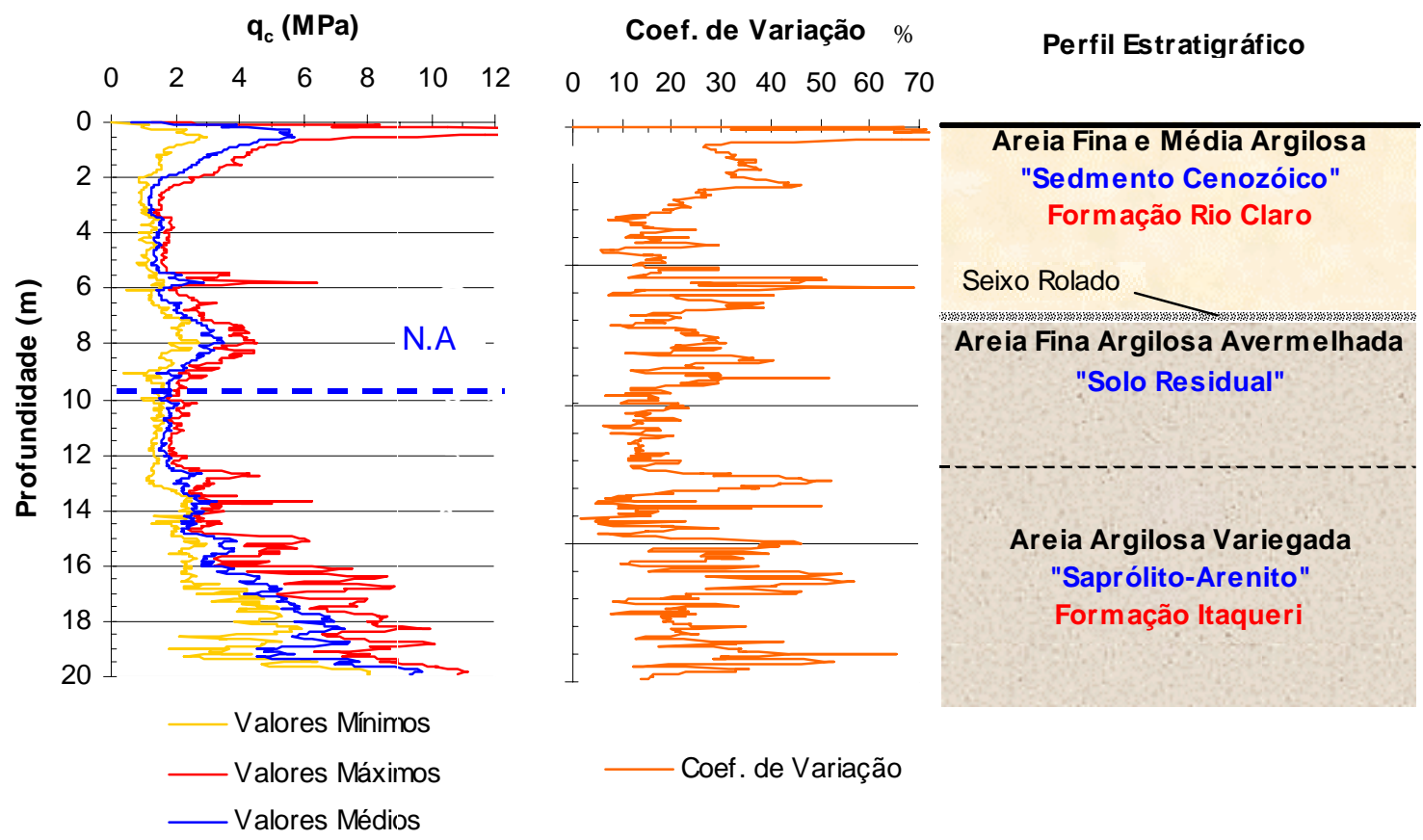

Figura 3.17 - Variabilidade do maciço de solos em função do $\mathrm{q}_{\mathrm{c}}$ e da estratigrafia para a campanha 02 de penetração contínua "CPTU". 


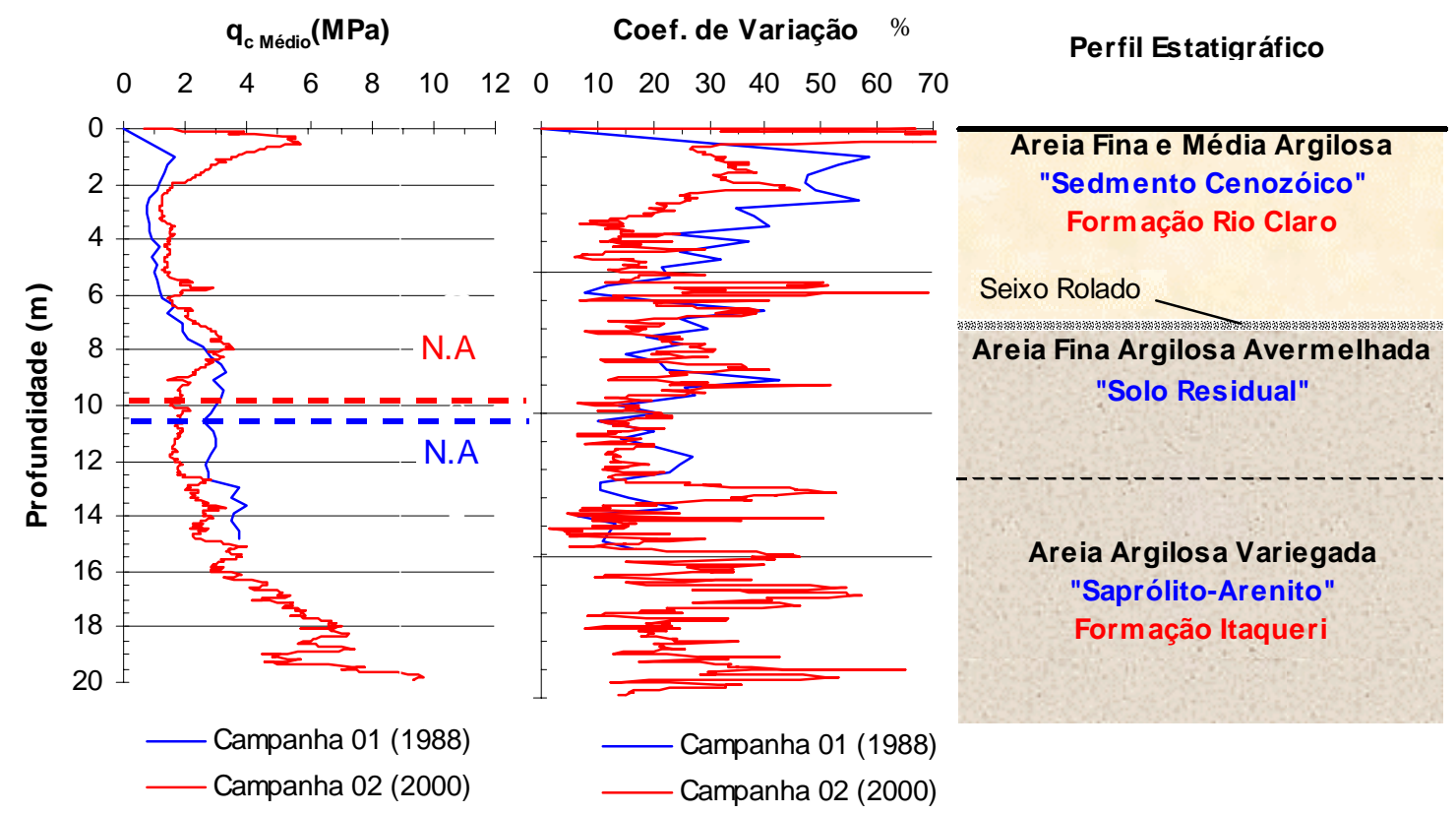

Figura 3.18 - Variabilidade do maciço de solos em função do $\mathrm{q}_{\mathrm{c}}$ e da estratigrafia para as campanhas 01 e 02 de penetração contínua "CPTU”.

Analisando-se as campanhas de SPT das Figuras 3.10 à 3.13, verifica-se que a estratigrafia local é constituída essencialmente por quatro formações:

a) Formação Rio Claro $\rightarrow$ composta de areia fina e média, argilosa. Esta camada apresenta-se muito porosa e pouco compacta. Possui coeficiente de variação entre 20 e $50 \%$. A variação da pressão de sucção com a profundidade, já que esta camada se encontra acima do nível d'água, é a principal responsável pela variabilidade do material.

b) Formação Itaqueri $\rightarrow$ situa-se abaixo da Formação Rio Claro, separada por uma camada de seixo de aproximadamente $0,20 \mathrm{~m}$, está dividida em duas subcamadas: uma de solo residual, possuindo uma variabilidade de cerca de $25 \%$, e outra de saprólito de arenito, a qual possui características bem mais heterogêneas, devido ao grau de alteração da rocha, mostrando-se, dessa forma, uma alta variabilidade.

c) Formação Serra Geral $\rightarrow$ encontra-se na parte inferior, no contato com uma alteração de basalto. 
d) Formação Botucatu $\rightarrow$ situa-se imediatamente abaixo da Formação Serra Geral e não pode ser perfurada por sondagem à percussão.

Estas mesmas análises e conclusões feitas acima podem ser feitas para as campanhas de CPT e CPTU, em que o coeficiente de variação para Formação Rio Claro é em torno de $35 \%$, e da Formação Itaqueri, cerca de $25 \%$.

Com relação à comparação de valores de $\mathrm{N}_{\text {SPT, }}$, visto na Figura 3.13, verifica-se que os valores médios da campanha 01 são maiores que os da campanha 03, que são maiores que os da campanha 02. Analisando-se, na Tabela 3.4, a pluviosidade dos quatro meses anteriores à realização das campanhas, observa-se que a campanha 01 acontece na época mais seca, em que o solo encontra-se mais resistente. Mas, se analisássemos, nesta mesma linha de raciocínio, as campanhas 02 e 03, isso não se justificaria, por isso os valores médios de $\mathrm{N}_{\mathrm{SPT}}$ da campanha 03 são maiores que o da campanha 02, devido à localização em que foram realizados estes ensaios, visto na Figura 3.7.a, e possivelmente por terem sido feitos por empresas diferentes.

Na comparação dos resultados dos valores de $\mathrm{q}_{\mathrm{c}}$ médio para as campanhas 01 e 02 de CPT e CPTU, respectivamente, observa-se que os valores da campanha 01 são maiores que os da campanha 02, até, mais ou menos, a linha de seixos quando se invertem. Dessa forma, assim como para as campanhas 02 e 03 de SPT, os resultados também não se justificam pela quantidade de chuvas acumuladas, visto na Tabela 3.4, mas explica-se pela localização em que foram realizados estes ensaios, visto na Figura 3.8.b, e possivelmente por terem sido feitos por empresas diferentes. 


\section{CAPÍTULO 4 - METODOLOGIA E PROCEDIMENTOS}

\section{1 - Considerações Gerais Sobre os Tubulões}

Os quatro tubulões a céu aberto (TE01,TE02, TE03 e TE04), utilizados na pesquisa, possuem uma base alargada de 1,50 m de diâmetro, 0,90 $\mathrm{m}$ de altura da base, 0,60 m de diâmetro do fuste, e suas bases estão assentadas na cota de $-8,0 \mathrm{~m}$. Entre a base do tubulão e o fuste, há uma camada de compensado de madeira de 0,02 m de espessura, seguida de uma camada de isopor (E.P.S) de 0,40 m e novamente uma camada de 0,02 m de compensado de madeira.

Após a execução dos tubulões, realizaram-se, em pesquisa anterior (SANTOS, 2001), um total de dez provas de carga estática. A presente pesquisa é uma sequiência da anterior, em que se realizaram 10 provas de carga dinâmica. A Figura 4.1 mostra o detalhe geométrico admitido no início da prova de carga estática e as Figuras 4.2.a à 4.5.c mostram os detalhes geométricos e as fotos provenientes de inspeções após as provas de carga dinâmica. 


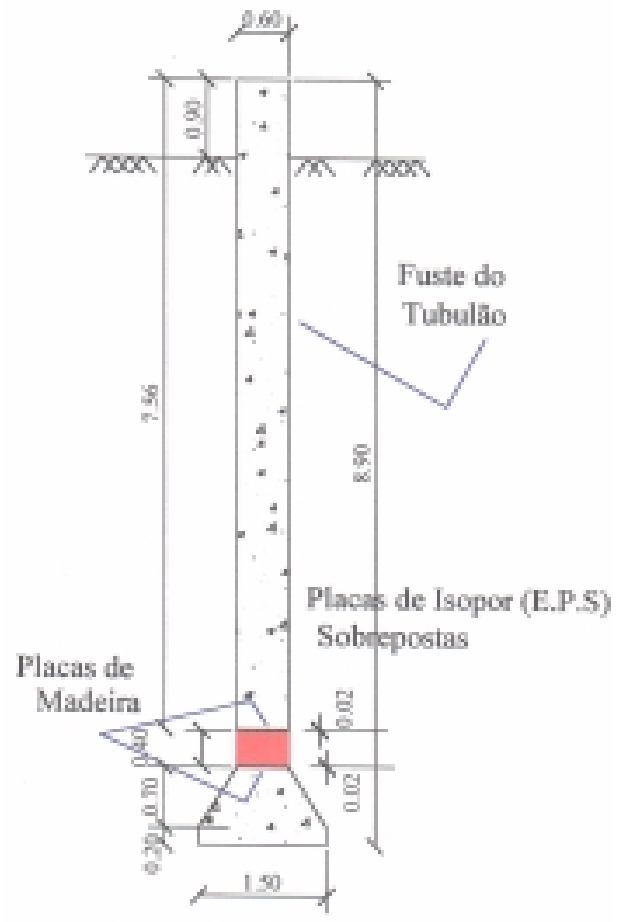

Base do Tubulilo

Figura 4.1 - Detalhe geométrico do tubulão antes da prova de carga estática

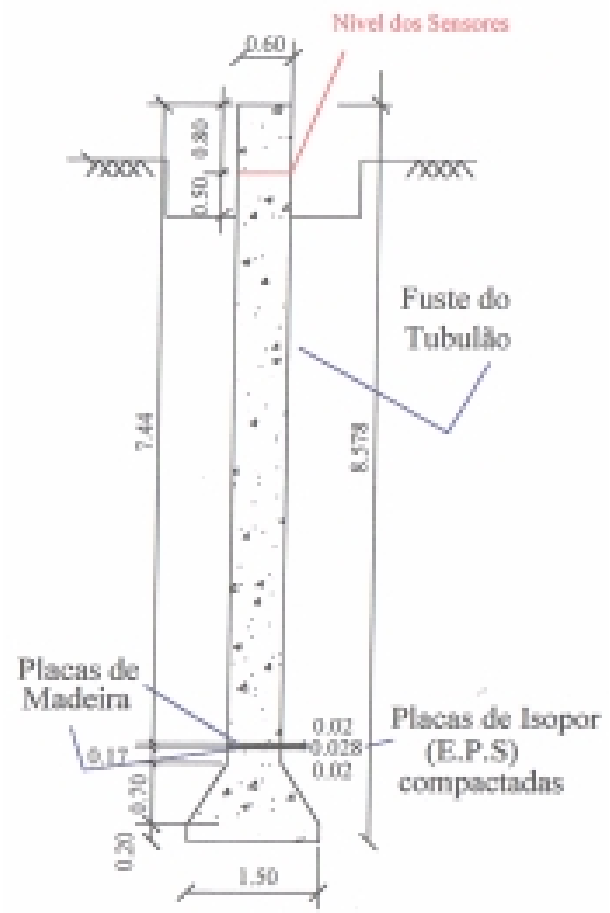

Base do Tubulāo

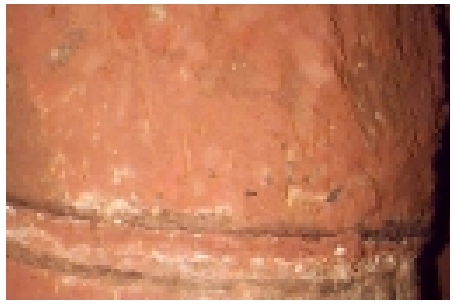

b)

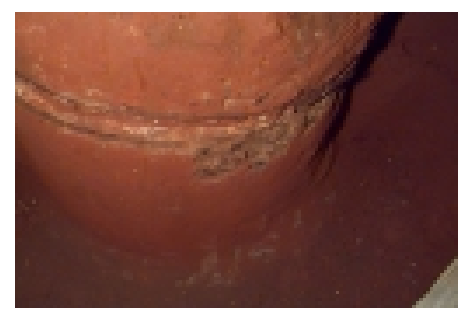

c)

a)

Figura 4.2 - a) Detalhe geométrico do tubulão TE01 após a prova de carga dinâmica

b) Foto da transição de materiais do fuste do tubulão TE01

c) Foto do encontro entre o fuste e a base do tubulão TE01 


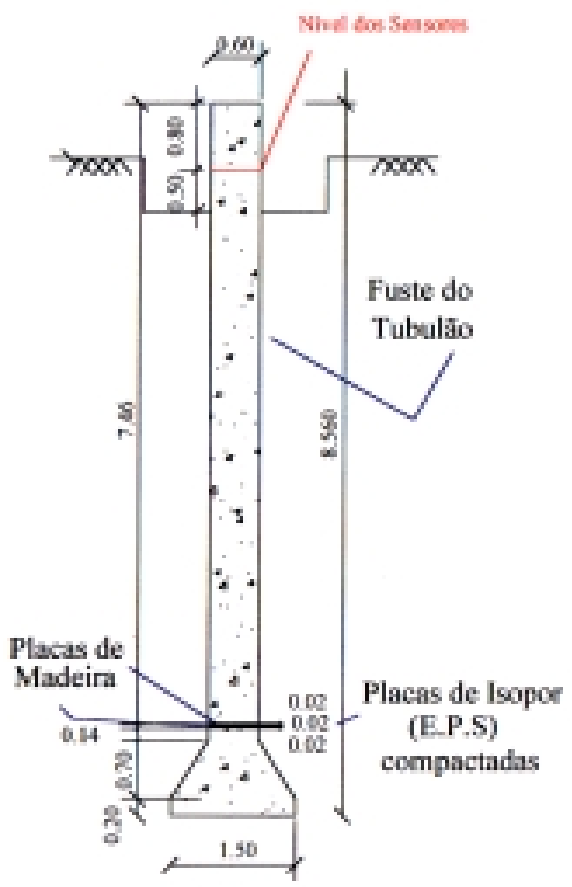

Base do Tubulāo

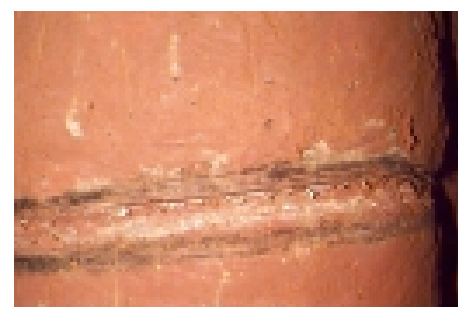

b)

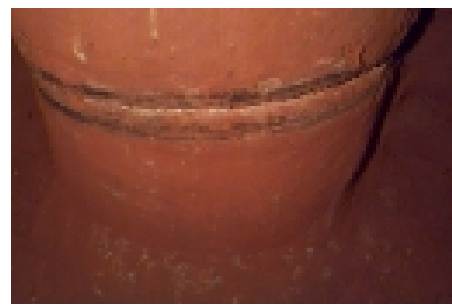

c)

a)

Figura 4.3 - a) Detalhe geométrico do tubulão TE02 após a prova de carga dinâmica

b) Foto da transição de materiais do fuste do tubulão TE02

c) Foto do encontro entre o fuste e a base do tubulão TE02

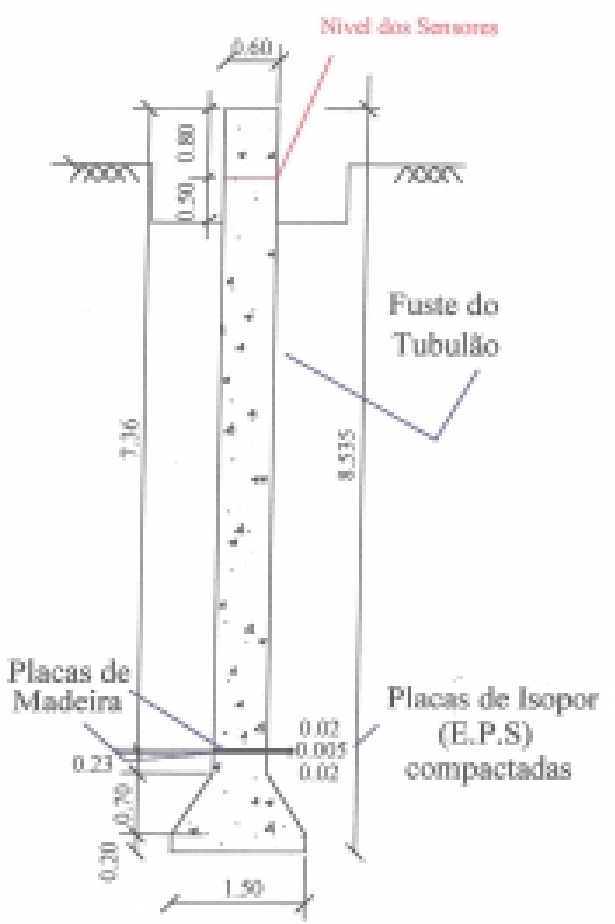

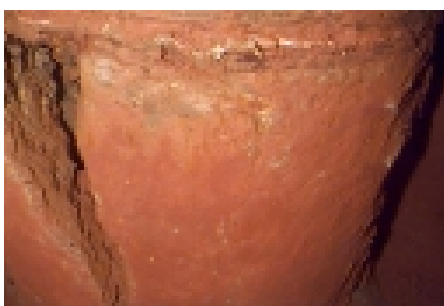

b)

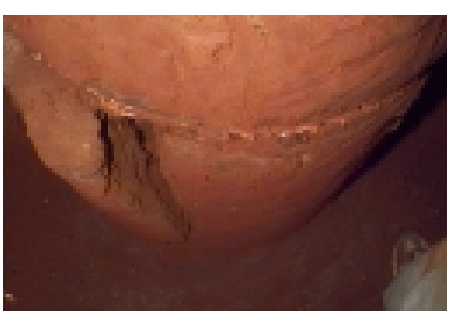

c)

Base do Tubulăo

a)

Figura 4.4 - a) Detalhe geométrico do tubulão TE03 após a prova de carga dinâmica

b) Foto da transição de materiais do fuste do tubulão TE03

c) Foto do encontro entre o fuste e a base do tubulão TE03 


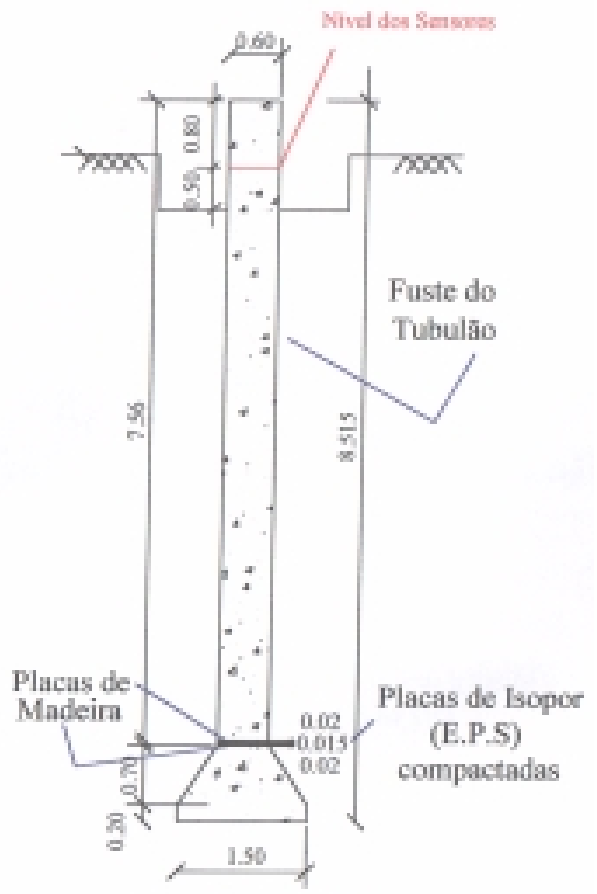

Base do Tubuld̋

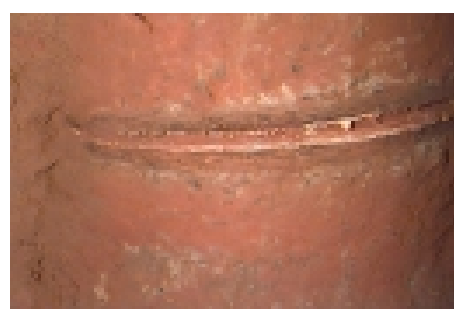

b)

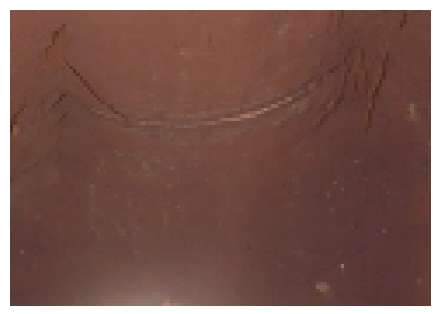

c)

a)

Figura 4.5 - a) Detalhe geométrico do tubulão TE04 após a prova de carga dinâmica

b) Foto da transição de materiais do fuste do tubulão TE04

c) Foto do encontro entre o fuste e a base do tubulão TE04

\section{2 - O Ensaio Dinâmico de Energia Crescente}

As provas de carga dinâmica de energia crescente foram realizadas de acordo com as recomendações da NBR-13208/94. Ao total, realizaram-se dez provas de carga de energia crescente em quatro tubulões especiais: TE01, TE02, TE03 e TE04. Dessas dez provas de carga, oito realizaram-se com o terreno não-inundado, e duas com o terreno pré-inundado por 12 horas. Os ensaios seguiram a sequiência vista na Tabela 4.1. A localização dos tubulões no campo experimental é mostrada na Figura 4.6. 
Tabela 4.1 - Seqüência de realização das provas de carga dinâmica de energia crescente

\begin{tabular}{c|c|c|c|c}
\hline $\begin{array}{c}\text { Prova de } \\
\text { Carga N }\end{array}$ & Data do Ensaio & Tubulão N & $\begin{array}{c}\text { Estado } \\
\text { doTerreno }\end{array}$ & $\begin{array}{c}\text { Nível D'água } \\
(\mathbf{m})\end{array}$ \\
\hline 01 & $05 / 06 / 2001$ & TE04 & Não-Inundado & $-10,10$ \\
\hline 02 & $05 / 06 / 2001$ & TE04 & Não-Inundado & $-10,10$ \\
\hline 03 & $05 / 06 / 2001$ & TE03 & Não-Inundado & $-10,10$ \\
\hline 04 & $05 / 06 / 2001$ & TE03 & Não-Inundado & $-10,10$ \\
\hline 05 & $05 / 06 / 2001$ & TE02 & Não-Inundado & $-10,10$ \\
\hline 06 & $05 / 06 / 2001$ & TE02 & Não-Inundado & $-10,10$ \\
\hline 07 & $05 / 06 / 2001$ & TE01 & Não-Inundado & $-10,10$ \\
\hline 08 & $05 / 06 / 2001$ & TE04 & Não-Inundado & $-10,10$ \\
\hline 09 & $06 / 06 / 2001$ & TE04 & Pré-Inundado & $-10,10$ \\
\hline 10 & $06 / 06 / 2001$ & TE01 & Pré-Inundado & $-10,10$ \\
\hline
\end{tabular}

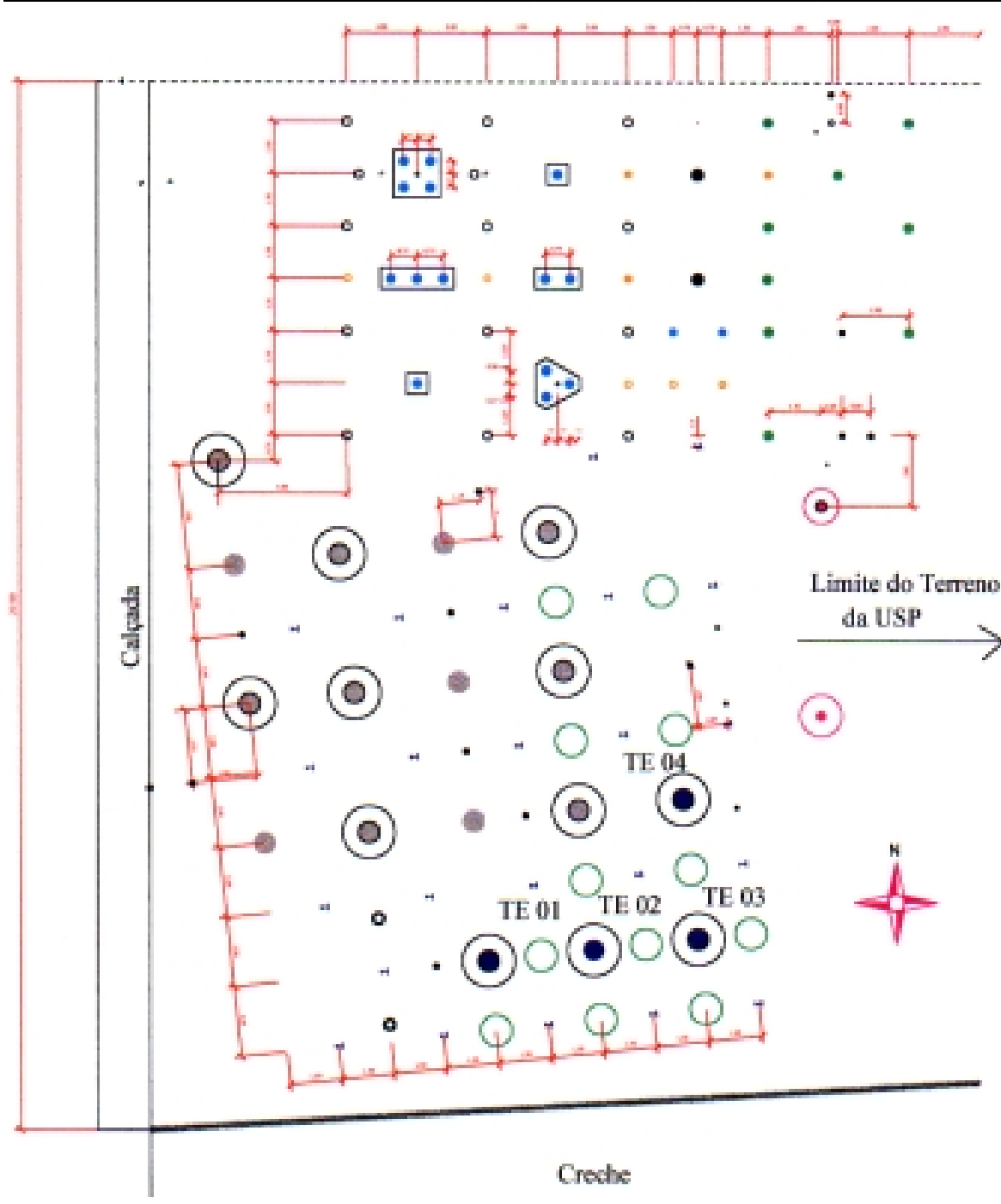

Figura 4.6 - Localização dos tubulões especiais no Campo Experimental de Fundações da EESC/USP 
Para a realização da prova de carga dinâmica de energia crescente, utilizou-se um bate estaca de queda livre com um martelo de $2800 \mathrm{~kg}$, um capacete de $500 \mathrm{~kg}$, um cepo de $30 \mathrm{~cm}$ de espessura e um coxim de $6 \mathrm{~cm}$. Os transdutores de deformação e os acelerômetros foram colocados a $0,80 \mathrm{~m}$ do topo dos tubulões, o que resulta em uma distância de 0,50 m ao maciço de solo. A Figura 4.7.a e 4.7.b mostram uma vista da realização da prova de carga dinâmica com controle através dos transdutores de deformação, acelerômetros e medidas de nega e repique.

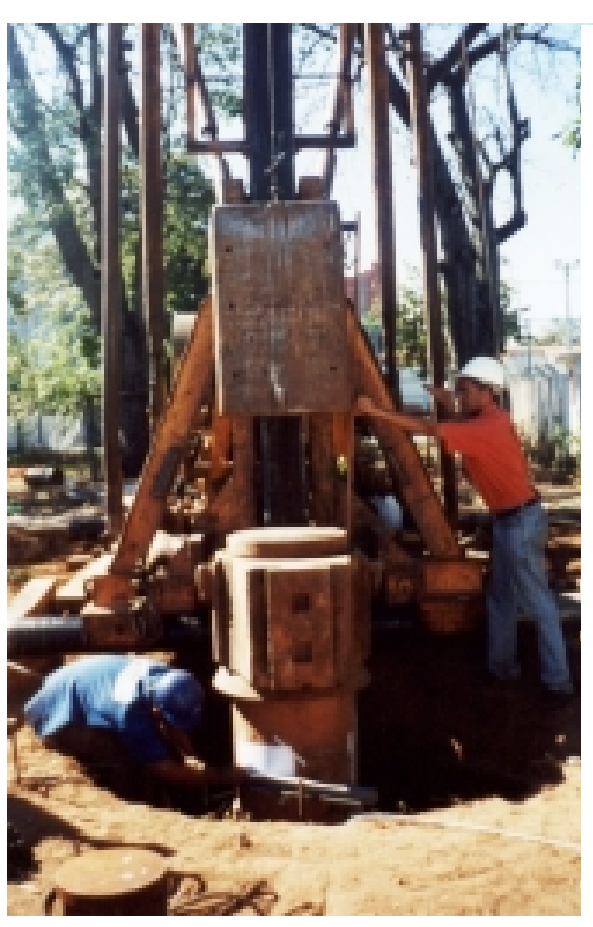

a)

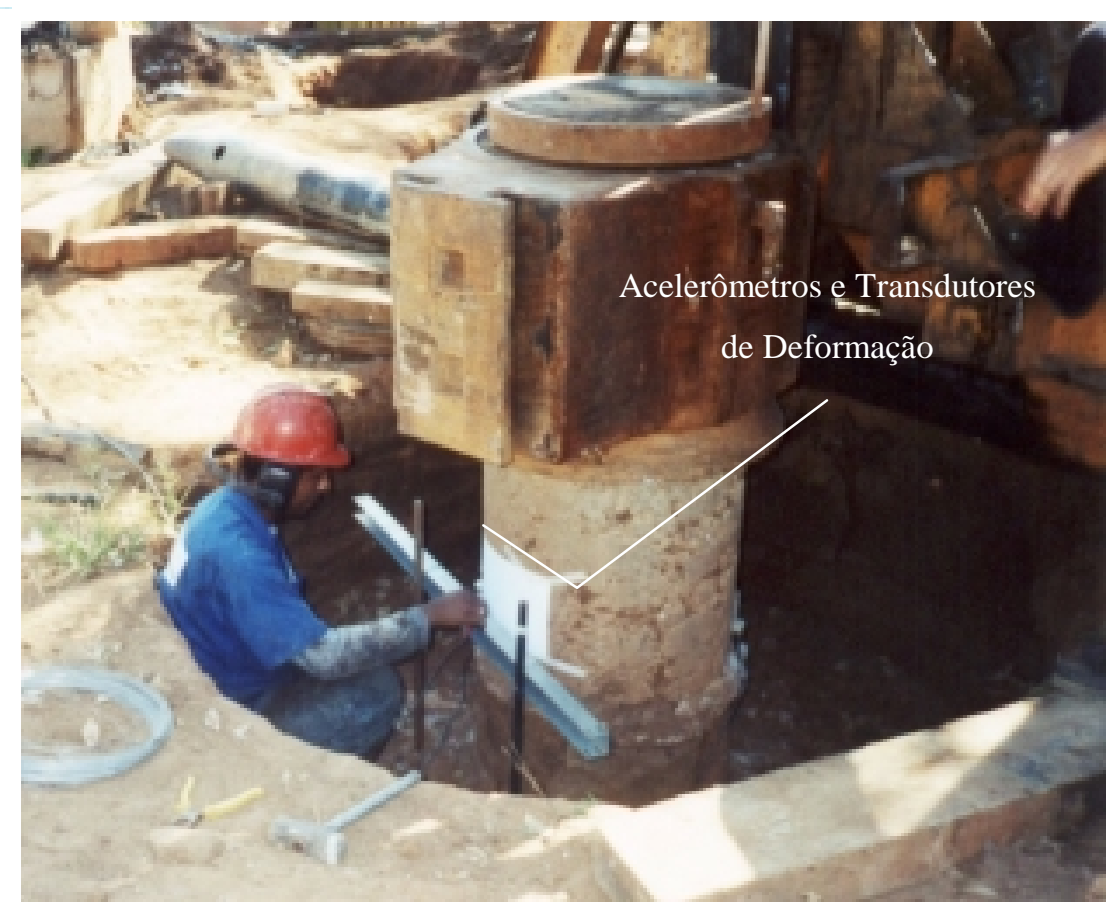

b)

Figura 4.7 - a) Vista da realização da prova de carga dinâmica de energia crescente

b) Vista de um dos acelerômetros e um dos transdutores de deformação

Fez-se a análise do ensaio de carregamento dinâmico de energia crescente utilizando-se a metodologia PDA e análises CAPWAP. 


\section{3 - Teor de Umidade e Sucção}

A partir dos valores de teores de umidade, a cada meio metro de profundidade, obtidos através de tradagem do terreno e dos resultados obtidos por MACHADO (1998), estimou-se a pressão de sucção e sua variação com a profundidade. Essa estimativa é mostrada no capítulo seguinte.

\section{4 - Altura de Queda do Martelo do Bate-Estaca}

A altura de queda do martelo do bate-estaca ficou limitada pela energia que aquele transmitia ao tubulão, sem que houvesse destruição da cabeça do mesmo. A Figura 4.8 mostra a destruição de parte da cabeça do tubulão TE01, após tentar-se aumentar a altura de queda do martelo para 1 metro.

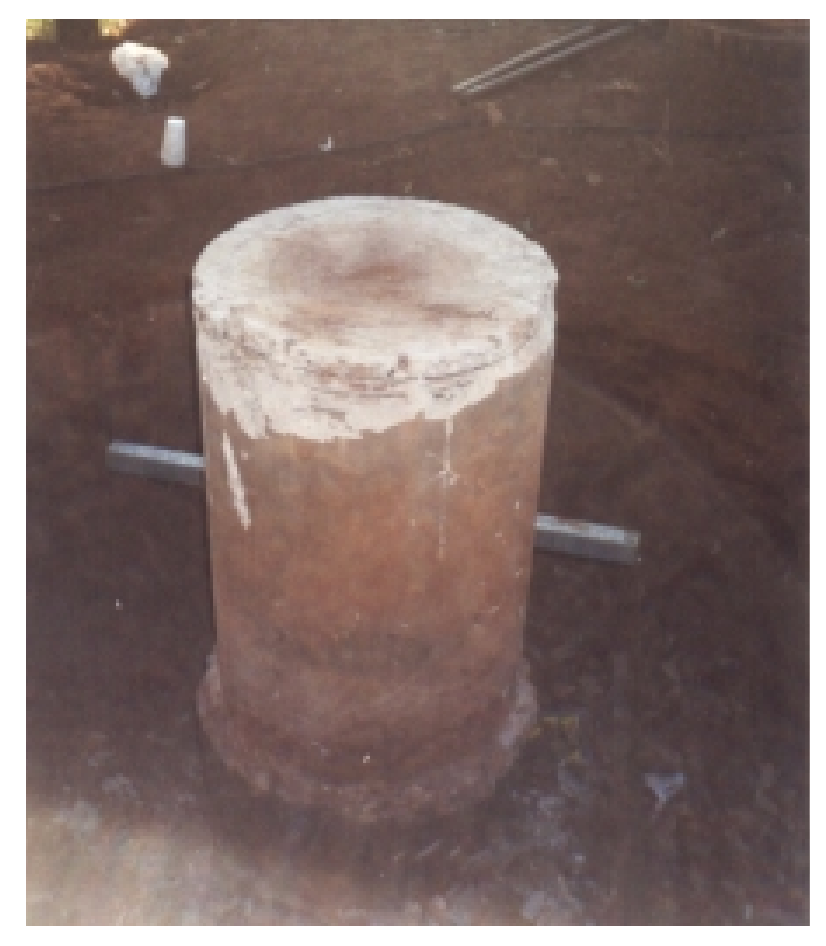

Figura 4.8 - Destruição de Parte da Cabeça do Tubulão TE01 


\section{5 - Ensaios Com e Sem Pré-Inundação do Terreno}

De acordo com a Tabela 4.1, realizaram-se oito ensaios sem pré-inundação do terreno e dois ensaios com pré-inundação do terreno. Salienta-se que os ensaios com pré-inundação do terreno foram realizados após $12 \mathrm{~h}$, ao invés de $48 \mathrm{~h}$, como é necessário para a completa inundação do mesmo. Isso se procedeu, devido à limitação de custo por parte da mobilização do bate-estaca e da impossibilidade da permanência do PDA até que se completasse o período. A Figura 4.9 mostra a inundação do tubulão TE01 sendo feita.

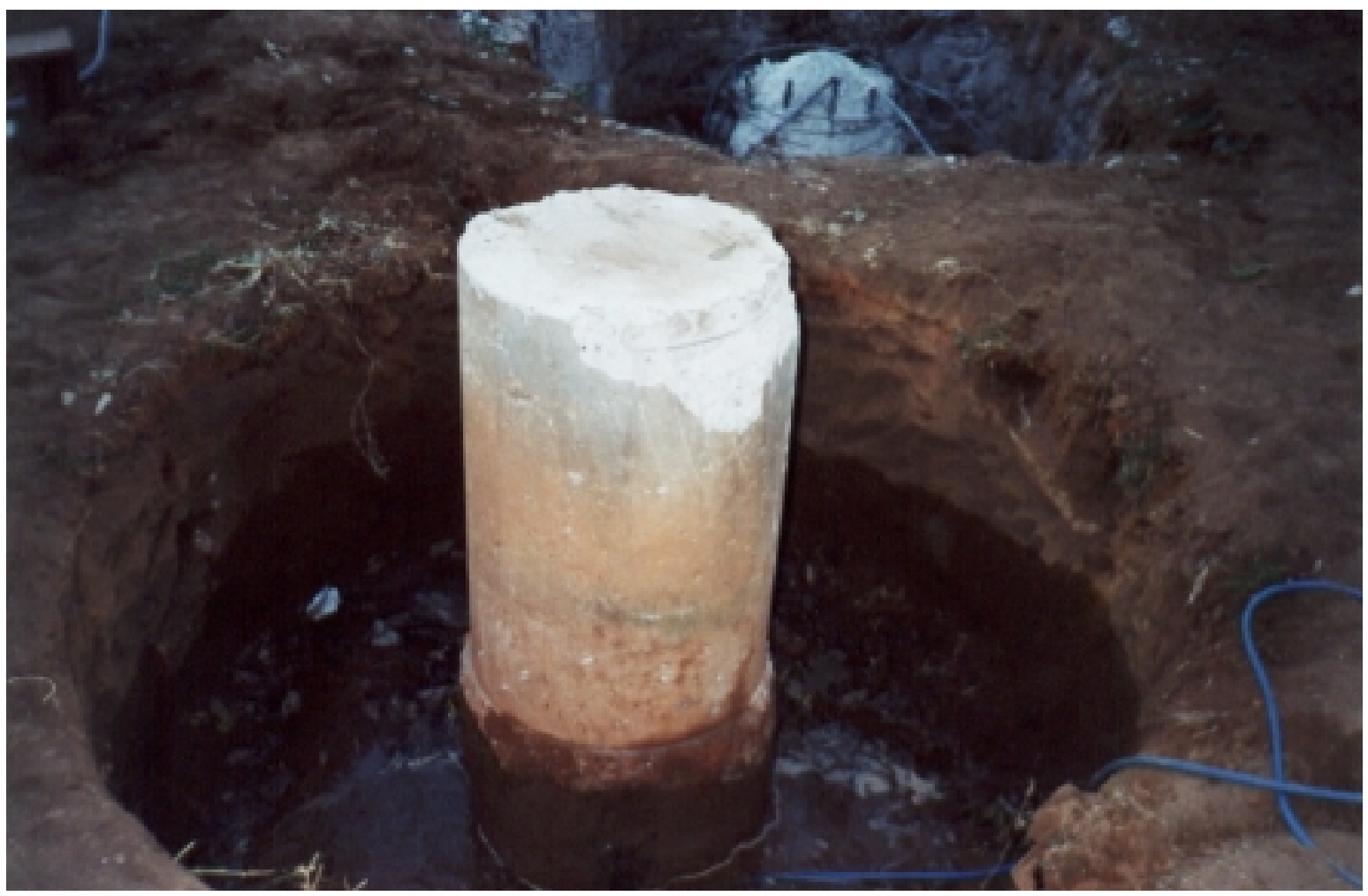

Figura 4.9 - Inundação do Tubulão TE01 


\section{CAPÍTULO 5 - MATERIAIS E EQUIPAMENTOS}

\section{1 - Esclerômetro}

O esclerômetro foi utilizado, para a determinação da resistência média à compressão do concreto e por correlação através desta obtenção do módulo de elasticidade médio do concreto. A Figura 5.1 mostra a utilização do esclerômetro no tubulão TE04.

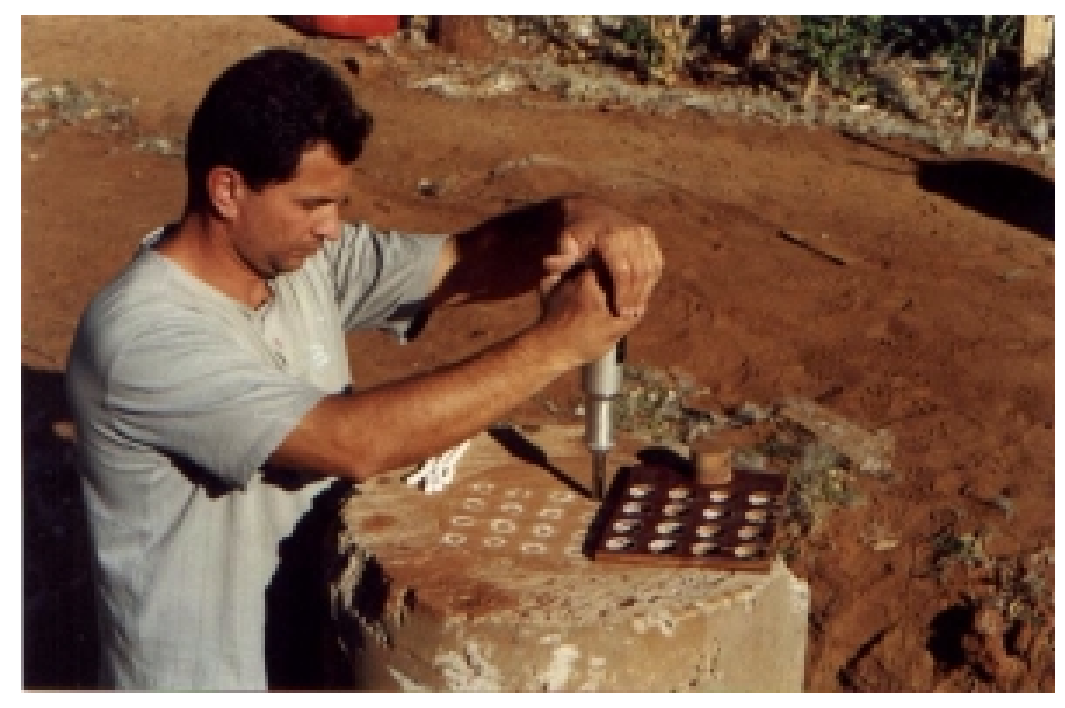

Figura 5.1 - Determinação da Resistência do Concreto Através do Esclerômetro

\section{2 - Parafina e Balança}

Utilizou-se uma balança com precisão de $0,01 \mathrm{~g}$ e parafina, para a determinação do peso específico médio do concreto, através do princípio de Arquimedes. A Figura 5.2 mostra o ensaio, para a determinação desta propriedade 


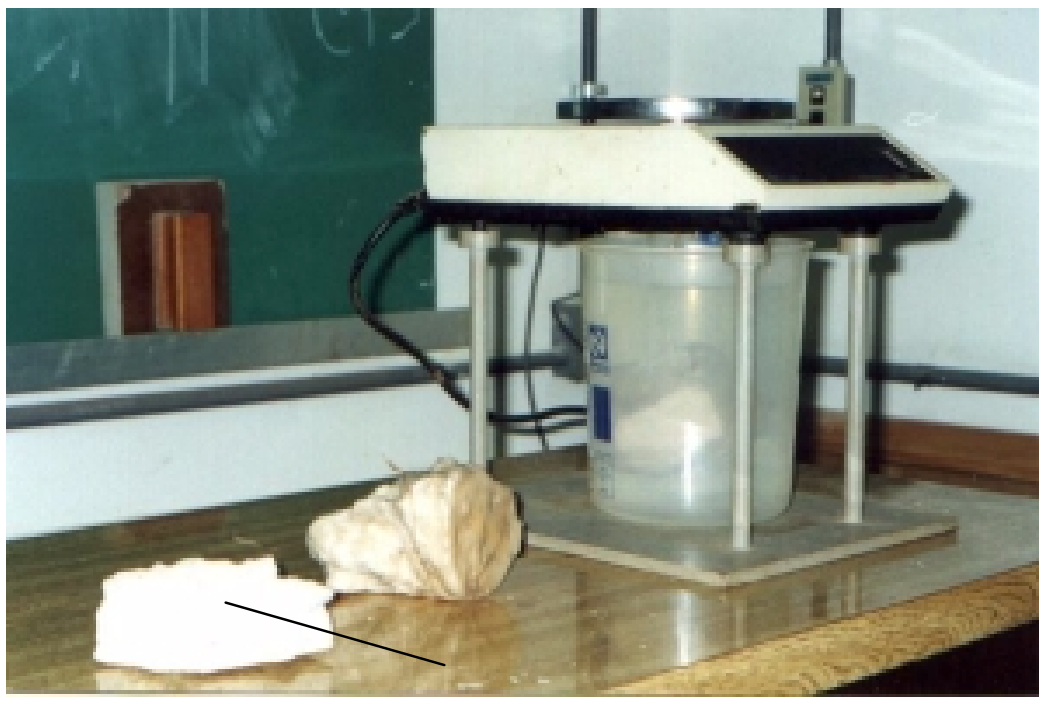

Figura 5.2 - Determinação do Peso Específico do Concreto

\section{3 - Prova de Carga Dinâmica de Energia Crescente}

\subsection{1 - Bate-Estaca e Capacete}

O bate-estaca utilizado, para aplicar a energia ao sistema, era de queda-livre e possuía um martelo de 2,8 toneladas. O capacete utilizado tinha $500 \mathrm{~kg}$, também se usaram um cepo e um coxim de $30 \mathrm{~cm}$ e $6 \mathrm{~cm}$ respectivamente. A Figura 5.3 mostra uma vista da realização da prova de carga dinâmica.

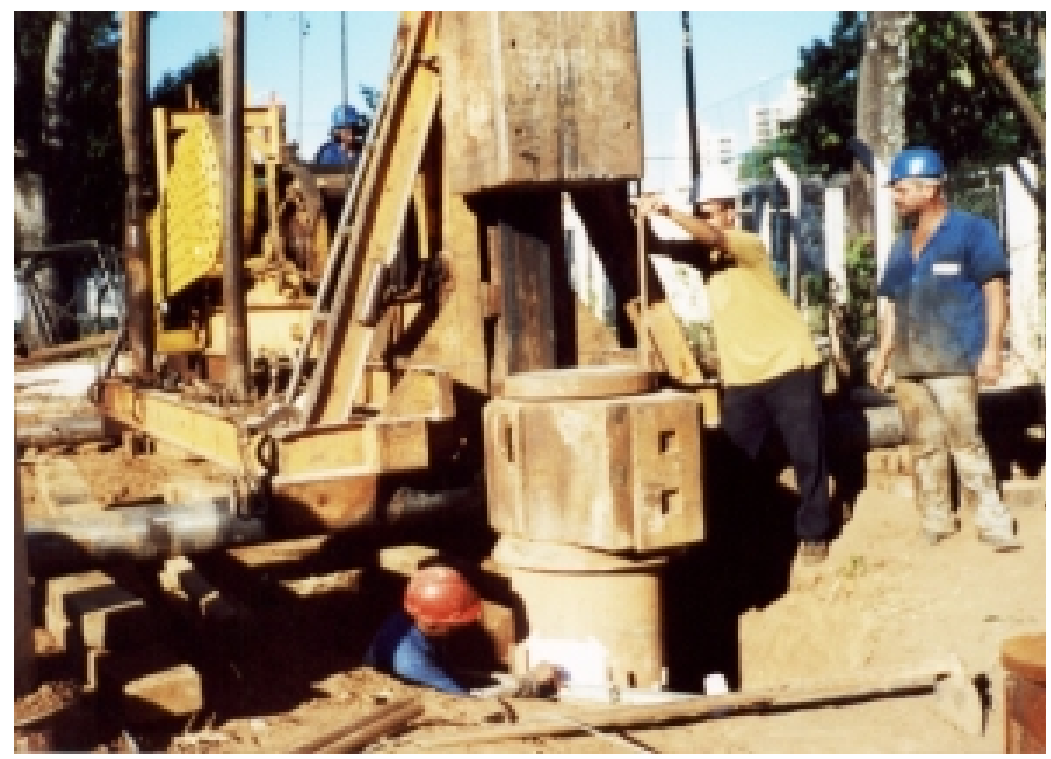

Figura 5.3 - Realização da Prova de Carga de Energia Crescente 


\subsection{2 - PDA (Pile Driving Analyser)}

O sistema de instrumentação P.D.A compõe-se de dois acelerômetros, dois transdutores de deformação e um analisador de cravação de estacas (P.D.A), os quais formam o equipamento de ensaio dinâmico. Os acelerômetros e transdutores de deformação (deflectômetro), vistos na Figura 5.4, foram colocados através de chumbadores, em posições diametralmente opostas. Os sinais coletados de cada medidor, a cada golpe, foram enviados através de cabos para o PDA, visto na Figura 5.5.
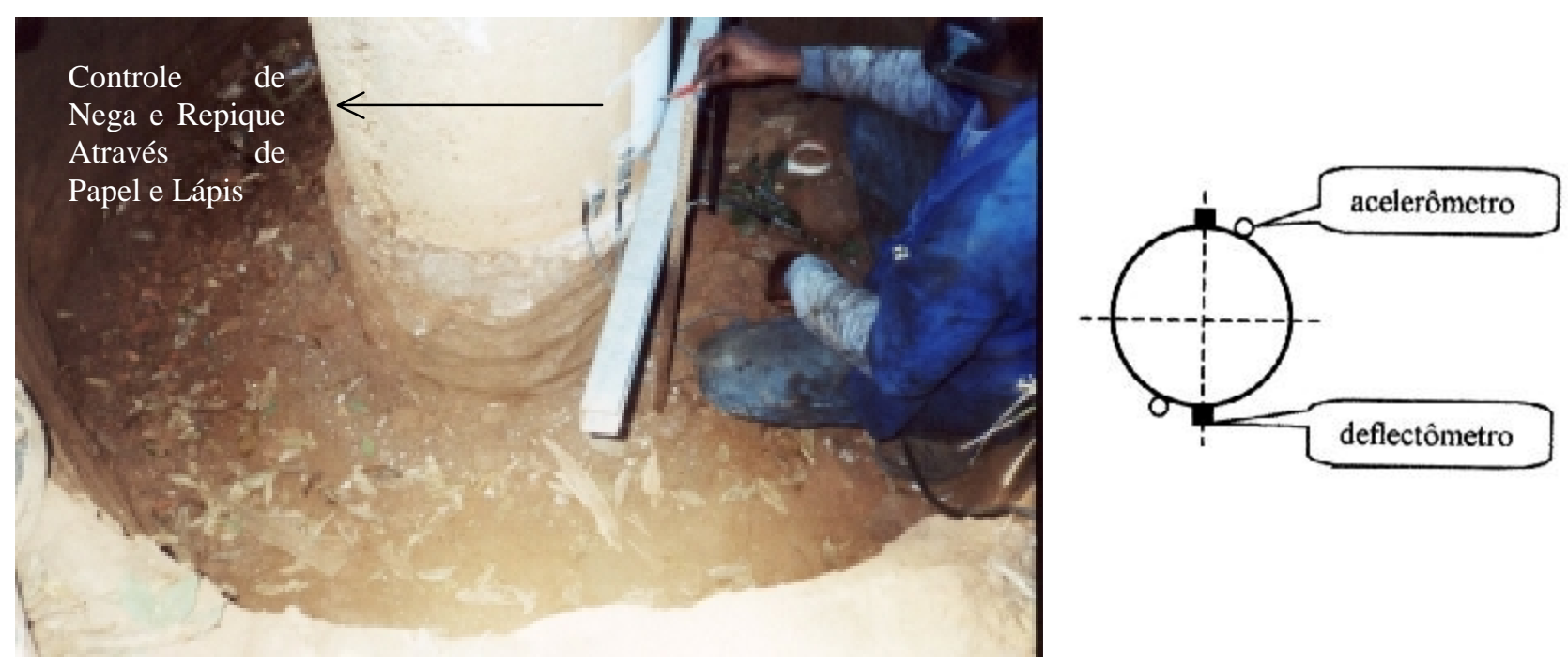

Figura 5.4 - Acelerômetro e Transdutores de Deformação

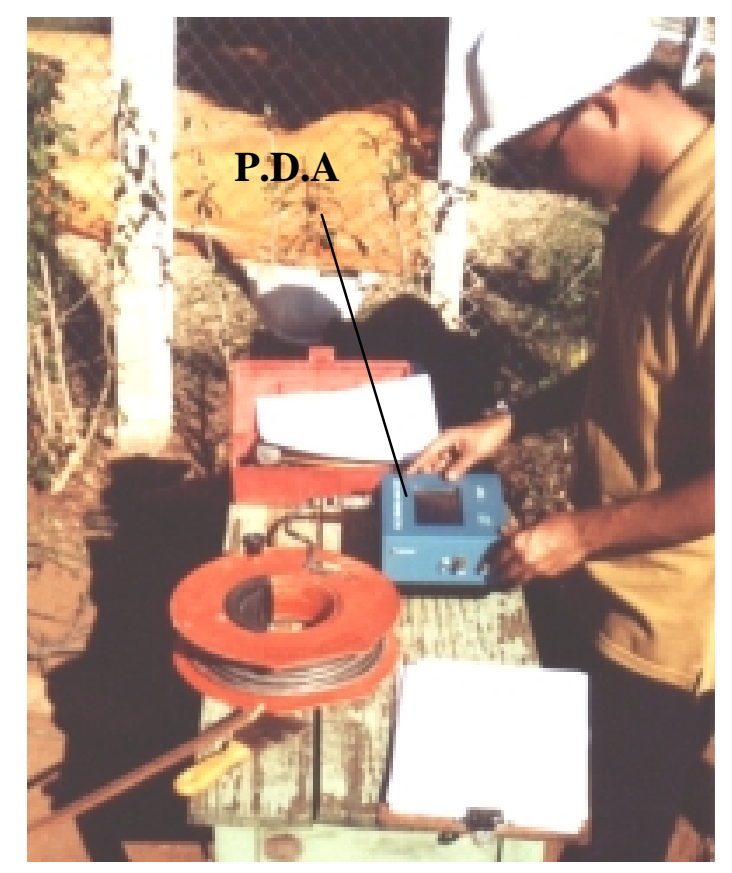

Figura 5.5 - P.D.A (Pile Driving Analizer) 


\section{4 - Estação Total}

Utilizou-se uma estação total Leika, para fazer o levantamento topográfico do Campo Experimental de Fundações da EESC/USP. A Figura 5.6 mostra o equipamento utilizado para o levantamento.

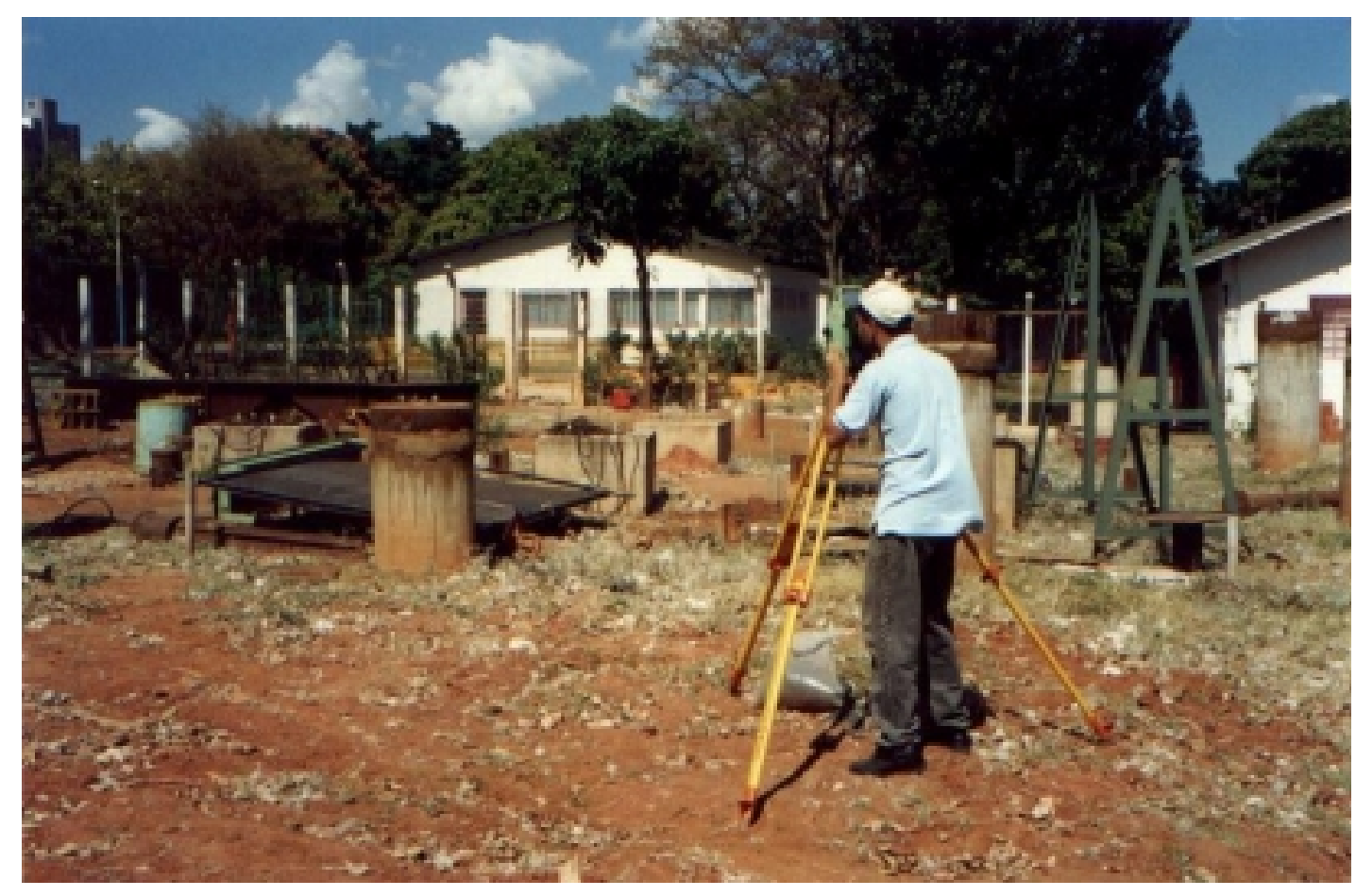

Figura 5.6 - Levantamento Topográfico feito com Estação Total 


\section{1 - Controle de Campo}

\subsection{1 - Propriedade do Concreto dos Tubulões}

Para melhor análise do ensaio dinâmico de energia crescente no programa CAPWAP, determinaram-se algumas propriedades do concreto dos tubulões. O módulo de elasticidade foi determinado através de correlação com a resistência à compressão, medida com o esclerômetro, e o peso específico do concreto foi determinado através do método da parafina (princípio de Arquimedes). Os resultados médios destas propriedades se encontram na Tabela 6.1.

Tabela 6.1 - Propriedade do concreto dos tubulões

\begin{tabular}{c|c|c|c}
\hline Estatística & Resistência à compressão & Módulo de Elasticidade & Peso Específico \\
\hline Valor Médio & $25,5 \mathrm{MPa}$ & $28278 \mathrm{MPa}$ & $23,25 \mathrm{kN} / \mathrm{m}^{3}$ \\
\hline Desvio Padrão & $4,7 \mathrm{MPa}$ & - & $0,62 \mathrm{kN} / \mathrm{m}^{3}$ \\
\hline Coeficiente de Variação & $16 \%$ & - & $3 \%$ \\
\hline
\end{tabular}

\subsection{2 - Estimativa da Sucção Durante os Ensaios}

A partir dos resultados de teor de umidade com a profundidade, obtidos da tradagem do terreno e dos resultados obtidos em laboratório por MACHADO (1998), fez-se a estimativa da pressão de sucção, no dia 05/06/2001, para representar a variação da pressão de suç̧ão, com a profundidade nos ensaios de carregamento dinâmico de energia crescente não-inundados, e outra no dia 06/06/2001, nos ensaios pré-inundados. Os resultados da variação da pressão de sucção estão apresentados na Figura 6.1 e 6.2. 


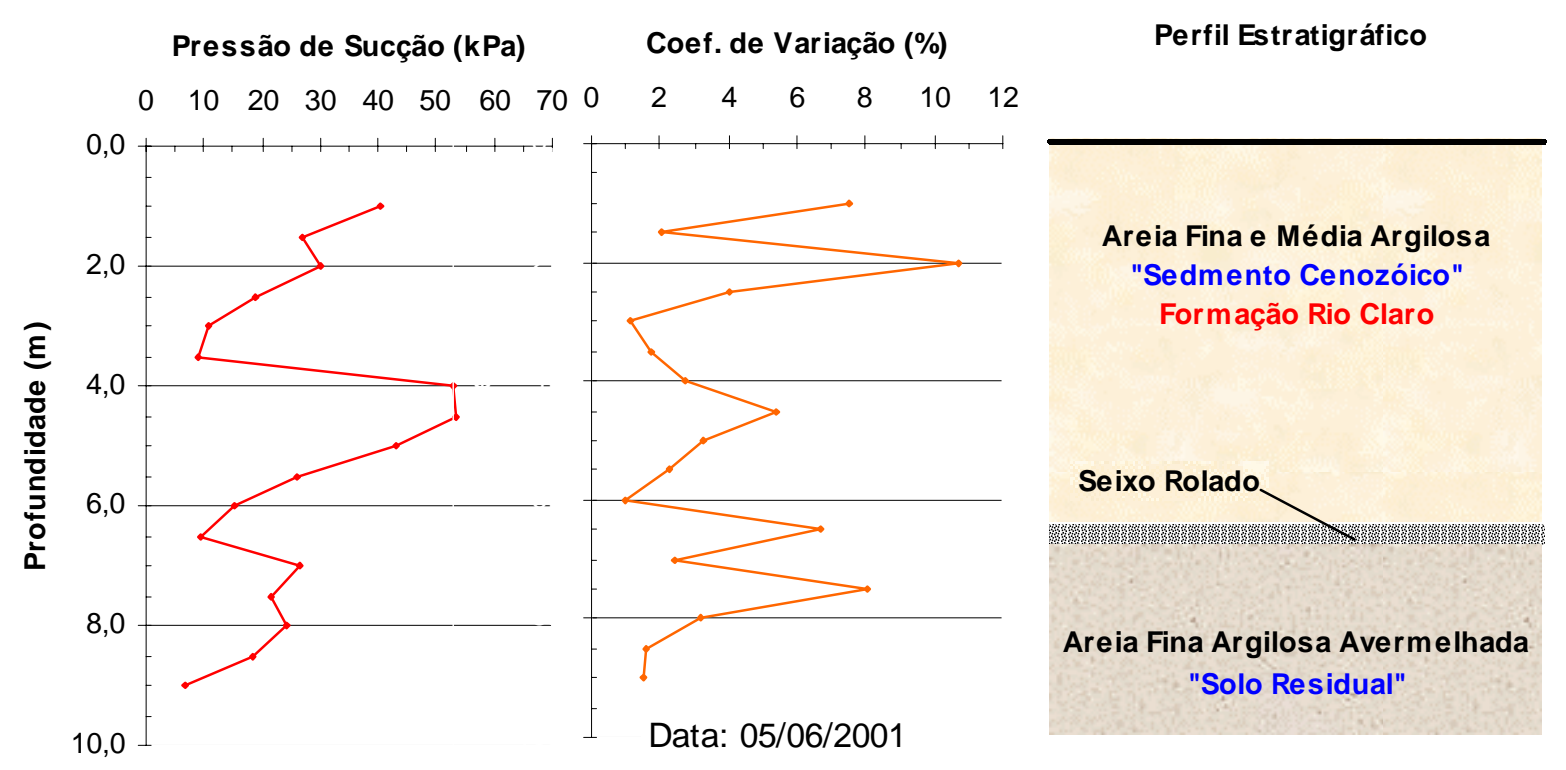

Figura 6.1 - Variação da pressão de sucção com a profundidade, terreno não-inundado

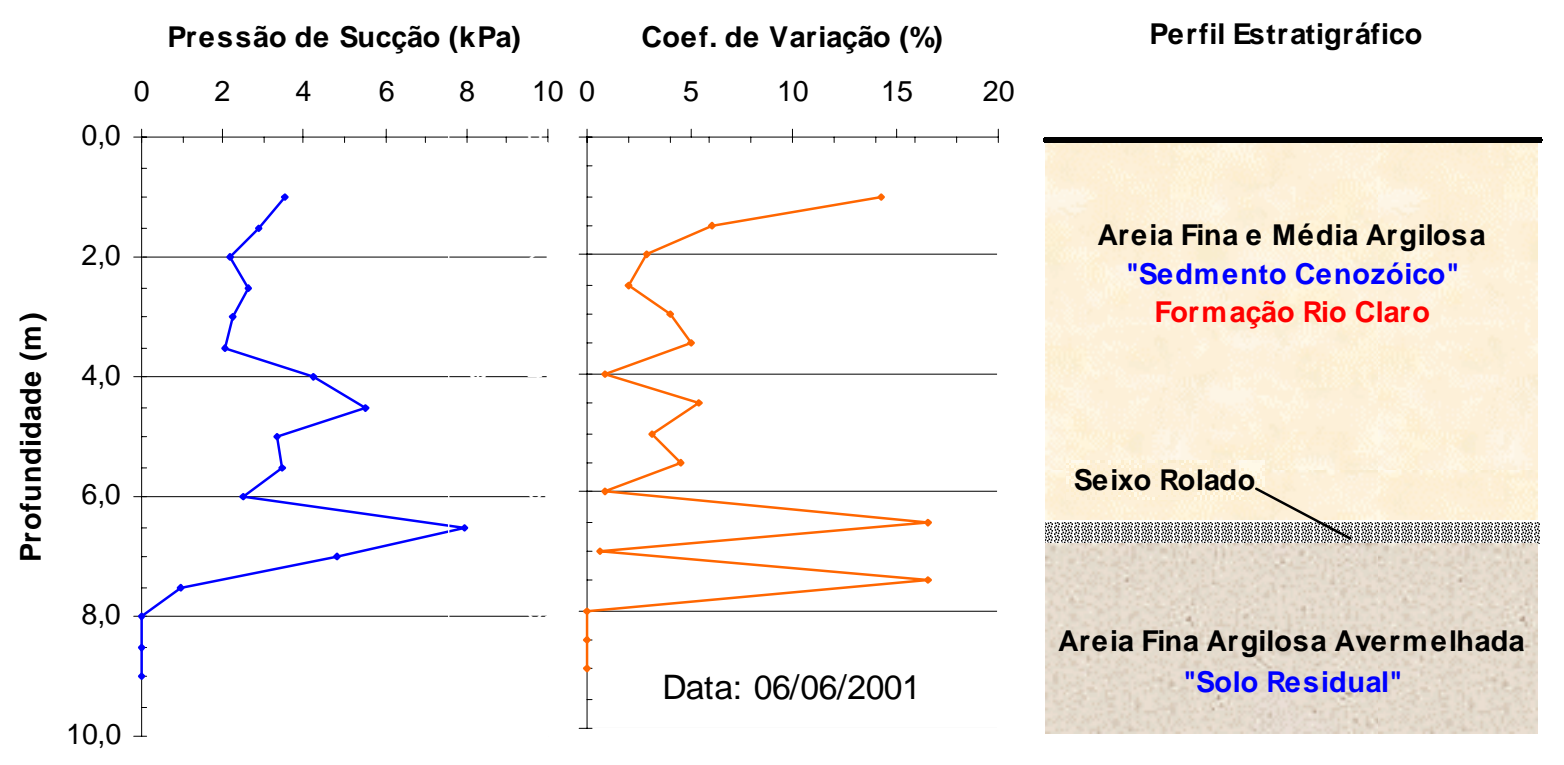

Figura 6.2 - Variação da pressão de sucção com a profundidade, terreno pré-inundado 


\subsection{3 - Medida de Deslocamentos}

Registrou-se, com PDA (Pile Driving Analyser), o deslocamento "DMX" do topo dos tubulões durante todos os golpes de energia crescente, em todos os ensaios. Esses deslocamentos compostos de duas parcelas - uma elástica " $K$ " chamada de repique e outra permanente "S" chamada de nega, também foram registrados através de papel e lápis, fixados no topo, Anexo 01. As Figuras 6.3 a 6.7 mostram que há uma boa correlação entre as medidas de deslocamento feitas através do PDA (DMX) e as feitas com papel e lápis (D).

TE01 - 1ำ Ensaio - Não-inundado

$\operatorname{DMX}(\mathrm{mm})$

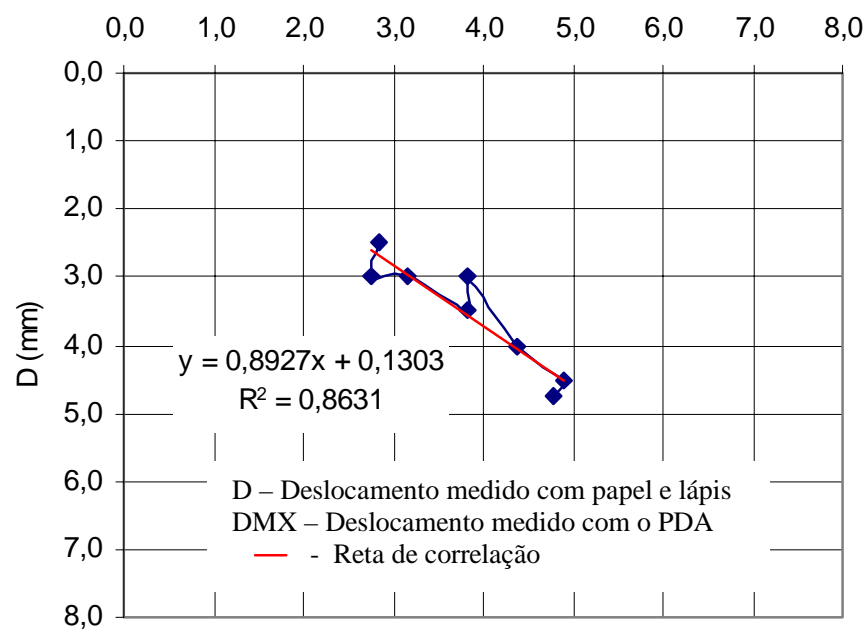

TE01 - 2º́nsaio - Pré-inundado $\mathrm{DMX}(\mathrm{mm})$

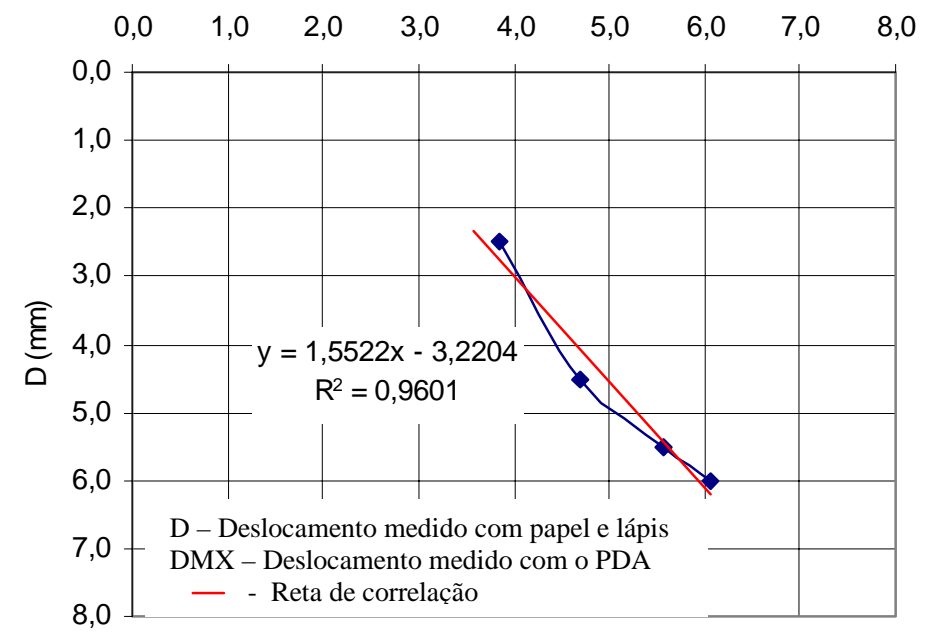

Figura 6.3 - Comparação entre medida de deslocamento do topo através do PDA e do papel e lápis para o TE 01

TE02 - 1ํ Ensaio - Não-inundado

$\operatorname{DMX}(\mathrm{mm})$

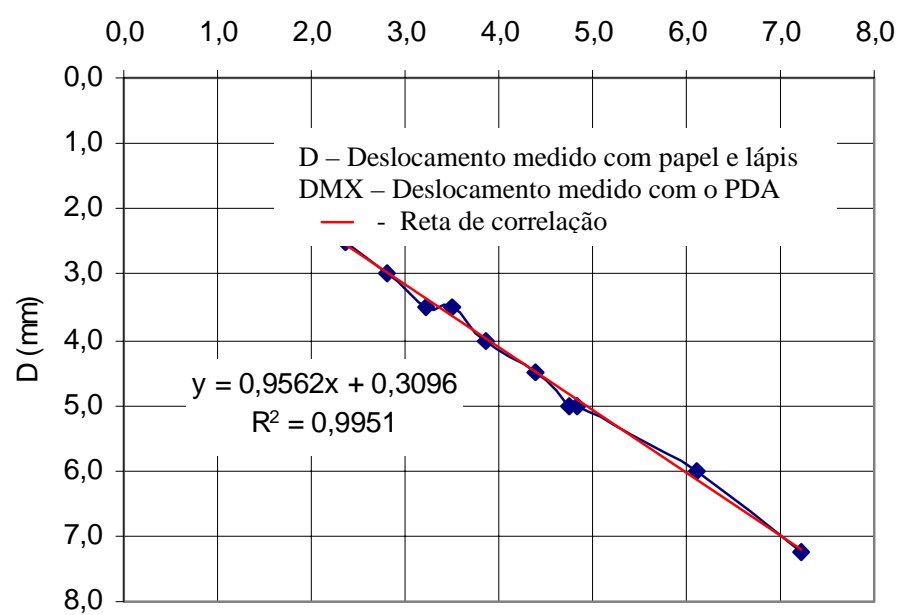

TE02 - 2o Ensaio - Não-inundado

$\operatorname{DMX}(\mathrm{mm})$

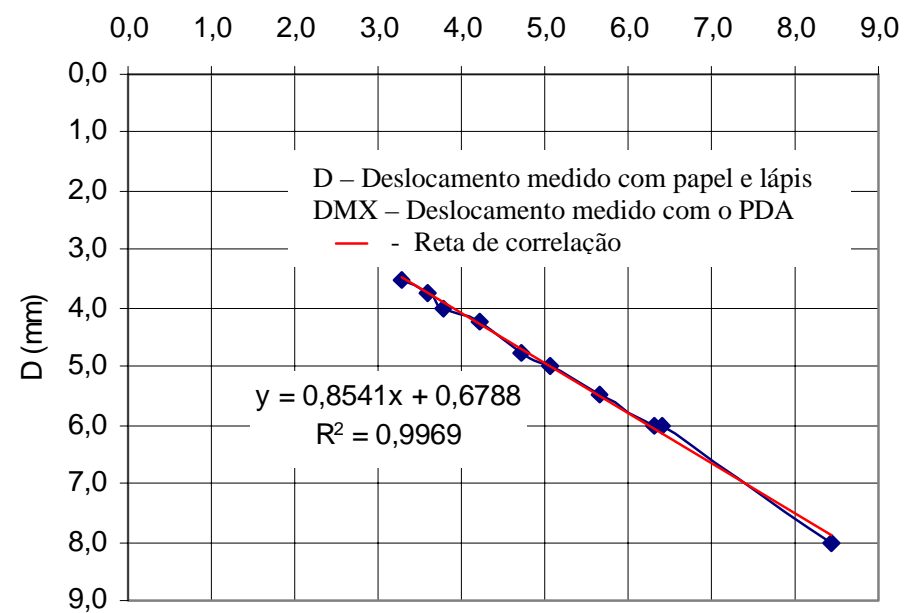

Figura 6.4 - Comparação entre medida de deslocamento do topo através do PDA e do papel e lápis para o TE 02 
TE03 - 1ํ Ensaio - Não-inundado

$\operatorname{DMX}(\mathrm{mm})$

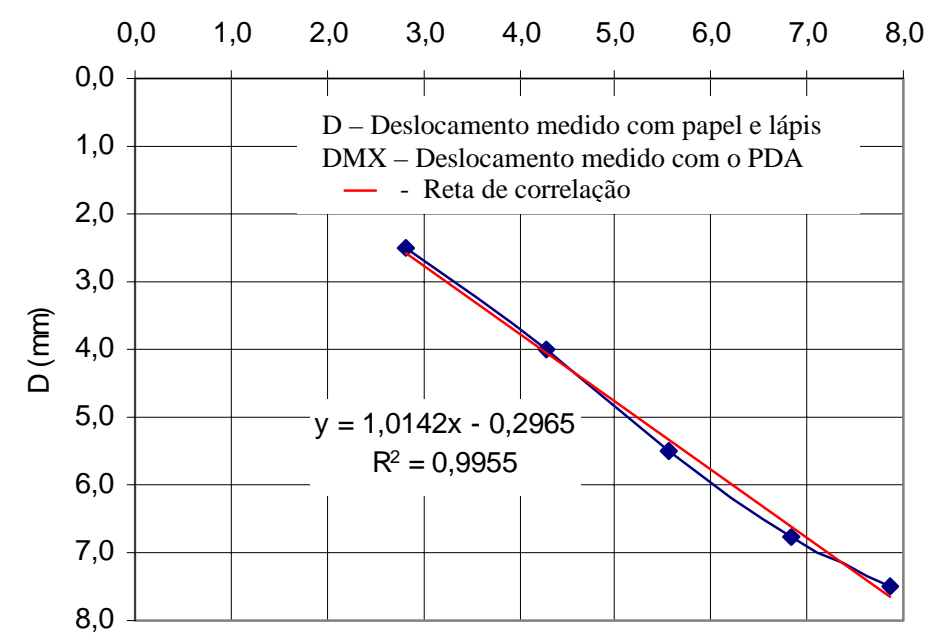

TE03 - 2ํ Ensaio - Não-inundado

$\mathrm{DMX}(\mathrm{mm})$

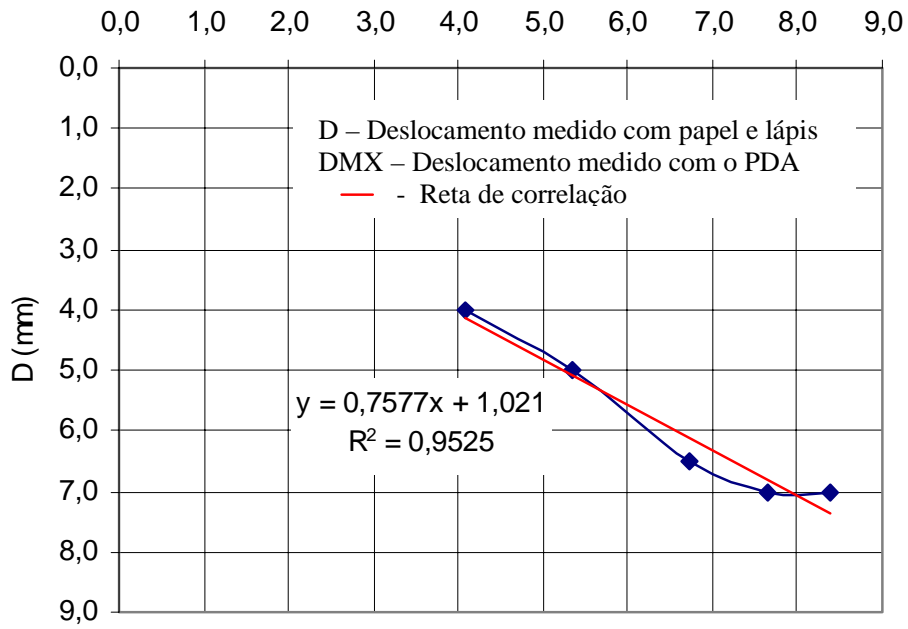

Figura 6.5 - Comparação entre medida de deslocamento do topo através do PDA e do papel e lápis para o TE 03

TE04 - 1 Ensaio - Não-Inundado $\mathrm{DMX}(\mathrm{mm})$

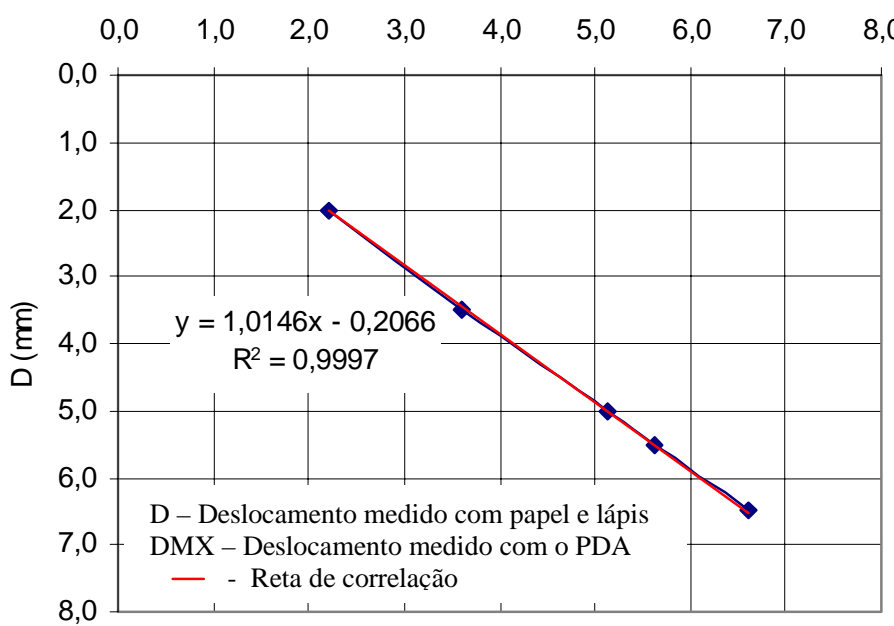

TE04 - 20 Ensaio - Não-inundado

$\operatorname{DMX}(\mathrm{mm})$

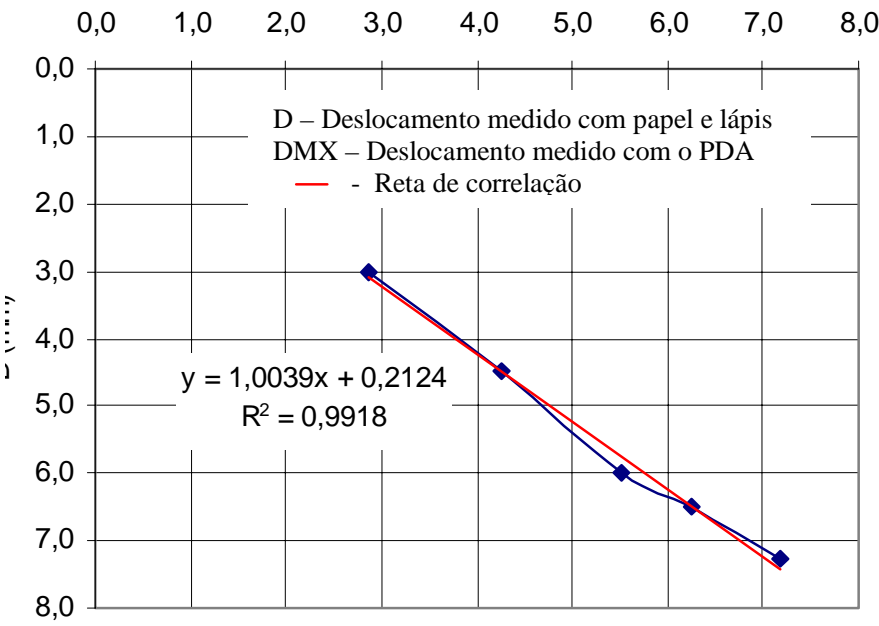

Figura 6.6 - Comparação entre medida de deslocamento do topo através do PDA e do papel e lápis para o TE 04 $1^{\circ}$ e $2^{\circ}$ Ensaios. 
TEO4 - 3ํㅡs Enaio - Não-inundado

$\operatorname{DMX}(\mathrm{mm})$

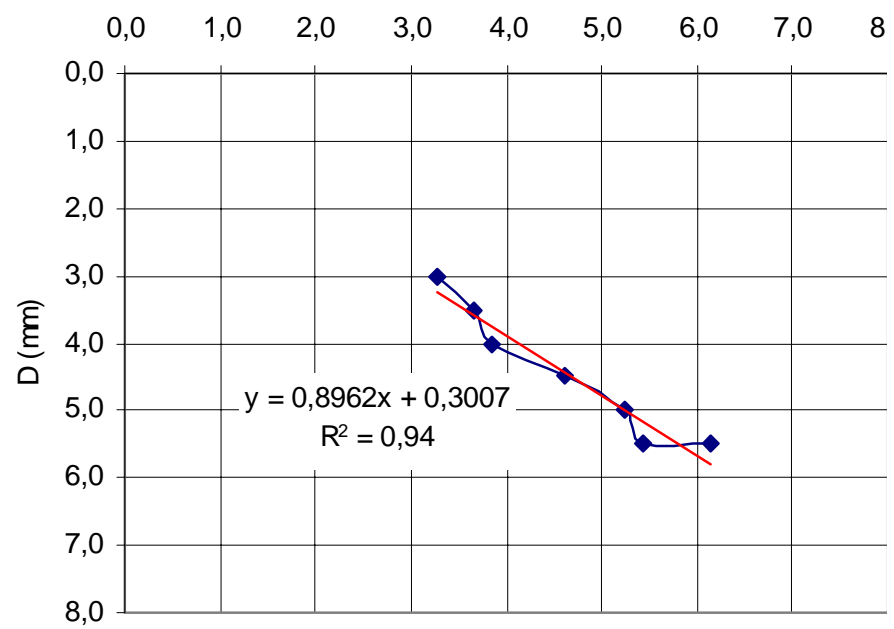

TE04 - 4ํㅡㅅㅗ. - Pré-Inundado

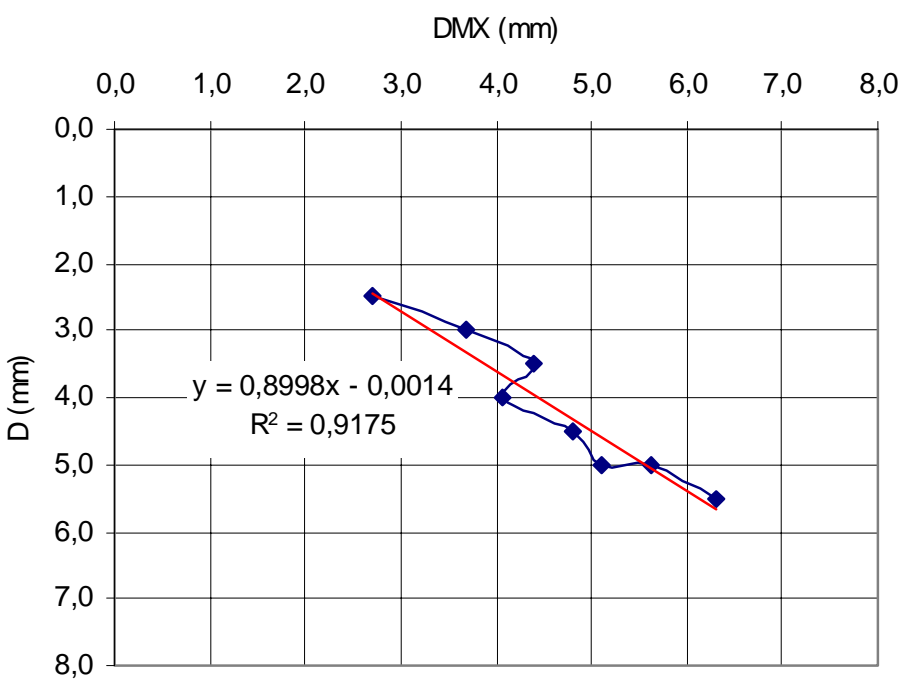

Figura 6.7 - Comparação entre medida de deslocamento do topo através do PDA e do papel e lápis para o TE $043^{\circ}$ e $4^{\circ}$ Ensaios

\section{2 - Resultados da Prova de Carga Dinâmica de Energia Crescente}

O ensaio de carregamento dinâmico de energia crescente nos tubulões consiste em aplicar impactos de energia crescente na cabeça do tubulões. A utilização de instrumentação dinâmica, $P D A$, durante este procedimento, permite a determinação da curva de resistência mobilizada x deslocamento dinâmico, analisada pelo método CASE. As curvas apresentadas nas Figuras 6.8 à 6.11 mostram a resistência total mobilizada analisadas pelo método CASE, considerando a constante de amortecimento igual a zero, ou seja, medidas do ensaio sem interpretação, para se obter resposta estática. 


\section{TE01}

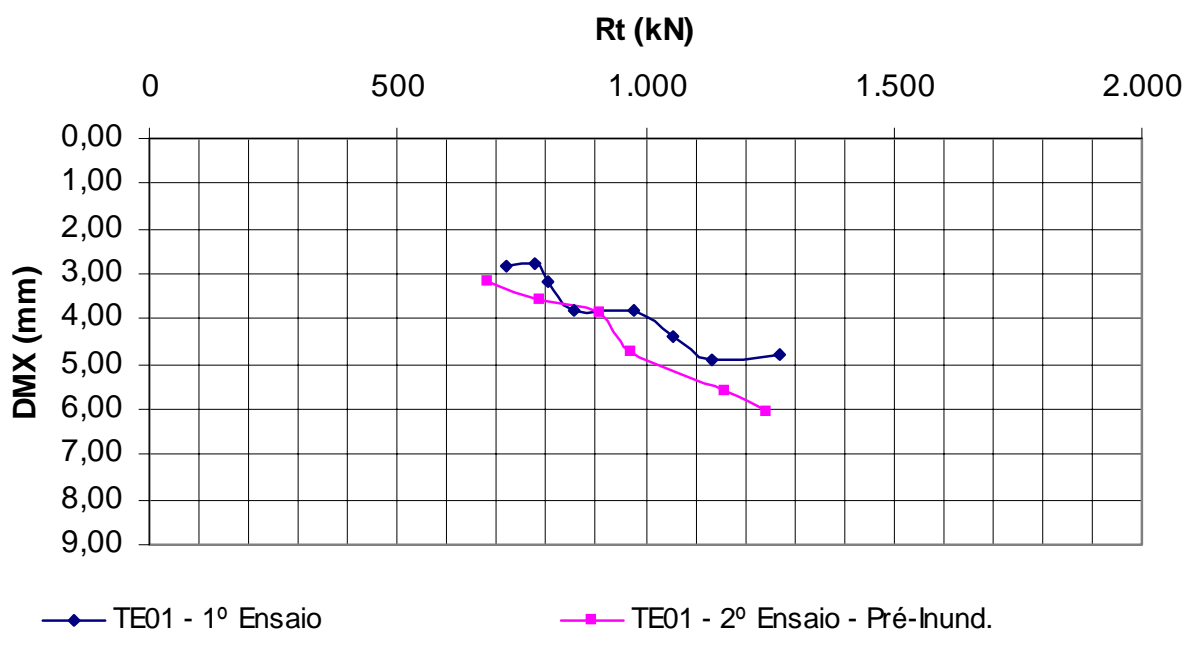

Figura 6.8 - Resistência total x deslocamento dinâmico para TE01

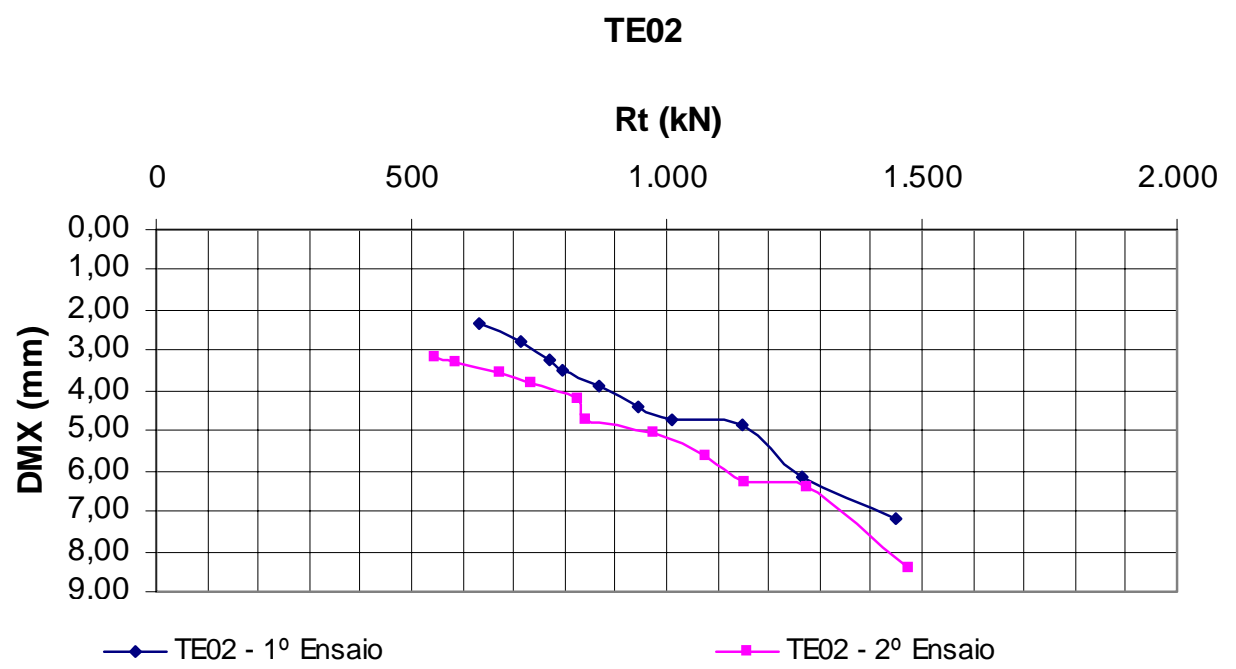

Figura 6.9 - Resistência total x deslocamento dinâmico para TE02 


\section{TE03}

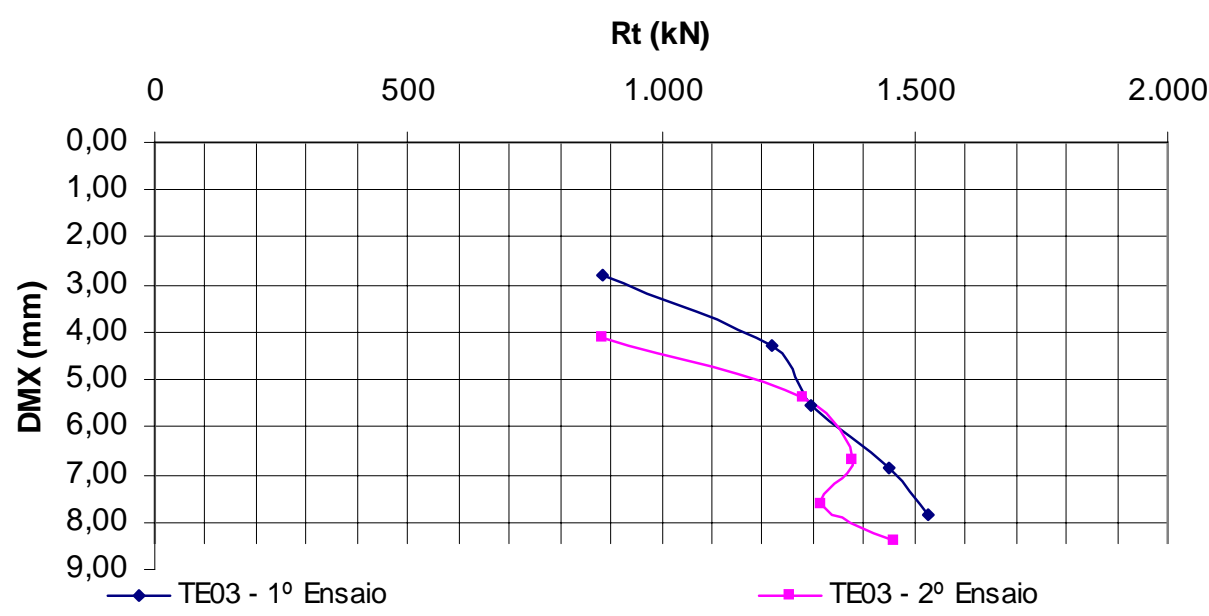

Figura 6.10 - Resistência total x deslocamento dinâmico para TE03

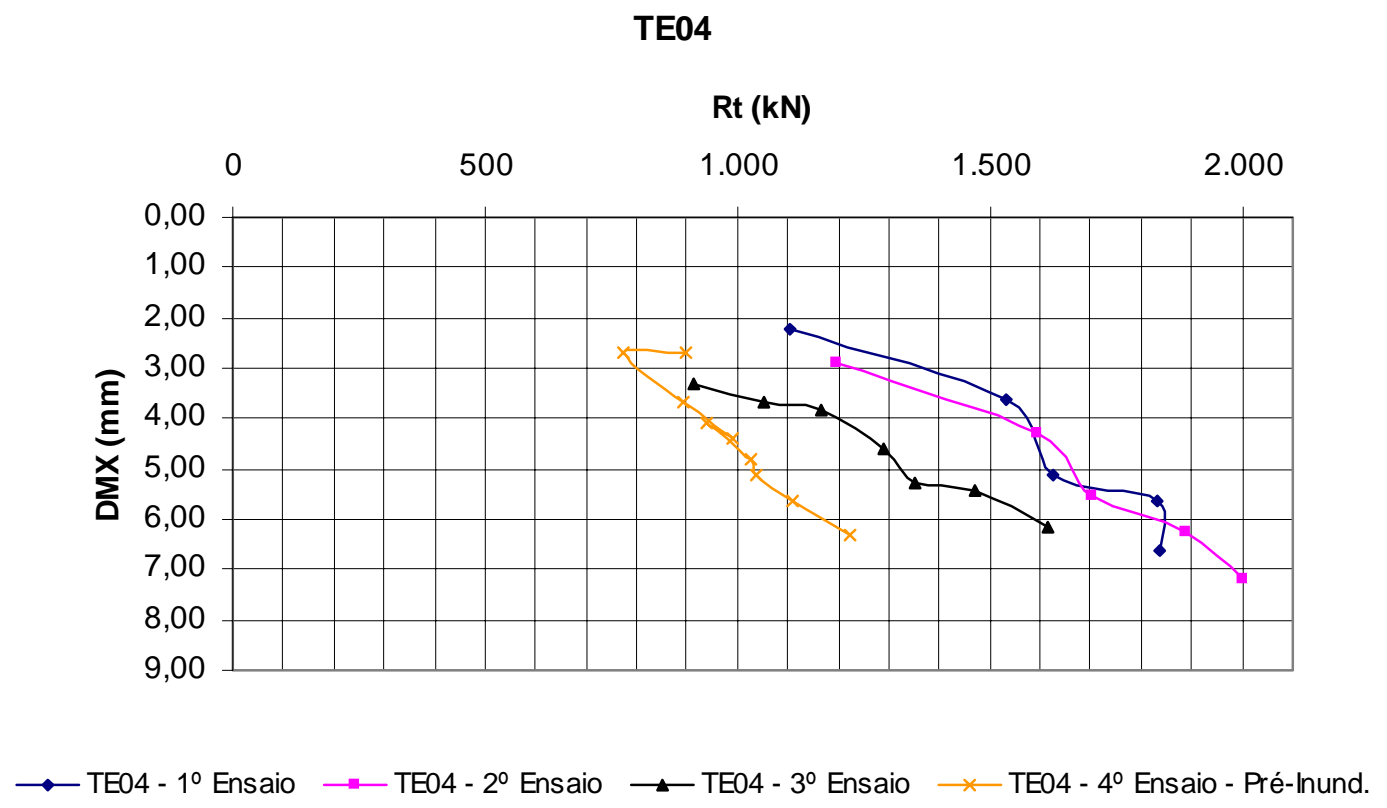

Figura 6.11 - Resistência total x deslocamento dinâmico para TE04 


\section{CAPÍTULO 7 - ANÁLISE DOS RESULTADOS}

Através dos sinais do $P D A$, os quais foram capturados pelo programa $C A P W A P$, e da modelagem do elemento estrutural de fundação, realizaram-se as análises do ensaio dinâmico.

\section{1 - Resultados dos Ensaios Estáticos e Dinâmicos}

As Figuras 7.1 à 7.4 mostram os resultados dos sucessivos carregamentos e descarregamentos nos ensaios estáticos e dinâmicos em termos de curva carga-recalque. A abreviação PCE significa prova de carga estática, e PCDEC, prova de carga dinâmica de energia crescente.

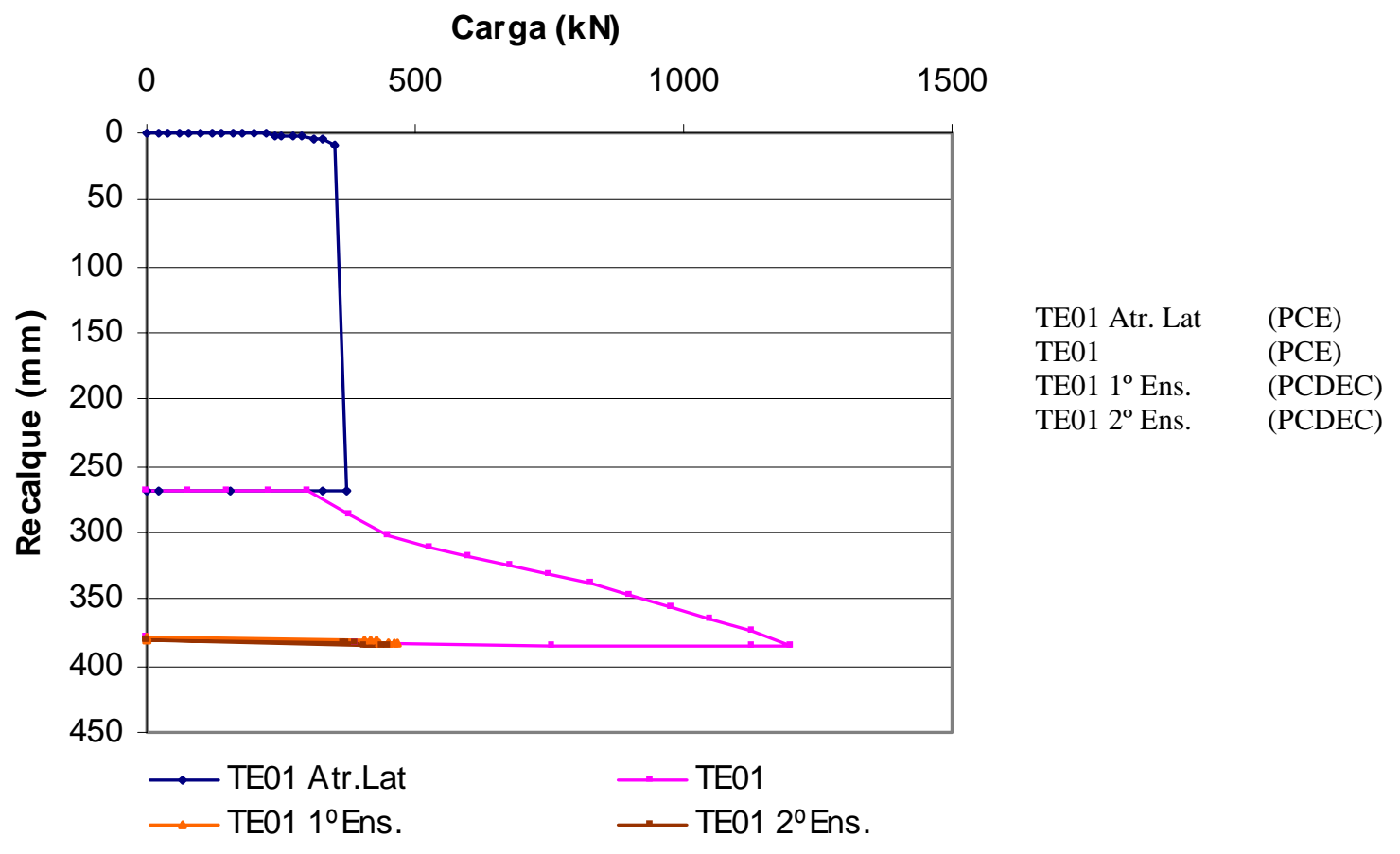

Figura 7.1 - Curva carga-recalque do tubulão TE01 


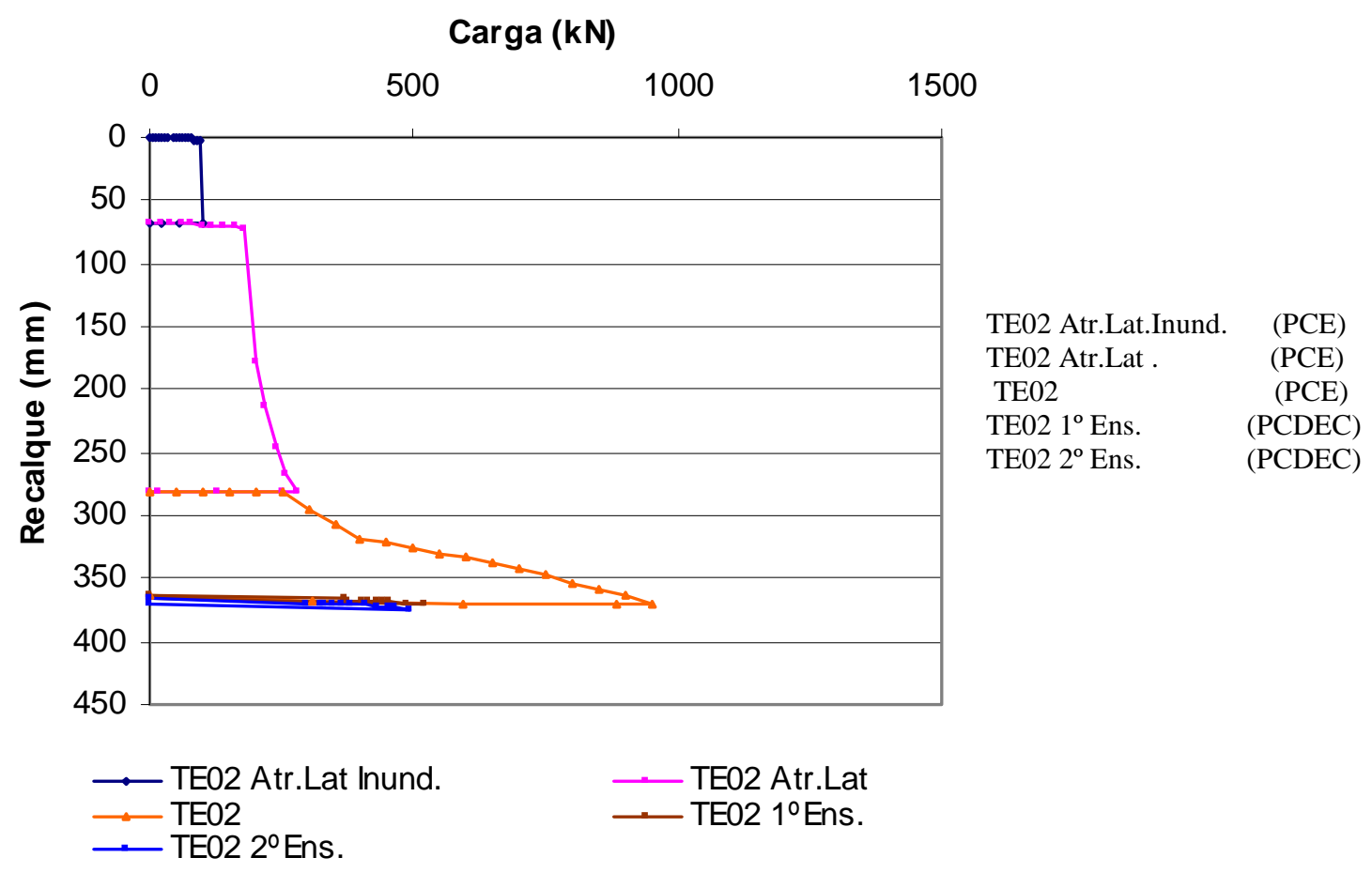

Figura 7.2 - Curva carga-recalque do tubulão TE02

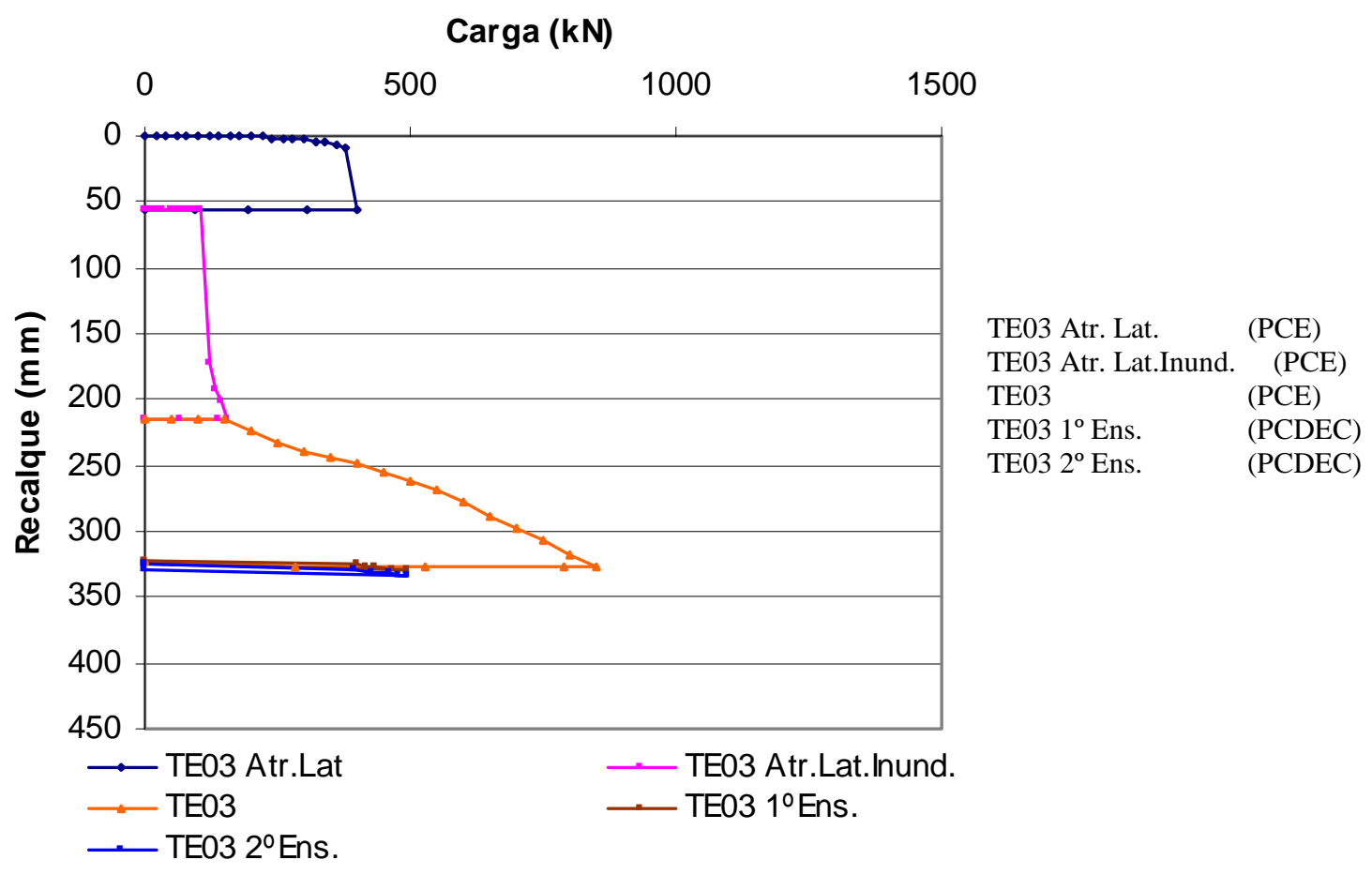

Figura 7.3 - Curva carga-recalque do tubulão TE03 


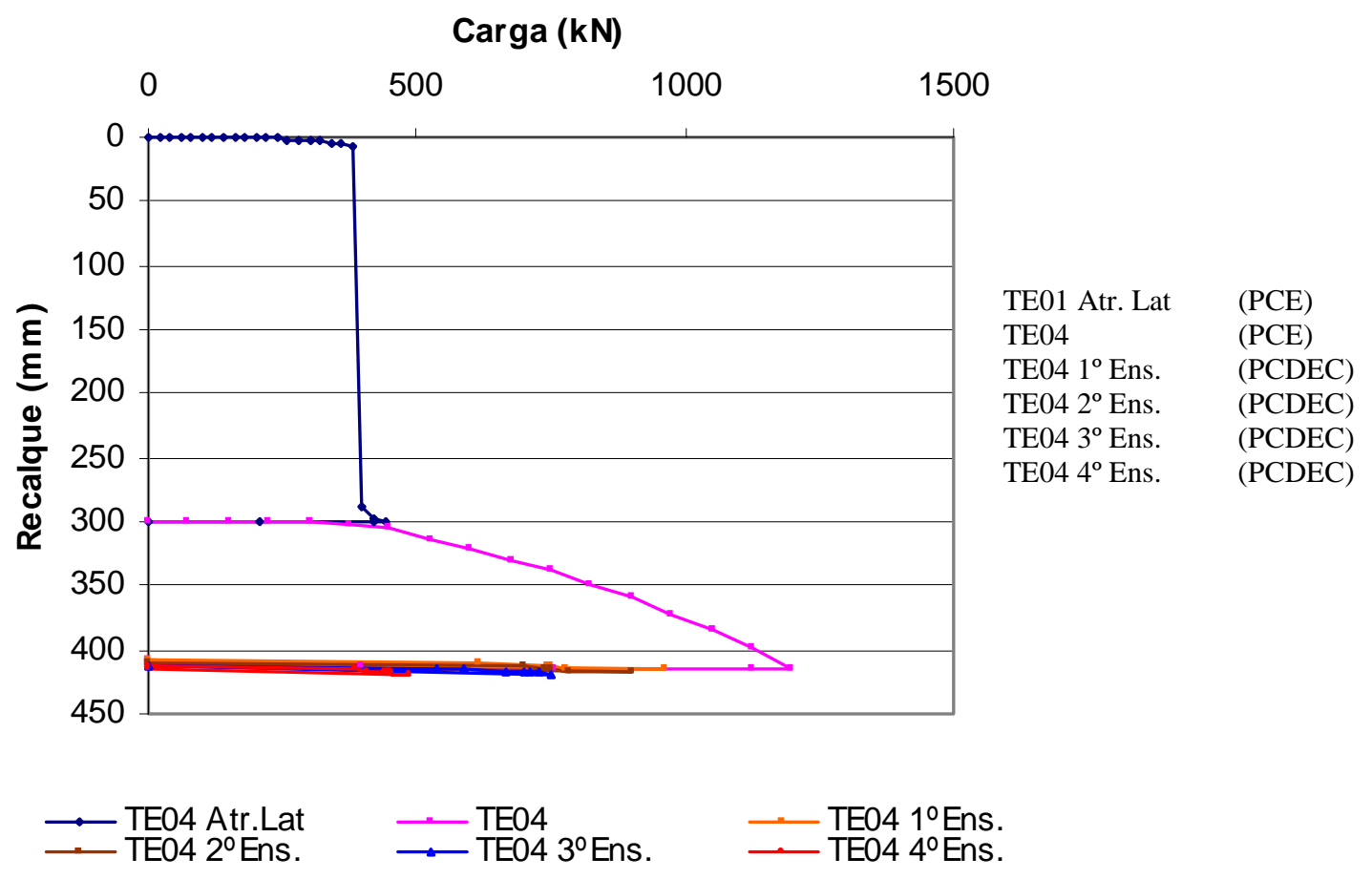

Figura 7.4 - Curva carga-recalque do tubulão TE04

Analisando-se as curvas das provas de carga estática realizadas nos quatros tubulões, observa-se que após a ruptura nítida do atrito lateral, observa-se um trecho linear, em que o recalque aumenta com o crescimento das cargas. Este comportamento pode ser comparado com a curva de adensamento do solo, em que acontece a recompressão do solo até a pressão de pré-adensamento e, depois desta, inicia-se um novo trecho, caracterizado por uma reta virgem, em que há um compressão do solo, devido à variação de pressão (pressão aplicada menos a pressão de pré-adensamento).

A pressão de pré-adensamento é a máxima pressão suportada por um solo desde a sua formação. Após a prova de carga estática, a máxima pressão aplicada no solo abaixo da base do tubulão, passou a ser a pressão de pré-adensamento.

As provas de carga dinâmica as quais sucederam as de carga estática mostram que as resistências mobilizadas encontram-se no trecho de recompressão da curva carga-recalque. A Tabela 7.1 mostra que as tensões máximas aplicadas no solo abaixo das bases dos tubulões nos ensaios dinâmicos são menores que nos estáticos. 
Tabela 7.1 - Tensões Máximas Aplicadas no Solo Abaixo das Bases dos Tubulões

\begin{tabular}{|c|c|c|}
\hline \multirow{2}{*}{ TUBUL ÕES } & \multicolumn{2}{|c|}{ MÁXIMA TENSÃO APLICADA } \\
\cline { 2 - 3 } & $\begin{array}{c}\text { PROVA DE CARGA } \\
\text { ESTÁTICA }\end{array}$ & $\begin{array}{c}\text { PROVA DE CARGA } \\
\text { DINÂMICA }\end{array}$ \\
\hline TE01 & $679 \mathrm{kPa}$ & $265 \mathrm{kPa}$ \\
\hline TE02 & $538 \mathrm{kPa}$ & $294 \mathrm{kPa}$ \\
\hline TE03 & $481 \mathrm{kPa}$ & $281 \mathrm{kPa}$ \\
\hline TE04 & $679 \mathrm{kPa}$ & $544 \mathrm{kPa}$ \\
\hline
\end{tabular}

A Tabela 7.2 mostra uma análise do último golpe de todas as provas de carga dinâmica, considerando a resistência total mobilizada e as parcelas de resistência por atrito lateral e de ponta, bem como a pressão de sucção média ao longo da profundidade. 
Tabela 7.2 - Análise do último golpe da prova de carga dinâmica de energia crescente

\begin{tabular}{|c|c|c|c|c|c|c|c|}
\hline \multicolumn{8}{|c|}{ TE01 - 1음aio (Não Inundado) } \\
\hline $\begin{array}{c}\mathrm{H} \\
\text { (Campo) } \\
(\mathrm{m})\end{array}$ & $\begin{array}{c}\text { EMX } \\
\text { (PDA) } \\
(\mathrm{kJ}) \\
\end{array}$ & $\begin{array}{c}\mathbf{R}_{\mathrm{L}} \\
\text { (Capwap) } \\
(\mathrm{kN})\end{array}$ & $\begin{array}{c}\mathbf{R}_{\mathrm{L}} \\
(\%)\end{array}$ & $\begin{array}{c}\mathbf{R}_{\mathrm{P}} \\
\text { (Capwap) } \\
(\mathrm{kN})\end{array}$ & $\begin{array}{c}\mathbf{R}_{\mathbf{P}} \\
\text { (\%) }\end{array}$ & $\begin{array}{c}\mathbf{R}_{\mathrm{T}} \\
(\text { Capwap) } \\
(\mathrm{kN})\end{array}$ & $\begin{array}{c}\text { Pressão de } \\
\text { Sucção } \\
\text { (kPa) }\end{array}$ \\
\hline 0,60 & 3,6 & 172,7 & $37 \%$ & 295,8 & $63 \%$ & 468,5 & 24,5 \\
\hline \multicolumn{8}{|c|}{ TE01 - 2 Ensaio (Pré-Inundado) } \\
\hline $\begin{array}{c}\mathrm{H} \\
\text { (Campo) } \\
(\mathrm{m})\end{array}$ & $\begin{array}{c}\text { EMX } \\
\text { (PDA) } \\
\text { (kJ) }\end{array}$ & $\begin{array}{c}R_{\mathrm{L}} \\
\text { (Capwap) } \\
(\mathrm{kN})\end{array}$ & $\begin{array}{c}\mathbf{R}_{\mathrm{L}} \\
(\%)\end{array}$ & $\begin{array}{c}\mathbf{R}_{\mathrm{P}} \\
(\text { Capwap) } \\
(\mathrm{kN})\end{array}$ & $\begin{array}{c}\mathbf{R}_{\mathbf{P}} \\
\text { (\%) }\end{array}$ & $\begin{array}{c}\mathbf{R}_{\mathrm{T}} \\
(\text { Capwap) } \\
(\mathbf{k N})\end{array}$ & $\begin{array}{c}\text { Pressão de } \\
\text { Sucção } \\
\text { (kPa) }\end{array}$ \\
\hline 0,60 & 3,8 & 101,4 & $23 \%$ & 346,4 & $77 \%$ & 447,8 & 2,8 \\
\hline \multicolumn{8}{|c|}{ TE02 - 1ํㅡsaio (Não Inundado) } \\
\hline $\begin{array}{c}\mathrm{H} \\
\text { (Campo) } \\
(\mathrm{m})\end{array}$ & $\begin{array}{c}\text { EMX } \\
\text { (PDA) } \\
(\mathrm{kJ})\end{array}$ & $\begin{array}{c}\mathrm{R}_{\mathrm{L}} \\
\text { (Capwap) } \\
(\mathrm{kN})\end{array}$ & $\begin{array}{c}\mathbf{R}_{\mathrm{L}} \\
(\%)\end{array}$ & $\begin{array}{c}\mathbf{R}_{\mathrm{P}} \\
(\text { Capwap) } \\
(\mathrm{kN})\end{array}$ & $\begin{array}{c}\mathbf{R}_{\mathbf{P}} \\
(\%)\end{array}$ & $\begin{array}{c}\mathbf{R}_{\mathrm{T}} \\
(\text { Capwap) } \\
(\mathbf{k N})\end{array}$ & $\begin{array}{c}\text { Pressão de } \\
\text { Sucção } \\
\text { (kPa) }\end{array}$ \\
\hline 1,00 & 6,8 & 210,8 & $41 \%$ & 308,1 & $59 \%$ & 518,9 & 24,5 \\
\hline \multicolumn{8}{|c|}{ TE02 - 2 Ensaio (Não Inundado) } \\
\hline $\begin{array}{c}\mathrm{H} \\
\text { (Campo) } \\
(\mathrm{m})\end{array}$ & $\begin{array}{c}\text { EMX } \\
\text { (PDA) } \\
\text { (kJ) }\end{array}$ & $\begin{array}{c}\mathbf{R}_{\mathrm{L}} \\
\text { (Capwap) } \\
(\mathrm{kN})\end{array}$ & $\begin{array}{c}\mathbf{R}_{\mathrm{L}} \\
(\%)\end{array}$ & $\begin{array}{c}\mathbf{R}_{\mathrm{P}} \\
(\text { Capwap) } \\
(\mathrm{kN})\end{array}$ & $\begin{array}{c}\mathbf{R}_{\mathbf{P}} \\
\text { (\%) }\end{array}$ & $\begin{array}{c}\mathbf{R}_{\mathrm{T}} \\
(\text { Capwap) } \\
(\mathrm{kN})\end{array}$ & $\begin{array}{c}\text { Pressão de } \\
\text { Sucção } \\
\text { (kPa) }\end{array}$ \\
\hline 1,00 & 7,0 & 19,3 & $4 \%$ & 475,7 & $96 \%$ & 495,0 & 24,5 \\
\hline \multicolumn{8}{|c|}{ TE03 - 1ํEsaio (Não Inundado) } \\
\hline $\begin{array}{c}\mathrm{H} \\
\text { (Campo) } \\
(\mathrm{m})\end{array}$ & $\begin{array}{c}\text { EMX } \\
\text { (PDA) } \\
(\mathrm{kJ})\end{array}$ & $\begin{array}{c}R_{\mathrm{L}} \\
\text { (Capwap) } \\
(\mathrm{kN})\end{array}$ & $\begin{array}{c}\mathbf{R}_{\mathrm{L}} \\
(\%)\end{array}$ & $\begin{array}{c}\mathbf{R}_{\mathrm{P}} \\
(\text { Capwap) } \\
(\mathrm{kN})\end{array}$ & $\begin{array}{c}\mathbf{R}_{\mathrm{P}} \\
(\%)\end{array}$ & $\begin{array}{c}\mathbf{R}_{\mathrm{T}} \\
(\text { Capwap) } \\
(\mathbf{k N})\end{array}$ & $\begin{array}{c}\text { Pressão de } \\
\text { Sucção } \\
\text { (kPa) }\end{array}$ \\
\hline 1,00 & 4,1 & 75,5 & $15 \%$ & 419,3 & $85 \%$ & 494,8 & 24,5 \\
\hline \multicolumn{8}{|c|}{ TE03 - 2 Ensaio (Não Inundado) } \\
\hline $\begin{array}{c}\mathrm{H} \\
\text { (Campo) } \\
(\mathrm{m})\end{array}$ & $\begin{array}{c}\text { EMX } \\
\text { (PDA) } \\
(\mathrm{kJ})\end{array}$ & $\begin{array}{c}\mathbf{R}_{\mathrm{L}} \\
\text { (Capwap) } \\
(\mathrm{kN})\end{array}$ & $\begin{array}{c}\mathbf{R}_{\mathrm{L}} \\
(\%)\end{array}$ & $\begin{array}{c}\mathbf{R}_{\mathrm{P}} \\
\text { (Capwap) } \\
(\mathrm{kN})\end{array}$ & $\begin{array}{c}\mathbf{R}_{\mathbf{P}} \\
(\%)\end{array}$ & $\begin{array}{c}\mathbf{R}_{\mathrm{T}} \\
\text { (Capwap) } \\
(\mathbf{k N})\end{array}$ & $\begin{array}{c}\text { Pressão de } \\
\text { Sucção } \\
\text { (kPa) }\end{array}$ \\
\hline 1,00 & 4,3 & 87,0 & $18 \%$ & 409,6 & $82 \%$ & 496,6 & 24,5 \\
\hline \multicolumn{8}{|c|}{ TE04 - 1 Ensaio (Não Inundado) } \\
\hline $\begin{array}{c}\mathrm{H} \\
\text { (Campo) } \\
(\mathrm{m})\end{array}$ & $\begin{array}{c}\text { EMX } \\
\text { (PDA) } \\
\text { (kJ) }\end{array}$ & $\begin{array}{c}R_{\mathrm{L}} \\
\text { (Capwap) } \\
(\mathrm{kN})\end{array}$ & $\begin{array}{c}\mathbf{R}_{\mathrm{L}} \\
(\%)\end{array}$ & $\begin{array}{c}\mathbf{R}_{\mathrm{P}} \\
(\text { Capwap) } \\
(\mathrm{kN})\end{array}$ & $\begin{array}{c}\mathbf{R}_{\mathbf{P}} \\
(\%)\end{array}$ & $\begin{array}{c}\mathbf{R}_{\mathrm{T}} \\
(\text { Capwap) } \\
(\mathrm{kN})\end{array}$ & $\begin{array}{c}\text { Pressão de } \\
\text { Sucção } \\
\text { (kPa) }\end{array}$ \\
\hline 1,00 & 8,0 & 274,2 & $29 \%$ & 687,8 & $71 \%$ & 962,0 & 24,5 \\
\hline \multicolumn{8}{|c|}{ TE04 - 2 Ensaio (Não Inundado) } \\
\hline $\begin{array}{c}\mathrm{H} \\
\text { (Campo) } \\
(\mathrm{m})\end{array}$ & $\begin{array}{c}\text { EMX } \\
\text { (PDA) } \\
\text { (kJ) }\end{array}$ & $\begin{array}{c}\mathbf{R}_{\mathrm{L}} \\
\text { (Capwap) } \\
(\mathrm{kN})\end{array}$ & $\begin{array}{l}\mathbf{R}_{\mathrm{L}} \\
(\%)\end{array}$ & $\begin{array}{c}\mathbf{R}_{\mathrm{P}} \\
(\text { Capwap) } \\
(\mathrm{kN})\end{array}$ & $\begin{array}{c}\mathbf{R}_{\mathbf{P}} \\
(\%)\end{array}$ & $\begin{array}{c}\mathbf{R}_{\mathrm{T}} \\
(\text { Capwap) } \\
(\mathbf{k N})\end{array}$ & $\begin{array}{c}\text { Pressão de } \\
\text { Sucção } \\
\text { (kPa) }\end{array}$ \\
\hline 1,00 & 9,5 & 361,8 & $40 \%$ & 538,4 & $60 \%$ & 900,2 & 24,5 \\
\hline \multicolumn{8}{|c|}{ TE04 - 3 Ensaio (Não Inundado) } \\
\hline $\begin{array}{c}\mathrm{H} \\
\text { (Campo) } \\
(\mathrm{m})\end{array}$ & $\begin{array}{c}\text { EMX } \\
\text { (PDA) } \\
\text { (kJ) }\end{array}$ & $\begin{array}{c}R_{\mathrm{L}} \\
\text { (Capwap) } \\
(\mathrm{kN})\end{array}$ & $\begin{array}{c}\mathbf{R}_{\mathrm{L}} \\
(\%)\end{array}$ & $\begin{array}{c}\mathbf{R}_{\mathrm{P}} \\
(\text { Capwap) } \\
(\mathrm{kN})\end{array}$ & $\begin{array}{c}\mathbf{R}_{\mathrm{P}} \\
\text { (\%) }\end{array}$ & $\begin{array}{c}\mathbf{R}_{\mathrm{T}} \\
(\text { Capwap) } \\
(\mathrm{kN})\end{array}$ & $\begin{array}{c}\text { Pressão de } \\
\text { Sucção } \\
\text { (kPa) }\end{array}$ \\
\hline 0,60 & 6,1 & 314,2 & $42 \%$ & 437,7 & $58 \%$ & 751,9 & 24,5 \\
\hline \multicolumn{8}{|c|}{ TE04 - 4º Ensaio (Pré-Inundado) } \\
\hline $\begin{array}{c}\mathrm{H} \\
\text { (Campo) } \\
(\mathrm{m})\end{array}$ & $\begin{array}{c}\text { EMX } \\
\text { (PDA) } \\
(\mathrm{kJ})\end{array}$ & $\begin{array}{c}R_{\mathrm{L}} \\
\text { (Capwap) } \\
(\mathrm{kN})\end{array}$ & $\begin{array}{c}\mathbf{R}_{\mathrm{L}} \\
(\%)\end{array}$ & $\begin{array}{c}\mathbf{R}_{\mathrm{P}} \\
(\text { Capwap) } \\
(\mathrm{kN})\end{array}$ & $\begin{array}{c}\mathbf{R}_{\mathbf{P}} \\
(\%)\end{array}$ & $\begin{array}{c}\mathbf{R}_{\mathrm{T}} \\
(\text { Capwap) } \\
(\mathrm{kN})\end{array}$ & $\begin{array}{c}\text { Pressão de } \\
\text { Sucção } \\
\text { (kPa) }\end{array}$ \\
\hline 0,60 & 4,5 & 62,3 & $13 \%$ & 426,4 & $87 \%$ & 488,7 & 2,8 \\
\hline
\end{tabular}

$\mathrm{R}_{\mathrm{T}}$ - Resistência Total mobilizada (Análise CAPWAP)

$\mathrm{R}_{\mathrm{L}}$ - Resistência Lateral mobilizada (Análise CAPWAP)

$\mathrm{R}_{\mathrm{P}}-$ Resistência de Ponta mobilizada (Análise CAPWAP) 
Para o tubulão TE01, comparando-se os dois ensaios dinâmicos sucessivos, verifica-se que, para níveis de energia aplicada próximos, no segundo ensaio, há uma diminuição da resistência total mobilizada, principalmente devido à perda de resistência por atrito lateral, causado pelo reensaio e pela diminuição da pressão de sucção.

Os ensaios dinâmicos no tubulão TE02 mostram que no segundo ensaio, há uma diminuição da resistência total mobilizada para níveis de energia aplicada próximos, devido à perda de resistência por atrito lateral, causada pelo reensaio deste.

Já no tubulão TE03, os ensaios dinâmicos mostram que a resistência total mobilizada para níveis de energia aplicada próximos torna-se praticamente constante, com pouca variação na porcentagem de resistência por atrito lateral e de ponta. Salientase que as análise neste tubulão mostraram a presença de danos no concreto, no encontro do fuste com a base, que foi confirmada com a inspeção do fuste.

Os ensaios dinâmicos no tubulão TE04, mostram que, no segundo ensaio, apesar de haver uma diminuição de resistência mobilizada total, considerando que a energia aplicada foi menor, a porcentagem da parcela de resistência por atrito lateral aumenta, e isso se deve a prováveis tensões residuais geradas de um ensaio para o outro. No terceiro ensaio, as porcentagens da parcela de resistência por atrito lateral tornam-se constantes, verificando-se ainda a presença de tensões residuais. No quarto ensaio, inundado, há uma diminuição da resistência total mobilizada, devido à dissipação das tensões residuais e da diminuição da pressão de sucção, e conseqüentemente, uma redução da porcentagem de resistência por atrito lateral. 


\section{2 - Evolução da Parcela de Resistência de Ponta(ou Base) e Lateral}

A Figura 7.5 apresenta a parcela de resistência de ponta e de resistência lateral para cada energia, resultado da análise $C A P W A P$ do ensaio de carregamento dinâmico.
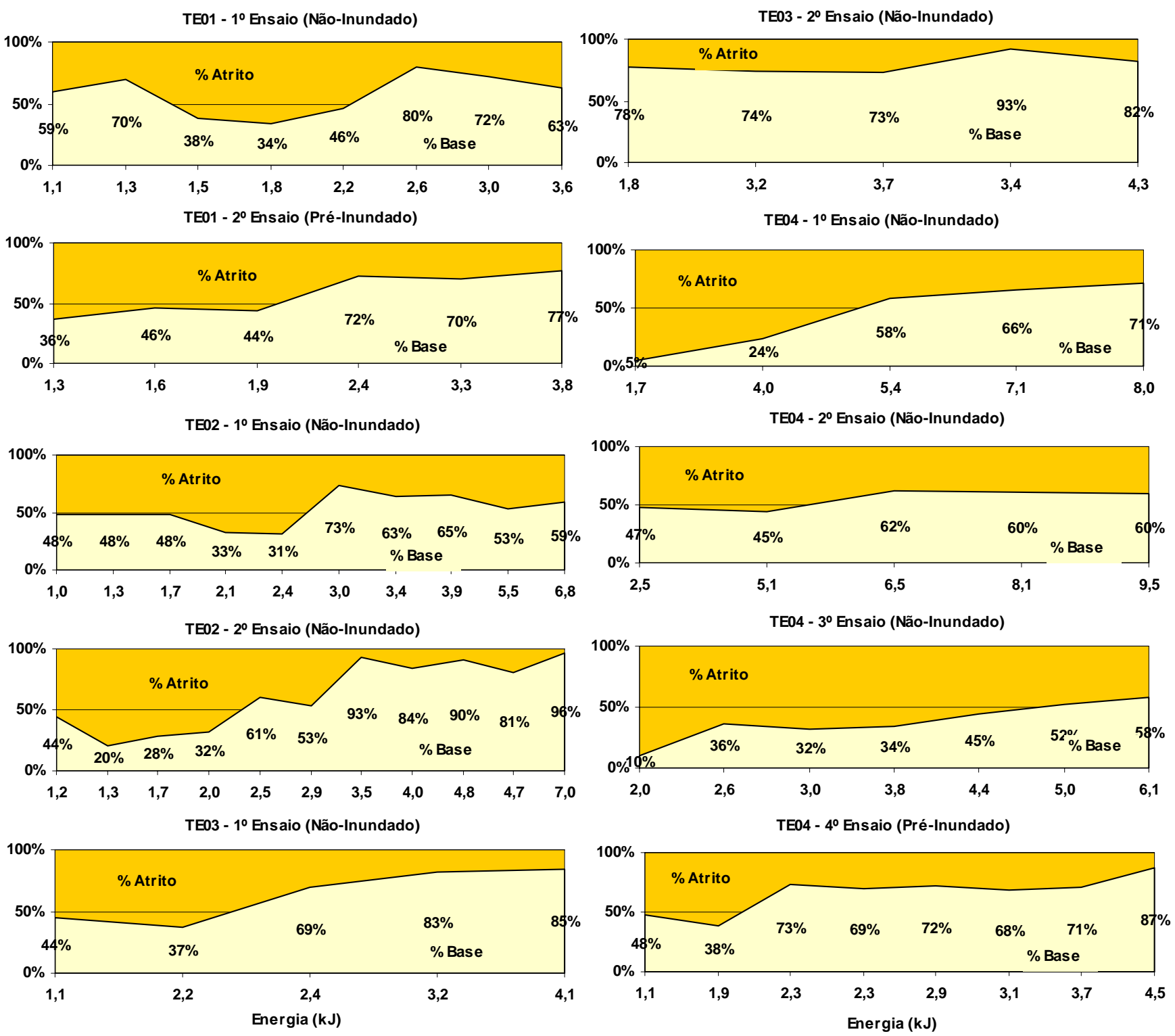

Figura 7.5 - Parcela de resistência de ponta e lateral em função da energia aplicada ao sistema. 
Analisando-se a Figura 7.5, observa-se que, em todos os ensaios realizados, no início, para baixos níveis de energia aplicada, a resistência de ponta é menor que $50 \%$ e, ao fim, para níveis maiores de energia, esta resistência é maior, isto é, há um crescimento gradativo da parcela de resistência de ponta com o aumento da energia aplicada ao sistema, com exceção do $1^{\circ}$ ensaio do tubulão TE01 e do $2^{\circ}$ ensaio do tubulão TE03.

Verifica-se, através dos gráficos da Figura 7.5, que o comportamento dos tubulões que foram ensaiados com pré-inundação são bastante semelhantes. Já os tubulões ensaiados sem inundação apresentam uma maior variabilidade quanto à forma da curva.

\section{3 - Análises Estatísticas do Ensaio Dinâmico}

Realizaram-se análises estatísticas das resistências mobilizadas: total, lateral, de ponta e máxima energia (EMX) em termos de valores mínimos, máximos, médios e coeficiente de variação em relação às alturas de queda de 0,$20 ; 0,40 ; 0,60 ; 0,80$ e 1,00 m. O aumento da altura de queda significa o aumento de energia aplicada. Os resultados podem ser vistos em anexo. As Figuras 7.6 à 7.13 mostram as análises descritas acima. 


\section{TUBULÕES NÃO INUNDADOS}

A Figura 7.6 mostra a variação da resistência mobilizada total, isto é, os valores mínimos, médios, máximos e o coeficiente de variação para as alturas de queda que variam de 0,20 m a 1,00 m. Observa-se que há um crescimento da resistência mobilizada total com o aumento da altura de queda, ou seja, aumento da energia. As resistências apresentam um coeficiente de variação aproximadamente constante, de cerca de $30 \%$.

Tubulões Não Inundados

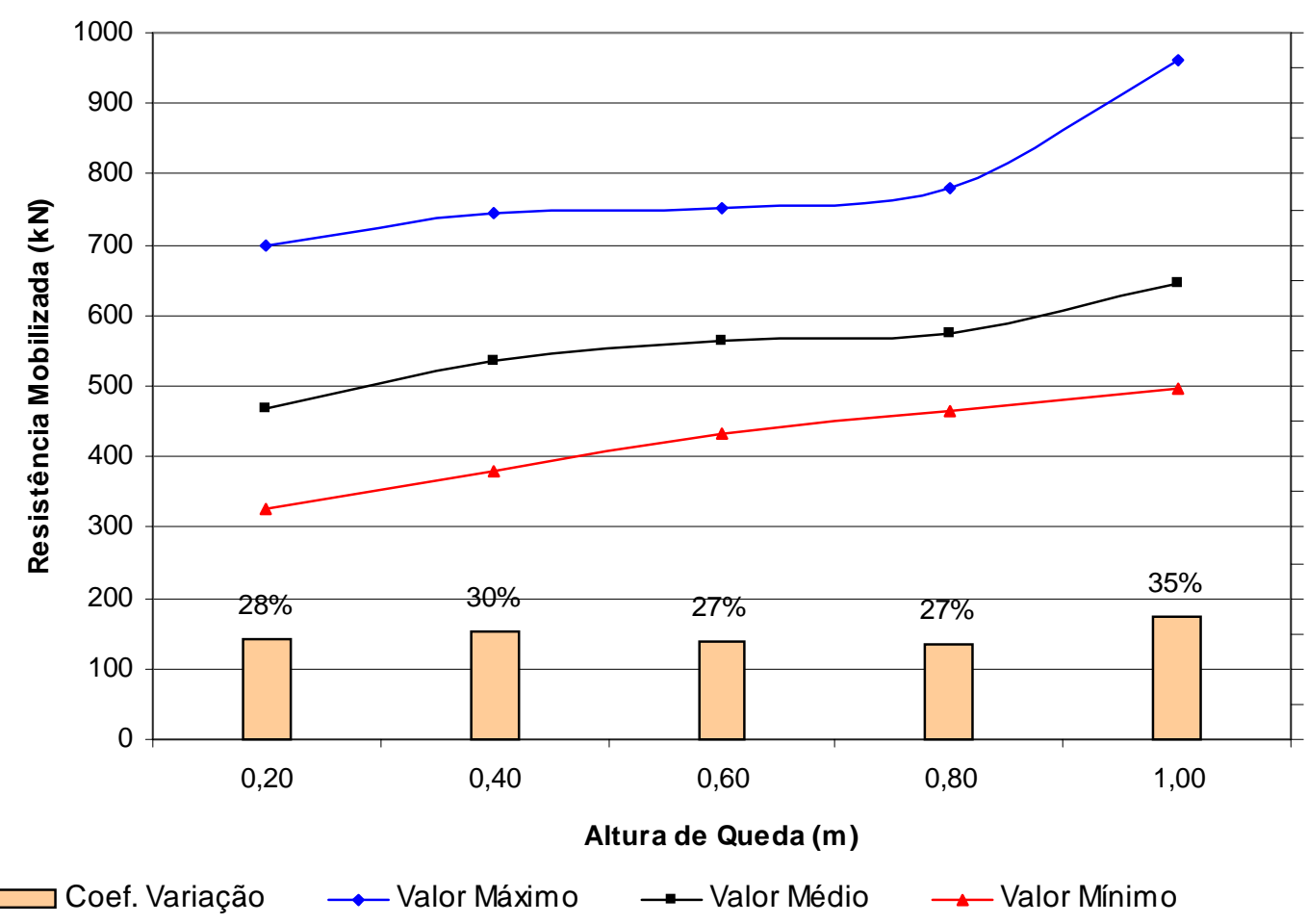

Figura 7.6 - Análise estatística da resistência mobilizada total 
A Figura 7.7 apresenta a análise estatística em relação aos valores da resistência lateral mobilizada. Verifica-se que há uma diminuição acentuada da resistência lateral mobilizada com o aumenta da altura de queda do martelo do bate-estaca. Devido à presença de tensões residuais, houve uma grande variabilidade na determinação desta resistência, que é demonstrada pelo alto coeficiente de variação que cresce com o aumento da energia

Tubulões Não Inundados

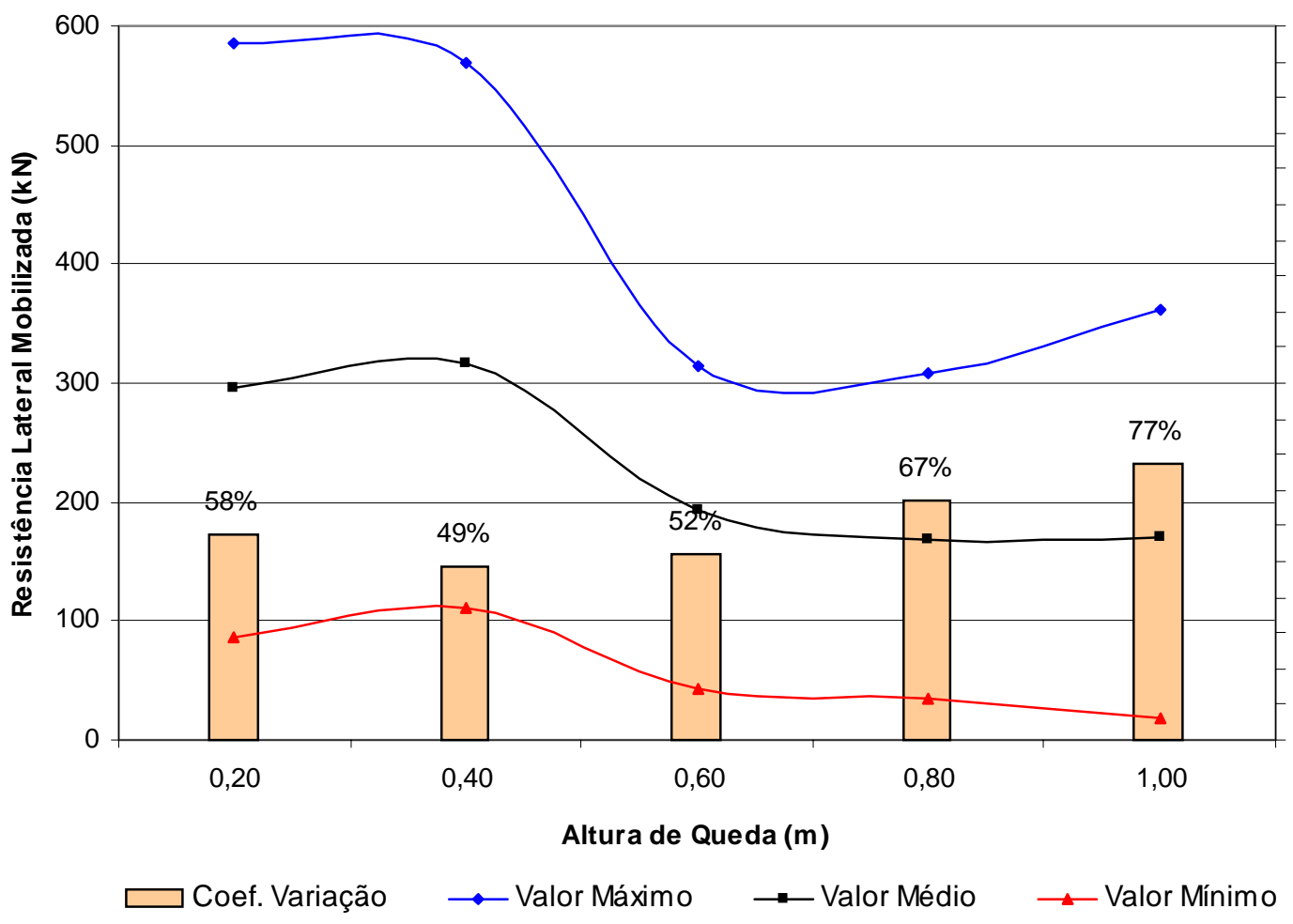

Figura 7.7 - Análise estatística da resistência lateral mobilizada 
A resistência de ponta mobilizada cresce com o aumento da altura de queda, como pode ser visto na Figura 7.8. O coeficiente de variação apresenta-se muito alto para baixas energias aplicadas e vai diminuindo, à medida que a energia vai aumentando. O coeficiente de variação para resistência de ponta e total tornam-se próximo, quando se aumenta o nível de energia.

Tubulões Não Inundados

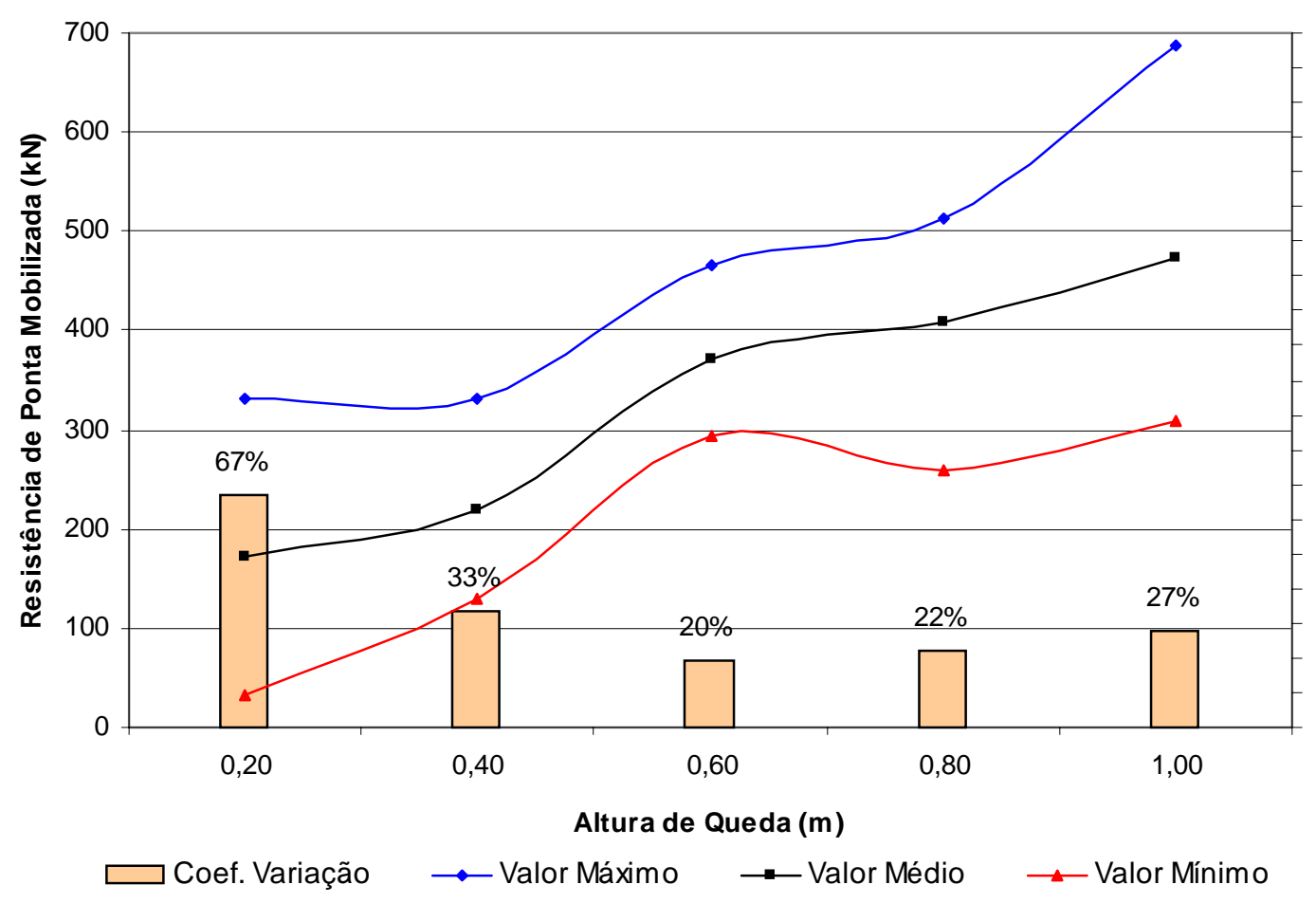

Figura 7.8 - Análise estatística da resistência de ponta mobilizada 
A Figura 7.9 apresenta a variação da energia máxima EMX, medida a nível dos sensores. Esta energia cresce linearmente, com o aumento da energia potencial aplicada, proveniente do aumento da altura de queda do martelo do bate-estaca. O coeficiente de variação é praticamente constante com o aumento de energia potencial aplicada, em torno de $32 \%$.

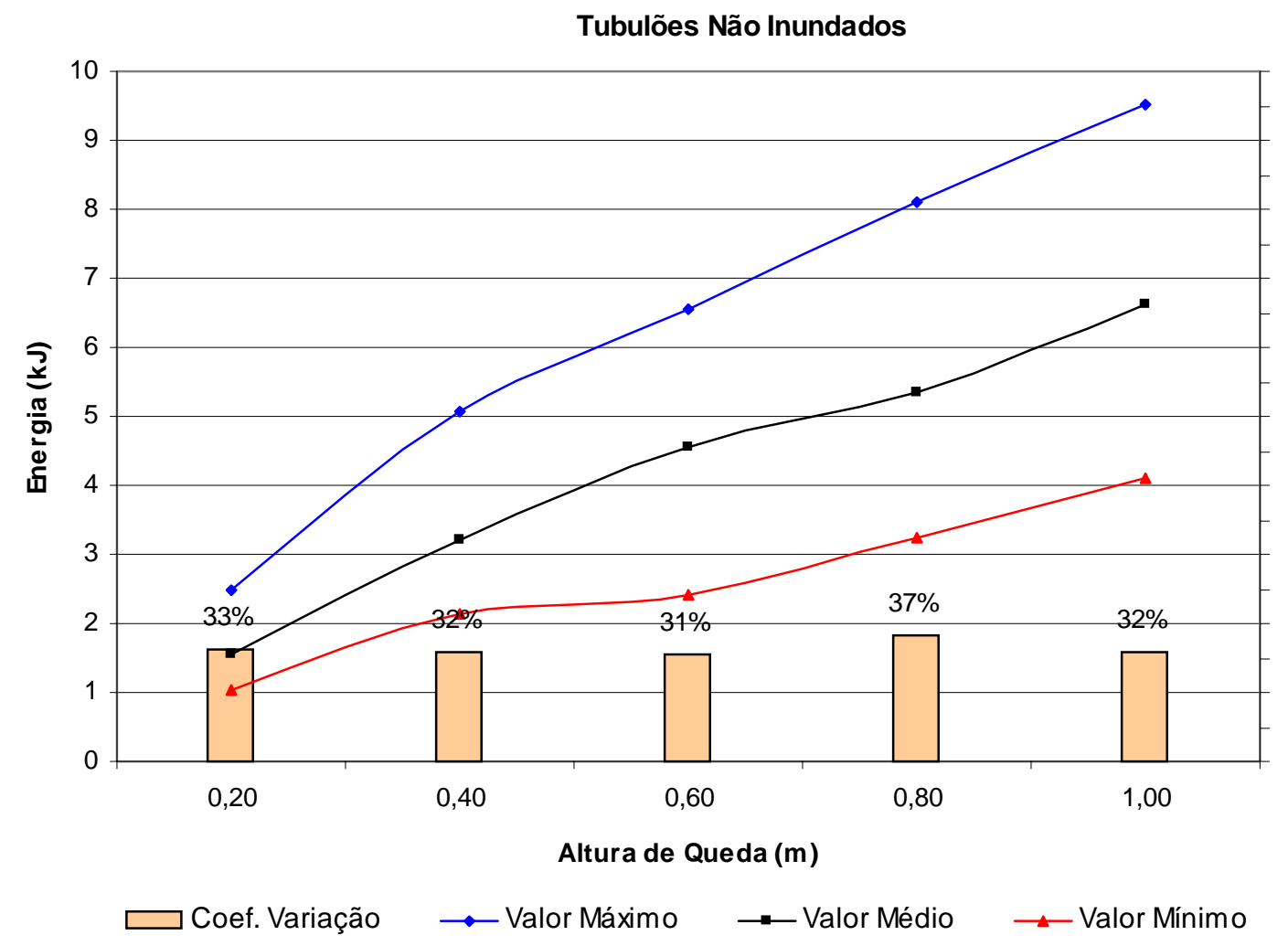

Figura 7.9 - Análise estatística da energia máxima aplicada 


\section{TUBULÕES PRÉ-INUNDADOS}

A Figura 7.10 mostra a variação da resistência mobilizada total. Observa-se que há um crescimento desta resistência com o aumento da energia. As resistências apresentam um coeficiente de variação aproximadamente constante, de cerca de $6 \%$, bem inferior aos vistos nos ensaios não inundados, quando os coeficientes de variação também eram praticamente constantes, de cerca de $30 \%$. Isso mostra que, no ensaio inundado, há uma maior homogeneidade, caracterizada pela redução dos coeficientes de variação em relação à resistência total mobilizada.

Tubulões Pré-Inundados

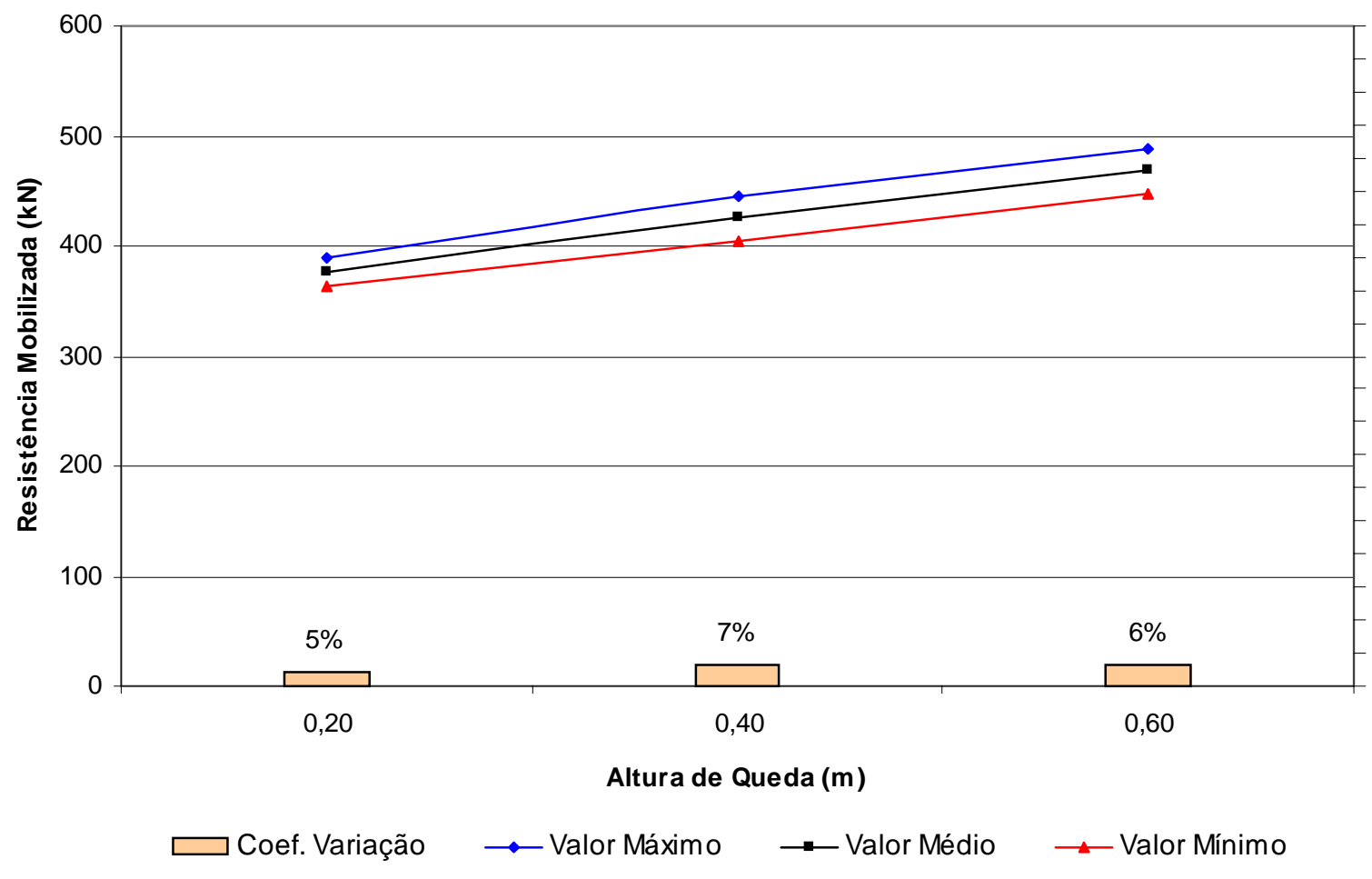

Figura 7.10 - Análise estatística da resistência mobilizada total 
A Figura 7.11 apresenta a análise estatística em relação aos valores da resistência lateral mobilizada. Verifica-se que há uma diminuição acentuada da resistência lateral mobilizada com o aumento da energia aplicada. O coeficiente de variação é baixo, mostrando homogeneidade do ensaio quanto à determinação da resistência lateral mobilizada, apesar de as análises para a altura de queda de 0,60 m apresentarem um coeficiente de variação alto, embora menor que o do ensaio não inundado

Tubulões Pré-Inundados

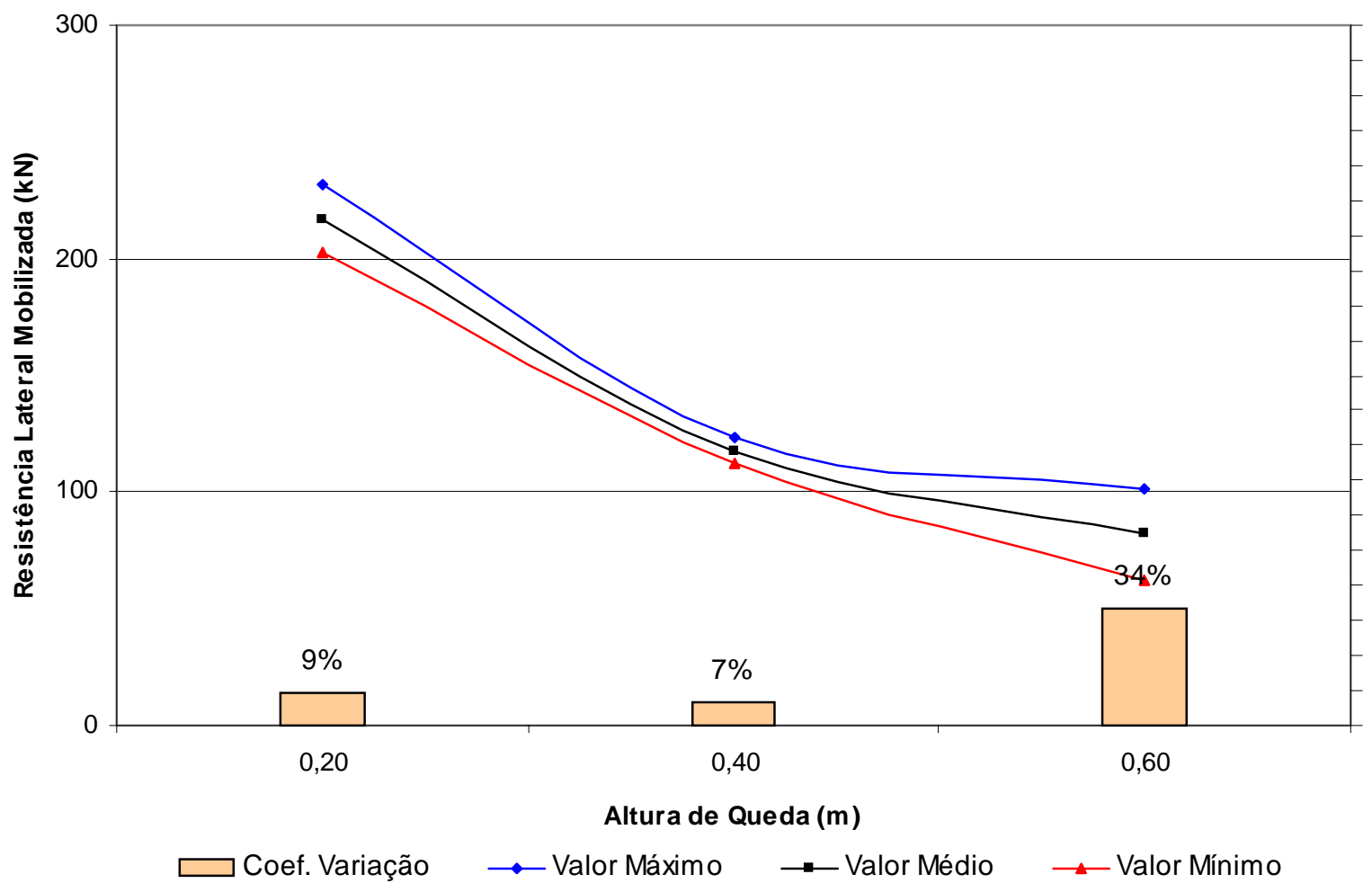

Figura 7.11 - Análise estatística da resistência lateral mobilizada 
A resistência de ponta mobilizada cresce com o aumento da energia aplicada, como pode ser visto na Figura 7.12. O coeficiente de variação oscila, apresentando maior variabilidade para baixas energias aplicadas, como aconteceu, também, nos tubulões não inundados, porém em maior magnitude. No geral, pode-se afirmar que houve maior homogeneidade em relação ao ensaio não inundado.

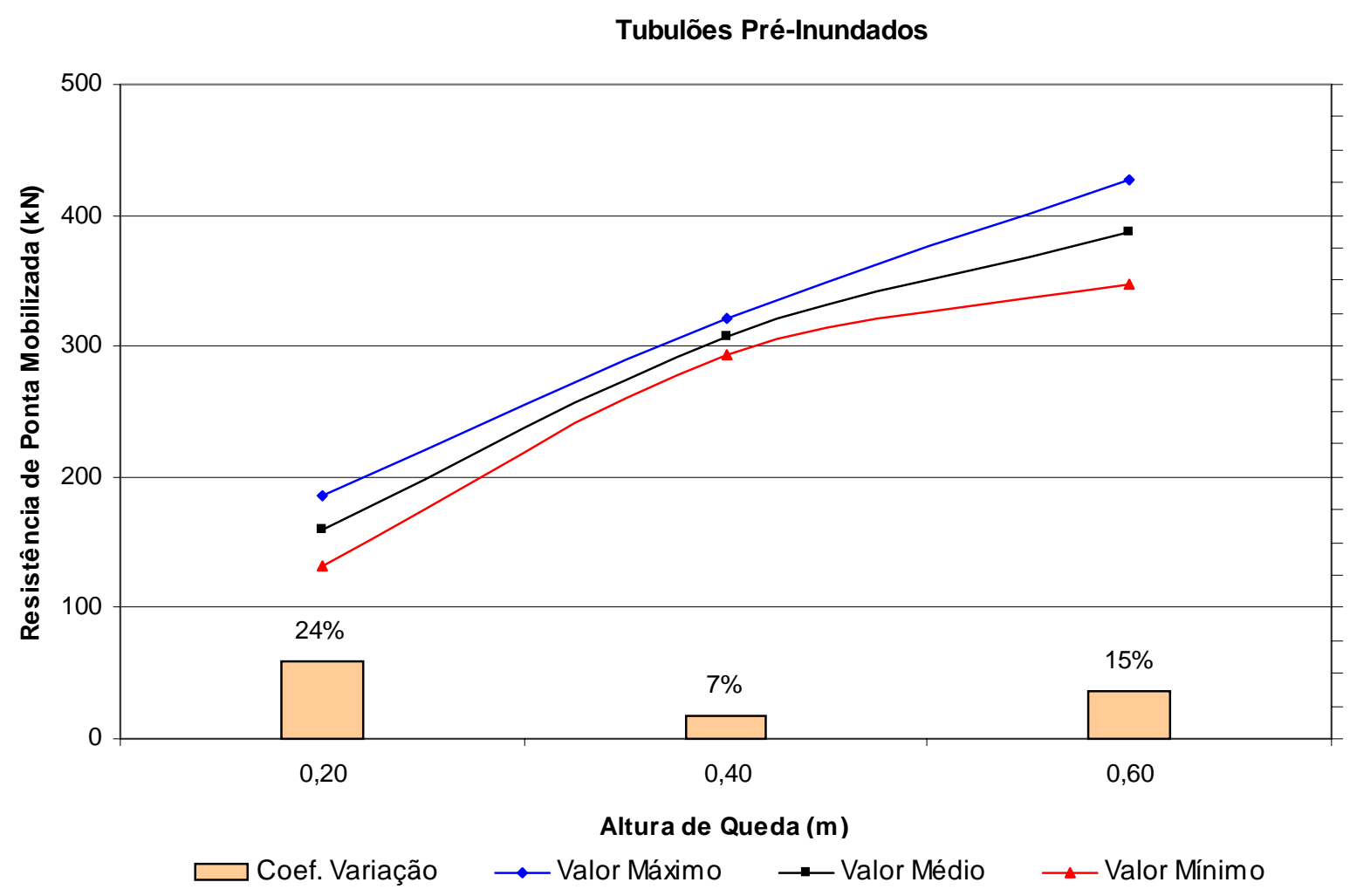

Figura 7.12 - Análise estatística da resistência de ponta mobilizada 
Na Figura 7.13 verifica-se a variação da energia máxima EMX, medida a nível dos sensores. Esta energia cresce linearmente, com o aumento da energia potencial aplicada, proveniente do aumento da altura de queda do martelo do bate-estaca. O coeficiente de variação oscila com o aumento de energia potencial aplicada. Também em relação à máxima energia medida, o ensaio inundado apresentou valores mais homogêneos que os não inundados.

Tubulões Pré-Inundados

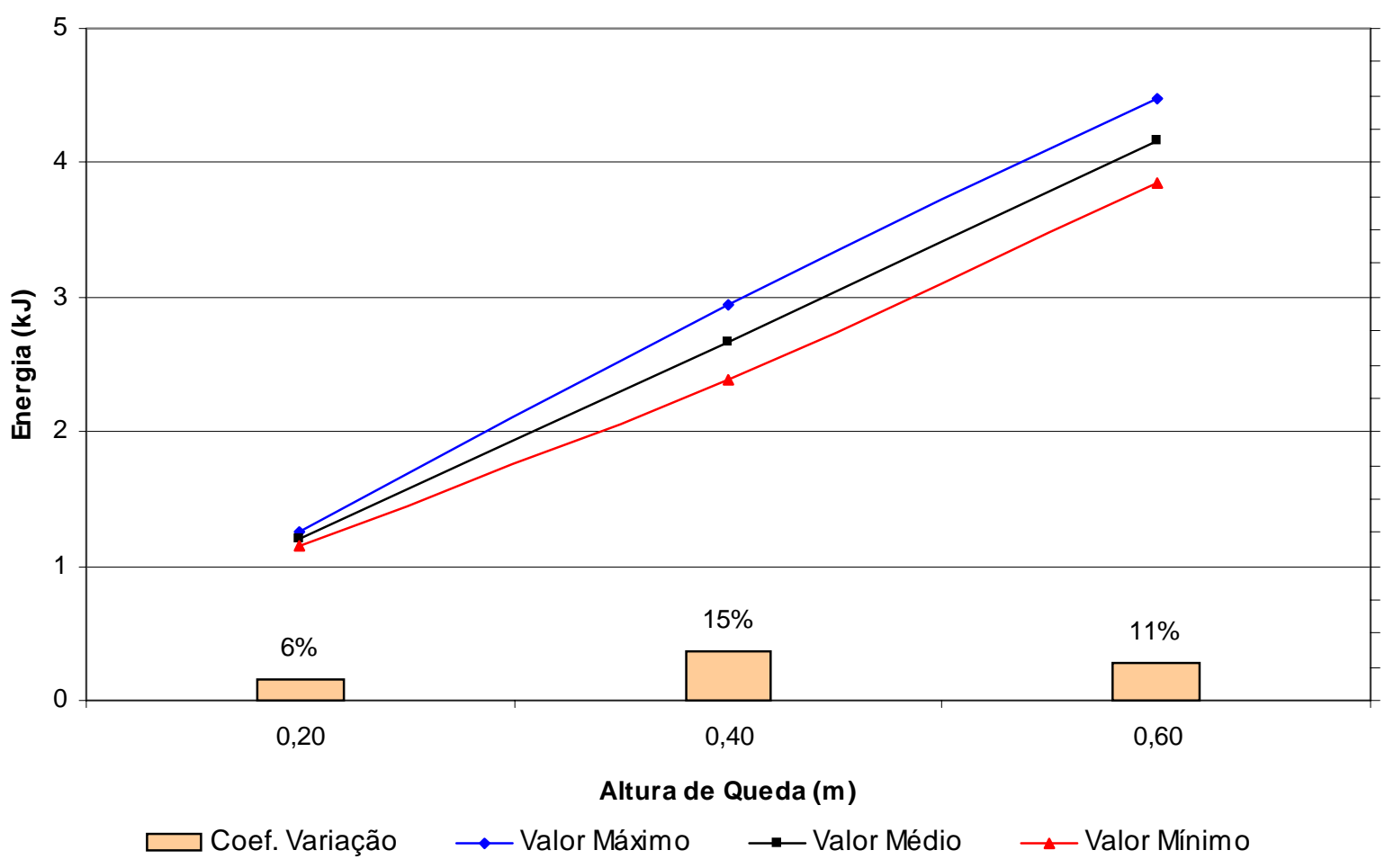

Figura 7.13 - Análise estatística da energia máxima aplicada 


\section{4 - Comparação entre as Provas de Carga Estática e Dinâmica}

As Tabelas 7.3 e 7.4 mostram os resultados analisados estatisticamente das provas de carga estática e dinâmica respectivamente.

Tabela 7.3 - Resultados das Provas de Carga Estática

\begin{tabular}{|c|c|c|c|c|c|c|c|c|c|c|}
\hline \multicolumn{11}{|c|}{ PROVA DE CARGA ESTÁTICA } \\
\hline \multirow{2}{*}{ Tubulões } & \multicolumn{5}{|c|}{ Ensaios Não Inundados } & \multicolumn{5}{|c|}{ Ensaios Pré-Inundados } \\
\hline & $\mathbf{R}$ & $\mathbf{R}_{\mathbf{L}}$ & $\mathbf{R}_{\mathbf{P}}$ & $\rho$ & $\mathbf{P}_{\text {Suc }}$ & $\mathbf{R}$ & $\mathbf{R}_{\mathbf{L}}$ & $\mathbf{R}_{\mathbf{P}}$ & $\rho$ & $\mathbf{P}_{\text {Suc }}$ \\
\hline & $(\mathbf{k N})$ & $(\mathbf{k N})$ & $(\mathbf{k N})$ & $(\mathbf{m m})$ & (kPa) & $(\mathbf{k N})$ & $(\mathbf{k N})$ & $(\mathbf{k N})$ & $(\mathbf{m m})$ & (kPa) \\
\hline TE01 & & 370 & & 8,9 & 39 & & & & & \\
\hline TE02 & & & & & & & 102 & & 2,5 & 0 \\
\hline TE02 & & 280 & & 2,7 & 25 & & & & & \\
\hline TE03 & & 400 & & 8,9 & 27 & & & & & \\
\hline TE03 & & & & & & & 156 & & 2,7 & 0 \\
\hline TE04 & & 440 & & 7,4 & 31 & & & & & \\
\hline Média & & 373 & & 6,9 & 30,5 & & 129 & & 2,6 & 0 \\
\hline Coef. Variaç. & & $18 \%$ & & $42 \%$ & $20 \%$ & & $30 \%$ & & $5 \%$ & - \\
\hline
\end{tabular}

Tabela 7.4 - Resultados Médios da Análise Estatística das Provas de Carga Dinâmica

\begin{tabular}{|c|c|c|c|c|c|c|c|c|c|c|c|c|}
\hline \multicolumn{10}{|c|}{ PROVAS DE CARGA DINÂMICA } \\
\hline $\begin{array}{c}\text { TUBULÔES } \\
\text { TE01 / TE02 } \\
\text { TE03 / TE04 }\end{array}$ & $\mathbf{E M X ~ / ~ H ~}$ & $\mathbf{R}$ & $\mathbf{R}_{\mathbf{L}}$ & $\mathbf{R}_{\mathbf{P}}$ & $\boldsymbol{\rho}$ & $\mathbf{P}_{\text {Suc }}$ & $\mathbf{E M X} / \mathbf{H}$ & $\mathbf{R}$ & $\mathbf{R}_{\mathbf{L}}$ & $\mathbf{R}_{\mathbf{P}}$ & $\boldsymbol{\rho}$ & $\mathbf{P}_{\text {Suc }}$ \\
\hline & $\mathbf{( k J )} /(\mathbf{m})$ & $(\mathbf{k N})$ & $\mathbf{( k N )}$ & $\mathbf{( k N )}$ & $(\mathbf{m m})$ & $(\mathbf{k P a})$ & $(\mathbf{k J} / \mathbf{m})$ & $(\mathbf{k N})$ & $(\mathbf{k N})$ & $(\mathbf{k N})$ & $(\mathbf{m m})$ & $(\mathbf{k P a})$ \\
\hline Média & $3,2 / 0,40$ & 534 & 315 & 219 & 4,3 & 24,5 & $1,2 / 0,2$ & 376 & 217 & 159 & 2,9 & 2,8 \\
\hline $\begin{array}{c}\text { Coef. } \\
\text { Variaç. }\end{array}$ & $32 \% /-$ & $30 \%$ & $49 \%$ & $33 \%$ & $13 \%$ & - & $6 \% /-$ & $5 \%$ & $9 \%$ & $24 \%$ & $11 \%$ & - \\
\hline Média & $4,6 / 0,60$ & 564 & 193 & 371 & 5,6 & 24,5 & $4,2 / 0,60$ & 468 & 82 & 386 & 6,2 & 2,8 \\
\hline $\begin{array}{c}\text { Coef. } \\
\text { Variaç. }\end{array}$ & $31 \% /-$ & $27 \%$ & $52 \%$ & $20 \%$ & $13 \%$ & - & $11 \% /-$ & $6 \%$ & $34 \%$ & $15 \%$ & $3 \%$ & - \\
\hline
\end{tabular}




\section{Legenda:}

R - Resistência Mobilizada

$\mathrm{R}_{\mathrm{L}}$ - Resistência Lateral Mobilizada

$\mathrm{R}_{\mathrm{P}}$ - Resistência de Ponta Mobilizada

H - Altura de Queda do Martelo do Bate-Estaca

$\rho$ - Recalque

$\mathrm{P}_{\text {suc }}$ - Pressão de Sucção

EMX - Máxima Energia Medida a Nível dos Sensores

Analisando-se a resistência lateral mobilizada nos ensaios não inundados, observa-se que o resultado médio das provas de carga estática apresenta-se cerca de 18 \% maior em relação ao das provas de carga dinâmica, o mesmo acontece com a pressão de sucção média, que se apresenta superior em cerca de $24 \%$. Salienta-se que a variabilidade no ensaio dinâmico é bem maior que no estático, se analisarmos os coeficientes de variação.

Com relação aos valores de resistência lateral mobilizada, estes podem ser explicados, devido à diferença na pressão de sucção, que exerce muita influência nesse tipo de solo, pois em solos não-saturados, quanto maior a pressão de sucção, maior a resistência do solo, quando solicitado.

Com relação aos ensaios pré-inundados, os resultados mostram que a resistência lateral mobilizada média no ensaio dinâmico é maior que no estático cerca de $68 \%$, apesar das pressões de sucção serem próximas. Os recalques associados a estes dois ensaios apresentam-se próximos um do outro. Verifica-se através dos baixos coeficientes de variação em relação aos ensaios não inundados, tanto na prova de carga estática quanto na dinâmica, que a inundação do terreno torna os resultados homogêneos.

O tempo de inundação no ensaio dinâmico foi de 12 horas, enquanto, no estático, foi de 48 horas. Acredita-se que o solo no ensaio estático estava mais saturado que no ensaio dinâmico, apesar de as pressões de sucção médias estarem próximas, sendo este o motivo do resultado estático ter sido inferior ao dinâmico. 


\section{5 - Análise do Modelo Físico}

A inspeção em todos os fustes dos tubulões foi de extrema importância para definição do comportamento físico destes nas provas de carga estática e dinâmica. Admitiu-se, tendo como base os resultados das inspeções nos tubulões TE01 e TE04, que houve mobilização da resistência lateral e de ponta nos dois tipos de ensaios, quando os tubulões eram solicitados nos seus topos. Verifica-se que houve alguma falha na instrumentação quanto aos tubulões TE02 e TE03. A Tabela 7.5 mostra o comprimento do isopor entre o fuste e a base do isopor antes e após as provas de carga.

Tabela 7.5 - Espessuras dos Isopores

\begin{tabular}{|c|c|c|c|c|}
\hline TUBULÕES & $\begin{array}{c}\text { Espessura do } \\
\text { Isopor Antes das } \\
\text { Provas de Carga }\end{array}$ & $\begin{array}{c}\text { Recalque Máximo } \\
\text { Instrumentação (PCE) + } \\
\text { Instrumentação (PCDEC) }\end{array}$ & $\begin{array}{c}\text { Espessura } \\
\text { Esperada Antes } \\
\text { da Inspeção }\end{array}$ & $\begin{array}{c}\text { Comprimento do } \\
\text { Isopor Após as } \\
\text { Provas de Carga }\end{array}$ \\
\hline TE01 & $40 \mathrm{~cm}$ & $38,14 \mathrm{~cm}$ & $1,86 \mathrm{~cm}$ & $2,8 \mathrm{~cm}$ \\
\hline TE02 & $40 \mathrm{~cm}$ & $36,96 \mathrm{~cm}$ & $3,04 \mathrm{~cm}$ & $2,0 \mathrm{~cm}$ \\
\hline TE03 & $40 \mathrm{~cm}$ & $32,93 \mathrm{~cm}$ & $7,07 \mathrm{~cm}$ & $0,5 \mathrm{~cm}$ \\
\hline TE04 & $40 \mathrm{~cm}$ & $41,51 \mathrm{~cm}$ & $-1,51 \mathrm{~cm}$ & $1,5 \mathrm{~cm}$ \\
\hline
\end{tabular}




\section{6 - Análise da Eficiência do Bate-Estaca}

Analisou-se a eficiência do bate-estaca, a qual, de início, é suposta constante. As figuras 7.14 à 7.23 mostram a relação entre a energia potencial disponível $\left(\mathrm{E}_{\mathrm{P}}\right)$ e a energia aplicada (EMX), medida ao nível dos sensores, para todos os ensaios dinâmicos realizados.

TE01 - 1ํㅡssaio (Não-Inundado)

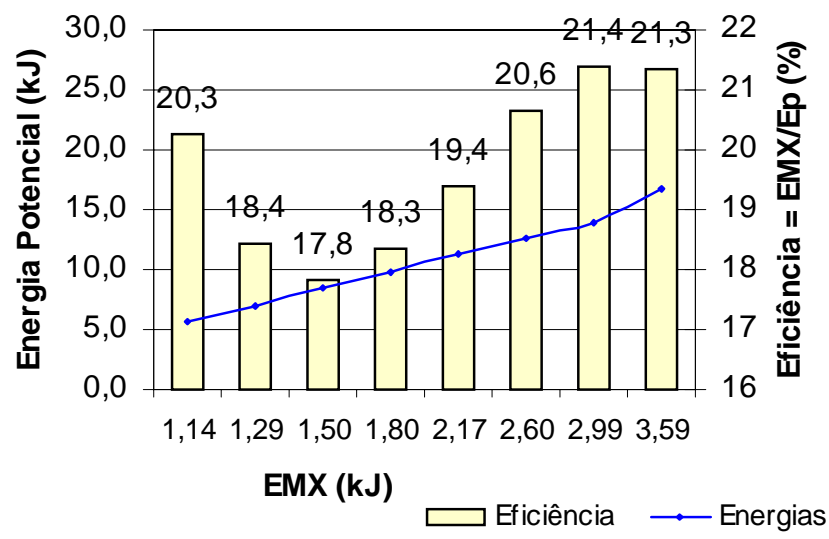

Figura 7.14 - Eficiência do Bate-Estaca para o $1^{\circ}$ Ensaio do TE01

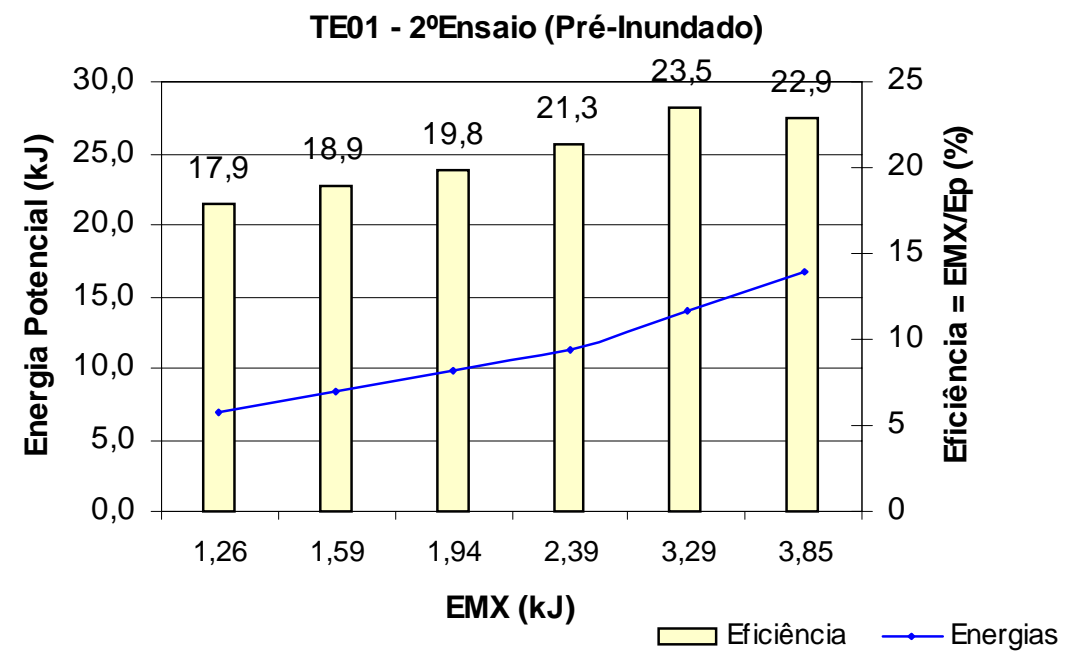

Figura 7.15 - Eficiência do Bate-Estaca para o $2^{\circ}$ Ensaio do TE01 


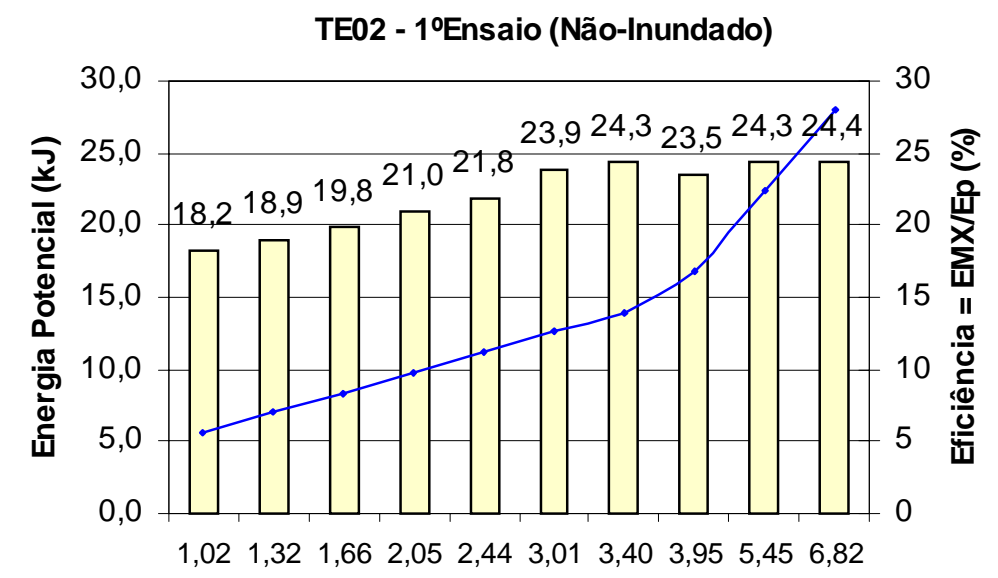

$\operatorname{EMX}(\mathrm{kJ})$

$\square$ Eficiência —Energias

Figura 7.16 - Eficiência do Bate-Estaca para o $1^{\circ}$ Ensaio do TE02

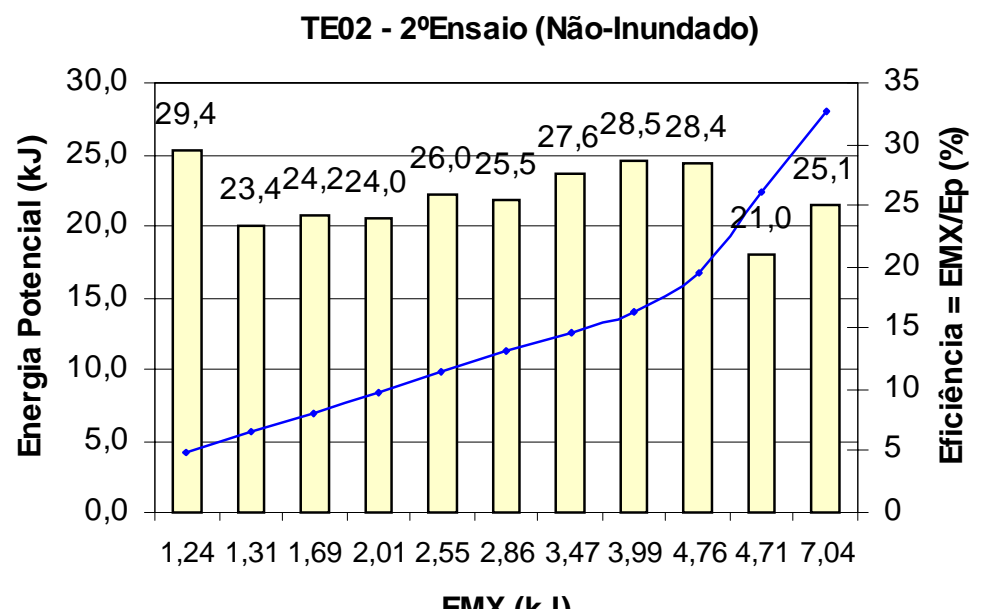

Figura 7.17 - Eficiência do Bate-Estaca para o $2^{\circ}$ Ensaio do TE02

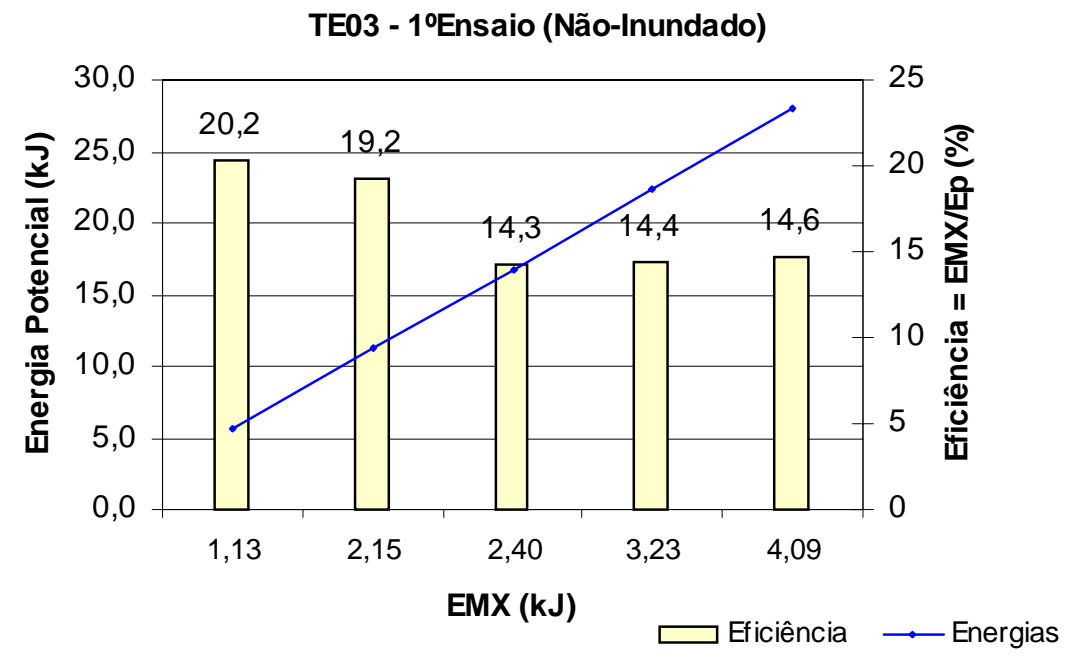

Figura 7.18 - Eficiência do Bate-Estaca para o $1^{\circ}$ Ensaio do TE03 


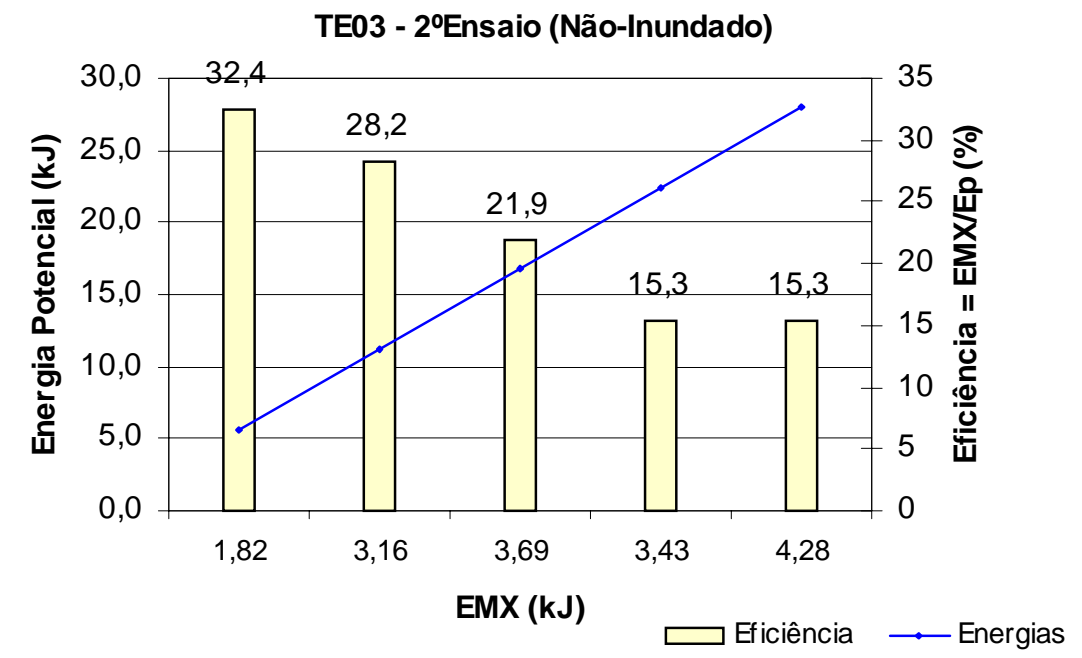

Figura 7.19 Eficiência do Bate-Estaca para o $2^{\circ}$ Ensaio do TE03

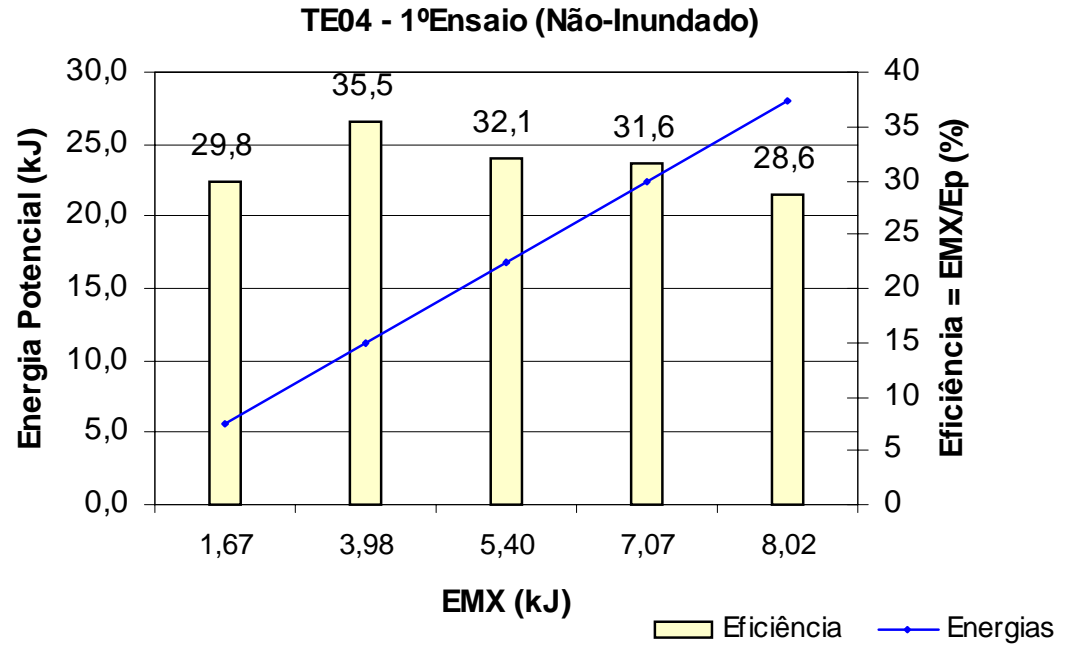

Figura 7.20 Eficiência do Bate-Estaca para o $1^{\circ}$ Ensaio do TE04

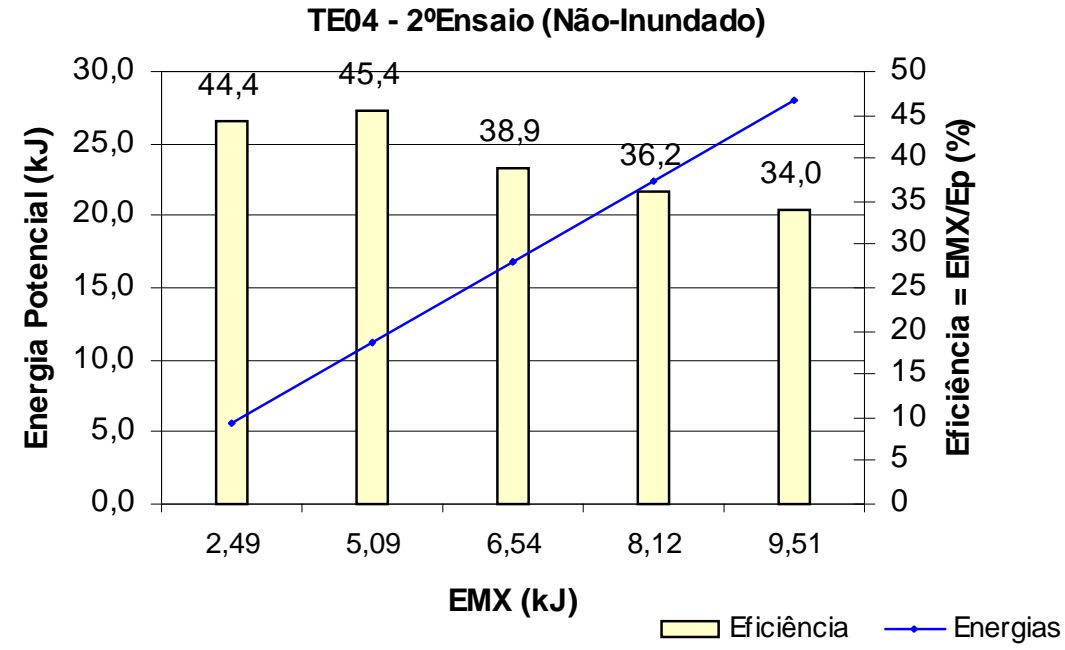

Figura 7.21 Eficiência do Bate-Estaca para o $2^{\circ}$ Ensaio do TE04 


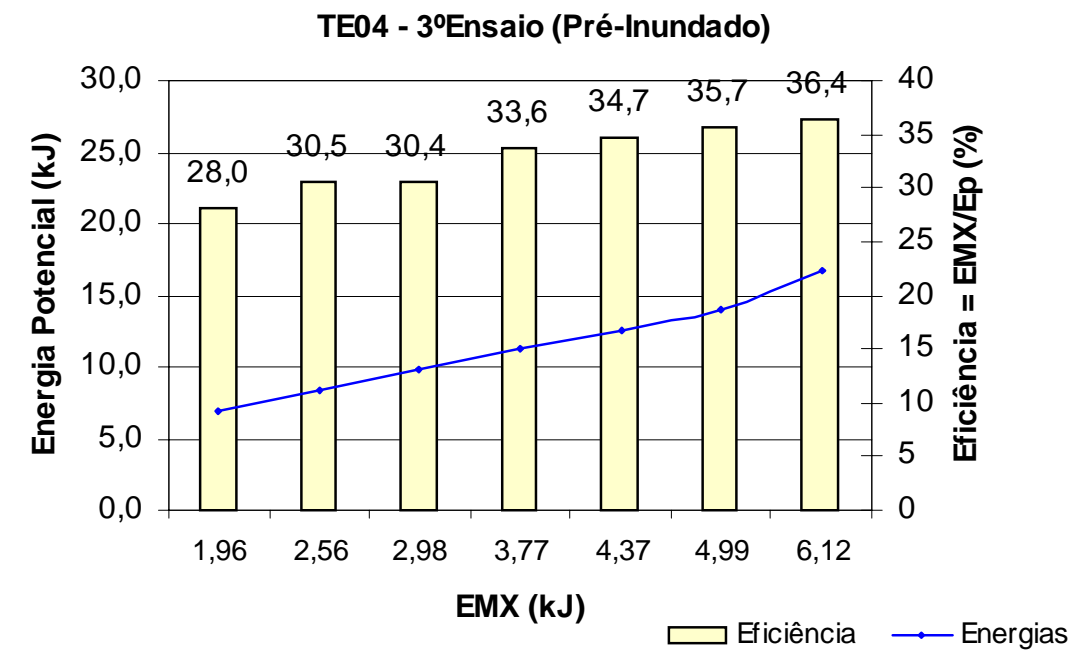

Figura 7.22- Eficiência do Bate-Estaca para o $3^{\circ}$ Ensaio do TE04

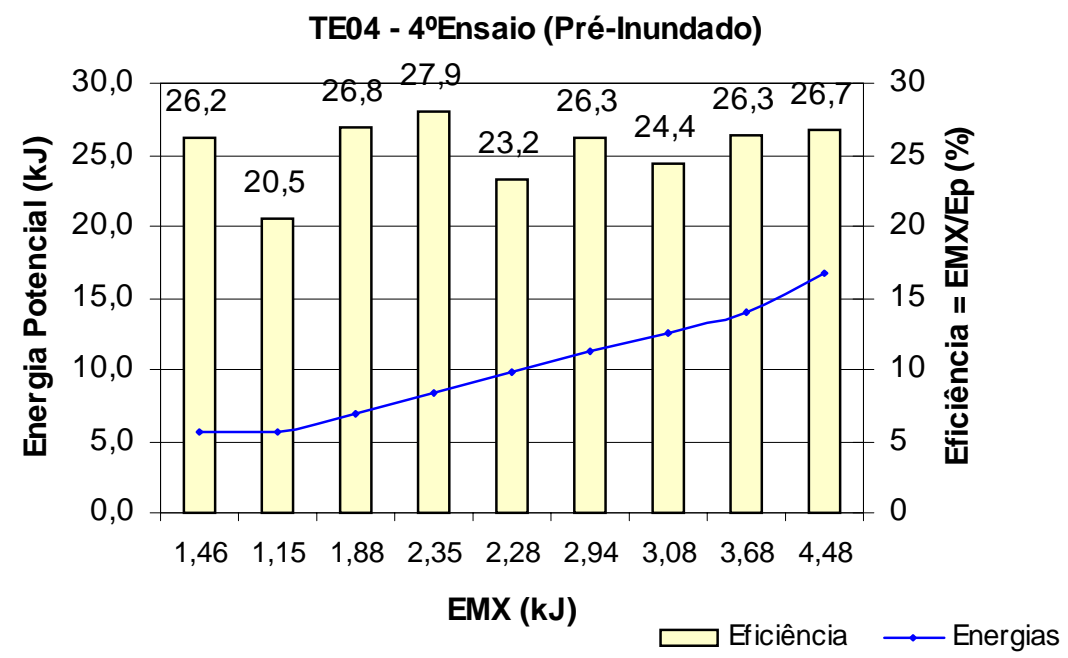

Figura 7.23- Eficiência do Bate-Estaca para o $4^{\circ}$ Ensaio do TE04

Analisando-se as figuras, observa-se que as eficiências não foram constantes, e que há uma tendência de aumento da eficiência com o aumento da energia aplicada. 


\section{CAPÍTULO 8 - CONCLUSÕES E SUGESTÕES}

\section{1 - Conclusões}

Através das análises das 10 provas de carga dinâmica de energia crescente, realizadas em quatro tubulões a céu aberto conclui-se que a prova de carga dinâmica de energia crescente é uma boa opção para verificar o comportamento de uma fundação em diversos aspectos do sistema.

Os reensaios dinâmicos nos tubulões provocam uma perda de resistência mobilizada total, devido à diminuição da resistência por atrito lateral, causada por diversos ciclos de carregamento e descarregamento.

As curvas carga-recalque resultantes das provas de carga estática nos quatros tubulões que antecederam os ensaios dinâmicos estão divididas em dois trechos: o primeiro mostra a ruptura do fuste do tubulão, e, no segundo, há um crescimento dos recalques com o aumento das cargas. Esta curva assemelha-se com a curva do ensaio de adensamento do solo, representando um tipo de reta virgem.

Os ensaios dinâmicos analisados pelo programa CAPWAP e plotados na curva carga-recalque, tendo como origem o final dos ensaios estáticos, mostram que as resistências mobilizadas encontram-se nas retas de recompressão dos ensaios estáticos. Fazendo uma análise com o ensaio de adensamento, o ensaio dinâmico não alcançou a máxima tensão, atingida no ensaio estático e chamada de tensão de pré-adensamento.

A prova de carga dinâmica de energia crescente ficou limitada a uma altura de queda que não causasse dano ao elemento estrutural de fundação.

O efeito dinâmico (relação entre resistência total do ensaio dinâmico e a resistência estática) no solo analisado, duas camadas sobrepostas de areia fina e média argilosa (sedimento cenozóico) e outra de areia fina argilosa avermelhada (solo residual) intercaladas por uma linha de seixo rolado variou entre 1,7 e 3,0. 
A medição dos deslocamentos ao nível dos sensores, através de papel e lápis, apresenta boa correlação com a medição feita através do PDA (Pile Driving Analyser) e mostra que, com um método simples, pode-se estimar a capacidade de carga do elemento de fundação.

A evolução das parcelas de resistência de ponta e lateral mostra que, para baixos níveis de energia aplicada em $80 \%$ dos casos analisados, a parcela de resistência de ponta é menor que $50 \%$ e, à medida que aumentam os níveis de energia esta parcela ultrapassa a porcentagem referida. Em $100 \%$ das provas de carga dinâmica, para a carga máxima aplicada, a parcela de resistência de ponta é, em média, de $73 \%$.

Para os tubulões não inundados, há um crescimento da resistência total mobilizada com o aumento de energia aplicada ao sistema. O coeficiente de variação foi praticamente constante em torno de $30 \%$.

Para os tubulões não inundados, a resistência lateral mobilizada diminui acentuadamente, com o aumento da energia aplicada ao sistema, e a grande variabilidade encontrada foi caracterizada pela presença de tensões residuais. Com relação à resistência de ponta mobilizada, esta cresce com o aumento da energia aplicada ao sistema. Sua variabilidade diminui com o aumento da energia aplicada.

Para os tubulões pré-inundados, há um crescimento da resistência total mobilizada com o aumento de energia aplicada, apresentando um coeficiente de variação de $6 \%$, mostrando que o ensaio com pré-inundação apresenta resultados mais homogêneos que os não inundados.

Ainda sobre os ensaios pré-inundados, a resistência lateral mobilizada diminui e a resistência de ponta mobilizada cresce com o aumento da energia aplicada ao sistema. O coeficiente de variação se eleva para a resistência lateral mobilizada e diminui para a resistência de ponta mobilizada. Salienta-se que, apesar de apresentar os mesmos comportamentos dos ensaios nos tubulões não inundados, os coeficientes de variação são mais baixos nos ensaios inundados, demonstrando que a presença da água no solo provoca uma homogeneidade nos resultados.

Com relação à energia máxima medida a nível dos sensores (EMX), conclui-se que cresce tanto nos ensaios não inundados quanto nos pré-inundados, com o aumento 
da energia potencial aplicada, apresentando uma variabilidade bem menor nos ensaios pré-inundados, mostrando, mais uma vez, a homogeneidade nos resultados deste ensaio.

A eficiência do bate-estaca não é constante, dessa forma, é necessário um estudo da eficiência, para verificar a variabilidade da energia aplicada, que influi na resistência total mobilizada.

A comparação entre as provas de carga estática e dinâmica para ensaios não inundados com relação à resistência lateral mostrou que a carga determinada, através do ensaio estático, foi cerca de $18 \%$ maior que a determinada no dinâmico. Tal comportamento é comprovado através da análise da pressão de sucção média, que, no ensaio estático, apresenta-se cerca de $24 \%$ maior que no ensaio dinâmico. Sendo assim, comprova-se que, para solos não-saturados e colapsíveis quanto maior a pressão de sucção, maior a resistência do solo quanto à solicitação. Com relação aos ensaios préinundados, os resultados mostraram que a resistência lateral no ensaio dinâmico é $68 \%$ maior que no estático, apesar de as pressões de sucção médias e dos recalques serem próximos. Neste caso, acredita-se que o tempo de inundação tenha influenciado. Os ensaios dinâmicos foram inundados por 12 horas, antes da realização deste, já os estáticos foram inundados com 48 horas de antecedência. Sendo assim, o solo, no ensaio estático, estava mais saturado que no ensaio dinâmico, apesar das pressões de sucções médias estarem próximas, mas, para bom conhecedor, a média, muitas vezes não é representativa.

Os resultados das provas de carga dinâmica de energia crescente mostram que a resposta do sistema isolado de fundação em tubulão é diferente a cada nível de energia aplicada e que a história de carregamento do elemento isolado de fundação é de extrema importância para análise dos ensaios nele realizados.

A variabilidade nos resultados dos ensaios SPT e CPTU são também verificadas nas provas de carga estática e dinâmica analisadas no Campo Experimental de Fundações da EESC/USP, não só neste trabalho, mas em todos os outros que o antecederam. 


\section{2 - Sugestões}

Sugerem-se os seguintes temas para pesquisas:

a) Fazer um estudo aprofundado sobre as tensões residuais nos ensaios de carregamento dinâmico, com o objetivo de quantificá-las;

b) Analisar minuciosamente a influência da pressão de sucção na resistência do solo, nos locais onde existem solos não-saturados e colapsíveis, através de ensaios estáticos e dinâmicos. Este estudo pode começar a partir de ensaios SPT e CPTU.

c) Fazer um estudo comparativo entre uma prova de carga dinâmica em um elemento de fundação e um ensaio SPT instrumentado, com acelerômetros e células de carga no mesmo maciço de solos ;

d) Fazer um estudo comparativo entre uma prova de carga estática em um elemento de fundação e um ensaio CPTU no mesmo maciço de solos ;

e) Verificar a homogeneidade nos ensaios de SPT e CPTU, com o solo inundado e sem inundação, através de várias campanhas; 


\section{Anexo 1 - Controle de Nega e Repique em Campo}

\begin{tabular}{c|c|c|c}
\hline \multicolumn{2}{c|}{ TE01 - 10 Ensaio (Não Inundado) } \\
\hline $\begin{array}{c}\mathbf{H} \\
\text { (Campo) } \\
(\mathbf{m})\end{array}$ & $\begin{array}{c}\mathbf{D} \\
\text { (Campo) } \\
\text { (mm) }\end{array}$ & $\begin{array}{c}\mathbf{S} \\
\text { (Campo) } \\
(\mathbf{m m})\end{array}$ & $\begin{array}{c}\mathbf{K} \\
\text { (Campo) } \\
(\mathbf{m m})\end{array}$ \\
\hline 0,20 & 2,50 & 0,00 & 2,50 \\
\hline 0,25 & 3,00 & 0,00 & 3,00 \\
\hline 0,30 & 3,00 & 0,00 & 3,00 \\
\hline 0,35 & 3,50 & 0,00 & 3,50 \\
\hline 0,40 & 3,00 & 0,00 & 3,00 \\
\hline 0,45 & 4,00 & 1,00 & 3,00 \\
\hline 0,50 & 4,50 & 1,50 & 3,00 \\
\hline 0,60 & 4,75 & 1,50 & 3,25 \\
\hline
\end{tabular}

\begin{tabular}{c|c|c|c}
\hline \multicolumn{4}{c}{ TE01 - 20 Ensaio (Inundado) } \\
\hline $\begin{array}{c}\text { H } \\
\text { (Campo) } \\
(\mathbf{m})\end{array}$ & $\begin{array}{c}\mathbf{D} \\
\text { (Campo) } \\
(\mathbf{m m})\end{array}$ & $\begin{array}{c}\mathbf{S} \\
(\text { Campo) } \\
(\mathbf{m m})\end{array}$ & $\begin{array}{c}\mathbf{K} \\
\text { (Campo) } \\
(\mathbf{m m})\end{array}$ \\
\hline 0,20 & - & - & - \\
\hline 0,25 & - & - & - \\
\hline 0,30 & - & - & - \\
\hline 0,35 & 2,50 & 1,00 & 1,50 \\
\hline 0,40 & 4,50 & 1,50 & 3,00 \\
\hline 0,50 & 5,50 & 1,50 & 4,00 \\
\hline 0,60 & 6,00 & 1,50 & 4,50 \\
\hline
\end{tabular}

\begin{tabular}{c|c|c|c}
\hline \multicolumn{2}{c}{ TE02 - 20 Ensaio (Não Inundado) } \\
\hline $\begin{array}{c}\text { H } \\
\text { (Campo) } \\
(\mathbf{m})\end{array}$ & $\begin{array}{c}\mathbf{D} \\
\text { (Campo) } \\
(\mathbf{m m})\end{array}$ & $\begin{array}{c}\mathbf{S} \\
\text { (Campo) } \\
(\mathbf{m m})\end{array}$ & $\begin{array}{c}\mathbf{K} \\
\text { (Campo) } \\
(\mathbf{m m})\end{array}$ \\
\hline 0,20 & 3,50 & 0,00 & 3,50 \\
\hline 0,25 & 3,75 & 0,00 & 3,75 \\
\hline 0,30 & 4,00 & 1,50 & 2,50 \\
\hline 0,35 & 4,25 & 1,50 & 2,75 \\
\hline 0,40 & 4,75 & 1,50 & 3,25 \\
\hline 0,45 & 5,00 & 1,50 & 3,50 \\
\hline 0,50 & 5,50 & 2,00 & 3,50 \\
\hline 0,60 & 6,00 & 2,00 & 4,00 \\
\hline 0,80 & 6,00 & 2,00 & 4,00 \\
\hline 1,00 & 8,00 & 3,00 & 5,00 \\
\hline
\end{tabular}

\begin{tabular}{c|c|c|c}
\hline \multicolumn{3}{c}{ TE03 - 10 Ensaio (Não Inundado) } \\
\hline $\begin{array}{c}\text { H } \\
\text { (Campo) } \\
(\mathbf{m})\end{array}$ & $\begin{array}{c}\mathbf{D} \\
\text { (Campo) } \\
(\mathbf{m m})\end{array}$ & $\begin{array}{c}\mathbf{S} \\
\text { (Campo) } \\
\text { (mm) }\end{array}$ & $\begin{array}{c}\mathbf{K} \\
\text { (Campo) } \\
(\mathbf{m m})\end{array}$ \\
\hline 0,20 & 2,50 & 0,00 & 2,50 \\
\hline 0,40 & 4,00 & 1,00 & 3,00 \\
\hline 0,60 & 5,50 & 1,50 & 4,00 \\
\hline 0,80 & 6,75 & 2,00 & 4,75 \\
\hline 1,00 & 7,50 & 2,50 & 5,00 \\
\hline
\end{tabular}

\begin{tabular}{|c|c|c|c|}
\hline \multicolumn{4}{|c|}{ TE02 - 1 Ensaio (Não Inundado) } \\
\hline $\begin{array}{c}\mathrm{H} \\
(\text { Campo) } \\
(\mathrm{m})\end{array}$ & $\begin{array}{c}\text { D } \\
(\text { Campo) } \\
(\mathrm{mm})\end{array}$ & $\begin{array}{c}\mathrm{S} \\
(\text { Campo) } \\
(\mathrm{mm})\end{array}$ & $\begin{array}{c}\mathrm{K} \\
(\mathrm{Campo}) \\
(\mathrm{mm})\end{array}$ \\
\hline 0,20 & 2,50 & 0,00 & 2,50 \\
\hline 0,25 & 3,00 & 0,00 & \\
\hline 0,30 & 3,50 & 1,00 & 2,50 \\
\hline 0,35 & 3,50 & 1,00 & 2,50 \\
\hline 0,40 & 4,00 & 1,00 & 3,00 \\
\hline 0,45 & 4,50 & 1,00 & 3,50 \\
\hline 0,50 & 5,00 & 1,00 & 4,00 \\
\hline 0,60 & 5,00 & 1,50 & 3,50 \\
\hline 0,80 & 6,00 & 1,50 & 4,50 \\
\hline 1,00 & 7,25 & 2,00 & 5,25 \\
\hline \multicolumn{4}{|c|}{ TE03 - 2 Ensaio (Não Inundado) } \\
\hline $\begin{array}{c}\mathrm{H} \\
\text { (Campo) } \\
(\mathrm{m})\end{array}$ & $\begin{array}{c}\text { D } \\
\text { (Campo) } \\
(\mathrm{mm})\end{array}$ & $\begin{array}{c}\mathrm{S} \\
(\mathrm{Campo}) \\
(\mathrm{mm})\end{array}$ & $\begin{array}{c}\mathrm{K} \\
\text { (Campo) } \\
(\mathrm{mm})\end{array}$ \\
\hline 0,20 & 4,00 & 0,00 & 4,00 \\
\hline 0,40 & 5,00 & 1,00 & 4,00 \\
\hline 0,60 & 6,50 & 1,50 & 5,00 \\
\hline 0,80 & 7,00 & 2,00 & 5,00 \\
\hline 1,00 & 7,00 & 3,00 & 4,00 \\
\hline
\end{tabular}




\begin{tabular}{c|c|c|c}
\hline \multicolumn{4}{c}{ TE04 - 10 Ensaio (Não Inundado) } \\
\hline $\begin{array}{c}\text { H } \\
\begin{array}{c}\text { Campo) } \\
(\mathbf{m})\end{array}\end{array}$ & $\begin{array}{c}\mathbf{D} \\
\text { (Campo) } \\
(\mathbf{m m})\end{array}$ & $\begin{array}{c}\text { S } \\
\text { (Campo) } \\
(\mathbf{m m})\end{array}$ & $\begin{array}{c}\mathrm{K} \\
\left(\begin{array}{c}\text { Campo) } \\
(\mathbf{m m})\end{array}\right.\end{array}$ \\
\hline 0,20 & 2,00 & 0,00 & 2,00 \\
\hline 0,40 & 3,50 & 1,00 & 2,50 \\
\hline 0,60 & 5,00 & 1,50 & 3,50 \\
\hline 0,80 & 5,50 & 1,50 & 4,00 \\
\hline 1,00 & 6,50 & 2,00 & 4,50 \\
\hline
\end{tabular}

\begin{tabular}{c|c|c|c}
\hline \multicolumn{3}{c}{ TE04 - 20 Ensaio (Não Inundado) } \\
\hline $\begin{array}{c}\mathbf{H} \\
\left(\begin{array}{c}\text { Campo) } \\
(\mathbf{m})\end{array}\right.\end{array}$ & $\begin{array}{c}\mathbf{D} \\
(\text { Campo) } \\
(\mathbf{m m})\end{array}$ & $\begin{array}{c}\mathbf{S} \\
(\text { Campo) } \\
(\mathbf{m m})\end{array}$ & $\begin{array}{c}\mathbf{K} \\
\left(\begin{array}{c}\text { Campo) } \\
(\mathbf{m m})\end{array}\right.\end{array}$ \\
\hline 0,20 & 3,00 & 0,00 & 3,00 \\
\hline 0,40 & 4,50 & 1,00 & 3,50 \\
\hline 0,60 & 6,00 & 1,50 & 4,50 \\
\hline 0,80 & 6,50 & 1,50 & 5,00 \\
\hline 1,00 & 7,25 & 2,00 & 5,25 \\
\hline
\end{tabular}

\begin{tabular}{c|c|c|c}
\hline \multicolumn{3}{c}{ TE04 - 3o Ensaio (Não Inundado) } \\
\hline $\begin{array}{c}\mathbf{H} \\
\left(\begin{array}{c}\text { Campo) } \\
(\mathbf{m})\end{array}\right.\end{array}$ & $\begin{array}{c}\mathbf{D} \\
(\text { Campo) } \\
(\mathbf{m m})\end{array}$ & $\begin{array}{c}\mathbf{S} \\
(\text { Campo) } \\
(\mathbf{m m})\end{array}$ & $\begin{array}{c}\mathrm{K} \\
(\text { Campo) } \\
(\mathbf{m m})\end{array}$ \\
\hline 0,20 & 2,50 & 0,00 & 2,50 \\
\hline 0,25 & 3,00 & 0,00 & 3,00 \\
\hline 0,30 & 3,50 & 0,00 & 3,50 \\
\hline 0,35 & 4,00 & 1,00 & 3,00 \\
\hline 0,40 & 4,50 & 1,00 & 3,50 \\
\hline 0,45 & 5,00 & 1,00 & 4,00 \\
\hline 0,50 & 5,50 & 1,50 & 4,00 \\
\hline 0,60 & 5,50 & 1,50 & 4,00 \\
\hline
\end{tabular}

\begin{tabular}{c|c|c|c}
\hline \multicolumn{4}{c|}{ TE04 - 4o Ensaio (Inundado) } \\
\hline $\begin{array}{c}\mathbf{H} \\
\begin{array}{c}\text { Campo) } \\
(\mathbf{m})\end{array}\end{array}$ & $\begin{array}{c}\mathbf{D} \\
\text { (Campo) } \\
(\mathbf{m m})\end{array}$ & $\begin{array}{c}\mathbf{S} \\
(\text { Campo) } \\
(\mathbf{m m})\end{array}$ & $\begin{array}{c}\mathbf{K} \\
(\text { Campo) } \\
(\mathbf{m m})\end{array}$ \\
\hline 0,20 & 2,50 & 0,00 & 2,50 \\
\hline 0,25 & 3,00 & 0,00 & 3,00 \\
\hline 0,30 & 3,50 & 0,00 & 3,50 \\
\hline 0,35 & 4,00 & 1,00 & 3,00 \\
\hline 0,40 & 4,50 & 1,00 & 3,50 \\
\hline 0,45 & 5,00 & 1,00 & 4,00 \\
\hline 0,50 & 5,00 & 1,00 & 4,00 \\
\hline 0,60 & 5,50 & 1,50 & 4,00 \\
\hline
\end{tabular}




\section{Anexo 2 - Levantamento Topográfico}

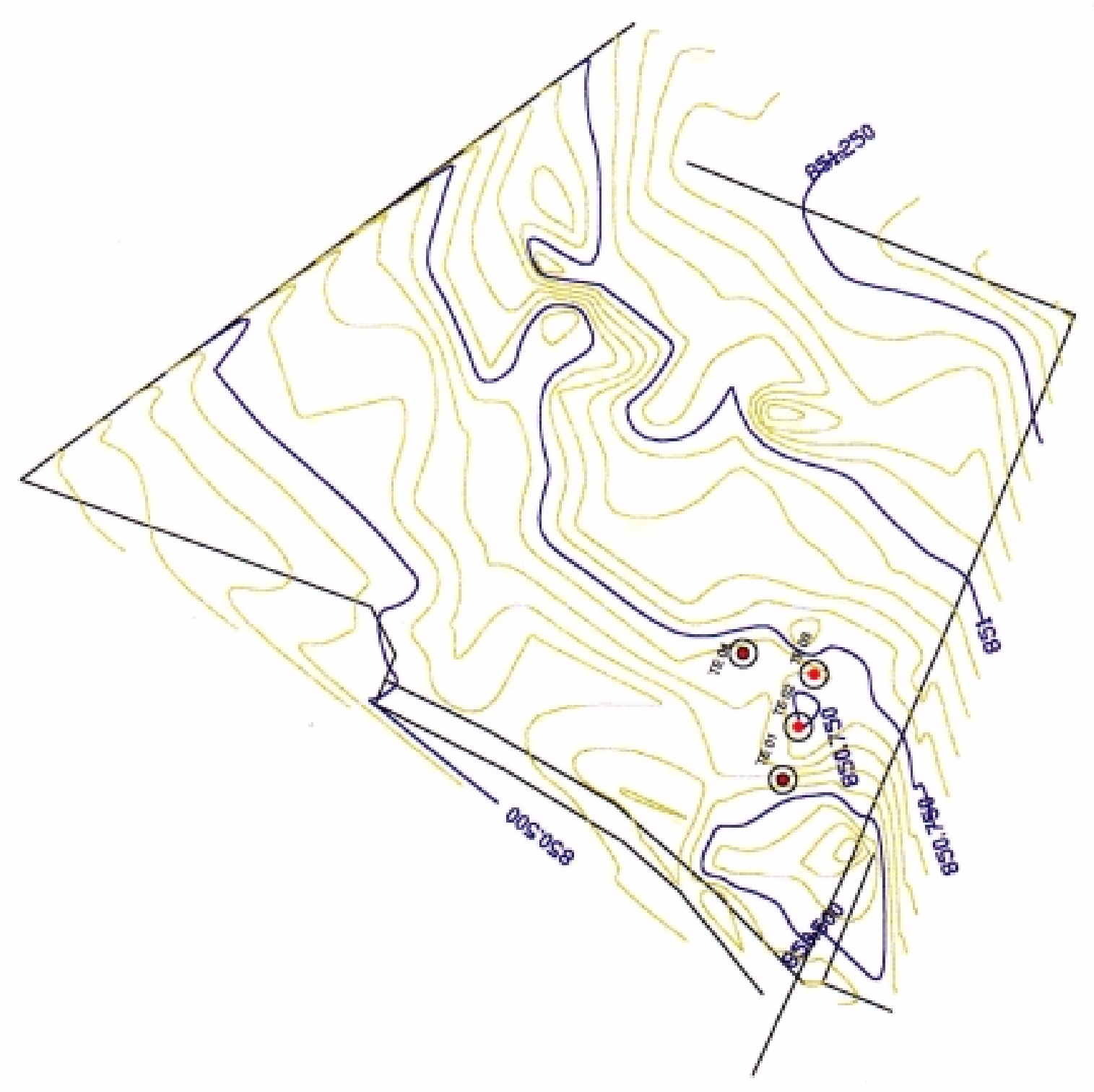


Anexo 3 - Análise Estatística do Ensaio Dinâmico

\begin{tabular}{|c|c|c|c|c|c|}
\hline \multicolumn{6}{|c|}{ TE01 - 1ํEnsaio (Não Inundado) } \\
\hline $\begin{array}{c}\mathrm{H} \\
\text { (Campo) } \\
(\mathrm{m})\end{array}$ & $\begin{array}{c}\text { DMX } \\
\text { (PDA) } \\
(\mathrm{mm})\end{array}$ & $\begin{array}{c}\text { EMX } \\
\text { (PDA) } \\
(\mathrm{kJ})\end{array}$ & $\begin{array}{c}\mathbf{R}_{\mathrm{L}} \\
\text { (Capwap) } \\
(\mathrm{kN})\end{array}$ & $\begin{array}{c}\mathbf{R}_{\mathrm{P}} \\
\text { (Capwap) } \\
(\mathrm{kN})\end{array}$ & $\begin{array}{c}\mathbf{R}_{\mathrm{T}} \\
(\text { Capwap) } \\
(\mathrm{kN})\end{array}$ \\
\hline 0,20 & 2,83 & 1,1 & 165,1 & 241,9 & 407,0 \\
\hline 0,40 & 3,83 & 2,2 & 243,4 & 203,9 & 447,3 \\
\hline 0,60 & 4,77 & 3,6 & 172,7 & 295,8 & 468,5 \\
\hline \multicolumn{6}{|c|}{ TE02 - 1ํㅡssaio (Não Inundado) } \\
\hline $\begin{array}{c}\mathrm{H} \\
\text { (Campo) } \\
(\mathrm{m})\end{array}$ & $\begin{array}{c}\text { DMX } \\
\text { (PDA) } \\
(\mathrm{mm})\end{array}$ & $\begin{array}{c}\text { EMX } \\
\text { (PDA) } \\
(\mathrm{kJ})\end{array}$ & $\begin{array}{c}\mathbf{R}_{\mathrm{L}} \\
\text { (Capwap) } \\
(\mathrm{kN})\end{array}$ & $\begin{array}{c}\mathbf{R}_{\mathrm{P}} \\
\text { (Capwap) } \\
(\mathrm{kN})\end{array}$ & $\begin{array}{c}\mathbf{R}_{\mathrm{T}} \\
(\text { Capwap) } \\
(\mathrm{kN})\end{array}$ \\
\hline 0,20 & 2,35 & 1,0 & 193,8 & 176,9 & 370,7 \\
\hline 0,40 & 3,87 & 2,4 & 285,0 & 128,8 & 413,8 \\
\hline 0,60 & 4,84 & 3,9 & 156,1 & 294,7 & 450,8 \\
\hline 0,80 & 6,12 & 5,5 & 228,2 & 260,3 & 488,5 \\
\hline 1,00 & 7,22 & 6,8 & 210,8 & 308,1 & 518,9 \\
\hline \multicolumn{6}{|c|}{ TE02 - 2 Ensaio (Não Inundado) } \\
\hline $\begin{array}{c}\mathrm{H} \\
\text { (Campo) } \\
(\mathrm{m})\end{array}$ & $\begin{array}{c}\text { DMX } \\
\text { (PDA) } \\
(\mathrm{mm})\end{array}$ & $\begin{array}{c}\text { EMX } \\
\text { (PDA) } \\
(\mathrm{kJ})\end{array}$ & $\begin{array}{c}R_{\mathrm{L}} \\
(\text { Capwap) } \\
(\mathrm{kN})\end{array}$ & $\begin{array}{c}\mathrm{R}_{\mathrm{P}} \\
\text { (Capwap) } \\
(\mathrm{kN})\end{array}$ & $\begin{array}{c}\mathbf{R}_{\mathrm{T}} \\
(\text { Capwap) } \\
(\mathrm{kN})\end{array}$ \\
\hline 0,20 & 3,29 & 1,3 & 258,2 & 66,5 & 324,7 \\
\hline 0,40 & 4,71 & 2,9 & 178,6 & 201,0 & 379,6 \\
\hline 0,60 & 6,31 & 4,8 & 43,3 & 408,6 & 451,9 \\
\hline 0,80 & 6,40 & 4,7 & 89,4 & 376,4 & 465,8 \\
\hline 1,00 & 8,43 & 7,0 & 19,3 & 475,7 & 495,0 \\
\hline \multicolumn{6}{|c|}{ TE03 - 1ํㅡsaio (Não Inundado) } \\
\hline $\begin{array}{c}\mathrm{H} \\
\text { (Campo) } \\
(\mathrm{m})\end{array}$ & $\begin{array}{c}\text { DMX } \\
\text { (PDA) } \\
(\mathrm{mm})\end{array}$ & $\begin{array}{c}\text { EMX } \\
\text { (PDA) } \\
(\mathrm{kJ})\end{array}$ & $\begin{array}{c}\mathbf{R}_{\mathrm{L}} \\
\text { (Capwap) } \\
(\mathrm{kN})\end{array}$ & $\begin{array}{c}\mathbf{R}_{\mathrm{P}} \\
\text { (Capwap) } \\
(\mathrm{kN})\end{array}$ & $\begin{array}{c}\mathbf{R}_{\mathrm{T}} \\
\text { (Capwap) } \\
(\mathrm{kN})\end{array}$ \\
\hline 0,20 & 2,83 & 1,1 & 222,5 & 177,8 & 400,3 \\
\hline 0,40 & 4,28 & 2,2 & 261,4 & 155,7 & 417,1 \\
\hline 0,60 & 5,55 & 2,4 & 132,3 & 299,2 & 431,5 \\
\hline 0,80 & 6,84 & 3,2 & 81,9 & 386,7 & 468,6 \\
\hline 1,00 & 7,85 & 4,1 & 75,5 & 419,3 & 494,8 \\
\hline \multicolumn{6}{|c|}{ TE03 - 2 Ensaio (Não Inundado) } \\
\hline $\begin{array}{c}\mathrm{H} \\
\text { (Campo) } \\
(\mathrm{m})\end{array}$ & $\begin{array}{l}\text { DMX } \\
\text { (PDA) } \\
(\mathrm{mm})\end{array}$ & $\begin{array}{c}\text { EMX } \\
\text { (PDA) } \\
(\mathrm{kJ})\end{array}$ & $\begin{array}{c}R_{\mathrm{L}} \\
\text { (Capwap) } \\
(\mathrm{kN})\end{array}$ & $\begin{array}{c}\mathbf{R}_{\mathrm{P}} \\
\text { (Capwap) } \\
(\mathrm{kN})\end{array}$ & $\begin{array}{c}\mathbf{R}_{\mathrm{T}} \\
\text { (Capwap) } \\
(\mathrm{kN})\end{array}$ \\
\hline 0,20 & 4,10 & 1,8 & 86,5 & 305,2 & 391,7 \\
\hline 0,40 & 5,36 & 3,2 & 110,7 & 318,8 & 429,5 \\
\hline 0,60 & 6,72 & 3,7 & 123,5 & 335,2 & 458,7 \\
\hline 0,80 & 7,65 & 3,4 & 35,0 & 441,6 & 476,6 \\
\hline 1,00 & 8,38 & 4,3 & 87,0 & 409,6 & 496,6 \\
\hline
\end{tabular}




\begin{tabular}{|c|c|c|c|c|c|}
\hline \multicolumn{6}{|c|}{ TE04 - 1ํEsaio (Não Inundado) } \\
\hline $\begin{array}{c}\mathrm{H} \\
\text { (Campo) } \\
(\mathrm{m})\end{array}$ & $\begin{array}{c}\text { DMX } \\
\text { (PDA) } \\
(\mathrm{mm})\end{array}$ & $\begin{array}{c}\text { EMX } \\
\text { (PDA) } \\
(\mathbf{k J})\end{array}$ & $\begin{array}{c}\mathbf{R}_{\mathrm{L}} \\
\text { (Capwap) } \\
(\mathrm{kN})\end{array}$ & $\begin{array}{c}\mathbf{R}_{\mathrm{P}} \\
\text { (Capwap) } \\
(\mathrm{kN})\end{array}$ & $\begin{array}{c}\mathbf{R}_{\mathrm{T}} \\
(\text { Capwap) } \\
(\mathrm{kN})\end{array}$ \\
\hline 0,20 & 2,21 & 1,7 & 585,7 & 31,9 & 617,6 \\
\hline 0,40 & 3,60 & 4,0 & 569,3 & 175,6 & 744,9 \\
\hline 0,60 & 5,14 & 5,4 & 314,3 & 435,3 & 749,6 \\
\hline 0,80 & 5,63 & 7,1 & 263,2 & 512,0 & 775,2 \\
\hline 1,00 & 6,62 & 8,0 & 274,2 & 687,8 & 962,0 \\
\hline \multicolumn{6}{|c|}{ TE04 - 2 Ensaio (Não Inundado) } \\
\hline $\begin{array}{c}\mathbf{H} \\
\text { (Campo) } \\
(\mathrm{m})\end{array}$ & $\begin{array}{c}\text { DMX } \\
\text { (PDA) } \\
(\mathrm{mm})\end{array}$ & $\begin{array}{c}\text { EMX } \\
\text { (PDA) } \\
(\mathrm{kJ})\end{array}$ & $\begin{array}{c}\mathbf{R}_{\mathrm{L}} \\
\text { (Capwap) } \\
(\mathrm{kN})\end{array}$ & $\begin{array}{c}\mathbf{R}_{\mathrm{P}} \\
\text { (Capwap) } \\
(\mathbf{k N})\end{array}$ & $\begin{array}{c}\mathbf{R}_{\mathrm{T}} \\
(\text { Capwap) } \\
(\mathrm{kN})\end{array}$ \\
\hline 0,20 & 2,87 & 2,5 & 366,3 & 331,0 & 697,3 \\
\hline 0,40 & 4,27 & 5,1 & 410,5 & 330,3 & 740,8 \\
\hline 0,60 & 5,52 & 6,5 & 284,7 & 465,6 & 750,3 \\
\hline 0,80 & 6,24 & 8,1 & 309,0 & 472,7 & 781,7 \\
\hline 1,00 & 7,17 & 9,5 & 361,8 & 538,4 & 900,2 \\
\hline \multicolumn{6}{|c|}{ TE04 - 3ํEsaio (Não Inundado) } \\
\hline $\begin{array}{c}\mathrm{H} \\
\text { (Campo) } \\
(\mathrm{m})\end{array}$ & $\begin{array}{c}\text { DMX } \\
\text { (PDA) } \\
(\mathrm{mm}) \\
\end{array}$ & $\begin{array}{c}\text { EMX } \\
\text { (PDA) } \\
(\mathbf{k J})\end{array}$ & $\begin{array}{c}R_{\mathrm{L}} \\
\text { (Capwap) } \\
(\mathrm{kN})\end{array}$ & $\begin{array}{c}\mathbf{R}_{\mathrm{P}} \\
\text { (Capwap) } \\
(\mathbf{k N})\end{array}$ & $\begin{array}{c}\mathbf{R}_{\mathrm{T}} \\
(\mathrm{Capwap}) \\
(\mathrm{kN})\end{array}$ \\
\hline 0,25 & 3,29 & 2,0 & 486,7 & 53,0 & 539,7 \\
\hline 0,40 & 4,62 & 3,8 & 466,1 & 236,1 & 702,2 \\
\hline 0,60 & 6,15 & 6,1 & 314,2 & 437,7 & 751,9 \\
\hline \multicolumn{6}{|c|}{ Estatística (Valor Mínimo) } \\
\hline $\begin{array}{c}\mathrm{H} \\
\text { (Campo) } \\
(\mathrm{m})\end{array}$ & $\begin{array}{c}\text { DMX } \\
\text { (PDA) } \\
(\mathrm{mm})\end{array}$ & $\begin{array}{c}\text { EMX } \\
\text { (PDA) } \\
(\mathrm{kJ}) \\
\end{array}$ & $\begin{array}{c}R_{\mathrm{L}} \\
\text { (Capwap) } \\
(\mathrm{kN})\end{array}$ & $\begin{array}{c}\mathbf{R}_{\mathrm{P}} \\
\text { (Capwap) } \\
(\mathbf{k N})\end{array}$ & $\begin{array}{c}\mathbf{R}_{\mathrm{T}} \\
(\mathrm{Capwap}) \\
(\mathrm{kN})\end{array}$ \\
\hline 0,20 & 2,87 & 1,0 & 86,5 & 31,9 & 324,7 \\
\hline 0,40 & 4,27 & 2,2 & 110,7 & 128,8 & 379,6 \\
\hline 0,60 & 5,52 & 2,4 & 43,3 & 294,7 & 431,5 \\
\hline 0,80 & 6,24 & 3,2 & 35,0 & 260,3 & 465,8 \\
\hline 1,00 & 7,17 & 4,1 & 19,3 & 308,1 & 494,8 \\
\hline \multicolumn{6}{|c|}{ Estatística (Valor Máximo) } \\
\hline $\begin{array}{c}\mathrm{H} \\
\text { (Campo) } \\
(\mathrm{m})\end{array}$ & $\begin{array}{c}\text { DMX } \\
\text { (PDA) } \\
(\mathrm{mm}) \\
\end{array}$ & $\begin{array}{c}\text { EMX } \\
\text { (PDA) } \\
(\mathrm{kJ})\end{array}$ & $\begin{array}{c}\mathbf{R}_{\mathrm{L}} \\
\text { (Capwap) } \\
(\mathrm{kN})\end{array}$ & $\begin{array}{c}\mathbf{R}_{\mathrm{P}} \\
(\text { Capwap) } \\
(\mathbf{k N}) \\
\end{array}$ & $\begin{array}{c}\mathbf{R}_{\mathrm{T}} \\
(\mathrm{Capwap}) \\
(\mathrm{kN})\end{array}$ \\
\hline 0,20 & 2,87 & 2,5 & 585,7 & 331,0 & 697,3 \\
\hline 0,40 & 4,27 & 5,1 & 569,3 & 330,3 & 744,9 \\
\hline 0,60 & 5,52 & 6,5 & 314,3 & 465,6 & 751,9 \\
\hline 0,80 & 6,24 & 8,1 & 309,0 & 512,0 & 781,7 \\
\hline 1,00 & 7,17 & 9,5 & 361,8 & 687,8 & 962,0 \\
\hline
\end{tabular}




\begin{tabular}{|c|c|c|c|c|c|}
\hline \multicolumn{6}{|c|}{ Estatística (Média) } \\
\hline $\begin{array}{c}\mathrm{H} \\
\text { (Campo) } \\
(\mathrm{m})\end{array}$ & $\begin{array}{c}\text { DMX } \\
\text { (PDA) } \\
\text { (mm) }\end{array}$ & $\begin{array}{c}\text { EMX } \\
\text { (PDA) } \\
(\mathrm{kJ})\end{array}$ & $\begin{array}{c}\mathbf{R}_{\mathrm{L}} \\
\text { (Capwap) } \\
(\mathrm{kN})\end{array}$ & $\begin{array}{c}\mathbf{R}_{\mathrm{P}} \\
\text { (Capwap) } \\
(\mathrm{kN})\end{array}$ & $\begin{array}{c}\mathbf{R}_{\mathrm{T}} \\
(\text { Capwap) } \\
(\mathrm{kN})\end{array}$ \\
\hline 0,20 & 3,0 & 1,6 & 295,6 & 173,0 & 468,6 \\
\hline 0,40 & 4,3 & 3,2 & 315,6 & 218,8 & 534,4 \\
\hline 0,60 & 5,6 & 4,6 & 192,6 & 371,5 & 564,2 \\
\hline 0,80 & 6,5 & 5,3 & 167,8 & 408,3 & 576,1 \\
\hline 1,00 & 7,6 & 6,6 & 171,4 & 473,2 & 644,6 \\
\hline \multicolumn{6}{|c|}{ Estatística (Coef. De Variação) } \\
\hline $\begin{array}{c}\mathbf{H} \\
\text { (Campo) } \\
(\mathrm{m})\end{array}$ & $\begin{array}{c}\text { DMX } \\
\text { (PDA) } \\
\text { (mm) }\end{array}$ & $\begin{array}{c}\text { EMX } \\
\text { (PDA) } \\
(\mathrm{kJ})\end{array}$ & $\begin{array}{c}\mathbf{R}_{\mathrm{L}} \\
\text { (Capwap) } \\
(\mathrm{kN})\end{array}$ & $\begin{array}{c}\mathbf{R}_{\mathrm{P}} \\
\text { (Capwap) } \\
(\mathrm{kN})\end{array}$ & $\begin{array}{c}\mathbf{R}_{\mathbf{T}} \\
\text { (Capwap) } \\
\text { (kN) }\end{array}$ \\
\hline 0,20 & $20 \%$ & $33 \%$ & $58 \%$ & $67 \%$ & $28 \%$ \\
\hline 0,40 & $13 \%$ & $32 \%$ & $49 \%$ & $33 \%$ & $30 \%$ \\
\hline 0,60 & $13 \%$ & $31 \%$ & $52 \%$ & $20 \%$ & $27 \%$ \\
\hline 0,80 & $11 \%$ & $37 \%$ & $67 \%$ & $22 \%$ & $27 \%$ \\
\hline 1,00 & $10 \%$ & $32 \%$ & $77 \%$ & $27 \%$ & $35 \%$ \\
\hline
\end{tabular}

\begin{tabular}{|c|c|c|c|c|c|}
\hline \multicolumn{6}{|c|}{ TE01 - 2 Ensaio (Pré-Inundado) } \\
\hline $\begin{array}{c}\mathrm{H} \\
\text { (Campo) } \\
(\mathrm{m})\end{array}$ & $\begin{array}{c}\text { DMX } \\
\text { (PDA) } \\
(\mathrm{mm})\end{array}$ & $\begin{array}{c}\text { EMX } \\
\text { (PDA) } \\
(\mathrm{kJ})\end{array}$ & $\begin{array}{c}\mathbf{R}_{\mathrm{L}} \\
(\text { Capwap) } \\
(\mathrm{kN})\end{array}$ & $\begin{array}{c}\mathbf{R}_{\mathrm{P}} \\
(\text { Capwap) } \\
(\mathrm{kN})\end{array}$ & $\begin{array}{c}\mathbf{R}_{\mathrm{T}} \\
(\text { Capwap) } \\
(\mathrm{kN})\end{array}$ \\
\hline 0,25 & 3,18 & 1,3 & 231,6 & 132,5 & 364,1 \\
\hline 0,40 & 4,71 & 2,4 & 112,1 & 292,8 & 404,9 \\
\hline 0,60 & 6,07 & 3,8 & 101,4 & 346,4 & 447,8 \\
\hline \multicolumn{6}{|c|}{ TE04 - 4º Ensaio (Pré-Inundado) } \\
\hline $\begin{array}{c}\mathrm{H} \\
\text { (Campo) } \\
(\mathrm{m})\end{array}$ & $\begin{array}{c}\text { DMX } \\
\text { (PDA) } \\
(\mathrm{mm})\end{array}$ & $\begin{array}{c}\text { EMX } \\
\text { (PDA) } \\
(\mathrm{kJ})\end{array}$ & $\begin{array}{c}\mathbf{R}_{\mathrm{L}} \\
(\text { Capwap) } \\
(\mathrm{kN})\end{array}$ & $\begin{array}{c}\mathbf{R}_{\mathrm{P}} \\
(\mathrm{Capwap}) \\
(\mathrm{kN})\end{array}$ & $\begin{array}{c}\mathbf{R}_{\mathrm{T}} \\
(\mathrm{Capwap}) \\
(\mathrm{kN})\end{array}$ \\
\hline 0,20 & 2,71 & 1,1 & 202,6 & 185,8 & 388,4 \\
\hline 0,40 & 4,81 & 2,9 & 123,6 & 322,0 & 445,6 \\
\hline 0,60 & 6,30 & 4,5 & 62,3 & 426,4 & 488,7 \\
\hline
\end{tabular}




\begin{tabular}{|c|c|c|c|c|c|}
\hline \multicolumn{6}{|c|}{ Estatística (Valor Mínimo) } \\
\hline $\begin{array}{c}\mathrm{H} \\
\text { (Campo) } \\
(\mathrm{m})\end{array}$ & $\begin{array}{c}\text { DMX } \\
\text { (PDA) } \\
(\mathrm{mm})\end{array}$ & $\begin{array}{c}\text { EMX } \\
\text { (PDA) } \\
(\mathrm{kJ})\end{array}$ & $\begin{array}{c}R_{L} \\
\text { (Capwap) } \\
(k N)\end{array}$ & $\begin{array}{c}\mathbf{R}_{\mathrm{P}} \\
\text { (Capwap) } \\
(\mathrm{kN})\end{array}$ & $\begin{array}{c}\mathbf{R}_{\mathrm{T}} \\
\text { (Capwap) } \\
(\mathrm{kN})\end{array}$ \\
\hline 0,20 & 2,87 & 1,1 & 202,6 & 132,5 & 364,1 \\
\hline 0,40 & 4,27 & 2,4 & 112,1 & 292,8 & 404,9 \\
\hline 0,60 & 5,52 & 3,8 & 62,3 & 346,4 & 447,8 \\
\hline \multicolumn{6}{|c|}{ Estatística (Valor Máximo) } \\
\hline $\begin{array}{c}\mathrm{H} \\
\text { (Campo) } \\
(\mathrm{m})\end{array}$ & $\begin{array}{c}\text { DMX } \\
\text { (PDA) } \\
(\mathrm{mm})\end{array}$ & $\begin{array}{c}\text { EMX } \\
\text { (PDA) } \\
(\mathrm{kJ})\end{array}$ & $\begin{array}{c}\mathbf{R}_{\mathrm{L}} \\
(\text { Capwap) } \\
(\mathrm{kN})\end{array}$ & $\begin{array}{c}\mathbf{R}_{\mathrm{P}} \\
\text { (Capwap) } \\
(\mathrm{kN})\end{array}$ & $\begin{array}{c}\mathbf{R}_{\mathrm{T}} \\
\text { (Capwap) } \\
(\mathrm{kN})\end{array}$ \\
\hline 0,20 & 2,87 & 1,3 & 231,6 & 185,8 & 388,4 \\
\hline 0,40 & 4,27 & 2,9 & 123,6 & 322,0 & 445,6 \\
\hline 0,60 & 5,52 & 4,5 & 101,4 & 426,4 & 488,7 \\
\hline \multicolumn{6}{|c|}{ Estatística (Média) } \\
\hline $\begin{array}{c}\mathrm{H} \\
\text { (Campo) } \\
(\mathrm{m})\end{array}$ & $\begin{array}{c}\text { DMX } \\
\text { (PDA) } \\
(\mathrm{mm})\end{array}$ & $\begin{array}{c}\text { EMX } \\
\text { (PDA) } \\
(\mathrm{kJ})\end{array}$ & $\begin{array}{c}\mathbf{R}_{\mathrm{L}} \\
(\text { Capwap) } \\
(\mathrm{kN})\end{array}$ & $\begin{array}{c}\mathbf{R}_{\mathrm{P}} \\
\text { (Capwap) } \\
(\mathrm{kN})\end{array}$ & $\begin{array}{c}\mathbf{R}_{\mathrm{T}} \\
(\text { Capwap) } \\
(\mathrm{kN})\end{array}$ \\
\hline 0,20 & 2,9 & 1,2 & 217,1 & 159,2 & 376,3 \\
\hline 0,40 & 4,8 & 2,7 & 117,9 & 307,4 & 425,3 \\
\hline 0,60 & 6,2 & 4,2 & 81,9 & 386,4 & 468,3 \\
\hline \multicolumn{6}{|c|}{ Estatística (Coef. De Variação) } \\
\hline $\begin{array}{c}\mathrm{H} \\
\text { (Campo) } \\
(\mathrm{m})\end{array}$ & $\begin{array}{c}\text { DMX } \\
\text { (PDA) } \\
(\mathrm{mm})\end{array}$ & $\begin{array}{c}\text { EMX } \\
\text { (PDA) } \\
(\mathrm{kJ})\end{array}$ & $\begin{array}{c}\mathbf{R}_{\mathrm{L}} \\
(\text { Capwap) } \\
(\mathrm{kN})\end{array}$ & $\begin{array}{c}\mathbf{R}_{\mathrm{P}} \\
\left(\begin{array}{c}\text { Capwap) } \\
(\mathrm{kN})\end{array}\right.\end{array}$ & $\begin{array}{c}\mathbf{R}_{\mathrm{T}} \\
(\text { Capwap) } \\
(\mathrm{kN})\end{array}$ \\
\hline 0,20 & $11 \%$ & $6 \%$ & $9 \%$ & $24 \%$ & $5 \%$ \\
\hline 0,40 & $2 \%$ & $15 \%$ & $7 \%$ & $7 \%$ & $7 \%$ \\
\hline 0,60 & $3 \%$ & $11 \%$ & $34 \%$ & $15 \%$ & $6 \%$ \\
\hline
\end{tabular}


Anexo 4 - Dados do Ensaio de Carregamento Dinâmico de Energia Crescente

\begin{tabular}{|c|c|c|c|c|c|}
\hline \multicolumn{6}{|c|}{ TE01 - 1ํEnsaio (Não Inundado) } \\
\hline $\begin{array}{c}\mathbf{H} \\
\text { (Campo) } \\
(\mathrm{m})\end{array}$ & $\begin{array}{c}\text { DMX } \\
\text { (PDA) } \\
(\mathrm{mm})\end{array}$ & $\begin{array}{c}\text { EMX } \\
\text { (PDA) } \\
\text { (kN.m) }\end{array}$ & $\begin{array}{c}\text { FMX } \\
\text { (PDA) } \\
(\mathrm{kN})\end{array}$ & $\begin{array}{c}\text { VMX } \\
\text { (PDA) } \\
(\mathrm{m} / \mathrm{s})\end{array}$ & $\begin{array}{c}\text { Rt } \\
\text { (PDA) } \\
\text { (kN) }\end{array}$ \\
\hline 0,20 & 2,83 & 1,14 & 682 & 0,44 & 719 \\
\hline 0,25 & 2,77 & 1,29 & 738 & 0,48 & 775 \\
\hline 0,30 & 3,16 & 1,50 & 806 & 0,52 & 802 \\
\hline 0,35 & 3,83 & 1,80 & 893 & 0,57 & 855 \\
\hline 0,40 & 3,83 & 2,17 & 1.014 & 0,65 & 977 \\
\hline 0,45 & 4,39 & 2,60 & 1.116 & 0,72 & 1.054 \\
\hline 0,50 & 4,91 & 2,99 & 1.199 & 0,77 & 1.132 \\
\hline 0,60 & 4,77 & 3,59 & 1.341 & 0,87 & 1.269 \\
\hline
\end{tabular}

\begin{tabular}{c|c|c|c|c|c}
\hline \multicolumn{7}{c}{ TE01 - 20 Ensaio (Inundado) } \\
\hline $\begin{array}{c}\mathbf{H} \\
\left(\begin{array}{c}\text { Campo) } \\
(\mathbf{m})\end{array}\right.\end{array}$ & $\begin{array}{c}\text { DMX } \\
\text { (PDA) } \\
(\mathbf{m m})\end{array}$ & $\begin{array}{c}\text { EMX } \\
\text { (PDA) } \\
(\mathbf{k N} \cdot \mathbf{m})\end{array}$ & $\begin{array}{c}\text { FMX } \\
\text { (PDA) } \\
(\mathbf{k N})\end{array}$ & $\begin{array}{c}\text { VMX } \\
\text { (PDA) } \\
(\mathbf{m} / \mathbf{s})\end{array}$ & $\begin{array}{c}\mathbf{R t} \\
\text { (PDA) } \\
(\mathbf{k N})\end{array}$ \\
\hline 0,25 & 3,18 & 1,26 & 585 & 0,44 & 680 \\
\hline 0,30 & 3,57 & 1,59 & 691 & 0,52 & 786 \\
\hline 0,35 & 3,86 & 1,94 & 792 & 0,60 & 907 \\
\hline 0,40 & 4,71 & 2,39 & 829 & 0,67 & 973 \\
\hline 0,50 & 5,58 & 3,29 & 1.004 & 0,81 & 1.159 \\
\hline 0,60 & 6,07 & 3,85 & 1.146 & 0,87 & 1.242 \\
\hline
\end{tabular}

\begin{tabular}{|c|c|c|c|c|c|}
\hline \multicolumn{6}{|c|}{ TE02 - 1ํㅡsaio (Não Inundado) } \\
\hline $\begin{array}{c}\mathrm{H} \\
\text { (Campo) } \\
(\mathrm{m})\end{array}$ & $\begin{array}{c}\text { DMX } \\
\text { (PDA) } \\
(\mathrm{mm})\end{array}$ & $\begin{array}{c}\text { EMX } \\
\text { (PDA) } \\
\text { (kN.m) } \\
\end{array}$ & $\begin{array}{c}\text { FMX } \\
\text { (PDA) } \\
(\mathrm{kN})\end{array}$ & $\begin{array}{c}\text { VMX } \\
\text { (PDA) } \\
\text { (m/s) }\end{array}$ & $\begin{array}{c}\text { Rt } \\
(\mathrm{PDA}) \\
(\mathrm{kN})\end{array}$ \\
\hline 0,20 & 2,35 & 1,02 & 665 & 0,36 & 631 \\
\hline 0,25 & 2,79 & 1,32 & 747 & 0,43 & 716 \\
\hline 0,30 & 3,22 & 1,66 & 841 & 0,48 & 772 \\
\hline 0,35 & 3,49 & 2,05 & 1.021 & 0,54 & 794 \\
\hline 0,40 & 3,87 & 2,44 & 1.060 & 0,59 & 869 \\
\hline 0,45 & 4,38 & 3,01 & 1.256 & 0,64 & 943 \\
\hline 0,50 & 4,75 & 3,40 & 1.382 & 0,68 & 1.009 \\
\hline 0,60 & 4,84 & 3,95 & 1.579 & 0,77 & 1.148 \\
\hline 0,80 & 6,12 & 5,45 & 1.798 & 0,93 & 1.267 \\
\hline 1,00 & 7,22 & 6,82 & 2.047 & 1,06 & 1.449 \\
\hline
\end{tabular}




\begin{tabular}{|c|c|c|c|c|c|}
\hline \multicolumn{6}{|c|}{ TE02 - 2 Ensaio (Não Inundado) } \\
\hline $\begin{array}{c}\mathbf{H} \\
\text { (Campo) } \\
(\mathrm{m})\end{array}$ & $\begin{array}{c}\text { DMX } \\
\text { (PDA) } \\
(\mathrm{mm})\end{array}$ & $\begin{array}{c}\text { EMX } \\
\text { (PDA) } \\
\text { (kN.m) }\end{array}$ & $\begin{array}{c}\text { FMX } \\
\text { (PDA) } \\
(\mathrm{kN})\end{array}$ & $\begin{array}{c}\text { VMX } \\
\text { (PDA) } \\
\text { (m/s) }\end{array}$ & $\begin{array}{c}\text { Rt } \\
\text { (PDA) } \\
\text { (kN) }\end{array}$ \\
\hline 0,15 & 3,19 & 1,24 & 857 & 0,41 & 547 \\
\hline 0,20 & 3,29 & 1,31 & 790 & 0,44 & 585 \\
\hline 0,25 & 3,59 & 1,69 & 864 & 0,49 & 673 \\
\hline 0,30 & 3,80 & 2,01 & 911 & 0,51 & 732 \\
\hline 0,35 & 4,23 & 2,55 & 1.097 & 0,59 & 824 \\
\hline 0,40 & 4,71 & 2,86 & 1.231 & 0,66 & 840 \\
\hline 0,45 & 5,06 & 3,47 & 1.440 & 0,75 & 975 \\
\hline 0,50 & 5,66 & 3,99 & 1.614 & 0,84 & 1.078 \\
\hline 0,60 & 6,31 & 4,76 & 1.770 & 0,98 & 1.155 \\
\hline 0,80 & 6,40 & 4,71 & 1.872 & 0,92 & 1.277 \\
\hline 1,00 & 8,43 & 7,04 & 2.224 & 1,20 & 1.475 \\
\hline
\end{tabular}

\begin{tabular}{|c|c|c|c|c|c|}
\hline \multicolumn{6}{|c|}{ TE03 - 1ํㅡsaio (Não Inundado) } \\
\hline $\begin{array}{c}\mathbf{H} \\
\text { (Campo) } \\
(\mathrm{m})\end{array}$ & $\begin{array}{c}\text { DMX } \\
\text { (PDA) } \\
(\mathrm{mm})\end{array}$ & $\begin{array}{c}\text { EMX } \\
\text { (PDA) } \\
\text { (kN.m) }\end{array}$ & $\begin{array}{c}\text { FMX } \\
\text { (PDA) } \\
(\mathrm{kN})\end{array}$ & $\begin{array}{c}\text { VMX } \\
\text { (PDA) } \\
(\mathrm{m} / \mathrm{s})\end{array}$ & $\begin{array}{c}\mathbf{R t} \\
\text { (PDA) } \\
\text { (kN) }\end{array}$ \\
\hline 0,20 & 2,83 & 1,13 & 654 & 0,54 & 884 \\
\hline 0,40 & 4,28 & 2,15 & 916 & 0,83 & 1.219 \\
\hline 0,60 & 5,55 & 2,40 & 1.134 & 1,04 & 1.296 \\
\hline 0,80 & 6,84 & 3,23 & 1.401 & 1,26 & 1.452 \\
\hline 1,00 & 7,85 & 4,09 & 1.740 & 1,44 & 1.529 \\
\hline
\end{tabular}

\begin{tabular}{|c|c|c|c|c|c|}
\hline \multicolumn{6}{|c|}{ TE03 - 2 Ensaio (Não Inundado) } \\
\hline $\begin{array}{c}\mathrm{H} \\
\text { (Campo) } \\
(\mathrm{m})\end{array}$ & $\begin{array}{c}\text { DMX } \\
\text { (PDA) } \\
(\mathrm{mm})\end{array}$ & $\begin{array}{c}\text { EMX } \\
\text { (PDA) } \\
\text { (kN.m) }\end{array}$ & $\begin{array}{c}\text { FMX } \\
\text { (PDA) } \\
(\mathrm{kN})\end{array}$ & $\begin{array}{c}\text { VMX } \\
\text { (PDA) } \\
(\mathrm{m} / \mathrm{s})\end{array}$ & $\begin{array}{c}\text { Rt } \\
(\mathrm{PDA}) \\
(\mathrm{kN})\end{array}$ \\
\hline 0,20 & 4,10 & 1,82 & 763 & 0,62 & 884 \\
\hline 0,40 & 5,36 & 3,16 & 1.122 & 0,93 & 1.278 \\
\hline 0,60 & 6,72 & 3,69 & 1.448 & 1,15 & 1.377 \\
\hline 0,80 & 7,65 & 3,43 & 1.722 & 1,31 & 1.315 \\
\hline 1,00 & 8,38 & 4,28 & 2.013 & 1,51 & 1.458 \\
\hline
\end{tabular}




\begin{tabular}{|c|c|c|c|c|c|}
\hline \multicolumn{6}{|c|}{ TE04 - 1ํEsaio (Não Inundado) } \\
\hline $\begin{array}{c}\mathrm{H} \\
\text { (Campo) } \\
(\mathrm{m})\end{array}$ & $\begin{array}{c}\text { DMX } \\
\text { (PDA) } \\
(\mathrm{mm}) \\
\end{array}$ & $\begin{array}{c}\text { EMX } \\
\text { (PDA) } \\
\text { (kN.m) }\end{array}$ & $\begin{array}{c}\text { FMX } \\
\text { (PDA) } \\
(\mathrm{kN})\end{array}$ & $\begin{array}{c}\text { VMX } \\
\text { (PDA) } \\
(\mathrm{m} / \mathrm{s})\end{array}$ & $\begin{array}{c}\text { Rt } \\
\text { (PDA) } \\
\text { (kN) }\end{array}$ \\
\hline 0,20 & 2,21 & 1,67 & 1.247 & 0,30 & 1.102 \\
\hline 0,40 & 3,60 & 3,98 & 1.728 & 0,57 & 1.535 \\
\hline 0,60 & 5,14 & 5,40 & 1.712 & 0,82 & 1.626 \\
\hline 0,80 & 5,63 & 7,07 & 2.095 & 0,98 & 1.830 \\
\hline 1,00 & 6,62 & 8,02 & 2.236 & 1,15 & 1.836 \\
\hline
\end{tabular}

\begin{tabular}{|c|c|c|c|c|c|}
\hline \multicolumn{6}{|c|}{ TE04 - 2 Ensaio (Não Inundado) } \\
\hline $\begin{array}{c}\mathrm{H} \\
\text { (Campo) } \\
(\mathrm{m})\end{array}$ & $\begin{array}{c}\text { DMX } \\
\text { (PDA) } \\
(\mathrm{mm})\end{array}$ & $\begin{array}{c}\text { EMX } \\
\text { (PDA) } \\
\text { (kN.m) }\end{array}$ & $\begin{array}{c}\text { FMX } \\
\text { (PDA) } \\
(\mathrm{kN})\end{array}$ & $\begin{array}{c}\text { VMX } \\
\text { (PDA) } \\
\text { (m/s) }\end{array}$ & $\begin{array}{c}\text { Rt } \\
\text { (PDA) } \\
\text { (kN) }\end{array}$ \\
\hline 0,20 & 2,87 & 2,49 & 1.378 & 0,39 & 1.197 \\
\hline 0,40 & 4,27 & 5,09 & 1.897 & 0,68 & 1.593 \\
\hline 0,60 & 5,52 & 6,54 & 2.038 & 0,95 & 1.704 \\
\hline 0,80 & 6,24 & 8,12 & 2.310 & 1,08 & 1.888 \\
\hline 1,00 & 7,17 & 9,51 & 2.476 & 1,26 & 2.004 \\
\hline
\end{tabular}

\begin{tabular}{|c|c|c|c|c|c|}
\hline \multicolumn{6}{|c|}{ TE04 - 3 Ensaio (Não Inundado) } \\
\hline $\begin{array}{c}\mathrm{H} \\
\text { (Campo) } \\
(\mathrm{m})\end{array}$ & $\begin{array}{c}\text { DMX } \\
\text { (PDA) } \\
\text { (mm) }\end{array}$ & $\begin{array}{c}\text { EMX } \\
\text { (PDA) } \\
\text { (kN.m) }\end{array}$ & $\begin{array}{c}\text { FMX } \\
\text { (PDA) } \\
\text { (kN) }\end{array}$ & $\begin{array}{c}\text { VMX } \\
\text { (PDA) } \\
\text { (m/s) }\end{array}$ & $\begin{array}{c}\text { Rt } \\
\text { (PDA) } \\
\text { (kN) }\end{array}$ \\
\hline 0,25 & 3,29 & 1,96 & 986 & 0,50 & 914 \\
\hline 0,30 & 3,66 & 2,56 & 1.092 & 0,57 & 1.053 \\
\hline 0,35 & 3,85 & 2,98 & 1.217 & 0,61 & 1.167 \\
\hline 0,40 & 4,62 & 3,77 & 1.380 & 0,69 & 1.291 \\
\hline 0,45 & 5,25 & 4,37 & 1.477 & 0,78 & 1.352 \\
\hline 0,50 & 5,43 & 4,99 & 1.610 & 0,86 & 1.468 \\
\hline 0,60 & 6,15 & 6,12 & 1.764 & 1,03 & 1.612 \\
\hline
\end{tabular}

\begin{tabular}{|c|c|c|c|c|c|}
\hline \multicolumn{6}{|c|}{ TE04 - 4 Ensaio (Inundado) } \\
\hline $\begin{array}{c}\mathrm{H} \\
\text { (Campo) } \\
(\mathrm{m})\end{array}$ & $\begin{array}{c}\text { DMX } \\
\text { (PDA) } \\
(\mathrm{mm})\end{array}$ & $\begin{array}{c}\text { EMX } \\
\text { (PDA) } \\
\text { (kN.m) }\end{array}$ & $\begin{array}{c}\text { FMX } \\
\text { (PDA) } \\
(\mathrm{kN})\end{array}$ & $\begin{array}{c}\text { VMX } \\
\text { (PDA) } \\
\text { (m/s) }\end{array}$ & $\begin{array}{c}\mathbf{R t} \\
(\mathrm{PDA}) \\
(\mathrm{kN})\end{array}$ \\
\hline 0,2 & 2,71 & 1,15 & 670 & 0,44 & 774 \\
\hline 0,25 & 3,69 & 1,88 & 855 & 0,54 & 890 \\
\hline 0,30 & 4,38 & 2,35 & 1.016 & 0,75 & 990 \\
\hline 0,35 & 4,07 & 2,28 & 907 & 0,66 & 937 \\
\hline 0,40 & 4,81 & 2,94 & 1.070 & 0,73 & 1.028 \\
\hline 0,45 & 5,10 & 3,08 & 1.076 & 0,77 & 1.039 \\
\hline 0,50 & 5,62 & 3,68 & 1.215 & 0,84 & 1.107 \\
\hline 0,60 & 6,30 & 4,48 & 1.525 & 1,01 & 1.223 \\
\hline
\end{tabular}




\section{REFERÊNCIAS BIBLIOGRÁFICAS}

ABEF-RESEARCH ON FOUNDATION ENGINEERING (1989). XIII Int. Conf. On

Soil Mech. And Found. Engineering. Rio de Janeiro, Outubro, 1989.

ABNT - NBR-6122 (1996) - "Projeto e Execução de Fundações - 33p

ABNT (1996) - NBR 13208: Estacas - Ensaio de Carregamento Dinâmico - Método de Ensaio.

ABNT/MB 3472 (1991). Estacas - Prova de Carga Estática.

AlBIERO, J. H.; CINTRA, J. C. A. (1996). Análise e Projeto de Fundações Profundas:

Tubulões e Caixões. Fundação: Teoria e Prática, Hachich et al. (eds.), Ed. Pini Ltda., São Paulo, Cap.8.2, p.302-327.

ALONSO, U. R.; GOLOMBEK, S. (1996). Execução de Fundações Profundas: Tubulões e Caixões. Fundação: Teoria e Prática, Hachich et al. (eds.), Ed. Pini Ltda., São Paulo, Cap.9.3, p.400-407.

ANDREO, C. S.; GONÇALVES, C. (2000). Utilização do Ensaio de Crregamento Dinâmico para Avaliação da carga Mobilizada em Estacas Quadradas Cravadas em Folhelho da Formação Taubaté/SP. In: SEFE IV, 4 Seminário de Engenharia de Fundações Especiais, São Paulo, 17-20 Julho, vol.1, p.148-155.

ANDREO, C. S.; GONÇALVES, C.; BERNARDES, G. P. (2000). Ensaios Dinâmicos Para Avaliação da Carga Admissível em Estacas Pré-Fabricadas de Concreto, Sujeitas a Ação do Atrito Negativo. In: SEFE IV, $4^{\circ}$ Seminário de Engenharia de Fundações Especiais, São Paulo, 17-20 Julho, vol.1, p.156-166. 
AOKI, N (1989) A new Dynamic Load Test Concept . In: XII ICSMFE, TC Pile Driving, Rio de Janeiro, v. 1, p.1-4.

AOKI, N. (1986). Controle “in situ” da Capacidade de Carga de Estacas Pré-fabricads via repique elástico da cravação. Publicação da ABMS/NRSP, ABEF E IE/SP, p.48.

AOKI, N. (1991) Carga Admissível de estacas através de ensaios dinâmicos. In: SEFE II, $2^{\circ}$ Seminário de Engenharia de Fundações Especiais, São Paulo, 19-21 Novembro, vol.2, p.269-292

AOKI, N. (1997). Determinação da Capacidade de Carga Última de Estaca Cravada em Ensaio de Carregamento Dinâmico de Energia Crescente. São Carlos. 111p. Tese (Doutorado) - Escola de Engenharia de São Carlos, Universidade de São Paulo.

AOKI, N. (2000). Reflexões sobre o Comportamento de Sistema Isolado de Fundação. Departamento de Geotecnia, USP - São Carlos, SP, 12p.

AOKI, N.; ALONSO, U. R. (1989). Correlation Between Different Evaluation Procedures of Static and Dynamic Load Tests and Rebound. XII International Conference on Soil Mechanics and Foundation Engineering. Rio de Janeiro. Vol.2, p. 1115-1116.

AOKI, N; NIYAMA, S. (1991). Correlação entre Provas de Carga Dinâmica e Estática. In: SEFE II, $2^{\circ}$ Seminário de Engenharia de Fundações Especiais, São Paulo, 19-21 Novembro, vol.1, p.285-293.

AUDIBERT, J. M. E. ; DOVER, A. R. (1981). Discussion of Pile Load Tests: Cyclic Loads and Varying Load Rates. ASCE. Paper 1600.

ÁVILA, I. A. (2001). Análise do comportamento de estacas metálicas cravadas na bacia de Taubaté através de provas de carga dinâmica de energia crescente. Dissertação de Mestrado. Escola de Engenharia de São Carlos. EESC-USP/São Carlos. 162p. 
BALECH, J. ; AOKI, N. (2000). Medidas de Tensão Dinâmica em Estacas de Ponta. In: SEFE IV, 4 Seminário de Engenharia de Fundações Especiais, São Paulo, 17-20 Julho, vol.1, p.177-190.

BERBERIAN, D. (1999). Engenharia de Fundações. 23.ed. Brasília, UNB.

BERNARDES, G. P. (1991). O Método CAPWAPC e sua Aplicação no Caso do Campo Experimental da EPUSP/ABEF. In: SEFE II, $2^{\circ}$ Seminário de Engenharia de Fundações Especiais, São Paulo, 19-21 Novembro, vol.1, p.31-39.

BERNARDES, G. P.; NORDAL, S. (1991). Estudo da Capacidade de Carga de Estacas Modelo Através de Ensaios Estáticos e Dinâmicos. In: SEFE II, $2^{\circ}$ Seminário de Engenharia de Fundações Especiais, São Paulo, 19-21 Novembro, vol.1, p.17-30.

BORTOLUCCI, A. A. (1983). Caracterização geológica-geotécnica da região urbana de São Carlos-SP. Dissertação de Mestrado, Escola de Engenharia de São Carlos, 67p.

BRANDL, H. (1985). Bearing Capacity of Piers with Large Diameters In XI INTERNATIONAL CONFERENCE ON SOIL MECHANICS AND FOUNDATION ENGINEERING, São Francisco, p.1525-1530.

BROMS, B.B.; CHANG, M.F; GOH, A.T.C. (1988). Bored Piles in Residual Soil and Weathered Rocks in Singapore. In DEEP FOUNDATIONS ON BORED AND AUGER PILES, Rotterdam, p.17-33.

CAMPELO, N. (2000). Comportamento de Tubulões Escavados a Céu Aberto, Submetidos a Carregamentos Dinâmicos, em Solo Colapsível. São Carlos. 319p. Tese (Doutorado) - Escola de Engenharia de São Carlos, Universidade de São Paulo.

CAMPELO, N.; CINTRA, J. C. A.; AOKI, N.; ALBIERO, J. H.; CARNEIRO, B. J. I. (2000). Análise de Resistência Mobilizada em Tubulões Através do PDA. In: SEFE IV, $4^{\circ}$ Seminário de Engenharia de Fundações Especiais, São Paulo, 17-20 Julho, vol.1, p.127-136. 
CAPUTO, H. P. (1977). Mecânica dos Solos e suas Aplicações. Vol.2, 3.ed. Rio de Janeiro, S.A.

CAPWAP - Case Pile Wave Analysis Program, Inc. (2000) CAPWAP for Windows Manual.

CARNEIRO, B. J. I. (1999). Comportamento de Tubulões à Céu Aberto, Instrumentados, em Solos Não-Saturado, Colapsível. São Carlos. 246p. Tese (Doutorado) - Escola de Engenharia de São Carlos, Universidade de São Paulo.

CARNEIRO, B. J. I. (1999). Comportamento de Tubulões à Céu Aberto, Instrumentados, em Solo Não-Saturado Colapsível. São Carlos. 246p. Tese (Doutorado) - Escola de Engenharia de São Carlos, Universidade de São Paulo.

CHANG, M. F. \& GOH, A. T. C. (1988). Performance of Bored Piles in Residual Soils and Weathered Rocks. In DEEP FOUNDATIONS ON BORED AND AUGER PILES, Rotterdam, p.303-313.

CHANG, M.F.; WONG, I.H. (1987). Shaft Friction of Drilled Piers in Weathered Rocks. In PROCEEDINGS VI INTERNATIONAL SEMINAR ROCKS MECHANICS, Canadá, p.313-318.

CHELLIS, R.D. (1951) Pile Foundations - Theory-Design-Practice. McGraw - Hill Book Company, Inc.

CHENG, S. M.; AHMAD, S. A. (1988). Dynamic Testing versus Static Loading Test: Five Case Histories. In: Proceeding of the Third International Conference on Application of Stress Wave Theory to Piles, Ottawa, Canada, p.477-489.

CINTRA, J. C. A. (1993). Solos do Interior de São Paulo - Fundações. Escola de Engenharia de São Carlos - USP, São Carlos, SP, p.250-260.

CINTRA, J. C. A. (1998). Fundações em Solos Colapsíveis. São Carlos, Serviço Gráfico 
da Escola de Engenharia de São Carlos, da Universidade de São Paulo.

CINTRA, J. C. A.; AOKI, N. (1999). Carga Admissível em Fundações Profundas. Projeto REENGE, Escola de Engenharia de São Carlos - USP, São Carlos, SP, 61p.

CLOUGH, R.W.; PENZIEN, J. (1975). Dynamics of structures. McGraw-Hill 629p.

DANZIGER, B.R.; LOPES, F.R.; COSTA, A.M.; PACHECO, M.P. (1996) A Discussion on the Uniqueness of CAPWAP - type Analysis. In: Proceedings of the Fifth International Conference on the Application of Stress Wave Theory to Piles, Orlando, Florida, 11-13 September, p.394-408.

DAVISSON, M. T. (1972). High Capacity Piles. Procedings of Lecture Series on Innovations in Foudations Construction, American Society of Civil Engineeres, Illlinois Section, Choicago, march 22, p. 81-112.

DE BEER, E. (1988). Different Behaviour of Bored and Driven Piles. In DEEP FOUNDATIONS ON BORED AND AUGER PILES, Rotterdam, p.47-81.

DÉCOURT, L. (1998). Ruptura de Fundações e Coeficiente de Segurança à Luz do Conceito de Rigidez. Anais do XI COBRAMSEG, ABMS, Brasília, p.1599-1606.

FALCONI, F. F.; MARZIONNA, J. D. (1999). Estaca Hélice-Contínua A Experiência Atual. São Paulo. ABMS/ABEF/INSTITUTO DE ENGENHARIA.

FELLENIUS, B. T. (1980). The Analysis of Results from Routine Pile Load Tests. Ground Engineering, p. 19-31, september.

FRANKE, E. (1989). Factors of Safety for Skin Friction and End Bearing. In XII INTERNATIONAL CONFERENCE ON SOIL MECHANICS AND FOUNDATION ENGINEERING, Rio de Janeiro, p.2725-2726.

FRANKE, E.; GARVRECHT, D. (1977). Test-Loading on 8 Large Bored Piles in Sand. In IX INTERNATIONAL CONFERENCE ON SOIL MECHANICS AND 
FOUNDATION ENGINEERING, Tokyo, p.529-532.

GGHIONNA, V.N.;.JAMIOLKOWSKI, M.; LANCELLOTTA, R.; PEDRONI, S. (1993). Base Capacity of Bored Piles in Sands from In situ Tests. In DEEP FOUNDATIONS ON BORED AND AUGER PILES, Rotterdam, p.67-75.

GOBLE, G.G.; RAUSCHE, F.; LIKINS JR. , G. E. (1980). The Analysis of Pile Driving - A State of the art. In: International Seminar on the Application of Stress Wave Theory to Piles, Stockholm.

GODOY, N. S. (1983). Interpretação de Prova de Carga em Estaca. In: ENCONTRO TÉCNICO SOBRE CAPACIDADE DE CARGA DE ESTACAS PRÉ-MOLDADAS, ABMS-ONRSP, p.25-60.

GONÇALVES, C.; ANDREO, C. S.; BERNARDES, G. P.; FORTUNATO, S. G. S. (1996). Estimativa da Carga de Ruptura de uma Estaca, Através da Execução de Prova de Carga Dinâmica com Auxílio do PDA. In: SEFE III, $3^{\circ}$ Seminário de Engenharia de Fundações Especiais, São Paulo, 25-27 Novembro, vol.1, p.285-293.

GRL - Goble Rausche Likins and Associates, Inc. (1996) Capwap Instruction to Dynamic Pile Testing Methods.

GUORAN, Z.; JIADUO, W. (2000). Comparative Analysis of Dynamic and Static Test of Foundation Pile. In: Proceeding of the Sixth International Conference on Application of Stress Wave Theory to Piles, São Paulo, Brasil, p.673-676.

HANNIGAN, P. J. (1990). Dynamic Monitoring and Analysis of Pile Foundation Installations. Prepared by Continuing Education Committee of DEDP FOUNDATION INSTITUTE.

HARTIKAINEN, J.; GAMBIN, M. P. (1994). Deep Foundations with Soil Excavation: Bored Piles, Root Piles, CFA, Slurry Trench Walls. In IV INTERNATIONAL CONFERENCE ON PILING AND DEEP FOUNDATIONS, Rotterdam, p.693-713. 
HEYDENRYCH, R. A.; DE BEER, J. H. (1975). The Use of Shaft Foundations. In VI REGIONAL CONFERENCE FOR AFRICA ON SOIL MECHANICS AND FOUNDATION ENGINEERING, Durban, p.161-165.

JAMIOLKOWSKI, M. \& LANCELLOTTA, R. (1988). Relevance of In-situ Test for Evaluation of Allowable Base Resistance of Bored Piles in Sands. In DEEP FOUNDATIONS ON BORED AND AUGER PILES, Rotterdam, p.101-119.

KLOSINSKI,B. (1977). Bearing Capacity of Large Diameter Bored Piles. In IX INTERNATIONAL CONFERENCE ON SOIL MECHANICS AND FOUNDATION ENGINEERING, Tokyo, p.609-612.

KOIKE, M.; MATSUI, T.; MATSUI, K. (1988). Vertical Loading Tests of Large Bored Piles and Their Estimation. In DEEP FOUNDATIONS ON BORED AND AUGER PILES, Rotterdam, p.531-539.

KORMANN, A. C. M.; CHAMECKI, P. R.; NETO, L. A. ; BERNARDES, G. P. (2000). Estaca Hélice Contínua em Argila Sobreadensada: Comportamento em Provas de Carga Estáticas e Dinâmicas. In: SEFE IV, $4^{\circ}$ Seminário de Engenharia de Fundações Especiais, São Paulo, 17-20 Julho, vol.1, p.58-70.

KRUIZINGA, J. (1988). Development of Skin Friction and Base Resistance of Instrumented Large Bored Piles Under Working Load Conditions. In DEEP FOUNDATIONS ON BORED AND AUGER PILES, Rotterdam, p.435-441.

LIMA, F. M. A. (1999), Análise de Prova de Carga Dinâmica em Estacas Metálicas do Tipo Trilho. São Carlos. 92p. Dissertação (Mestrado) - escola de Engenharia de São Carlos, Universidade de São Paulo.

LIU, C. et al. (1996). Determining the Bearing Capacity of Large-Diameter Bored Castin situ Piles by High Strain Dinamic Pile-Testing. Proc. $5^{\text {th }}$ Int. Conf. Applic of StressWave Theory to Piles, p. 797-804. 
LOTEN, H. V.; SANDBERGEN, R.; STARINK, T. W. (1988). Model Tests on Static and Dynamic Bearing Capacity of Piles. In: Proceeding of the Third International Conference on Application of Stress Wave Theory to Piles, Ottawa, Canada, p.368-376.

MACHADO, J. R. A. (1995). Avaliação da Capacidade de Carga, com Base no Repique Elástico medido no Final da Cravação. São Paulo, 265p. Dissertação (Mestrado) - Escola Politécnica da Universidade de São Paulo.

MACHADO, S. L. (1998). Aplicações de conceitos de elastoplasticidade a solos não saturados. Tese de Doutorado. Escola de Engenharia de São Carlos. EESC-USP/São Carlos. 361p.

MAIORANO, R. M. S. et al. (1996). Residual Stres System Arising from Different Methods of Pile Installation. Proc. 5th Int. Conf. Applic. of Stress-Wave Theory to Piles, p.518-528.

MASSAD, F. (1991). Estacas Escavadas em compressão Axial: Comportamento e Parâmetros Visando a Estimativa dos Recalques. In: SEFE II, $2^{\text {o }}$ Seminário de Engenharia de Fundações Especiais, São Paulo, 19-21 Novembro, vol.1, p.255-264.

MASSAD, F. (1992). Sobre a Interpretação de Provas de Carga em Estacas, Considerando as Cargas Residuais na ponta e A Reversão do Atrito Lateral. Parte I: Solos Relativamente Homogêneos. Solos e Rochas 15 (2), p.103-115.

MASSAD, F. ; WINZ, H. C. (2000). Capacidade de Carga em Estacas Verticais: Influência da Velocidade de Carregamento em Provas de Carga. In: SEFE IV, $4^{\circ}$ Seminário de Engenharia de Fundações Especiais, São Paulo, 17-20 Julho, vol.1, p.177190.

MATSUI, T. (1993). Case Studies on Cast-in-place Bored Piles and Some Considerations for Design. In DEEP FOUNDATIONS ON BORED AND AUGER PILES, Rotterdam, p.77-101. 
MELLO, V. F. B. (1975). Deformações como Base Fundamental de Escolha de Fundações. Geotecnia. Revista da Sociedade Portuguesa de Geotecnia, No 12, p.55-75.

MEYERHOF, G.G. (1988). Some Problems in Predicting Behaviour of Bored Pile Fundations. In DEEP FOUNDATIONS ON BORED AND AUGER PILES, Rotterdam, p.133-143.

MILITITSKY, J. (1991). Provas de Carga Estática. In: SEMINÁRIO DE ENGENHARIA DE FUNDAÇÕES ESPECIAIS, 2. , São Paulo, 1991. Anais. V.2, p. $203-228$.

MORDHORST, C. (1988). The Ultimate Bored Pile Load Capacity in Granular Soils: A Case History Against the Current Effective Stress Design Theory in Comparison to a Penetration Based Design Method. In DEEP FOUNDATIONS ON BORED AND AUGER PILES, Rotterdam, p.451-455.

NAVAJAS, S. ; NIYAMA, S. (1996). Ensaio de Carregamento Dinâmico em Estacas Moldadas In Loco numa Obra Portuária. In: SEFE III, $3^{\circ}$ Seminário de Engenharia de Fundações Especiais, São Paulo, 25-27 Novembro, vol.1, p.285-293.

NIYAMA, S. (1983). Medições Dinâmicas na Cravação de Estacas. São Paulo. Dissertação (Mestrado) - Escola Politécnica da Universidade de São Paulo.

NIYAMA, S.(1991) Provas de Carga Dinâmicas em Estacas. In: SEFE II, $2^{\circ}$ Seminário de Engenharia de Fundações Especiais, São Paulo, 19-21 Novembro, vol.2, p.229-268.

NIYAMA, S.; AOKI, N.; CHAMECKI, P. R. (1996). Verificação de Desempenho. Fundação: Teoria e Prática, Hachich et al. (eds.), Ed. Pini Ltda., São Paulo, Cap.20 p.723-751.

NIYAMA, S; BON JR. W.; MARTINS, J. A. A.; et al. Instrumentação e Monitoração do Teste de Cravação de uma Estaca num Solo Calcário na Bacia de Curimã, Cear. In: 
COMBRAMSEF, 7, Olinda. Anais, v.III, p. 151-167, 1982.

POULOS, H. G. (1981). Cyclic Axial Response of Single Pile. Journal of the Geotechnical Engineering Division. ASCE, Vol.107, Nº GT1, Janeiro.

RAUSCHE, F.; GOBLE, G.G.; LIKINS JR., G.E. (1985) Dynamic Determination of Pile Capacity. Journal of Geotechnical Engineering. ASCE, vol.111, No.3, p 367-383, March.

REESE, L. C. (1978). Design and Construction of Drilled Shafts. Journal of The Geotechinical Engineering Division, GT1, p.95-116, january.

REESE, L. C.; O’NEILL, M. W. (1988). Field Load Tests of Drilled Shafts. In DEEP FOUNDATIONS ON BORED AND AUGER PILES, Rotterdam, p.145-191.

SANTOS, T. R. S. (2001). Atrito lateral e resistência de base em tubulões a céu aberto em solos colapsíveis. Dissertação de Mestrado. Escola de Engenharia de São Carlos. EESC-USP/São Carlos. 161p.

SMITH, E.A.L. (1960) Pile Driving Analysis by the Wave Equation. Journal of the Soil Mechanics and Foundations Division. ASCE, vol.86, SM4, p 35-61, Aug.

SOUZA Filho, J. M. ; ABREU, P. S. B. (1990). Procedimentos para Controle de Cravação de Estacas Pré-moldadas de Concreto. $6^{\circ}$ CBGE e COBRAMSEF, Salvador, vol. 2, p.309-320.

TERZAGHI, K. (1943). Theoretical Soil Mechanics. John Wilei and Sons, Inc., New York, p. 137-143.

TERZAGHI, K. ; PECK, R. B. (1948). Soil Mechanics in Engineering Practice. John Wiley \& Sons Inc., New York, 1948.

UTO, K. ; FUYUFI, M. et al. (1985). Dynamic Bearing Capacity, Wave Theory, Pile Driving Control, Procedings of the International symposium on Penatrability and 
Drivability of Piles. San Francisco, v. 1, p.201-204.

VAN DER VEEN, C. (1953). The Bearing Capacity of a Pile. In: $3^{\text {rd }}$ INTERNAICONAL CONFERENCE ON SOIL MECHANICS AND FOUNDATION ENGINEERING, Zurich. v.2, p.84-90.

VAN IMPE, W. F. (1991). Deformations of Deep Foundations. In X INTERNATIONAL CONFERENCE ON SOIL MECHANICS AND FOUNDATION ENGINEERING, Florence, p.1031-1061.

VELloso, P. P. C. (1987) Fundações - Aspectos Geotécnicos. Publicação do Departamento de Engenharia Civil da PUC-RJ, v.2, p. 300C-300H.

VESIC, A. S. (1975). Principles of Pile Foundation Design. Duke University School of engineering. Soil Mechanics Series nº38, March.

WHITAKER, T.; BUlLEN, F.R. (1981) Pile Testing and Pile Driving Formulae. In: Piles and Foundations, edited by F.E.Young. Thomas Telford Ltd, p. 121-134.

YAO, H. L. et al. (1988). Experiences of Dynamic Pile Loading Tests in Taiwan. Proccedings of Third International Conference on Application of Stress-Wave, Ottawa, Canada, p.805-813.

ZHENG, Y. M.;ZHENG, J. M.; CHEN, B. (2000). Correlation Analyses of Dynamic and Static Loading tests for Nine Piles. In: Proceeding of the Sixth International Conference on Application of Stress Wave Theory to Piles, São Paulo, Brasil, p.651656. 